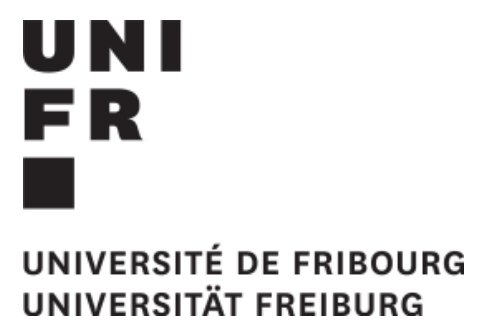

Department of Physics

University of Fribourg (Switzerland)

High energy resolution off-resonant X-ray spectroscopy

\title{
THESIS
}

presented to the Faculty of Science of the University of Fribourg (Switzerland)

in consideration for the award of the academic grade of Doctor rerum naturalium

by

\section{Wojciech Błachucki}

from

Poland

Thesis No: 1932

Editor: UniPrint 

Accepted by the Faculty of Science of the University of Fribourg (Switzerland) upon the recommendation of

Prof. Dr. Philipp Aebi, Université de Fribourg (President of the jury)

Dr. hab. Joanna Hoszowska, Université de Fribourg (Thesis Supervisor)

Prof. Dr. Jean-Claude Dousse, Université de Fribourg (Internal expert)

Dr. Jakub Szlachetko, Paul Scherrer Institute, Villigen, Switzerland (External expert)

Dr. hab. Marc Simon, Université Pierre et Marie Curie, Paris, France (External expert)

Fribourg, October $16^{\text {th }}, 2015$

Thesis supervisor

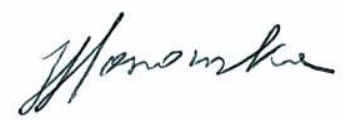

Dr. hab. Joanna Hoszowska
Dean

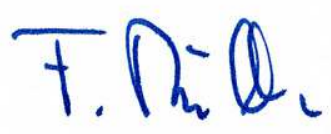

Prof. Dr. Fritz Müller 



\section{Contents}

Page

Abstract $\ldots \ldots \ldots \ldots \ldots \ldots \ldots \ldots \ldots \ldots \ldots \ldots \ldots \ldots \ldots \ldots \ldots \ldots \ldots \ldots \ldots \ldots \ldots$

Résumé $\ldots \ldots \ldots \ldots \ldots \ldots \ldots \ldots \ldots \ldots \ldots \ldots \ldots \ldots \ldots \ldots$ VII

Streszczenie $\ldots \ldots \ldots \ldots \ldots \ldots \ldots \ldots \ldots \ldots \ldots \ldots \ldots \ldots \ldots \ldots \ldots \ldots \ldots \ldots$

I Introduction to X-ray spectroscopy $\ldots \ldots \ldots \ldots \ldots \ldots \ldots \ldots \ldots$

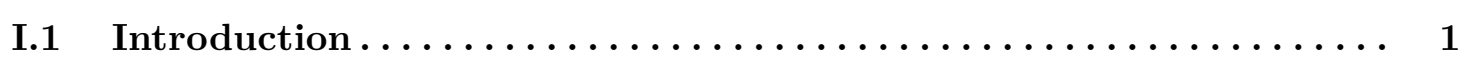

I.2 X-ray emission spectroscopy $(\mathrm{XES}) \ldots \ldots \ldots \ldots \ldots \ldots \ldots \ldots \ldots$

I.3 X-ray absorption spectroscopy $(\mathrm{XAS}) \ldots \ldots \ldots \ldots \ldots \ldots \ldots$

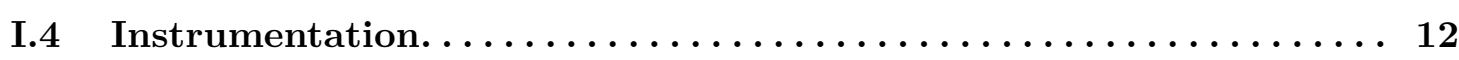

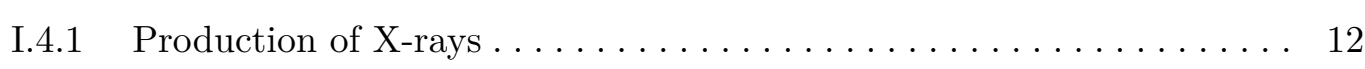

I.4.2 Detection of X-rays $\ldots \ldots \ldots \ldots \ldots \ldots \ldots \ldots \ldots \ldots \ldots \ldots \ldots \ldots \ldots \ldots \ldots \ldots$

II High energy resolution off-resonant spectroscopy (HEROS) ...... 21

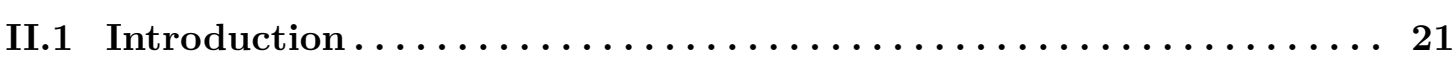

II.2 Theoretical background..................... 22

II.3 Resonant X-ray emission spectroscopy (RXES) . . . . . . . . 26

II.4 Development of HEROS ...................... 29

II.5 Examples of applications of HEROS $\ldots \ldots \ldots \ldots \ldots \ldots \ldots \ldots$

III Self-absorption-free HEROS. . . . . . . . . . . . . . . . 39

III.1 Introduction $\ldots \ldots \ldots \ldots \ldots \ldots \ldots \ldots \ldots \ldots \ldots \ldots \ldots \ldots \ldots$

III.2 Self-absorption in X-ray spectroscopy . . . . . . . . . . . 39

III.3 Experimental $\ldots \ldots \ldots \ldots \ldots \ldots \ldots \ldots \ldots \ldots \ldots \ldots \ldots \ldots \ldots$

III.3.1 $\mid$ Experimental setup $\ldots \ldots \ldots \ldots \ldots \ldots \ldots \ldots \ldots \ldots \ldots \ldots \ldots$

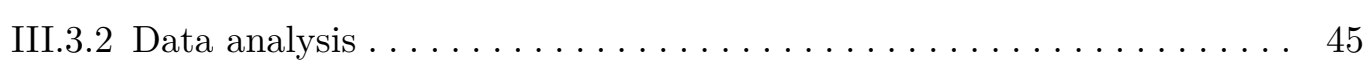


III.4 Results and discussion $\ldots \ldots \ldots \ldots \ldots \ldots \ldots \ldots \ldots \ldots \ldots$

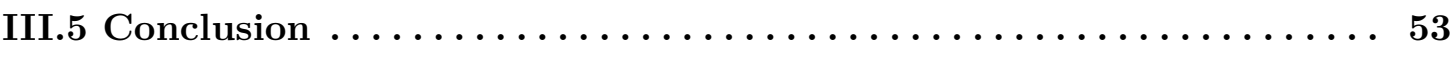

IV Time-resolved chemical speciation with HEROS ............ 55

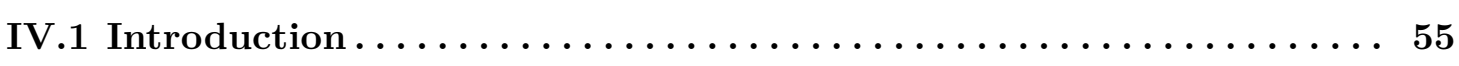

IV.2 Experimental $\ldots \ldots \ldots \ldots \ldots \ldots \ldots \ldots \ldots \ldots \ldots \ldots \ldots$

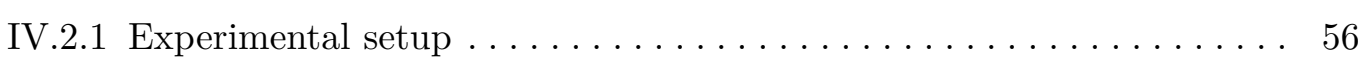

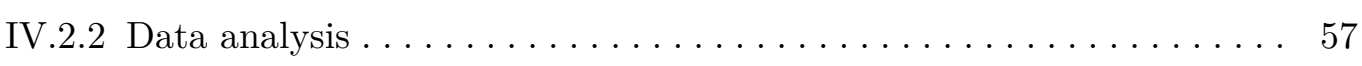

IV.3 Calculation of XAS spectra with FEFF $\ldots \ldots \ldots \ldots \ldots \ldots \ldots$

IV.4 Results and discussion $\ldots \ldots \ldots \ldots \ldots \ldots \ldots \ldots \ldots \ldots$

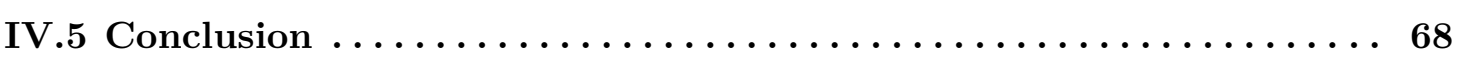

V HEROS at X-ray free-electron laser facilities $\ldots \ldots \ldots \ldots \ldots \ldots \ldots 9$

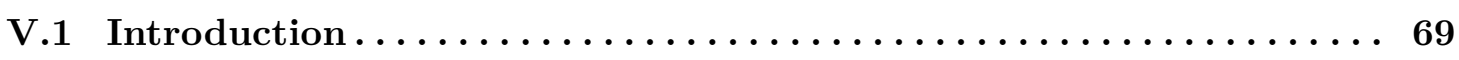

V.2 X-ray free-electron lasers $\ldots \ldots \ldots \ldots \ldots \ldots \ldots \ldots \ldots \ldots \ldots$

V.3 Experimental ............................. 73

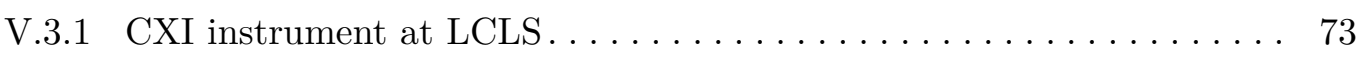

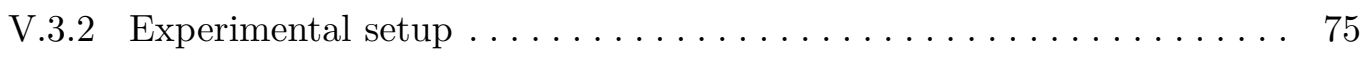

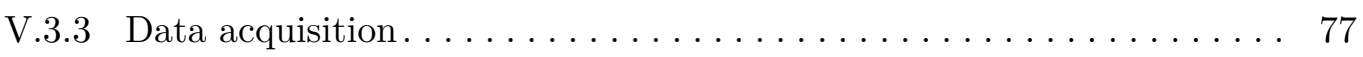

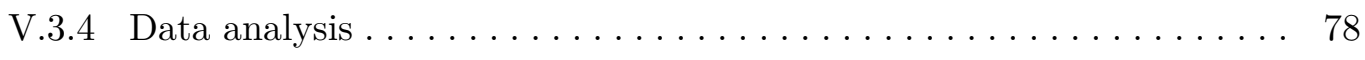

V.4 Results and discussion $\ldots \ldots \ldots \ldots \ldots \ldots \ldots \ldots \ldots \ldots \ldots$

V.5 Conclusion $\ldots \ldots \ldots \ldots \ldots \ldots \ldots \ldots \ldots \ldots \ldots \ldots \ldots \ldots$

List of figures $\ldots \ldots \ldots \ldots \ldots \ldots \ldots \ldots \ldots \ldots \ldots \ldots \ldots \ldots \ldots \ldots \ldots \ldots$

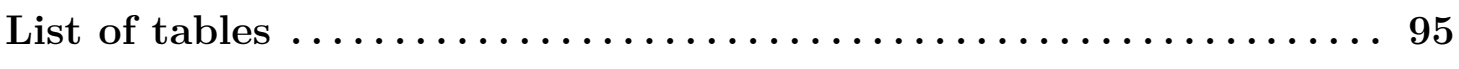

References............................... 97

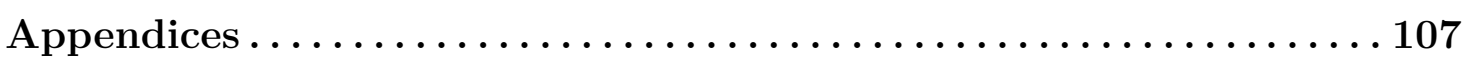

A Reconstruction algorithms with Mathematica.............. 109

B The lcls.py module ........................... 113

Acknowledgements.............................. 121

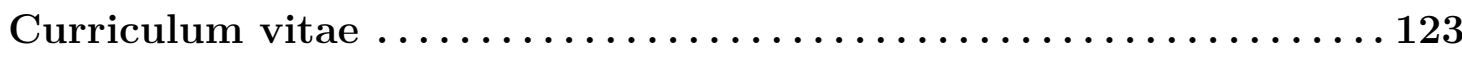

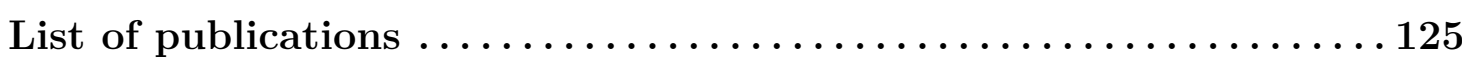




\section{Abstract}

This work treats of the high energy resolution off-resonant X-ray spectroscopy (HEROS) method of determining the density of unoccupied electronic states in the vicinity of the absorption edge. HEROS is an alternative to the existing X-ray absorption spectroscopy (XAS) methods and opens the way for new studies not achievable before.

HEROS makes use of high energy resolution X-ray emission spectroscopy (XES) to study spectra of inelastically scattered photons in off-resonant conditions, i.e., for incident photon energies below the atomic core level binding energy of interest. It has been shown that spectra of the off-resonantly inelastically scattered X-rays carry information on the occupancy of the discrete valence electronic states as well as the states above the ionization threshold (in the continuum). Provided that the incident photon beam energy bandwidth is less than the initial state lifetime broadening and a high resolution wavelength-dispersive detection system is used, HEROS allows to probe the density of unoccupied states with high energy resolution. This is possible because in the off-resonant inelastic X-ray scattering process the scattered photons' spectra are not broadened by the studied absorption edge core hole lifetime. Further, in HEROS the studied material is irradiated with a monochromatic X-ray beam of energy fixed below the given ionization threshold and the spectrometer (in the geometry of von Hámos or Johansson) equipped with position sensitive detector allows recording emission spectra in one shot with typically tens of electronvolts-coverage. This scanning-free arrangement thus allows to probe the density of unoccupied states with time resolution limited only by the experimental setup's efficiency. The swift way of probing the electronic structure of matter, provided by HEROS, is highly desirable in time-resolved spectroscopic studies on dynamically changing chemical systems. This also makes HEROS a method of choice in case of extremely bright pulsed X-ray sources (such as X-ray free-electron lasers, XFELs) where the target is damaged after every pulse and the intensity variations severely limit the usability of XAS methods. Moreover, the HEROS spectral profiles are not modified by the self-absorption effect. 
Chapter $\mathrm{I}$ is a short introduction to X-ray spectroscopy. A brief description of the main physical phenomena and quantities involved in the XES and XAS studies is presented, and the experimental methods as well as the instrumentation used in XES and XAS are highlighted.

Chapter II is focused on the principles of high resolution resonant and off-resonant $\mathrm{X}$-ray spectroscopy. The theoretical background of resonant X-ray scattering is presented, and the new method HEROS is introduced. Examples of HEROS applications in different fields are also mentioned.

Chapter III is dedicated to a study showing that HEROS can be used to measure absorption spectra unaffected by the self-absorption effect. In the fluorescence mode $\mathrm{XAS}$, the fluorescence yield is measured at the incident beam energy varying across the studied absorption edge. The self-absorption effect arises from the strong variation of the photoabsorption coefficient in the resonant regime, and is enhanced by the sample thickness and concentration. In HEROS, an emission spectrum is measured for a single incident beam energy fixed below the ionization threshold of interest. As a consequence, the self-absorption effect is reduced to only the probability of reabsorption of the produced fluorescence radiation escaping from the target which is typically nearly constant in the measured emission energy range. The emission spectrum measured with HEROS can be further used to calculate an absorption spectrum using the Kramers-Heisenberg formalism. This approach is supported by the presented Ta $L_{3}$ edge absorption spectra obtained with the HEROS technique at the SuperXAS beamline of the Swiss Light Source of the Paul Scherrer Institute, Switzerland. The Ta $L \alpha_{1}$ HEROS spectra were recorded for nine Ta samples of different thicknesses, and the Ta $L_{3}$ edge absorption spectra were reconstructed. The shapes of both the measured emission spectra and the reconstructed absorption spectra were found to be independent of the sample thicknesses and thus of the self-absorption effect. This work was published in Physical Review Letters [1].

In Chapter IV] a time-resolved in situ HEROS study is described in which chemical speciation of a silica supported Ta catalyst under reaction conditions was attained at the Swiss Light Source of the Paul Scherrer Institute, Switzerland. HEROS is a powerful tool to follow chemical reactions not only due to its high speed in probing the density of unoccupied states, but also because it needs no correction for the self-absorption effect which varies with the substrates' concentration changes during reaction. Analysis of the HEROS spectra measured one by one with 40 s-acquisition time during oxidation of both the inactive starting Ta complex and the one activated in hydrogen delivered 
several interesting findings. These include e.g., formation of dimeric Ta species caused by reaction with oxygen and a step-wise character of the transition of the inactive Ta catalyst to its oxidized form. The data presented in this work was published in the Physical Chemistry Chemical Physics journal [2].

The results presented in Chapter $\mathrm{V}$ demonstrate that HEROS is applicable at $\mathrm{X}$-ray free-electron laser facilities. In this work the HEROS technique was applied to the investigation of the electronic structure of copper in different oxidation states at the Linac Coherent Light Source (Menlo Park, California, USA) operated in the self-seeding mode. The experimental HEROS spectra for $\mathrm{Cu}^{1+}$ were compared to the ones for $\mathrm{Cu}^{0}$ and $\mathrm{Cu}^{2+}$ reported in Ref. [3], and to calculations based on theoretical XAS spectra retrieved from FEFF 9.6 program and on reference XAS spectra. It was shown that HEROS provides detailed electronic and structural information with high intensity femtosecond pulsed sources as well. Furthermore, it was shown that HEROS allows measuring single-shot spectra for each XFEL pulse separately, which makes it a method of choice for XFELs where the appreciable pulse-to-pulse intensity variations influence only the overall HEROS signal yield and leaves the shape of the measured spectra unaffected. 



\section{Résumé}

Ce travail de thèse est consacré à la méthode HEROS (spectroscopie X hors-résonance en haute résolution), une méthode permettant d'étudier les niveaux électroniques inoccupés dans le voisinage des bords d'absorption. La méthode HEROS qui représente une alternative aux méthodes d'absorption XAS traditionnelles ouvre la voie à de nouvelles investigations irréalisables auparavant.

La méthode HEROS tire profit des avantages de la spectroscopie d'émission X en haute résolution (XES) pour étudier les spectres de photons ayant subi une diffusion inélastique hors-résonance, c.à.d. à des énergies incidentes juste en-dessous des énergies de liaison des niveaux atomiques profonds d'intérêt. Il a été démontré que les spectres de rayons $\mathrm{X}$ diffusés inélastiquement à des énergies hors-résonance contiennent des informations sur le taux d'occupation des niveaux atomiques discrets de valence et des niveaux du continu au-dessus du seuil d'ionisation. Si la résolution en énergie du faisceau de photons incidents est plus petite que la largeur naturelle de l'état atomique initial et si les mesures sont effectuées avec un instrument ayant un grand pouvoir de résolution comme par exemple un spectromètre à cristal, la méthode HEROS permet de déterminer en haute-résolution la densité des niveaux atomiques inoccupés. Ceci est possible parce que dans la diffusion inélastique hors-résonance les raies spectrales des photons diffusés ne sont pas élargies par les durées de vie moyenne des lacunes de cœur associées aux bords d'absorption étudiés. De surcroît, dans la méthode HEROS, l'échantillon analysé est irradié avec un faisceau de rayons X monochromatiques dont l'énergie est fixée au-dessous du seuil d'absorption. Par ailleurs, l'emploi de spectromètres à cristal de type von Hámos ou Johansson équipés de détecteurs sensibles à la position permet de mesurer le spectre des photons diffusés sur un domaine d'énergie s'étalant sur plusieurs dizaines d'électronvolts sans qu'aucun réglage du faisceau incident ou du spectromètre ne soit nécessaire. Ce montage ne nécessitant aucun ajustement permet donc de déterminer la densité d'états électroniques inoccupés avec une résolution temporelle limitée uniquement par l'efficacité du spectromètre. L'analyse 
rapide de la structure électronique d'échantillons par la méthode HEROS est donc particulièrement bien adaptée à des mesures spectroscopiques nécessitant une résolution temporelle comme par exemple l'étude de la dynamique de réactions chimiques. La technique HEROS représente aussi la méthode de prédilection dans le cas où l'échantillon doit être irradié avec des faisceaux de rayons X pulsés extrêmement intenses comme ceux produits par les sources XFELs (lasers X à électrons libres) parce que dans ce cas l'échantillon est endommagé après chaque impulsion de faisceau et les variations importantes d'intensité entre les différentes impulsions ne permettent pas l'emploi des méthodes d'absorption XAS traditionnelles. De surcroît, les spectres HEROS ne sont pas affectés par l'effet d'auto-absorption.

Le chapitre \est une courte introduction à la spectroscopie des rayons X. Il contient une brève présentation des phénomènes physiques essentiels et des grandeurs principales intervenant dans les études XES et XAS. Les méthodes expérimentales et l'instrumentation utilisée en spectroscopie XES et XAS sont également décrites.

Le chapitre II est concentré sur les principes de la spectroscopie X en hauterésolution dans le cas d'excitations résonantes et hors-résonance. Les fondements théoriques de la diffusion élastique résonante de photons ainsi que la nouvelle méthode HEROS y sont présentés. Plusieurs exemples d'application de la méthode HEROS dans différents domaines sont également discutés.

Le chapitre III concerne plus spécifiquement une étude montrant que la méthode HEROS peut être utilisée pour mesurer des spectres d'absorption, lesquels sont dans ce cas insensibles à l'effet d'auto-absorption. Dans la méthode XAS en mode fluorescence, l'intensité des photons de fluorescence est mesurée en variant l'énergie du faisceau photonique incident à travers le bord d'absorption étudié. L'effet d'auto-absorption est dû au fait que le rayonnement de fluorescence de l'échantillon analysé varie rapidement dans le voisinage du bord à cause de la brusque augmentation du coefficient d'absorption à la résonance. Les corrections à apporter à l'intensité de fluorescence mesurée augmentent avec l'épaisseur et la densité de l'échantillon. Dans la méthode HEROS, l'échantillon est irradié avec un faisceau d'énergie constante fixée au-dessous du seuil d'ionisation d'intérêt. En conséquence, l'effet d'auto-absorption est limité à la probabilité de réabsorption du rayonnement de fluorescence émis par l'échantillon, laquelle est quasi-constante pour l'intervalle d'énergie correspondant au spectre d'émission mesuré. Les spectres d'émission collectés au moyen de la méthode HEROS peuvent être ensuite transformés en spectres d'absorption en utilisant le formalisme mathématique de Kramers-Heisenberg. La validité de la méthode HEROS et son indépendance de l'ef- 
fet d'auto-absorption sont démontrées à l'aide du spectre d'absorption correspondant au bord $L_{3} \mathrm{du}$ Ta. Les mesures ont été réalisées auprès de la ligne de faisceau SuperXAS de la Source suisse de lumière (SLS) de l'Institut Paul Scherrer (PSI), à Villigen, Suisse. Les spectres HEROS $L \alpha_{1}$ ont été mesurés pour neuf feuilles métalliques de Ta d'épaisseur différente. A partir de chaque spectre HEROS, le spectre d'absorption $L_{3}$ a été reconstruit hors-faisceau. Il est démontré que la forme des spectres d'émission et des spectres d'absorption reconstruits est indépendante de l'épaisseur des échantillons et donc de l'effet d'auto-absorption. Ces résultats ont été publiés dans la revue Physical Review Letters [1].

Le chapitre IV présente un exemple d'application in situ de la méthode HEROS pour l'étude de la dynamique de réactions chimiques impliquant un catalyseur de Ta sur un support de silice. L'expérience a été réalisée à SLS. Grâce à ses propriétés de résolution temporelle, HEROS représente un outil efficace pour l'étude de la dynamique de réactions chimiques non seulement parce que cette méthode permet de sonder la densité d'états inoccupés dans des temps très courts mais aussi parce qu'elle ne nécessite pas de correction des spectres pour l'effet d'auto-absorption, lequel dépend de la densité de l'échantillon et peut donc varier durant la réaction. L'analyse des spectres HEROS mesurés successivement, chacun durant $40 \mathrm{~s}$, pendant la phase d'oxydation des échantillons (complexe de Ta initialement inactif et complexe de Ta activé en atmosphère d'hydrogène) a fourni des résultats très intéressants, comprenant par exemple la formation de dimères de Ta produits par réaction avec l'oxygène et la nature progressive, par étape, de la transition du catalyseur de Ta inactif vers sa forme oxydée. Cette étude a été publiée dans la revue scientifique Physical Chemistry Chemical Physics [2].

Les résultats présentés dans le chapitre $\mathrm{V}$ prouvent que la méthode HEROS peut être utilisée pour des mesures utilisant des faisceaux de photons produits par des lasers $\mathrm{X}$ à électrons libres. Dans ce travail, la technique HEROS a été appliquée à l'étude de la structure électronique du cuivre dans différents états d'oxydation. L'expérience a été réalisée à LCLS (LINAC Coherent Light Source,) à Menlo Park, Californie, USA avec un faisceau de photons quasi-monochromatiques obtenu en opérant l'accélérateur dans le mode self-seeding. Les spectres HEROS du $\mathrm{Cu}^{1+}$ obtenus ont été comparés aux spectres d'absorption $\mathrm{du} \mathrm{Cu}^{0}$ et $\mathrm{Cu}^{2+}$ présentés dans la Réf. [3] ainsi qu'aux spectres HEROS calculés à partir de spectres XAS de référence et de spectres XAS théoriques reconstruits avec le programme FEFF 9.6. Les résultats montrent que la méthode HEROS permet d'obtenir des informations détaillées sur la structure électronique des échantillons aussi dans le cas de sources de rayons $\mathrm{X}$ pulsées de très forte intensité 
et de très courte durée (femto-seconde). De plus, cette expérience a démontré que la méthode HEROS permet de mesurer un spectre pour chaque impulsion de faisceau, ce qui en fait la méthode de prédilection pour des mesures auprès de sources XFEL car les variations importantes d'intensité entre les différentes impulsions ne touchent que l'intensité globale des spectres HEROS mais pas leur forme spectrale. 


\section{Streszczenie}

Niniejsza praca doktorska traktuje o metodzie poza-rezonansowej spektroskopii rentgenowskiej wysokiej rozdzielczości (ang. high energy resolution off-resonant X-ray spectroscopy, HEROS), pozwalającej na badanie gęstości stanów nieobsadzonych w pobliżu progu absorpcji. Metoda HEROS jest alternatywą do istniejących metod rentgenowskiej spektroskopii absorpcyjnej (ang. X-ray absorption spectroscopy, XAS) i otwiera drogę do dotychczas nieosiągalnych badań.

Metoda HEROS wykorzystuje rentgenowską spektroskopię emisyjną (ang. X-ray emission spectroscopy, XES) do badania widm fotonów rozproszonych niesprężyście w warunkach poza-rezonansowych, tzn. gdy energia fotonów rozpraszanych jest niewiele mniejsza od danego poziomu energetycznego atomu. Wykazano, że widma fotonów rozproszonych niesprężyście w warunkach poza-rezonansowych zawierają informację o gęstości nieobsadzonych dyskretnych stanów walencyjnych, jak i nieobsadzonych stanów formujących continuum stanów. Pod warunkiem, że rozdzielczość energetyczna wiązki padającej jest mniejsza od naturalnej szerokości energetycznej stanu początkowego atomu, oraz że pomiar jest wykonany z użyciem spektrometru o wysokiej rozdzielczości (jak np. spektrometr krystaliczny), metoda HEROS pozwala na określenie gęstości stanów nieobsadzonych z wysoką precyzją. Jest to możliwe, gdyż w procesie poza-rezonansowego niesprężystego rozpraszania promieniowania rentgenowskiego struktury widmowe rozproszonych fotonów nie są poszerzone przez czas życia dziury na badanym poziomie energetycznym atomu. W dodatku, w metodzie HEROS badany materiał jest naświetlony monochromatyczną wiązką fotonów o energii poniżej energii danego poziomu energetycznego, a użyty spektrometr, w geometrii von Hámos'a lub Johansson'a i wyposażony w detektor pozycjo-czuły (ang. position sensitive detector), umożliwia mierzenie widm emisyjnych w około kilkudziesięcioelektronowoltowym zakresie na raz, bez konieczności jakichkolwiek zmian ustawień wiązki lub układu detekcyjnego. Stąd, rozwiązanie doświadczalne użyte w metodzie HEROS - nie wymagające zmian położeń elementów optycznych - pozwala na pomiar gęstości stanów 
nieobsadzonych z rozdzielczością czasową ograniczoną jedynie przez wydajność spektrometru. Analiza struktury elektronowej materiałów z dużą szybkością, umożliwiona przez metodę HEROS, jest wysoce pożądana w badaniach spektroskopowych w czasie rzeczywistym, np. w badaniach nad przebiegiem reakcji chemicznych. Ma ona także istotne znaczenie w przypadkach zastosowania impulsowych źródeł promieniowania rentgenowskiego o bardzo wysokiej jasności, takich jak lasery rentgenowskie (ang. X-ray free-electron lasers, XFELs), w których to przypadkach próbka jest uszkodzona po każdym pulsie, a duże wahania intensywności pomiędzy pulsami znacząco ograniczają stosowalność metod XAS. Ponadto, widma zmierzone metodą HEROS nie są dotknięte efektem samoabsorpcji.

Rozdział I] jest krótkim wprowadzeniem do spektroskopii rentgenowskiej. Zawiera on zwięzły opis podstawowych zjawisk i wielkości fizycznych związanych z badaniami w spektroskopii emisyjnej i w spektroskopii absorpcyjnej. Opisano w nim również metody doświadczalne oraz aparaturę pomiarową używane w spektroskopiach XES i XAS.

Rozdział[II koncentruje się na rezonansowej i poza-rezonansowej spektroskopii rentgenowskiej wysokiej rozdzielczości. Opisano w nim podstawy teoretyczne rezonansowego rozpraszania promieniowania rentgenowskiego oraz nową metodę HEROS. Przedstawiono także przykłady zastosowań metody HEROS w różnych dziedzinach.

Rozdział III jest poświęcony doświadczeniu pokazującemu, że metodę HEROS można użyć do pomiaru widm absorpcyjnych niedotkniętych efektem samoabsorpcji. W spektroskopii XAS w trybie fluorescencji, widmo promieniowania fluorescencyjnego jest mierzone dla energii wiązki padającej o różnych wartościach w zasięgu badanego progu absorpcji. Efekt samoabsorpcji wynika z dużej zmienności współczynnika absorpcji w obszarze rezonansu i nasila się z rosnącymi grubością i gęstością próbki. W metodzie HEROS, widmo emisyjne jest mierzone dla pojedynczej energii wiązki padającej o wartości poniżej danej krawędzi absorpcji. W konsekwencji, efekt samoabsorpcji jest zredukowany do jedynie prawdopodobieństwa reabsorpcji wyemitowanego promieniowania fluorescencyjnego opuszczającego próbkę, które to prawdopodobieństwo jest zazwyczaj prawie stałe w zakresie mierzonych wartości energii emisji. Widmo emisyjne zmierzone metodą HEROS można następnie użyć do obliczenia widma absorpcyjnego, korzystając z formalizmu matematycznego Kramers'a-Heisenberg'a. Niewrażliwość metody HEROS na efekt samoabsorpcji jest pokazana na przykładzie zmierzonych nią widm absorpcyjnych progu $L_{3}$ tantalu (Ta). Pomiary wykonano na linii SuperXAS synchrotronu Swiss Light Source (SLS) w Paul Scherrer Institute (PSI) w Villigen (Szwajcaria). Za pomocą metody HEROS zmierzono widma emisyjne w obszarze ener- 
gii emisji $L \alpha_{1}$ Ta dla dziewięciu próbek tantalowych o różnych grubościach. Otrzymane widma następnie użyto do zrekonstruowania widm absorpcyjnych krawędzi $L_{3}$ Ta. Zaobserwowano, że kształty krzywych widmowych w widmach zarówno emisyjnych, jak i absorpcyjnych, są niezależne od grubości poszczególnych próbek i zatem od efektu samoabsorpcji. Otrzymane wyniki opublikowano w czasopiśmie Physical Review Letters [1].

W Rozdziale IV opisano przykład zastosowania metody HEROS w doświadczeniu in situ, mającym na celu zbadanie przebieg reakcji chemicznej z udziałem katalizatora tantalowego na nośniku krzemionkowym. Doświadczenie przeprowadzono w synchrotronie SLS. Użyteczność metody HEROS w badaniach nad przebiegiem reakcji chemicznych w czasie rzeczywistym wynika nie tylko z dużej szybkości pomiaru gęstości stanów nieobsadzonych, jaką ta metoda umożliwia. Dużą zaletą metody HEROS jest również jej niewrażliwość na efekt samoabsorpcji, który zależy od stężeń substratów, mogących zmieniać się podczas reakcji. Analiza mierzonych kolejno metodą HEROS widm, każde z czasem akwizycji 40 s, podczas utleniania badanych próbek (nieaktywny związek Ta oraz związek Ta aktywowany w atmosferze wodoru), dostarczyła kilka ciekawych wyników. Są to np. formowanie się dimerów tantalu oraz etapowy charakter przejścia nieaktywnego katalizatora tantalowego w swoją utlenioną formę. Doświadczenie to opublikowano w czasopiśmie naukowym Physical Chemistry Chemical Physics [2].

Praca opisana w Rozdziale V pokazuje, że metoda HEROS jest stosowalna w pomiarach z użyciem wiązki fotonowej lasera rentgenowskiego. W pracy tej użyto metodę HEROS do zbadania struktury elektronowej atomów miedzi w różnych stopniach utlenienia. Pomiary przeprowadzono w ośrodku LCLS (LINAC Coherent Light Source) w Menlo Park (Kalifornia, USA), z wiązką lasera rentgenowskiego pracującego w trybie self-seeding. Widma emisyjne zmierzone metodą HEROS dla $\mathrm{Cu}^{1+}$ porównano z widmami otrzymanymi tą samą metodą dla $\mathrm{Cu}^{0}$ i $\mathrm{Cu}^{2+}$ opublikowanymi w Ref. [3] oraz z obliczeniami przeprowadzonymi na podstawie referencyjnych widm absorpcyjnych jak i na podstawie widm absorpcyjnych obliczonych za pomocą programu FEFF 9.6. Pokazano, że metoda HEROS dostarcza szczegółowych informacji o strukturze elektronowej badanego materiału również w przypadku użycia bardzo jasnych, impulsowych źródeł promieniowania rentgenowskiego o bardzo krótkim czasie trwania pulsów (femtosekundy). W dodatku, przeprowadzone doświadczenie pokazało, że metoda HEROS umożliwia pomiar widm osobno dla każdego pulsu promieniowania z lasera rentgenowskiego, co czyni ją bardzo atrakcyjną w zastosowaniach ze źródłami XFEL, ze względu 
na znaczne fluktuacje intensywności promieniowania pomiędzy pulsami, które mają wpływ jedynie na całkowitą intensywność mierzonych widm, pozostawiając kształt krzywych widmowych niezmienionym. 




\section{Chapter I}

\section{Introduction to X-ray spectroscopy}

\section{I.1 Introduction}

In this chapter a brief introduction to X-ray spectroscopy is presented. X-ray spectroscopy has a long history and nowadays lively progress in this scientific field is still being made. Books and review articles treating of this subject are published every year. To obtain a profound introduction to the field of X-ray spectroscopy one may wish to refer to e.g. X-ray fluorescence spectrometry (R. Jenkins, 1999) [4] or to X-ray and inner-shell processes (edited by R. L. Johnson, H. Schmidt-Böcking and B. F. Sonntag, 1997) [5].

Development of knowledge on the structure of atom at the beginning of $20^{\text {th }}$ century was tightly bound with the evolving understanding of the electromagnetic radiation's nature [6]. Despite the fact that before Wilhelm Röntgen X-rays were already observed, it was he who did a systematic research on X-ray radiation (also referred to as Röntgen radiation) and inspired new studies at the end of $19^{\text {th }}$ century. Together with Max Planck's suggestion in 1900 that electromagnetic radiation is quantized (it comes in discrete amounts) started evolution of quantum mechanics which soon was to break classical understanding (or rather ununderstanding) of the structure of atom. In 1913 Niels Bohr, inspired by Planck's suggestion and Ernest Rutherford's nuclear picture of atom from 1911, introduced the planetary model of atom which predicted one quantum number. In the same year, in 1913, William Henry Bragg and his son William Lawrence Bragg studied diffraction of X-rays on crystals and Henry Moseley noticed regularities in characteristic X-ray radiation. Two years later Arnold Sommerfeld developed Bohr's model by additional quantum numbers. Albert Einstein's work Zur Quantentheorie der Strahlung from 1916 presented quantum mechanical description of radiation. The experiment done by Otto Stern and Walther Gerlach in 1921 proved 
spatial quantization of atomic electrons' magnetic momenta. The Compton effect discovered in 1922 confirmed that electromagnetic radiation consists of quanta (the term photon was introduced by Gilbert Lewis in 1926). The intense development of quantum theory in the years 1923 - 1928 was crowned by establishing Paul Dirac's equation. Quantum mechanics around 1930 was already a theory well describing atomic electrons and its further development was focused on nuclear and particle physics.

According to the current state of knowledge, atom is a bound system of nucleus and electrons. Almost whole atom's mass is concentrated in the nucleus which is composed of neutrons and protons. The atomic number $Z$, which is equal to the number of nuclear protons, determines spatial configuration of states around the nucleus occupiable by electrons. This configuration is described by the Schrödinger equation and is not continuous but allows electrons to move around the nucleus only on certain surfaces, on so called orbitals. Electron associated to a given orbital has constant negative energy whereas energies associated to different orbitals, called binding energies or orbital energies or energy levels, are not the same. Orbitals which are more distant from the nucleus have lower energies and are more densely located. In materials, such as solids, Coulombic potentials of neighboring atoms' nuclei overlap forming a continuous band of states allowing electrons to travel freely in the material's structure. The energy threshold separating the atomic orbitals' energies from those of the continuum states is called Fermi level. The number of electronic states available on different orbitals and in continuum is usually described with a continuous energy-dependent function called density of states (DOS).

Motion of atomic electrons is quantized and is described by three parameters: principal $n$, angular $l$ and magnetic $m$ quantum numbers. The allowed values of $n$ are positive integers, angular quantum numbers $l$ can have values $0,1, \ldots, n-1$ and quantum numbers $m:-l,-l+1, . ., 0, \ldots, l-1, l$. Quantum numbers define different orbitals and their energies. Group of orbitals of the same $n$ is called shell and group of the same $n$ and $l$ is termed subshell. If the spin-orbit interaction is considered, the subshells are described by the quantum numbers $n, l$ and $j$, where $j=l \pm \frac{1}{2}$. Most common notations used when referring to different orbitals are given by the so called atomic notation and the notation introduced by the International Union of Pure and Applied Chemistry (IUPAC) [7] (see Tab. I.1).

Each neutral atom of atomic number $Z$ has $Z$ electrons. Since electrons are fermions, at most two electrons can have the same energy and thus at most two electrons can be associated to one orbital. The way the electrons are distributed among the 
Table I.1: Correspondence between atomic levels, IUPAC subshell notations and associated orbitals.

\begin{tabular}{|c|c|c|c|}
\hline $\begin{array}{l}\text { Quantum numbers } \\
\quad n l j\end{array}$ & Atomic level & $\begin{array}{c}\text { Subshell } \\
\text { by IUPAC }\end{array}$ & $\begin{array}{l}\text { Orbitals } \\
(n l m)\end{array}$ \\
\hline $101 / 2$ & $1 s_{1 / 2}$ & $K$ & $\left(\begin{array}{lll}1 & 0 & 0\end{array}\right)$ \\
\hline $201 / 2$ & $2 s_{1 / 2}$ & $L_{1}$ & $\left(\begin{array}{lll}2 & 0 & 0\end{array}\right)$ \\
\hline $211 / 2$ & $2 p_{1 / 2}$ & $L_{2}$ & $\left(\begin{array}{lll}2 & 1 & 0\end{array}\right)$ \\
\hline $213 / 2$ & $2 p_{3 / 2}$ & $L_{3}$ & $\left(\begin{array}{lll}2 & 1 & 1\end{array}\right),\left(\begin{array}{lll}2 & 1 & -1\end{array}\right)$ \\
\hline $301 / 2$ & $3 s_{1 / 2}$ & $M_{1}$ & $\left(\begin{array}{lll}3 & 0 & 0\end{array}\right)$ \\
\hline $311 / 2$ & $3 p_{1 / 2}$ & $M_{2}$ & $\left(\begin{array}{lll}3 & 1 & 0\end{array}\right)$ \\
\hline $313 / 2$ & $3 p_{3 / 2}$ & $M_{3}$ & $\left(\begin{array}{lll}3 & 1 & 1\end{array}\right),\left(\begin{array}{lll}3 & 1 & -1\end{array}\right)$ \\
\hline $323 / 2$ & $3 d_{3 / 2}$ & $M_{4}$ & $\left(\begin{array}{lll}3 & 2 & 1\end{array}\right),\left(\begin{array}{lll}3 & 2 & -1\end{array}\right)$ \\
\hline $325 / 2$ & $3 d_{5 / 2}$ & $M_{5}$ & $\left(\begin{array}{lll}3 & 2 & 2\end{array}\right),\left(\begin{array}{lll}3 & 2 & 0\end{array}\right),\left(\begin{array}{lll}3 & 2 & -2\end{array}\right)$ \\
\hline $401 / 2$ & $4 s_{1 / 2}$ & $N_{1}$ & $\left(\begin{array}{lll}4 & 0 & 0\end{array}\right)$ \\
\hline $411 / 2$ & $4 p_{1 / 2}$ & $N_{2}$ & $\left(\begin{array}{lll}4 & 1 & 0\end{array}\right)$ \\
\hline $413 / 2$ & $4 p_{3 / 2}$ & $N_{3}$ & $\left(\begin{array}{lll}4 & 1 & 1\end{array}\right),\left(\begin{array}{lll}4 & 1 & -1\end{array}\right)$ \\
\hline $423 / 2$ & $4 d_{3 / 2}$ & $N_{4}$ & $\left(\begin{array}{lll}4 & 2 & 1\end{array}\right),\left(\begin{array}{lll}4 & 2 & -1\end{array}\right)$ \\
\hline $425 / 2$ & $4 d_{5 / 2}$ & $N_{5}$ & $\left(\begin{array}{lll}4 & 2 & 2\end{array}\right),\left(\begin{array}{lll}4 & 2 & 0\end{array}\right),\left(\begin{array}{lll}4 & 2 & -2\end{array}\right)$ \\
\hline $435 / 2$ & $4 f_{5 / 2}$ & $N_{6}$ & $(432),(430),(43-2)$ \\
\hline $437 / 2$ & $4 f_{7 / 2}$ & $N_{7}$ & 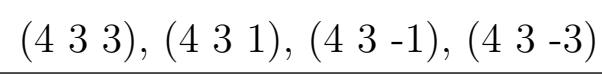 \\
\hline
\end{tabular}

available states is described by the so called Aufbau principle. In a simplified picture, the orbitals' occupancy is arranged in such a way that the whole system's potential energy is minimal, which results in fully occupied inner (core) orbitals with usually unoccupied outer (valence) orbitals.

An excited or singly ionized atom with a vacancy in a core level may decay radiatively: an outer shell electron fills the inner shell vacancy and a photon is emitted. The energy of the photon is given by the difference of the binding energies of the two atomic levels involved in the transition. If there is a single vacancy in the initial and final state, the transition is named diagram transition. The most probable diagram transitions are $E 1$ transitions, i.e., transitions which satisfy the electric dipole selection rules $(\Delta l= \pm 1, \Delta j=0, \pm 1$, parity change between the initial and final state wave function $\Delta \pi=$ yes). Different notations are used in the literature for radiative or X-ray transitions. The clearest one consists to define the transition by the subshells where the vacancy is located in the initial and final state, using for the subshells the IUPAC 
notation, e.g. $K-L_{3}$, or the atomic notation, e.g. $1 s-2 p_{3 / 2}$. An alternative consists to use the terminology introduced by Siegbahn, e.g. $K \alpha_{1}$ instead of $K-L_{3}$. The most intense $K, L$ and $M$ E1 diagram transitions are presented graphically in Fig. I.1 with their corresponding Siegbahn notation. If there is more than one vacancy in the initial and final state, the X-ray is emitted with a slightly higher energy than the parent diagram line. Such X-rays are called satellite $X$-ray lines, while the additional holes which are not directly involved in the transition are named spectator vacancies. In general, the shift in energy increases with the principal quantum number of the subshell where the transition electron comes from and decreases with the principal quantum number of the spectator vacancy.

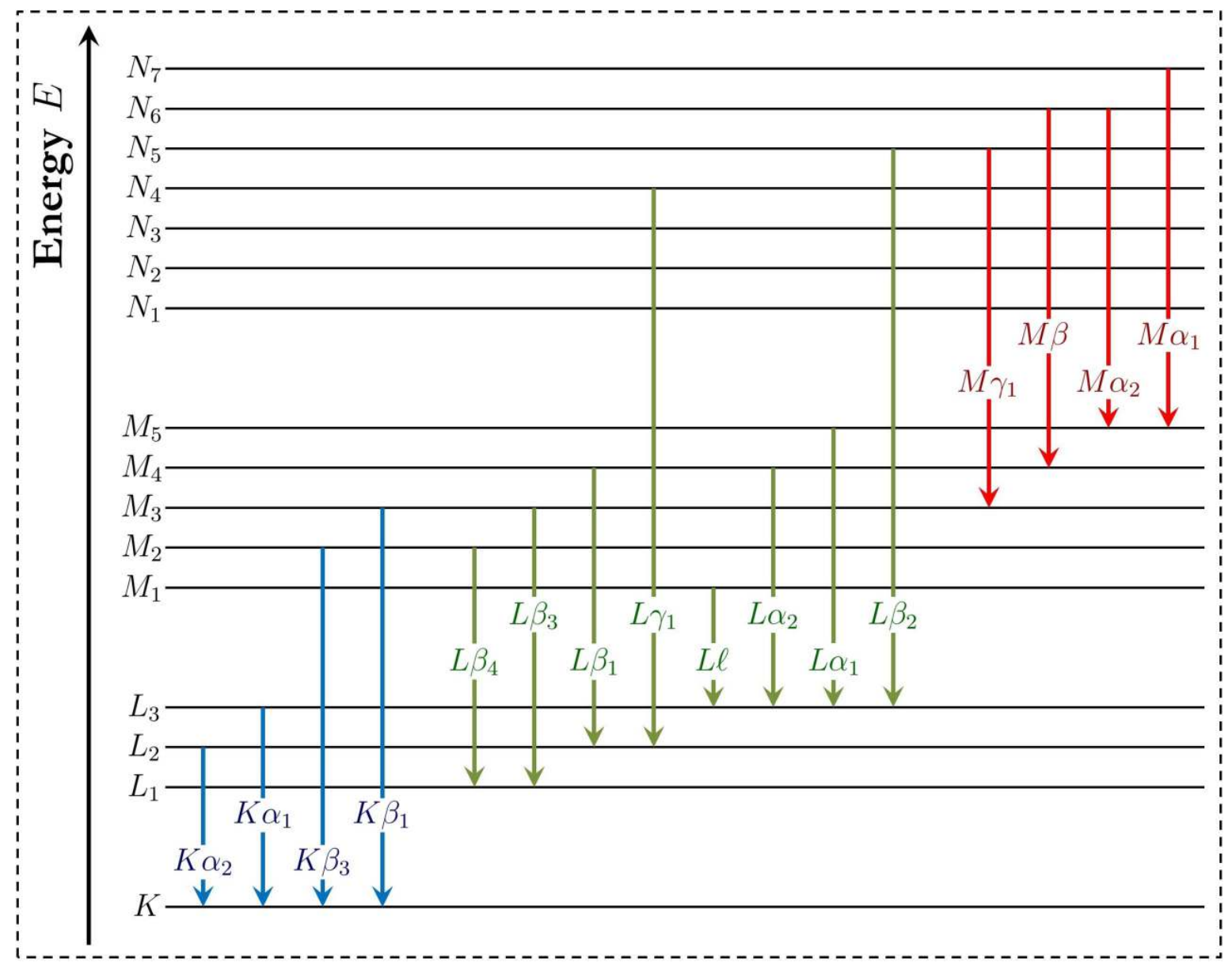

Figure I.1: Most intense $K, L$ and $M$ X-ray transitions. The arrows show electron transition paths (the transitions of the vacancies occur in the opposite directions). The transitions are labeled with their corresponding Siegbahn notation. The vertical axis corresponds to the electrons' binding energy. The energy spacing of the atomic levels is not at scale.

Atoms can interact with electromagnetic radiation through different processes whose cross sections are predominantly dependent on the radiation energy and atomic num- 
ber $Z$ of the interacting atoms. Cross sections of the possible photon-atom interaction processes are plotted for $\mathrm{Ta}(Z=73)$ as a function of the incident photon energy in Fig. I.2, In photoabsorption, an electron located on an orbital $i$ of energy $E_{i}$ absorbs the energy $\hbar \omega_{1}$ of the electromagnetic radiation which results either in its promotion to an unoccupied state located on a higher unoccupied orbital (photoexcitation), or, if the absorbed energy is high enough, i.e. if $\hbar \omega_{1}>\left|E_{i}\right|$, the electron (named in this case

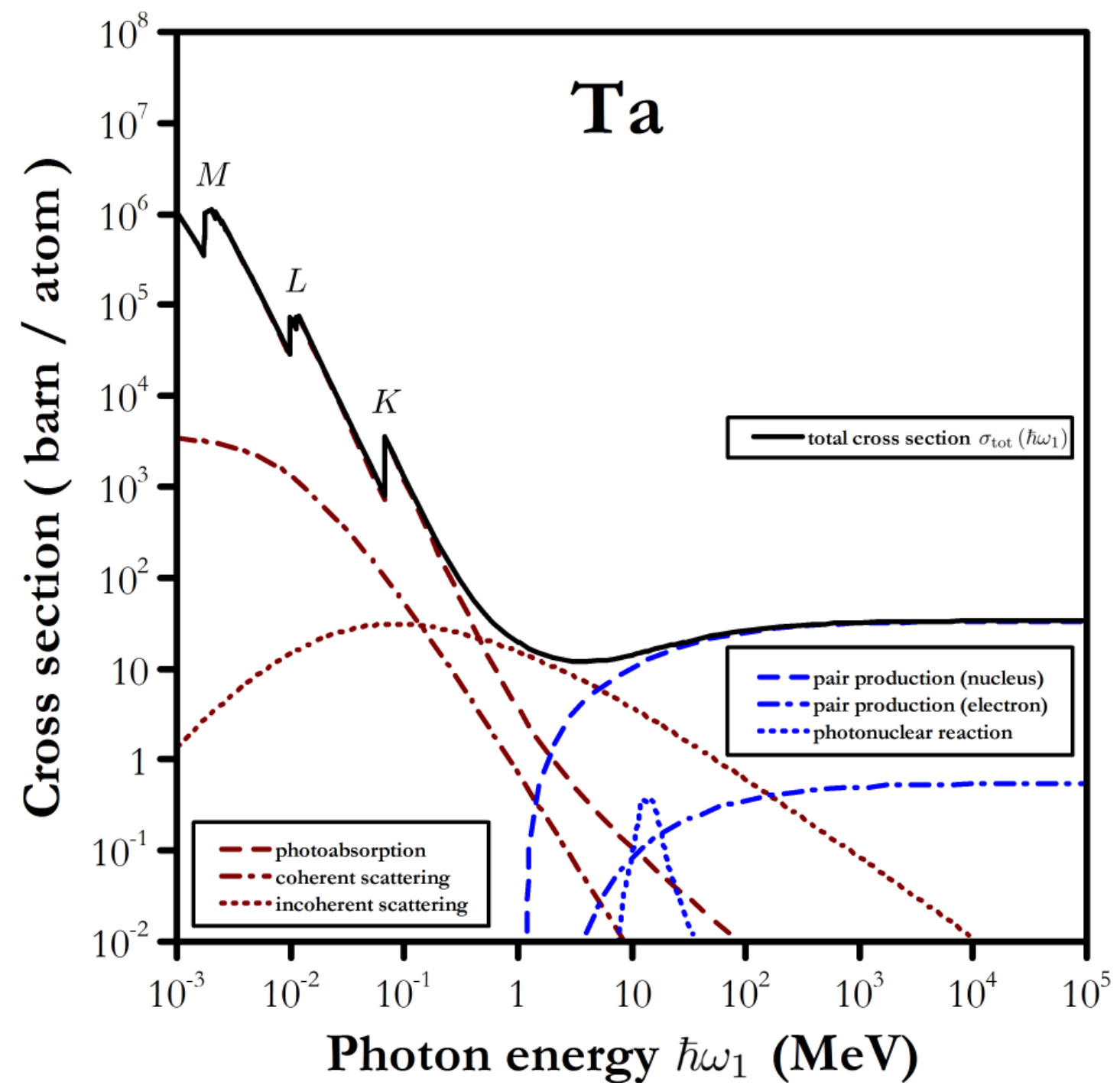

Figure I.2: Total cross section $\sigma_{\text {tot }}$ for interaction of photons with Ta atoms $(Z=73)$ plotted as a function of the incident photon energy $\hbar \omega_{1}$. Also shown are the contributions from different processes. The values of the cross section for the photonuclear reaction were taken from Ref. [8] and cross sections for all the remaining interaction processes come from Ref. [9]. Local discontinuities in the $\sigma_{\text {tot }}\left(\hbar \omega_{1}\right)$ dependence, observed for incident beam energy crossing binding energies of subsequent Ta $K-, L-$, and $M$-shell orbitals, are called absorption edges. 
photoelectron) is ejected from the atom (photoionization or photoeffect). The minimum energy needed to remove an electron on the level $i$, here denoted by $\left|E_{i}\right|$, out of an atom is referred to as ionization threshold. Removal of an electron from an orbital leads to the creation of a so called vacancy (or hole) in this orbital, which results into an atom's excited or ionized state. Photons can be also scattered on atomic electrons through coherent scattering or incoherent scattering. Coherent (also referred to as elastic or classical) scattering is an elastic collision of photons with inner shell electrons (it is then described as Rayleigh scattering) or with electrons located on valence orbitals or in the continuum (Thomson scattering). Coherent scattering leaves the atom in its ground state. In incoherent scattering (also known as inelastic scattering or Compton scattering), a photon scatters on an atomic electron and provides it with a part of its energy. The scattered photon has different energy than that of the incident photon and propagates along another direction. Incoherent scattering occurs mostly on electrons from valence orbitals and depends smoothly on $Z$. In the pair production process, the interaction of a photon with the strong electric field of the nucleus or of the electrons causes that photon energy is converted into an electron-positron pair. Due to the energy conservation, pair production can occur only if the photon energy is higher than twice the electron's rest mass energy (i.e. if $\hbar \omega_{1} \geqslant 1.022 \mathrm{MeV}$ ). In photonuclear reaction (also called nuclear photoelectric effect or photodisintegration) a photon is absorbed by the nucleus which is left in an excited state before decaying via the emission of a $\gamma$-ray or internal conversion process.

Interaction of an atom with electromagnetic radiation (or with charged particles) may lead to its ionization. The ion (i.e. the atom with one or more vacancies) deexcites to its ground state through fluorescence or through Auger decay. In fluorescence an electron from a higher level $f$ fills the vacancy with the emission of a photon whose energy $\hbar \omega_{2}$ is equal to $\left|E_{i}\right|-\left|E_{f}\right|$. Such a transition leads to the creation of a vacancy in the level $f$, which is next filled by another electron and so on until all core holes are filled. Fluorescence is thus a spontaneous cascade of radiative atomic deexcitations. In Auger decay the electron transition from the level $f$ to the level $i$ is accompanied by the ejection of another atomic electron (this process is also called radiationless decay). The Auger decay is an autoionizing process since it increases the ionization degree of the atom by one unit. If one of the two vacancies in the final state is in the same shell as the vacancy in the initial state, the Auger transition is named Coster-Kronig (CK) transition. For instance, if the initial hole in the subshell $L_{1}$ is filled by a $L_{3}$ electron with the simultaneous emission of a $M_{5}$ electron, the transition $L_{1}-L_{3} M_{5}$ is 
a CK transition. Note that CK transitions are energetically allowed only for certain regions of the periodic table.

\section{I.2 X-ray emission spectroscopy (XES)}

$\mathrm{X}$-ray radiation is an electromagnetic radiation of energy in the order of $0.1-100 \mathrm{keV}$ (i.e., of wavelengths in the range $10-0.01 \mathrm{~nm}$ ), covering thus the energy range between the ultraviolet and the gamma rays. X-ray spectrometry is the ensemble of methods used to measure X-ray spectra. Depending on their energy, X-rays are usually divided into three categories, namely soft $X$-rays (below $2 \mathrm{keV}$ ), tender $X$-rays (between $2 \mathrm{keV}$ and $\sim 8 \mathrm{keV}$ ) and hard $X$-rays (above $\sim 8 \mathrm{keV}$ ). Application of X-ray spectrometry to study the X-ray radiation emitted from matter through different atomic processes is the scope of the discipline called $X$-ray emission spectroscopy (XES) 10, 11]. The spectra measured in XES are called X-ray emission spectra or XES spectra.

As mentioned in Section I.1, the creation of a vacancy in any atomic level leads to a cascade of spontaneous electronic deexcitations (fluorescence) governed by the selection rules. The photons emitted in this process are essentially X-rays and XES is used to measure their spectral energy distribution. Creation of a vacancy can be achieved in two ways: by irradiating the investigated material with a beam of X-rays of energy high above the binding energy of a given absorption edge or by bombarding the target with charged particles (electrons, protons or highly charged ions). The latter case is not discussed in this work. XES applied to the detection of X-ray-induced fluorescence is referred to as non-resonant XES (NXES). In NXES studies the excitation photon beam does not need to be of a well defined energy as long as it provides X-rays of energy above the ionization threshold of interest. Fluorescence photons have energies strictly correlated with the energies of the electronic levels involved in the deexcitations. Furthermore, for valence-to-core level transitions the intensity of the fluorescent radiation is proportional to the occupancy of the valence orbitals. NXES provides thus an element-specific tool to determine not only the energy differences between the atomic levels but also the density of occupied states.

For illustration, the NXES $\mathrm{Cu} K \mathrm{X}$-ray emission spectrum from a $\mathrm{CuO}$ sample is depicted in Fig. I.3. Shown are the strong core-to-core $K \alpha_{1}, K \alpha_{2}$ and $K \beta_{1,3} \mathrm{X}$-ray lines corresponding respectively to the $L_{3}-K, L_{2}-K$ and $M_{3,2}-K$ electron transitions (see Fig. I.1), as well as the weak valence-to-core $K \beta_{2,5}\left(N_{2,3^{-}}, M_{4,5^{-}} K\right)$ and $K \beta^{\prime \prime} \mathrm{X}$-ray lines. The intensity ratio of about 2 between the $K \alpha_{1}$ and $K \alpha_{2}$ lines originates from the number 
of electrons in the $2 p_{3 / 2}(4)$ and $2 p_{1 / 2}$ (2) levels. The $K \beta_{1,3}$ line is less intense than the $K \alpha_{1,2}$ lines because the overlap between the $1 s$ and $3 p$ levels is smaller than that of the 1 s and $2 p$ wave functions, which leads to a smaller transition probability. The spin-orbit doublet $K \beta_{1,3}$ is not resolved because for $\mathrm{Cu}$ the energy separation between the $M_{3}$ and $M_{2}$ subshells $(2.2 \mathrm{eV})$ is smaller than the natural width (see below) of the two transitions (about $3.4 \mathrm{eV}$ ). The intensity of the valence-to-core X-ray lines is about 1000 times weaker than that of the $K \alpha_{1,2}$ lines due to the nearly-vanishing overlap of the wave functions corresponding to the $1 s$ and valence orbitals. Valence-to-core X-ray transitions are nevertheless of interest because valence orbitals are uniquely sensitive to spatial distribution of neighboring atoms. Depending on the chemical surrounding of the fluorescing atoms, the measured valence-to-core emission lines may have different intensities and can be shifted in energy. NXES grants therefore the access to the study of the chemical environment of the fluorescing atoms, in particular the ligand orbitals and bond distances (see e.g. Refs. $[12[14]$ ).

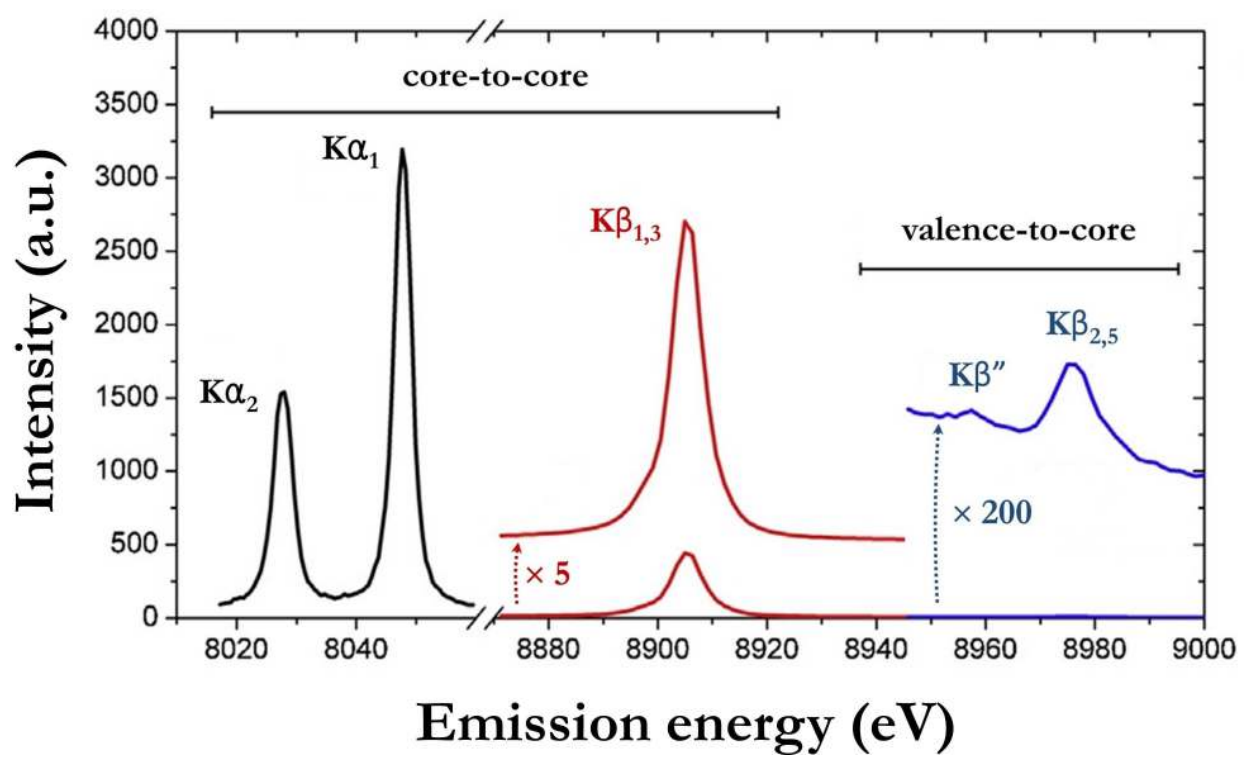

Figure I.3: High-resolution $K \mathrm{X}$-ray emission spectrum of $\mathrm{Cu}$ from a $\mathrm{CuO}$ oxide sample (taken from Ref. [15]). Transitions involving electrons from the $2 p, 3 p$ and valence levels are shown.

The width of a measured X-ray line results from the lifetime broadening of the corresponding transition and the energy resolution of the employed detector. The lifetime broadening is due to the finite lifetimes of the vacancy in the initial and final levels. These finite lifetimes $\tau_{i}$ and $\tau_{f}$ lead via the Heisenberg uncertainty principle to some uncertainty $\frac{\hbar}{\tau}$ on the energy of the two levels. As a consequence the energy of the transition will be affected by the uncertainty $\Delta E=\frac{\hbar}{\tau_{i}}+\frac{\hbar}{\tau_{f}}$. Actually, it can be 
shown that for a given X-ray transition, the energy distribution of the emitted photons corresponds to a Lorentzian function whose width is equal to the uncertainty $\Delta E$. This width is called the natural width of the transition $\left(\Gamma_{\text {nat }}\right)$. On the other hand, the instrumental response of the detector can be well reproduced in most cases by a Gaussian function. The energy resolution of the detector $\Gamma_{\text {instr }}$ is then given by the full width at half maximum (FWHM) of the Gaussian, i.e., by $\Gamma_{\text {instr }} \cong 2.35 \times \sigma_{\text {instr }}$, where $\sigma_{\text {instr }}$ is the standard deviation of the Gaussian. As the convolution of a Lorentzian with a Gaussian results in a so-called Voigt function, the shapes of measured X-ray lines correspond to Voigt profiles. Thus, to extract the natural width of a measured X-ray line, the latter should be deconvolved, using the known instrumental broadening. However, reliable results can only be obtained if the energy resolution of the detector is comparable to the natural linewidth of the transition, which requires the use of high energy resolution instruments such as crystal spectrometers (see Section I.4.2).

$\mathrm{X}$-ray emission has unique properties when the incident photon energy is around a given absorption edge. In this case (resonant regime), X-ray emission can occur via fluorescence or via a coherent absorption-emission process. XES applied in the resonant regime is called resonant XES (RXES) and it is discussed in Section II.3.

\section{I.3 X-ray absorption spectroscopy (XAS)}

X-ray absorption spectroscopy (XAS) [16, 17] corresponds to an ensemble of experimental techniques aiming at measuring the absorption of $\mathrm{X}$-ray radiation in materials for changing radiation energy. X-ray absorption spectra (or XAS spectra) represent therefore the variation of the absorption of the incoming X-ray radiation by the irradiated sample as a function of the radiation energy. The absorption of an X-ray beam of intensity $I_{0}$ perpendicular to the sample is defined by: $I_{\text {abs }}(z)=I_{0}\left(1-\mathrm{e}^{-\mu_{\text {tot }} z}\right)$, where $z$ stands for the penetration depth of the radiation into the sample and $\mu_{\text {tot }}$ represents the total linear absorption coefficient. The latter depends on the energy of the radiation and on the absorbing material. If the sample thickness or the distance $z$ is expressed in $\frac{\mathrm{g}}{\mathrm{cm}^{2}}$, the total mass absorption coefficient $\frac{\mu_{\text {tot }}}{\rho}$, where $\rho$ is the sample density, is preferably used. For a collimated X-ray beam of energy $\hbar \omega_{1}$, the total linear absorption coefficient is given by: $\mu_{\text {tot }}\left(\hbar \omega_{1}\right)=\sigma_{\mathrm{ph}}\left(\hbar \omega_{1}\right)+\sigma_{\text {coh }}\left(\hbar \omega_{1}\right)+\sigma_{\text {incoh }}\left(\hbar \omega_{1}\right)$, where $\sigma_{\mathrm{ph}}$, $\sigma_{\text {coh }}$ and $\sigma_{\text {incoh }}$ represent the cross sections for the photoelectric effect and the elastic and inelastic scattering processes, respectively. For the energy range corresponding to X-rays, the cross sections $\sigma_{\text {coh }}$ and $\sigma_{\text {incoh }}$ are much smaller than $\sigma_{\mathrm{ph}}$ and they vary 
only smoothly with $\hbar \omega_{1}$ so that the overall shape of the absorption spectrum and the characteristic features of the latter originate mainly from the photoeffect process. If the incoming energy $\hbar \omega_{1}$ is bigger than the electron binding energy of a given subshell, the photoeffect becomes energetically possible, which leads to an abrupt increase of $\mu_{\text {tot }}$ at this energy. These step-like increases of $\mu_{\text {tot }}$ or $I_{\text {abs }}$ in XAS spectra are called absorption edges (see Fig. I.2). If the energy $\hbar \omega_{1}$ of the incoming X-rays is smaller but close to the absorption edge, the photoelectron is no longer removed from the atom but it can be promoted into an unfilled or unoccupied outer level. This so-called photoexcitation gives rise to fine structures that are observed around the absorption edge. The photoexcitation cross section depends mainly on the occupancy of the valence and interatomic orbitals. As a result, while XES spectra provide information on the density of occupied electronic states, XAS spectra reflect the density of unoccupied states around and above the Fermi level. In both the photoionization and photoexcitation, the whole photon energy is given to the photoelectron and the photon disappears. For this reason, the term photoabsorption has relevance for photoionization as well as for photoexcitation.

The methods used in XAS are: transmission mode, fluorescence mode (or fluorescence yield) and electron yield [19,20]. Their basic concepts are depicted in Fig. I.4(a). In the transmission mode the studied material is irradiated with an X-ray beam of energy $\hbar \omega_{1}$ and the intensities of the incident beam $I_{0}$ and of the transmitted beam $I_{\mathrm{t}}$ are measured. Depending on the attenuation length $z$ (which depends on the sample thickness and irradiation angle), the total linear attenuation coefficient $\mu_{\text {tot }}$ can be calculated using the Bouguer-Lambert-Beer law $I_{\mathrm{t}}\left(\hbar \omega_{1}, z\right)=I_{0}\left(\hbar \omega_{1}\right)-I_{\text {abs }}\left(\hbar \omega_{1}, z\right)=$ $I_{0}\left(\hbar \omega_{1}\right) \mathrm{e}^{-\mu_{\text {tot }}\left(\hbar \omega_{1}\right) z}$. Fluorescence mode XAS makes use of the XES methods, which allows to study how the fluorescence intensity $I\left(\hbar \omega_{2}\right)$ changes with the incident photon energy $\hbar \omega_{1}$. It has been observed that the fluorescence yield $F Y\left(\hbar \omega_{1}, \hbar \omega_{2}\right)=\frac{I\left(\hbar \omega_{1}, \hbar \omega_{2}\right)}{I_{0}\left(\hbar \omega_{1}\right)}$ depends on the photoabsorption coefficient $\mu_{\mathrm{ph}} \sim \sigma_{\mathrm{ph}}$ and its variation in $\hbar \omega_{1}$ provides the same information as the absorption spectra measured in the transmission mode XAS [19]. The fluorescence mode XAS spectrum can be obtained using either the total fluorescence yield (TFY) or the partial fluorescence yield (PFY). In TFY the fluorescence yield $F Y$ is integrated over a broad emission energy range $\hbar \omega_{2}$, while in $\mathrm{PFY}$ it is integrated over a selected emission energy range. In particular, $F Y$ integrated over an energy band centered at a given fluorescence line and narrower than the natural linewidth of the latter is referred to as high resolution XAS (HR-XAS) or high-energy resolution fluorescence detected XAS (HERFD-XAS) 21, 22]. HR-XAS 


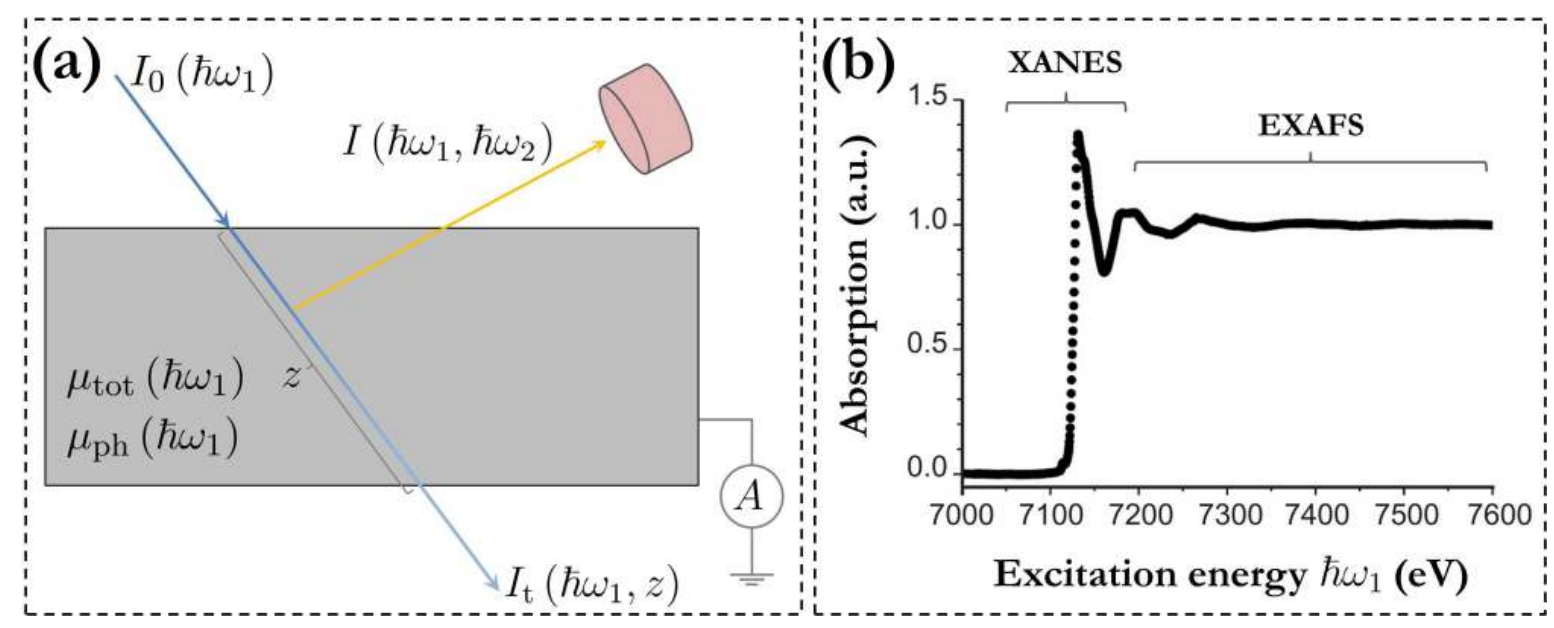

Figure I.4: (a) An outline of the XAS methods' experimental setups. The gray rectangle symbolizes the studied sample which is made of material characterized by total linear attenuation coefficient $\mu_{\text {tot }}$ and linear photoabsorption coefficient $\mu_{\mathrm{ph}}$. The blue lines show path of the incident and the transmitted X-ray beams. The orange line marks the exit path of the fluorescence radiation and the detecting system is marked with the pink cylinder. See text for explanation. (b) The $K$ edge XAS spectrum of $\mathrm{Fe}$ atoms in a celadon ceramic measured in the fluorescence mode [18]. The region of the absorption spectral curve in a close vicinity of the ionization threshold is termed $X$-ray absorption near edge structure (XANES) and the one starting from tens of electronvolts above the edge is called extended $X$-ray absorption fine structure (EXAFS). The most prominent feature in XANES is called white line. The plot in (b) was reproduced from Ref. 18 .

spectra provide more detailed information on the $\mu_{\mathrm{ph}}\left(\hbar \omega_{1}\right)$ dependence and is widely used for chemical speciation (see e.g. Refs. 23 26]). The fluorescence lines chosen in HR-XAS measurements are typically the ones induced by the core-to-core electron deexcitations. They are characterized by a much higher intensity as compared to the fluorescence originating from valence-to-core electronic transitions and by a much better separation in the emission energy scale. In XAS studies done in electron yield (EY) mode, the studied sample is irradiated with an X-ray beam and the electric current in the sample is measured. Interaction with radiation leads indeed to an increase of the number of free electrons in the material, with the main contribution of photoelectrons and Auger electrons ejected from the atoms as a result of photoabsorption. The electron yield can be therefore used as a probe of the photoabsorption coefficient and it has been demonstrated that it provides the same information as compared to other XAS methods 20, 27].

As shown in Fig. I.2, the variation of the photoabsorption cross section as a function 
of the X-ray energy $(0.1-100 \mathrm{keV})$ has in general a downward trend. Locally absorption grows by jumps as the photon energy crosses subsequent ionization thresholds enabling electrons from consecutive orbitals to undergo photoionization into the continuum. The dependence of the photoabsorption cross section on the incident photon energy (i.e. excitation energy) in the vicinity of an ionization threshold is illustrated in Fig. I.4(b) for the $K$ edge absorption spectrum of iron. As shown, the absorption spectrum is characterized mainly by a sudden jump-like increase of the absorption as the X-ray energy crosses the absorption edge. Furthermore, there are subtle features which arise from a changing density of unoccupied discrete states localized around the Fermi level and above. The fragment of the absorption spectral curve in a close vicinity of the ionization threshold is termed X-ray absorption near edge structure (XANES) or near edge X-ray absorption fine structure (NEXAFS) or X-ray absorption fine structure (XAFS). The region extending from tens of electronvolts above the edge is called extended X-ray absorption fine structure (EXAFS). The XANES features reflect the density of empty valence states [28]. Analysis of the EXAFS oscillations, which arise from photoexcitation to unoccupied states localized in interatomic orbitals, provides information on the local geometric structure around the absorbing atom [29].

\section{I.4 Instrumentation}

\section{I.4.1 Production of X-rays}

Production of X-rays that can be used in XES and XAS experiments can be realized in different ways. Commonly employed methods are based on irradiating a given material with charged particles (typically electrons or protons) which induce Bremsstrahlung and fluorescence. In less common approaches a secondary fluorescer is inserted in the primary X-ray beam, which provides a characteristic X-ray radiation of a better defined spectral energy distribution, however, at the cost of the intensity. $\gamma$ rays from radionuclides ( such as ${ }^{241} \mathrm{Am},{ }^{109} \mathrm{Cd},{ }^{153} \mathrm{Gd},{ }^{155} \mathrm{Eu},{ }^{145} \mathrm{Sm}$ ) are also used, both directly and in the secondary fluorescer mode. In this section only production of X-rays with $\mathrm{X}$-ray tubes and synchrotrons is discussed.

An X-ray tube consists mainly of two electrodes placed in a high vacuum and connected to a very stable high-voltage generator able to provide voltages of typically 40 $100 \mathrm{kV}$. When the generator is on, electrons are emitted by the cathode (which is typically a coil of tungsten wire), accelerated in the electric field between the electrodes and 
impinge the anode, which leads to the emission of Bremsstrahlung and characteristic $\mathrm{X}$-rays whose energy depends on the element the anode is made of. The emitted radiation escapes the tube through a sealing window (typically made of beryllium) which absorbs low-energy X-rays. The intensity of the produced photon beam is bigger for higher atomic number $Z$ of the anode material, for higher electric currents and higher voltages. Depending on the experimental conditions, low-power and high-power X-ray tubes are used, capable of working with powers of $0.5-1 \mathrm{~kW}$ and $2-4 \mathrm{~kW}$, respectively. Very low-power compact X-ray tubes are also available $(\sim 10 \mathrm{~W})$; in these devices the cathode may be irradiated with a laser beam which leads to the emission of electrons through the photoelectric effect. In the low-power and the high-power X-ray tubes the anode (typically made of $\mathrm{Sc}, \mathrm{Cr}, \mathrm{Cu}, \mathrm{Mo}, \mathrm{Rh}, \mathrm{Ag}, \mathrm{W}$ or $\mathrm{Au}$ ) heats up strongly. To maintain a low and stable temperature the anode element is plated or cemented on a block of copper connected to a water cooling system. The X-ray beam escaping from an X-ray tube is polychromatic, as presented in Fig. I.5(a). Its spectrum contains the continuous distribution of Bremsstrahlung photons (determined by the tube's voltage) and the discrete emission lines from the anode's material fluorescence. X-ray tubes are compact and relatively bright X-ray sources and are mainly applied in laboratory setups.

Synchrotrons are highly specialized facilities dedicated to the production of a very bright and monochromatic electromagnetic radiation of energy ranging from tens of $\mathrm{eV}$ to hundreds of $\mathrm{keV}$. In synchrotrons an electron beam (in which the electrons are grouped in bunches) is accelerated to $\mathrm{GeV}$-energies and is kept circulating along a storage ring by means of bending magnets. Relativistic electrons pass through magnetic fields generated by bending magnets and so called insertion devices (wigglers and undulators) installed in the storage ring. Interaction of electrons with the magnetic fields causes change of the electron propagation direction which leads to the emission of electromagnetic radiation. The electromagnetic beam produced at synchrotrons has a pulsed structure with pulse durations ranging typically from picoseconds to nanoseconds. At bending magnets and insertion devices, experimental stations (so called beamlines) are built and equipped with specialized optics used for collimation, monochromatization and focusing of the photon beam. Depending on the photon beam characteristics and equipment installed, different beamlines allow for studies in many specialized scientific fields, such as XAS, X-ray scattering, X-ray diffraction and X-ray imaging to mention a few of them.

One of the main characteristics of X-ray sources is the brilliance defined as the 

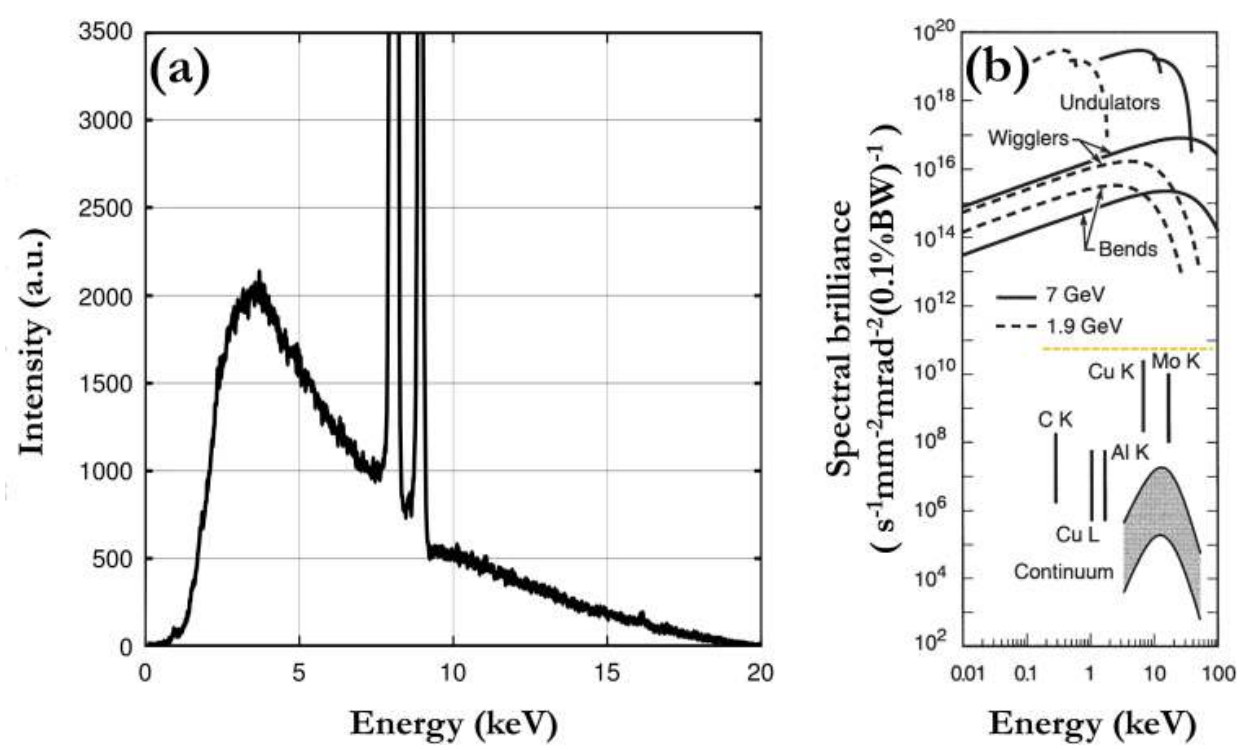

Figure I.5: (a) Spectrum of an X-ray beam produced with an X-ray tube with $\mathrm{Cu}$ anode operated at a voltage of $20 \mathrm{kV}$ [30]. The spectrum contains continuous contribution from the Bremsstrahlung photons ending at $20 \mathrm{keV}$ and the discrete $\mathrm{Cu} K \alpha_{1,2}$ and $K \beta_{1,3}$ fluorescence lines. The cutoff seen below $3.5 \mathrm{keV}$ is an effect of absorption of the low-energy X-rays in the tube's window. The plot was reproduced from Ref. [30]. (b) Comparison of spectral brilliances of different X-ray sources. Below the orange dashed line: X-ray tubes with different anode materials; above: synchrotron's bending magnets (Bends) and insertion devices. The synchrotron's spectral brilliances are given for two electron beam energies. The plot was reproduced from Ref. 31].

number of produced photons per unit time, per source size (in the plane transverse to the observation direction) and per unit divergence of the produced photon beam. In case of synchrotrons the observation direction lies in the storage ring's plane and in the same plane is defined the beam's divergence. Brilliance is higher for higher rates of the photon production, for smaller photon source sizes and smaller photon beam's divergences. The spectral brilliance is the brilliance per $0.1 \%$ bandwidth $(B W)$, i.e., the brilliance divided by $0.1 \%$ of the energy of the produced photons. The spectral brilliance thus grows with increasing monochromaticity of the produced photon beam. From among all the insertion devices used at synchrotrons, undulators have the highest spectral brilliances and, as shown in Fig. I.5(b), the reachable values are in the order of $10^{9}$ higher than the ones achievable with X-ray tubes. Synchrotrons are $3^{\text {rd }}$ generation $\mathrm{X}$-ray sources while $4^{\text {th }}$ generation sources, the so called $X$-ray free-electron lasers (XFELs), operate since 2009. XFEL is described more in detail in Section V.2. 


\section{I.4.2 Detection of X-rays}

\section{Introduction}

Depending on the type of employed detectors, X-ray spectrometry is usually divided into two categories, namely the energy-dispersive and wavelength-dispersive X-ray spectrometry (EDS and WDS, respectively). In this section a brief description of the instrumentation used in EDS and WDS is presented. An exhaustive introduction to X-ray spectrometry methods can be found in, e.g., Refs. 32 34].

\section{Energy-dispersive X-ray spectrometry (EDS)}

In EDS detectors such as gas counters, scintillators and solid state detectors, the X-ray energy $E$ is converted into a voltage pulse of height $V[32,33]$. Such detectors are characterized by the following parameters: quantum counting efficiency, linearity, proportionality and resolution. Quantum counting efficiency is the ratio of the intensity of the beam absorbed in the detector to the intensity of the beam incident on it. It reflects therefore the detector's efficiency. Linearity refers to whether the number of electronic pulses produced by the device is in linear dependence with the incident photon beam intensity. If so, the detector is said to be linear. The detector is proportional if the heights of the produced voltage pulses are linearly dependent on the X-ray energies. Finally, the resolution of the detector is a measure of the scatter $\Delta V$ of the output voltage pulses' heights $V$ induced by the absorption of monoenergetic photons. The relative energy resolution is given by $\frac{\Delta E}{E}=\frac{\Delta V}{V}$ so that the (absolute) energy resolution of an EDS detector is $\Delta E=\frac{\Delta V}{V} E$. The distribution in energy of monoenergetic photons measured with an EDS detector corresponds in most cases to a Gauss function. The energy resolution of the detector is then just equal to the full width at half maximum (FWHM) of this Gaussian. High resolution is important to separate close-lying X-ray lines.

The lowest resolution among commonly used X-ray detectors have scintillation detectors. These devices are composed of two parts: a scintillation material optically coupled to a photomultiplier. The scintillator is typically a sodium iodide crystal doped with thallium. The interaction of X-rays with the scintillator causes the emission of visible light. The photomultiplier converts the pulses of visible light into electronic signals which are next amplified and registered by the connected electronics. Scintillation detectors are proportional and can be used to detect tender and hard X-rays.

Another type of instrumentation used in EDS are gas flow proportional detectors. 
They consist of a cylindrical tube (with few cm-diameter) and a thin wire (with thickness of tens of $\mu \mathrm{m}$ ) placed inside the tube along its radial axis. The tube is filled with inert gas (typically Ar) mixed with a quench gas (typically methane) and closed on one side by a very thin foil (entrance window) made of an X-ray poorly absorbing material. To compensate the possible loss of gas through the thin window, the gas pressure is kept constant in the chamber by a gas circulation system. An electric potential difference of about $1400-1800 \mathrm{~V}$ is applied between the tube and the wire. An X-ray passing through the gas medium ionizes it and the produced electric charges are separated in the tube by the applied electric field. The separated charges are collected on the electrodes, which leads to a short voltage variation that is detected by the connected electronics. Gas flow proportional detectors are mainly used for the detection of soft and tender X-rays. Gas detectors provide a few times higher resolution than scintillation detectors. Gas scintillation detectors, combining principles of both scintillators and gas detectors, are also met. These devices consist of a gas tube and a photomultiplier. Recombination of inert gas' ions created by ionizing radiation causes emission of ultraviolet photons which are next registered by a photomultiplier.

The best resolution in EDS is achieved with solid state detectors. The main part of these devices is a semiconductor diode, made of $\mathrm{Si}$ or $\mathrm{Ge}$, to which a reverse bias voltage of about $1000 \mathrm{~V}$ is applied, which removes remaining charge carriers. Incoming X-rays ionize the diode's medium and create hole-electron pairs whose numbers depend on the energies of the absorbed photons. The free electrons are swept from the diode by the reverse bias voltage and collected on the electrodes which build with the semiconductor a small capacitor. The electric charge accommodated on the capacitor is released at a certain frequency and an output voltage pulse is formed whose height depends on the charge collected and thus on the X-ray energy. Solid state detectors are therefore proportional. To keep the dark noise at small values, i.e., to preserve the resolution, solid state detectors must be operated at low temperature. Small size detectors are cooled down using Peltier elements, detectors with bigger volumes (up to some tens of $\mathrm{cm}^{3}$ ) with liquid nitrogen.

\section{Wavelength-dispersive X-ray spectrometry (WDS)}

Detection of X-ray radiation in WDS is done with X-ray spectrometers [34. X-ray spectrometers are detecting systems composed of a crystal (also called analyzer), which spatially disperses X-rays of different energies through the Bragg diffraction, and a detector, which registers the Bragg-diffracted photons. In contrast to EDS, where the 
detectors act as both counters and analyzers, in WDS the measured X-rays are analyzed by the crystal and the detector's role is reduced to count the spatially dispersed photons. As a result, the spectrometer's energy resolution depends only on the divergence of the incident beam, the crystal's Darwin width and the diffraction angle. The obtained relative energy resolution $\frac{\Delta E}{E}$ is typically of the order of $10^{-4}$, i.e., more than 100 times better than the one of common EDS detectors.

According to the Bragg's law, photons of energy $E$ will be diffracted by a crystal at a Bragg angle $\theta$ meeting the relation $E(\theta)=\frac{h c}{2 d_{h k l}} \frac{n}{\sin \theta}$, where $h$ stands for the Planck's constant, $c$ for the speed of light in vacuum, $n(n=1,2,3 \ldots)$ for the diffraction order and $d_{h k l}$ for the spacing of the crystal's diffraction planes defined by the Miller's indices $(h k l)$. The Bragg angle $\theta$ is the angle between the diffraction planes and the direction of propagation of the incident (or the diffracted) photon beam. Depending on the cut of the crystal, diffraction planes can be parallel to the irradiated surface of the crystal plate or perpendicular to it. In the first case (Bragg case) the WDS is named reflection- or Bragg-type crystal spectrometer, in the second case (Laue case) transmission- or Laue-type crystal spectrometer.

In Laue-type spectrometers the analyzed X-ray beam has to pass through the crystal's bulk before it reaches the detector. Since absorption grows drastically with decreasing X-ray energy, transmission-type spectrometers are usually not used for detection of photons of energy below about $15 \mathrm{keV}$. On the other hand, design of the Bragg-type spectrometers restricts the range of usable reflection angles to above $20^{\circ}$, which corresponds to photon energies below $7-12 \mathrm{keV}$ (note that $E(\theta) \sim \sin ^{-1} \theta$ ).

The crystals used in X-ray spectrometers are plane or curved and single- or multiplecrystal arrangements can be employed. Plane-crystal spectrometers provide the best resolution but are extremely inefficient because of the tiny diffracting area of the crystal which can cover only very small solid angles with respect to the X-ray source. With curved crystal spectrometers the diffracting area is much bigger but the corresponding increase of the solid angle is attenuated by the larger distance between the X-ray source and the crystal. This distance is indeed in the same order of magnitude as the radius of curvature and the latter cannot be too small (typically $20 \mathrm{~cm}-300 \mathrm{~cm}$ ) to preserve a curvature of good enough quality. In addition the limited crystal's reflectivity and, in the Laue case, the absorption in the crystal of the incoming and diffracted radiation contribute to further diminish the spectrometer's efficiency. Curved-crystal spectrometers have a slightly worse resolution as compared to plane-crystal setups.

Among Bragg-type curved-crystal spectrometers two different setup's geometries 
are distinguished, depending on whether the crystals used are bent in the dispersive or nondispersive plane. In the former case, a Johann [35] or Johansson geometry 36] can be used, whereas the latter case corresponds to the von Hámos geometry [37]. In the geometries of Johann and Johansson, since the analyzing crystal is bent in the dispersive plane, the focusing on the detector (in these geometries the detector serves only to count the diffracted photons) is realized only if the X-ray source, the crystal and the detector are placed on the so-called Rowland circle whose radius is half the one of the crystal's curvature. In these point-to-point focusing geometries photons of only one energy can be focused for a given Bragg angle so that an X-ray spectrum has to be scanned by varying the angle of both the crystal and detector step by step. As a result, measurements of X-ray spectra with spectrometers in the standard Johann's or Johansson's geometry are time consuming. This problem is not encountered with the von Hámos spectrometer equipped with a position sensitive detector (PSD). In this case, X-ray spectra covering energy ranges of typically tens of eV can be recorded in one shot. It can be noted here that Johann and Johansson spectrometers equipped with a PSD and operated with a defocused source can also collect photons within a certain energy range at once 38 .

\section{Comparison between EDS and WDS}

The relative resolutions and useful energy ranges of different energy-dispersive X-ray detectors are presented in Tab. I.2. The resolution of a Bragg-type wavelength-dispersive spectrometer equipped with different crystals is also given for comparison. Because of their poor resolution, scintillation and gas detectors are usually used as counters, i.e., for measurements of X-ray beam intensities. In particular, gas detectors are commonly used for monitoring the intensity of synchrotron radiation beams, in transmission mode XAS measurements and in wavelength-dispersive spectrometers with a point-to-point focusing geometry. Solid state X-ray detectors are characterized by a broad energy range detection (few to tens of $\mathrm{keV}$ ) and have a much better resolution as compared to scintillators and gas detectors. They allow the simultaneous measurement of many fluorescence lines within a short collecting time and are frequently used to determine the chemical composition of complex samples.

WDS instruments are not as flexible as EDS detectors in terms of covered energy ranges (in general different crystals are needed to cover different energy ranges). They are also less efficient and more complicated to operate but their energy resolution and their precision are far beyond those of EDS detectors. 
Table I.2: Comparison of useful energy ranges and resolutions between different types of X-ray energy-dispersive detectors and a Bragg-type crystal spectrometer. The resolutions are given for the energy of the $K \alpha$ fluorescence of $\mathrm{Cu}$ (8.04 $\mathrm{keV}$ ). The useful energy ranges and resolutions of the EDS detectors were taken from Ref. [32]. The spectrometer's resolutions were calculated with the XOP program [39]. Only the contribution of the Darwin's width was considered. The useful energy range quoted for the crystal spectrometer requires the use of several different crystals.

\begin{tabular}{l|c|c}
\hline Detector type & Useful energy range $(\mathrm{keV})$ & Resolution $\frac{\Delta E}{E}$ \\
\hline Energy-dispersive detectors & $6-60$ & \\
Scintillation & $0.2-8$ & $4 \times 10^{-1}$ \\
Gas flow proportional & $1.5-25$ & $1 \times 10^{-1}$ \\
Solid state (Si(Li)) & $1-15$ & $2 \times 10^{-2}$ \\
Wavelength-dispersive & & \\
spectrometers (Bragg-type) & & $8 \times 10^{-5}$ \\
$\mathrm{LiF}(200)$ & & $3 \times 10^{-5}$ \\
$\mathrm{LiF}(220)$ & & $1 \times 10^{-4}$ \\
$\operatorname{Si}(111)$ & & $1 \times 10^{-5}$ \\
$\operatorname{Si}(333)$ & & $2 \times 10^{-6}$ \\
$\operatorname{Si}(444)$ & & $3 \times 10^{-4}$ \\
$\operatorname{Ge}(220)$ & & \\
$\operatorname{Ge}(440)$ & & \\
\hline
\end{tabular}





\section{Chapter II}

\section{High energy resolution off-resonant spectroscopy (HEROS)}

\section{II.1 Introduction}

$\mathrm{X}$-ray emission spectroscopy (XES) is an ensemble of experimental methods dedicated to measurements of spectra of X-ray radiation emitted from matter. XES allows studying different features of the electronic structure of atoms and molecules in gases, liquids and solids. Resonant X-ray emission spectroscopy (RXES) is XES applied in the resonant conditions, i.e., when the incident photon energy is close to or above the binding energy of a given atomic core electron. RXES is used to study two X-ray scattering processes: resonant elastic X-ray scattering (REXS) 40,41 and resonant inelastic X-ray scattering (RIXS) [42, 43]. The REXS process delivers information on the spatial modulations of charge, spin and orbital degrees of freedom, whereas the RIXS process provides data on the density of unoccupied electronic states and the geometric orientation of the interacting atoms.

This work treats of the inelastic scattering of X-rays in the off-resonant conditions, i.e., on the inelastic scattering of photons having energies below a given absorption threshold. This process is also know as resonant X-ray Raman scattering. As is explained in Section II.2, the off-resonant inelastic X-ray scattering opens the way to studies of the occupancy of the electronic states situated below the Fermi level (i.e., valence discrete states) as well as the ones above the Fermi level (in the continuum). 


\section{II.2 Theoretical background}

Interaction of electromagnetic radiation with atomic electrons in the resonant regime, i.e., for incident photons energies not differing much from the binding energy of a given electronic level leads to enhanced (also called anomalous) X-ray scattering. The scattering can occur either elastically, where the photon energy remains unaffected by the interaction, or inelastically, where the energies of the incident and scattered photons differ. These two processes are distinguished using the terms resonant elastic X-ray scattering (REXS) and resonant inelastic X-ray scattering (RIXS). Some authors use the term resonant X-ray Raman scattering when referring to RIXS.

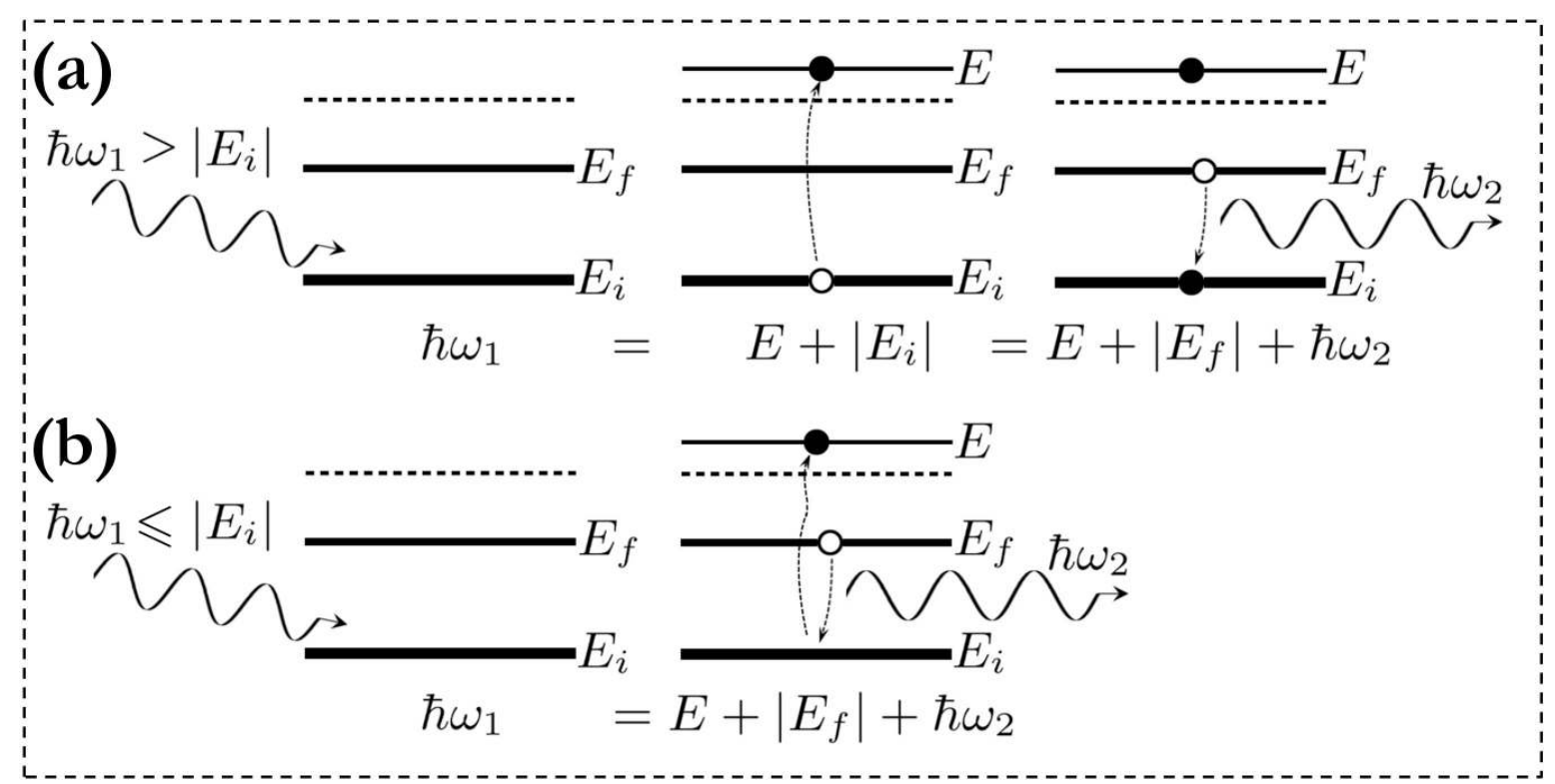

Figure II.1: Nonresonant and resonant inelastic scattering of X-rays of energy $\hbar \omega_{1}$ on atomic electrons involving excitation from the initial state of energy $E_{i}$ to an above-Fermi level unoccupied state of energy $E$ and deexcitation from the final state of energy $E_{f}$ with emission of a photon of energy $\hbar \omega_{2}$. The expressions below the diagrams indicate the total energy conservation of the atom-radiation system. For incident photon energies greater than the binding energy of a given core level the X-ray scattering process is stepwise and leads to characteristic fluorescence (a). In the case of on-resonance and off-resonant scattering, excitation and deexcitation occur coherently and the deep-core hole exists only in a virtual intermediate state (b).

The process of resonant inelastic scattering of X-rays on atomic electrons is shown schematically in Fig. II.1. The cross sections for the RIXS interaction channels depend on the photon energy and on whether the states involved in the scattering are situated in 
the continuum or if they are the discrete valence states. For the off-resonant scattering, i.e., when the energy of the incident X-ray photon is insufficient to promote a corelevel electron to an unoccupied state in the continuum (see Fig. II.1(b)), excitation and deexcitation occur coherently and the photoelectron is given additional energy at the expense of the emitted photon energy. The energy conservation implies that $\hbar \omega_{2}(E)=\hbar \omega_{1}-\left|E_{f}\right|-E$, meaning that the emission induced by an off-resonant excitation carries information on the unoccupied states to which the photoelectrons are promoted. Note that for the off-resonant scattering $\hbar \omega_{2}(E)<\left|E_{i}\right|-\left|E_{f}\right|$. Due to coherence of the core-hole excitation and deexcitation only the final state width contributes to the broadening of the scattered X-rays' spectrum. For photon excitation energies $\hbar \omega_{1}$ corresponding to an absorption threshold $\left|E_{i}\right|$, i.e., on-resonance, the X-ray scattering leads to resonance fluorescence. For incident photon energies above a given absorption threshold an electron from a core level $i$ is excited to an unoccupied state of energy $E$ localized in the continuum (see Fig. II.1(a)). The excitation is followed by deexcitation of an electron from another core level $f$ of energy $E_{f}$ and emission of X-ray fluorescence. Due to the energy conservation the emitted photon has an energy $\hbar \omega_{2}=\left|E_{i}\right|-\left|E_{f}\right|$ and the resulting emission spectrum is broadened by both the initial $i$ and final $f$ state widths. In the case of inelastic X-ray scattering on sub-Fermi level discrete state of energy $E_{\text {discrete, }}$, the energy conservation implies that $\hbar \omega_{2}=\hbar \omega_{1}-\left|E_{f}\right|+\left|E_{\text {discrete }}\right|$, and for resonance fluorescence the photoelectron energy $E=\hbar \omega_{1}-\left|E_{i}\right|$ is equal to $E_{\text {discrete. Note the constant energy transfer (energy loss) }}$ $\hbar \omega_{1}-\hbar \omega_{2}$ for the inelastic X-ray scattering on discrete states.

The cross section for scattering of X-rays on atomic electrons was first described by Kramers and Heisenberg [44] who transformed the classical dispersion formula introduced by Lorentz by application of the correspondence principle. The derivation of the Kramers-Heisenberg formula based on the quantum electrodynamics, starting from the Schrödinger equation, was performed by Dirac [45]. The author treated the Hamiltonian describing the scattering electromagnetic wave as a perturbation to the non-excited atom's Hamiltonian under minimal coupling approximation, i.e., taking into account only the interaction of the radiation with the interacting electron's charge distribution. Healy and Woolley [46, 47] showed that the Kramers-Heisenberg dispersion formula can also be obtained using the multipolar form of the non-relativistic Hamiltonian, i.e., including also effects of polarization, magnetization and diamagnetic fields on the radiation-electron interaction under assumption of non-relativistic velocities of the electron in the radiation field. 
In the approach of Tulkki and Åberg [48,49] the scattering radiation was described with a Hamiltonian from the Dirac equation. The authors treated the scattering radiation Hamiltonian as a perturbation to the non-excited atom's Hamiltonian and considered the interacting atom as a many-body system that can undergoes a transition from its initial state $|i\rangle$ to the final state $|f\rangle$ directly or through an intermediate state $|n\rangle$. The transition matrix $T_{f \leftrightarrow i}$ was derived by solving the starting Lippmann-Schwinger equation (which is a representation of the Schrödinger equation) describing an inelastic scattering process $\hbar \omega_{1}+A_{i}=\hbar \omega_{2}+A_{f}$, where $A_{i}$ and $A_{f}$ are the atom's energies before and after the scattering event, respectively. The found transition matrix was used to describe the scattering differential cross section $\left(\frac{\mathrm{d} \sigma}{\mathrm{d} \Omega}\right)_{f \leftrightarrow i} \sim\left|T_{f \leftrightarrow i}\right|^{2}$. The obtained generalized Kramers-Heisenberg formula has the following form [49]:

$$
\begin{aligned}
\left(\frac{\mathrm{d}^{2} \sigma\left(\hbar \omega_{1}\right)}{\mathrm{d}\left(\hbar \omega_{2}\right) \mathrm{d} \Omega}\right)_{f \leftrightarrow i}= & r_{0}^{2}\left(\frac{\hbar \omega_{2}}{\hbar \omega_{1}}\right) \delta\left(\hbar \omega_{1}+E_{i}-\hbar \omega_{2}-E_{f}\right) \\
& \times \mid\langle f|\exp (\imath \boldsymbol{k} \cdot \boldsymbol{r})| i\rangle\left(\boldsymbol{e}_{1} \cdot \boldsymbol{e}_{2}^{*}\right)+\frac{1}{m} \sum_{n}\left(\frac{\left\langle f\left|\boldsymbol{p} \cdot \boldsymbol{e}_{1}\right| n\right\rangle\left\langle n\left|\boldsymbol{p} \cdot \boldsymbol{e}_{2}^{*}\right| i\right\rangle}{E_{i}-E_{n}-\hbar \omega_{2}}\right. \\
& \left.+\frac{\left\langle f\left|\boldsymbol{p} \cdot \boldsymbol{e}_{2}^{*}\right| n\right\rangle\left\langle n\left|\boldsymbol{p} \cdot \boldsymbol{e}_{1}\right| i\right\rangle}{E_{i}-\mathcal{E}_{n}+\hbar \omega_{1}}\right)\left.\right|^{2},
\end{aligned}
$$

where $r_{0}$ and $m$ stand for electron's classical radius and rest mass, respectively. The symbols $\boldsymbol{e}_{1}$ and $\boldsymbol{e}_{2}$ denote unit complex vectors of the polarization of the incident and the scattered photons, respectively. The momentum operator is denoted by $\boldsymbol{p}$ and the term $\exp (\imath \boldsymbol{k} \cdot \boldsymbol{r})$ (with the imaginary unit $\iota$ ) comes from the vector potential associated with the scattering photon. The symbols $E_{n}$ and $\mathcal{E}_{n}$ both refer to the stationary intermediate-state energy, however, the latter accounts for the lifetime effects $\Gamma_{n}$ and in the case of non-overlapping intermediate states can be approximated by $E_{n}-\frac{1}{2} \imath \Gamma_{n}$. Note that the first-order term in Eq. II.1 describes the elastic scattering cross section and was used to be called by Fermi Golden Rule No. 2 [50]. The term containing the sum over all intermediate states $\left|\sum_{n}(\ldots)\right|^{2}$ refers to inelastic scattering (the two interaction channels are outlined in Fig. II.1), and was originally derived by Kramers and Heisenberg [44. It also refers to what Fermi used to call Golden Rule No. 1 [50]. Due to convergent reasoning of these researchers the generalized Kramers-Heisenberg formula is sometimes called generalized Fermi's golden rule or similarly.

Tulkki and Åberg considered off-resonant X-ray scattering $\left(\hbar \omega_{1} \ll\left|E_{i}\right|-\Gamma_{i}\right)$ within the dipole approximation $(\exp (\imath \boldsymbol{k} \cdot \boldsymbol{r}) \approx 1)$. They showed that in case of a good separation between the electronic states localized below Fermi level and in the continuum, 
the resonant term of Eq. II.1 can be split into a discrete and a continuous part. The obtained continuous part, describing the cross section for the inelastic X-ray scattering involving the unoccupied above-Fermi level states, is of the form [49]:

$$
\begin{aligned}
\frac{\mathrm{d} \sigma\left(\hbar \omega_{1}\right)}{\mathrm{d}\left(\hbar \omega_{2}\right)}=2 \pi r_{0}^{2} \int_{0}^{\infty} & {\left[\frac{\hbar \omega_{2}}{\hbar \omega_{1}} \frac{\left(\left|E_{i}\right|-\left|E_{f}\right|\right)\left(\left|E_{i}\right|+E\right)}{\left(\left|E_{i}\right|+E-\hbar \omega_{1}\right)^{2}+\Gamma_{i}^{2} / 4}\right.} \\
& \times \frac{\Gamma_{f} / 2 \pi}{\left(\hbar \omega_{1}-\hbar \omega_{2}-\left|E_{f}\right|-E\right)^{2}+\Gamma_{f}^{2} / 4} \\
& \left.\times g_{f \leftrightarrow i} \frac{\mathrm{d} g_{i}}{\mathrm{~d} E}(E)\right] \mathrm{d} E
\end{aligned}
$$

with final-to-initial state transition oscillator strength $g_{f \leftrightarrow i}$ and energy-distribution of the initial state-to-continuum transition oscillator strength $\frac{\mathrm{d} g_{i}}{\mathrm{~d} E}(E)$. The symbols $\Gamma_{i}$ and $\Gamma_{f}$ denote lifetime broadenings of the initial and the final states, respectively. Note that $\frac{\mathrm{d} g_{i}}{\mathrm{~d} E}(E)$ is proportional to the density of unoccupied states and is directly measured in X-ray absorption spectroscopy, whereas the fluorescence yield, which is measured in X-ray emission spectroscopy, is proportional to $\frac{\mathrm{d} \sigma\left(\hbar \omega_{1}\right)}{\mathrm{d}\left(\hbar \omega_{2}\right)}$. Eq. II.2 thus allows to retrieve an absorption spectrum from an off-resonant emission spectrum and vice versa.
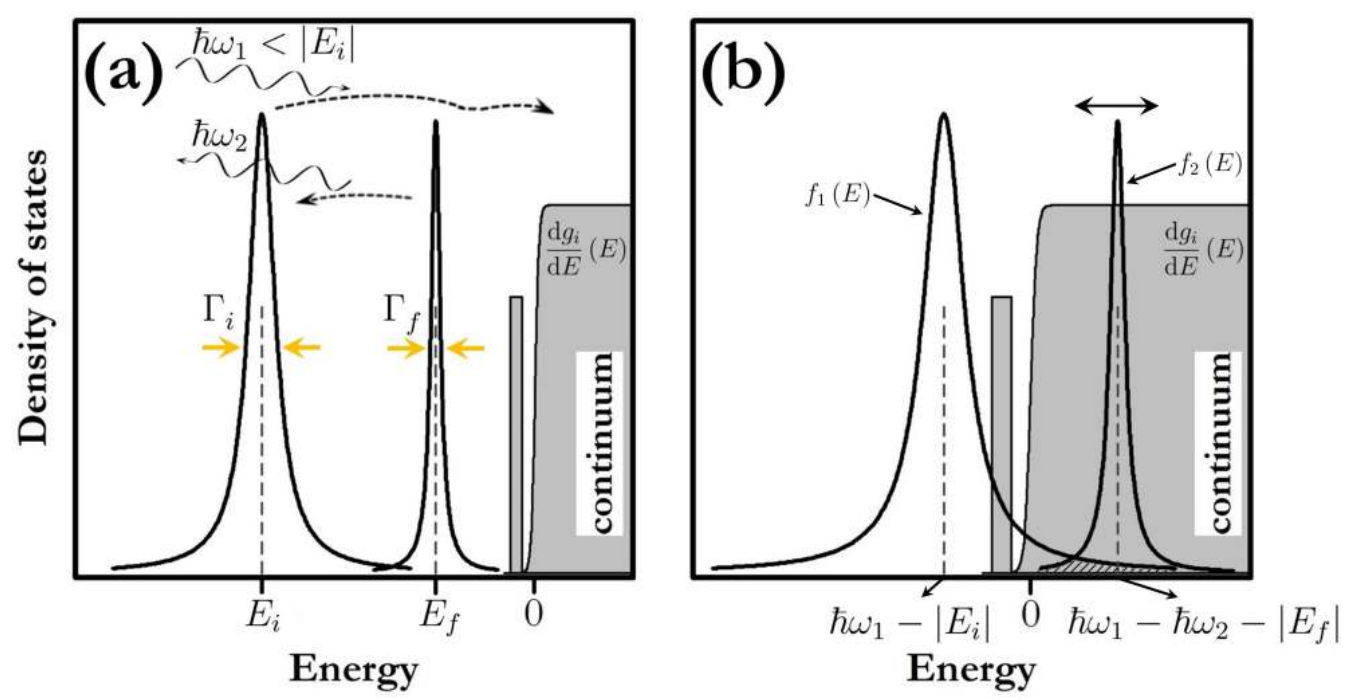

Figure II.2: Schematic of the off-resonant X-ray scattering. Typical distribution of the electronic states involved in the scattering is presented in (a). It includes the occupied initial $i$ and final $f$ states as well as the unoccupied states localized below the Fermi level (the discrete states) and in the continuum. The two Lorentzian functions and $\frac{\mathrm{d} g_{i}}{\mathrm{~d} E}(E)$ in the integrand in Eq. II.2 are depicted in (b) together with a discrete state distribution. The cross section described by Eq. II.2 can be interpreted as the common area under the two Lorentzian functions and the $\frac{\mathrm{d} g_{i}}{\mathrm{~d} E}(E)$ curve (hatched area). 
The integrand in Eq. II.2 is a product of three functions having the same variable $E$ : two Lorentzian functions and $\frac{\mathrm{d} g_{i}}{\mathrm{~d} E}(E)$. The Lorentzian functions, $f_{1}(E)$ and $f_{2}(E)$, have the same widths as the density distribution functions of the initial and the final states, $\Gamma_{i}$ and $\Gamma_{f}$, respectively (see Fig. II.2). The cross section described by Eq. II.2 is associated with the common area under the three functions constituting the integrand, as presented in Fig. II.2(b). If the incident photon energy is fixed below the initial state energy, the cross section depends only on the position of the $f_{2}(E)$ curve which is centered at $\hbar \omega_{1}-\hbar \omega_{2}-\left|E_{f}\right|$. As a consequence, one may conclude that an emission spectrum recorded for the incident photon energy fixed below an absorption threshold directly reflects the density of unoccupied states.

\section{II.3 Resonant X-ray emission spectroscopy (RXES)}

It is common to present the data recorded with RXES in the form of a three-dimensional plot showing the normalized emission intensity as a function of the incident beam energy and the emitted photons' energy. Such a plot is usually referred to as $3 D R X E S$ plane or 3D RIXS plane. The exemplary 3D RXES plane shown in Fig. II.3(a), presents the Ta $L \alpha_{1}$ XES data recorded for an incident beam energy tuned across the Ta $L_{3}$ edge energy $\left|E_{L_{3}}\right|=9.881 \mathrm{keV}$. As can be seen in Fig. II.3(b), the emission spectrum for an incident beam energy well above the absorption edge is simply a fluorescence line. Detuning the incident beam energy below the ionization threshold results in an asymmetric shape of the XES spectra. Such spectral profiles, which depend on the density of unoccupied states situated below the Fermi level (i.e., discrete valence states) as well as the ones above the Fermi level (in the continuum) (see Section II.2 for more details), are a consequence of the mechanism of the RIXS process in the off-resonant regime. The emission spectra integrated over an energy range centered at a selected emission line (here: Ta $L \alpha_{1}$ line) yield an absorption spectrum (see Fig. II.3(c)). The narrower the integration range, the more pronounced are the features in the absorption spectrum. In particular, if the integration is done over an energy range smaller than a given core level lifetime broadening, the obtained absorption spectrum is called high resolution XAS spectrum (HR-XAS spectrum). The diagonal line in Fig. II.3(a) connects the maxima of the photon intensity distributions corresponding to the scattering on a discrete state. The positions of the maxima are determined by the constant energy transfer condition (see Section II.2 for more details). The probability of scattering on the discrete state as a function of the scattering X-ray's energy is 


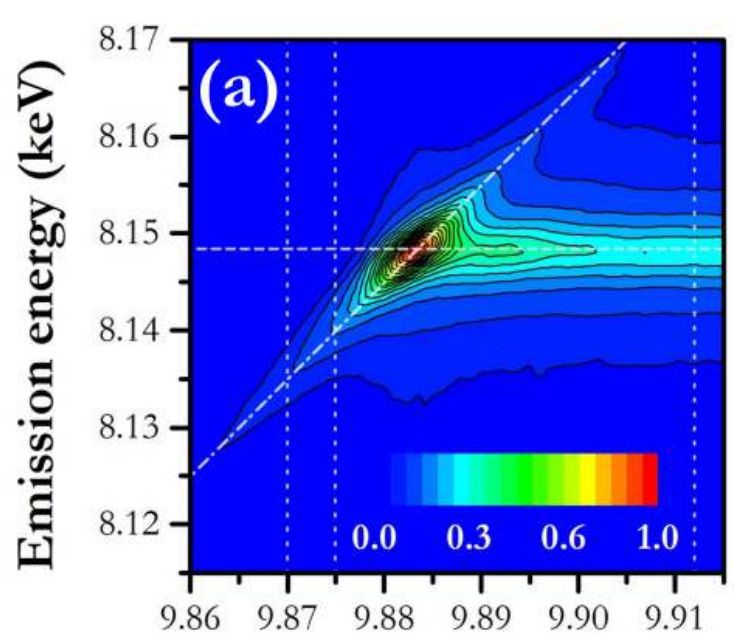

Excitation energy (keV)

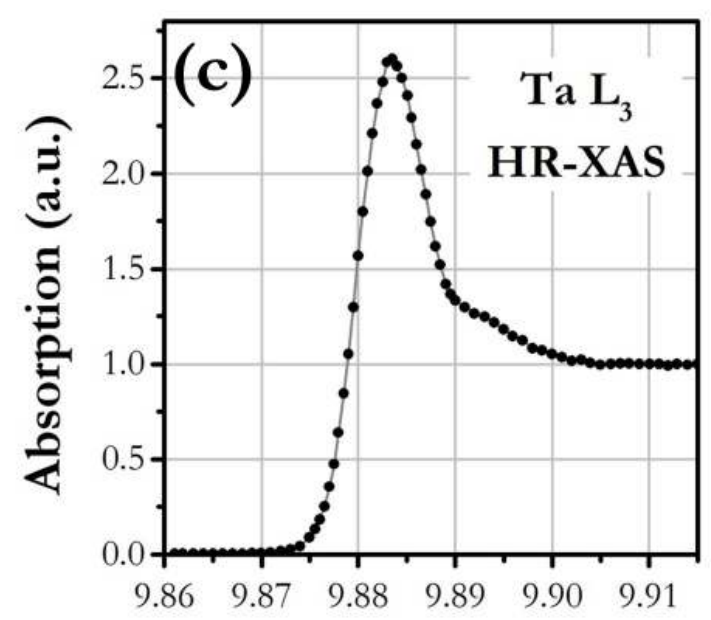

Excitation energy (keV)

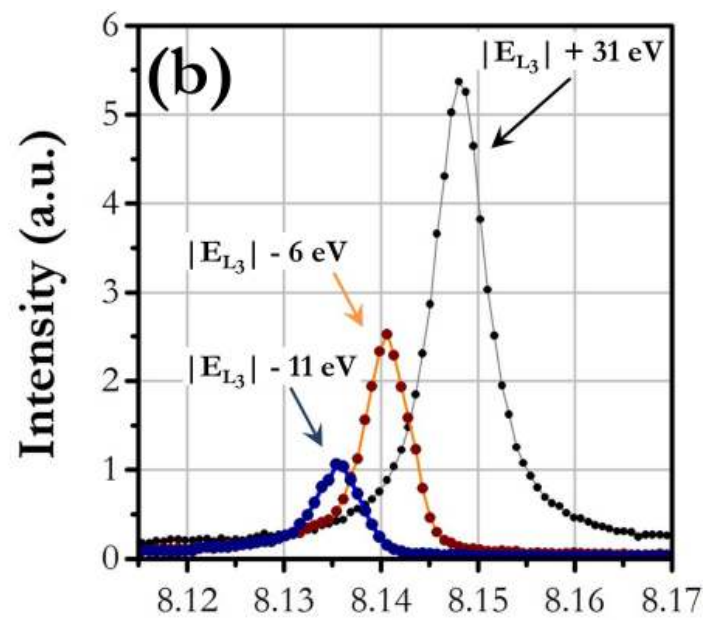

Emission energy (keV)

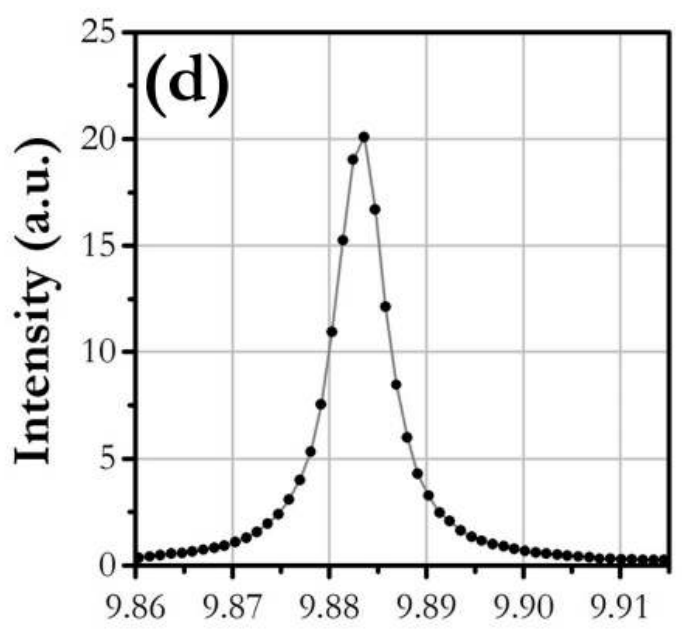

Excitation energy (keV)

Figure II.3: (a) 3D RXES plane showing Ta $L \alpha_{1}$ XES spectra as a function of the incident beam energy varied across Ta $L_{3}$ ionization threshold. (b) Emission spectra for three different incident beam energies marked with dotted lines in (a). For excitation energies well above the Ta $L_{3}$ absorption edge a normal Ta $L \alpha_{1}$ fluorescence line is detected. Emission spectra recorded for off-resonant excitation energies are characterized by a spectral shift, a decrease in intensity and an asymmetric spectral profile. (c) Ta $L_{3}$ edge high resolution XAS (HR-XAS) spectrum obtained by integration of the XES spectra over $2 \mathrm{eV}$-wide emission energy range centered at the Ta $L \alpha_{1}$ fluorescence line (dashed line in (a)). (d) Probability of X-ray scattering on the discrete state as a function of the incident $\mathrm{X}$-ray energy. The data points are the fluorescence yields along the diagonal dash-dotted line in (a) and the corresponding excitation energies.

presented in Fig. II.3(d). One should note that in the case metallic Ta it is very likely that there is a manifold of discrete sub-Fermi level states that merge into the 
continuum band. As a result, an appreciably broad white line is observed in the Ta $L_{3}$ edge absorption spectrum in Fig. II.3(c) as well as the broad probability distribution in Fig. II.3(d).

An alternative way of presenting RXES data is a three-dimensional plot similar to that in Fig. II.3(a) but with the emission energy scale replaced with the energy transfer (i.e., the difference between the incident and the scattered photons' energies) scale, as shown in Fig. II.4(a). Because of the constant energy transfer condition ruling inelastic $\mathrm{X}$-ray scattering on the discrete states, such a plot provides a convenient way to deduce the initial and the final states' lifetime broadening, assuming that the experimental resolution and the incident beam energy bandwidth are known. Section through a 3D RXES plane along the constant energy transfer determined by the energy conservation (see Section II.2 for more details), presented in Fig. II.4(b), yields a distribution function whose width reflects the initial state lifetime broadening $\Gamma_{i}$ (here: hole on the Ta $L_{3}$ level) convolved with the incident beam energy bandwidth. Section through

\section{Energy transfer (keV)}

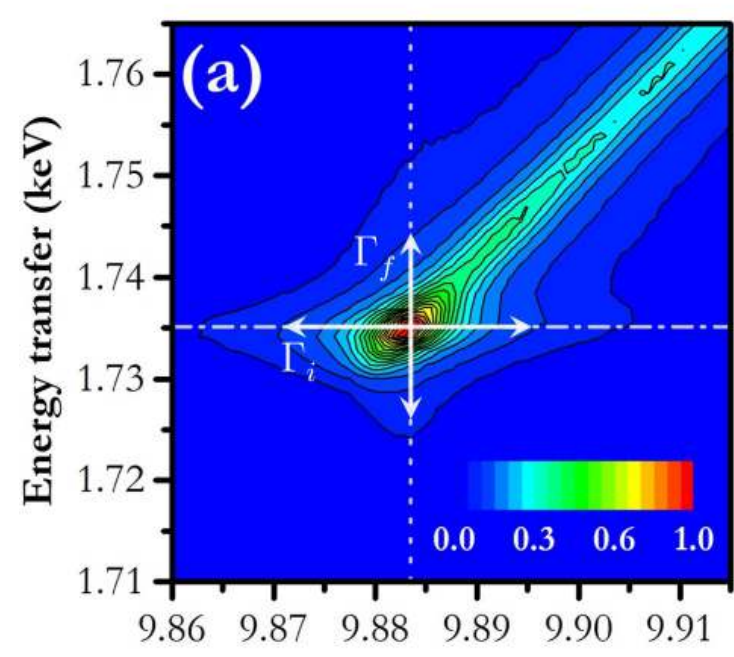

Excitation energy (keV)

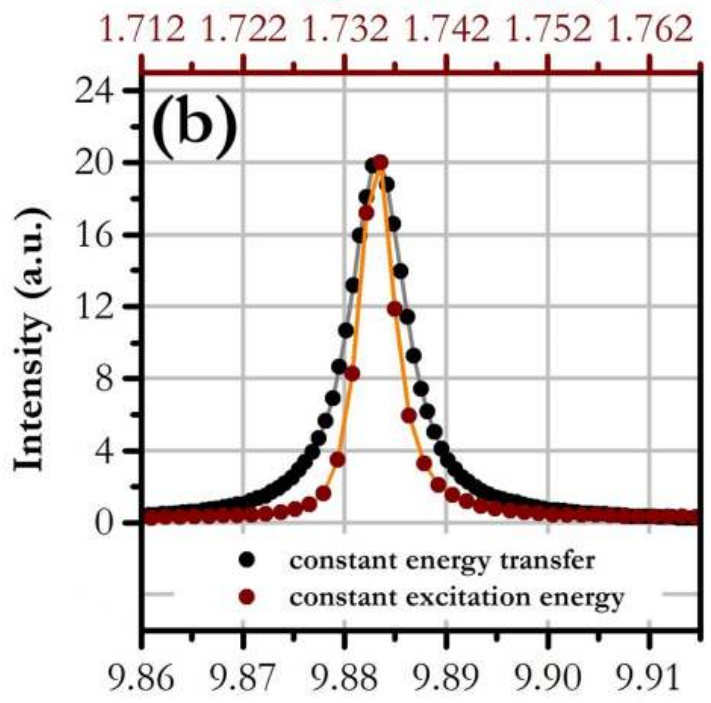

Excitation energy (keV)

Figure II.4: (a) 3D RXES plane showing the data from Fig. II.3(a) with the emission energy scale replaced with the energy transfer scale. (b) Sections through the 3D RXES plane in (a) for constant energy transfer (dash-dotted line) and excitation energy (dotted line). The obtained curves reflect the X-ray scattering probability on discrete states and their widths the initial state lifetime broadening for the constant energy transfer case, and the final states lifetime broadening for the constant excitation energy case.

a constant incident beam energy corresponding to excitation to the given discrete state provides a distribution function of a width depending on the final state lifetime 
broadening $\Gamma_{f}$ (here: hole on the Ta $M_{5}$ level) and the detection resolution. The described features are easily readable for atoms with well separated discrete sub-Fermi level states, which is usually the case for gaseous elements. In case of solids, such as metallic Ta, the discrete states are very likely to overlap with each other and extend to the Fermi level. This may make them hardly distinguishable and the initial and the final states' lifetime broadenings read from a 3D RXES plane may appear bigger than they really are.

\section{II.4 Development of HEROS}

The first measurements in the off-resonant regime were performed by Sparks [51], who did a systematic research on off-resonant X-ray emission from different elements. The apparatus he used, an X-ray tube with a single crystal monochromator and an energy-dispersive solid-state detector, was sufficient to allow observation of asymmetric structures in the off-resonant XES spectra. Moreover, the measured data revealed a dependence of the detected structures' positions on the energy of the atomic state from which the radiative decay occurred. Few years after Sparks' pioneering experiment, Tulkki and Åberg derived a formula describing cross section for the off-resonant inelastic X-ray scattering process starting from a generalized Kramers-Heisenberg formula 44 , 49]. Their finding brought new light to interpretation of the off-resonant XES spectra revealing that their shape is modulated by the density of unoccupied electronic states of the interacting atoms. This could not be observed in the work of Sparks due to the low resolution of the used detection setup. Because of the low cross section of the offresonant inelastic X-ray scattering only few off-resonant XES studies were successfully attempted since the work of Tulkki and Åberg. Nonetheless, with the development of high-resolution spectrometers the influence of the density of unoccupied states on the shape of the off-resonant XES spectra was confirmed experimentally with both conventional $\mathrm{Cu} K \alpha$ X-ray sources [52,53] and synchrotron radiation sources [54 57].

The major problems that need be confronted in off-resonant XES studies on the density of unoccupied states are: the very low cross section of the inelastic X-ray scattering $\left(\sim 10^{3}\right.$ smaller than the photoabsorption cross section) and the need of highresolution detection systems. To overcome these requirements, single- or multiplecrystal spectrometers working in a point-to-point geometry are typically used at $3^{\text {rd }}$ and

$4^{\text {th }}$ generation X-ray sources $[54,55,58,59$. However, studies done with such detection setups allow only point-by-point measurements of the emission spectra which definitely 
extends the recording time and makes them inapplicable in many studies, especially at X-ray free-electron lasers (XFELs) facilities. Only recently, a wavelength-dispersive von Hámos-geometry-based spectrometer was used to measure in high resolution singleshot spectra of off-resonantly scattered X-rays, establishing thus the 'high energy resolution off-resonant spectroscopy' (HEROS) 60 62.

The HEROS method brings two important advantages to the studies on the density of unoccupied states. First, a combination of a wavelength-dispersive spectrometer (typically in the geometry of von Hámos or Johansson, and equipped with a position sensitive detector) with a fixed incident beam energy makes the HEROS experimental setup fully scanning-free. It allows to probe the unoccupied states with an acquisition time limited only by the spectrometer's efficiency, unlike the XAS methods where the adjustment of the monochromator crystals takes additional time. Second, because of the nature of the off-resonant inelastic X-ray scattering itself, where - as noted by Tulkki and Åberg [49] - the initial state lifetime broadening has no part in broadening of the scattered X-rays' spectrum, as well the wavelength-dispersive setup, the spectra recorded with HEROS are of very high resolution. HEROS allows as precise determination of the density of unoccupied states as the one achievable with high resolution XAS (HR-XAS). The most limiting factor in the HEROS studies is the very low X-ray scattering cross section in the off-resonant regime (order of $10^{3}$ smaller than the photoabsorption cross section). It narrows the applicability of this approach down to concentrated samples or very bright X-ray sources, such as XFELs. This limitation can be, however, overcome by the employment of multicrystal arrangements which may possibly shorten the data acquisition time and allow for studies on diluted samples. Nevertheless, probing the unoccupied states with HEROS is much quicker than with XAS methods which is of key meaning in in situ research where real-time determination of the density of unoccupied states is necessary to understand complex and dynamic chemical reactions.

The possibility of using the measured off-resonant emission spectra to calculate the absorption spectra using Eq. II.2 was already recognized by Hayashi et al. [54, 55]. The authors retrieved the $\mathrm{Cu} K$ edge absorption spectrum from a series of measured off-resonant emission spectra and showed that the obtained XANES exhibit the same features as the ones detected with the fluorescence mode XAS. Morever, the independence of the off-resonant emission spectra on the initial state lifetime broadening made the structures in the deduced absorption spectra much more pronounced, hence the lifetime-broadening-suppressed XANES (LBS-XANES) acronym was introduced (or 
alternatively: lifetime-broadening-removed XANES, LBR-XANES). Furthermore, the authors reported that analytical deduction of XANES allows correction for the final state lifetime broadening which narrows the spectral features even more. Another acronym was therefore introduced - lifetime-broadening-free XANES (LBF-XANES) - referring to analytically deduced XANES spectra which are free of both the initial and the final state lifetime broadenings. However, numerical implementation of the analytical correction for the final state width does not always give satisfactory result, especially in cases of low-quality off-resonant emission spectra. For this reason in this work the final state lifetime broadening is not corrected for and the HEROS-XAS acronym is used to describe LBS-XANES absorption spectra calculated by means of

the Kramers-Heisenberg formula modified by Tulkki and Åberg [44, 49] based on the emission spectra measured with HEROS. The numerical algorithms used in this work for calculation of LBS-XANES were written in the Wolfram Mathematica software and are presented in Appendix A (algorithm for LBF-XANES calculation, although unused, is also enclosed).

One should note that in some cases there are significant discrepancies in absorption spectra measured in the fluorescence mode (such as HR-XAS, LBS-XANES, LBF-XANES, HEROS-XAS) and the ones obtained in the transmission mode (see e.g. Refs. 63, 64]). Even fluorescence-mode XAS can provide different absorption spectra depending on the detected decay channel [65, 66]. Nevertheless, the XANES spectra obtained with RXES, especially in cases where core-core decay channels are detected, deliver to a good approximation the same information as measurements done in the transmission mode.

\section{II.5 Examples of applications of HEROS}

\section{Lifetime-broadening-suppressed $\mathrm{Cu} K$-edge XANES}

In the work of Hayashi et al. [54,55] the experimental method was based on the use of high resolution single-crystal point-to-point-geometry-based spectrometer, which is essentially different than the single-shot spectroscopy method employed in HEROS. However, since the authors were first to study at a synchrotron the density of unoccupied states with off-resonant XES with energy resolution similar to that of HEROS, one should perhaps mention their work among applications of HEROS. Hayashi et al. studied $\mathrm{CuO}$ and $\mathrm{CuCl}_{2} \cdot 2 \mathrm{H}_{2} \mathrm{O}$ at a synchrotron and recorded emission spectra in the $\mathrm{Cu} K \alpha_{1}$ energy range with resolution of $1.1 \mathrm{eV}$ (determined by FWHM of the elastic 
$\mathrm{X}$-ray scattering peak) for several incident beam energies fixed below $\mathrm{Cu} K$ ionization threshold. In the measured off-resonant XES spectra, of which the ones recorded for

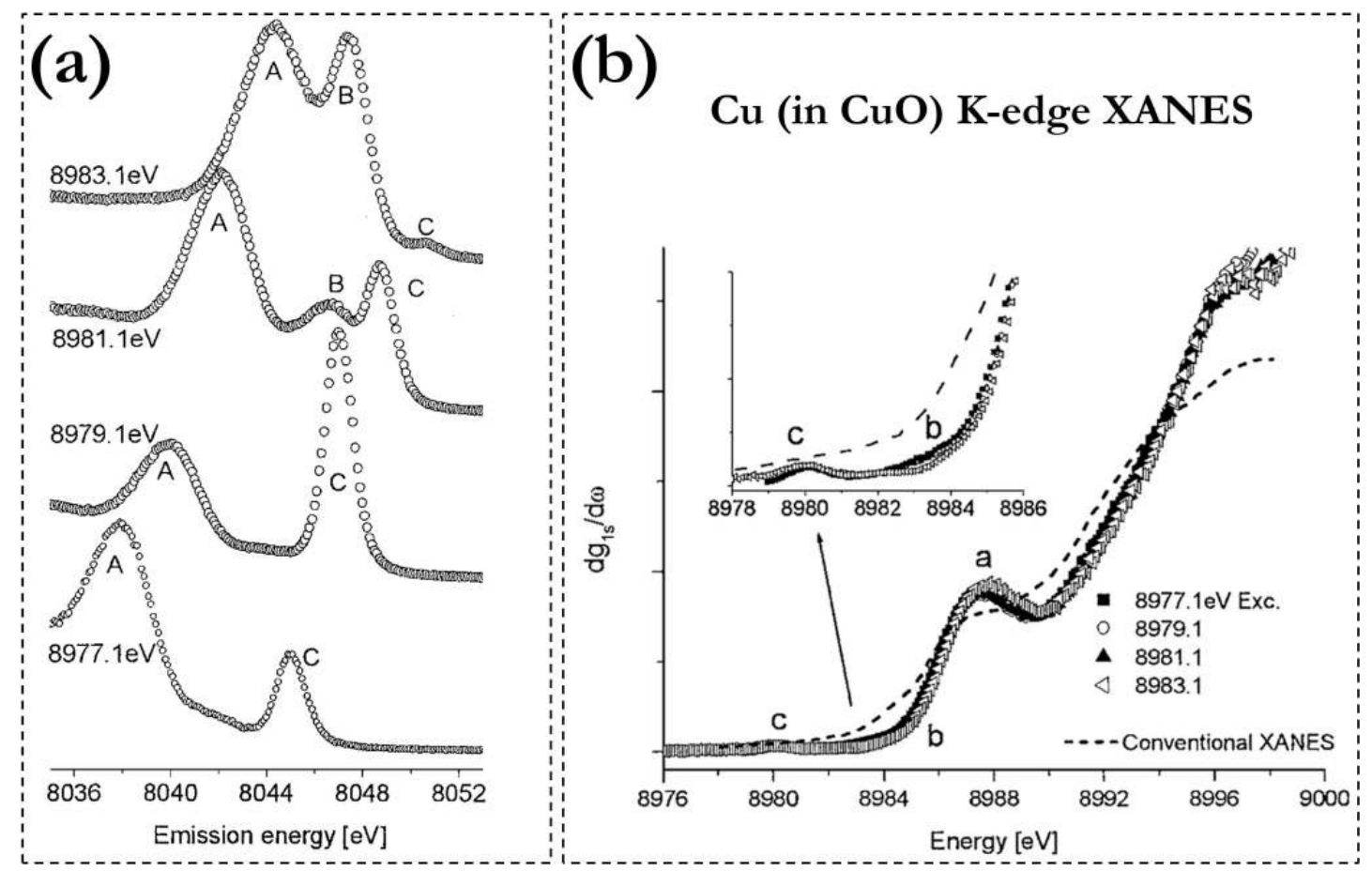

Figure II.5: Measurements on the $\mathrm{CuO}$ compound performed by Hayashi et al. [55]. (a) Emission spectra recorded in the $\mathrm{Cu} K \alpha_{1}$ energy range for four different incident beam energies fixed below $\mathrm{Cu} K$ edge binding energy. (b) $\mathrm{Cu} K$ edge LBS-XANES spectra deduced analytically from the spectra in (a), compared to absorption spectra measured with the conventional fluorescence mode XAS. The spectral features A, B and C in (a) correspond to the features $\mathrm{a}, \mathrm{b}$ and $\mathrm{c}$ in (b), respectively. The plots were reproduced from Ref. [55].

$\mathrm{CuO}$ are presented in Fig. II.5(a), the authors observed structures arising from scattering on the $\mathrm{Cu} 3 d$ discrete state as well as on the above-Fermi level states. The emission spectra were next used to calculate the $\mathrm{Cu} K$ edge absorption spectra by means of the Kramers-Heisenberg formula modified by Tulkki and Åberg [44, 49, within over $20 \mathrm{eV}$-wide XANES energy range (see Fig. II.5(b) for the results obtained for $\mathrm{CuO}$ ). Despite different shapes of the measured off-resonant XES spectra, the computed absorption curves converged. Further comparison between the calculated XANES and the $\mathrm{Cu} K$ edge absorption spectra measured in the conventional fluorescence mode XAS revealed that the former exhibited the same spectral features but in a much higher resolution. Hayashi et al. proposed the term lifetime-broadening-suppressed XANES (LBS-XANES) to describe the XANES spectra obtained in the way reported in their work. 


\section{In situ chemical speciation of $\mathrm{Pt}$ species with HEROS at a subsecond time resolution}

The HEROS method was first used by Szlachetko et al. in a time-resolved in situ study on the platinum(II) acetylacetonate complex $\mathrm{Pt}(\mathrm{acac})_{2}$ during its decomposition in hydrogen at a temperature of $150{ }^{\circ} \mathrm{C}[60]$. The experiment was performed at the SuperXAS beamline of Swiss Light Source (Paul Scherrer Institute, Switzerland). The authors recorded emission spectra in the $\mathrm{Pt} L \alpha_{1}$ energy range at an incident beam energy of $11.537 \mathrm{keV}$, i.e. $27 \mathrm{eV}$ below $\mathrm{Pt} L_{3}$ edge binding energy, with a wavelengthdispersive spectrometer in the von Hámos geometry consisting of a cylindrically bent Ge(660) crystal and a micro-strip detector. The off-resonant emission spectra, measured one by one with acquisition time of $0.5 \mathrm{~s}$ each (see Fig. II.6(a)), changed during the chemical reaction which indicated a varying occupancy of the Pt atoms' valence orbitals (mainly Pt $5 d$ orbitals) as well as their reduction from $\mathrm{Pt}^{2+}$ to $\mathrm{Pt}^{0}$. Temporal evolution of the position and the intensity of the main spectral structure, illustrated in Fig. II.6(b), revealed that the decomposition did not pass continuously but had a stepwise character. The two-step reduction mechanism of $\mathrm{Pt}(\mathrm{acac})_{2}$ decomposition in hydrogen was not observed in previous experiments 67].
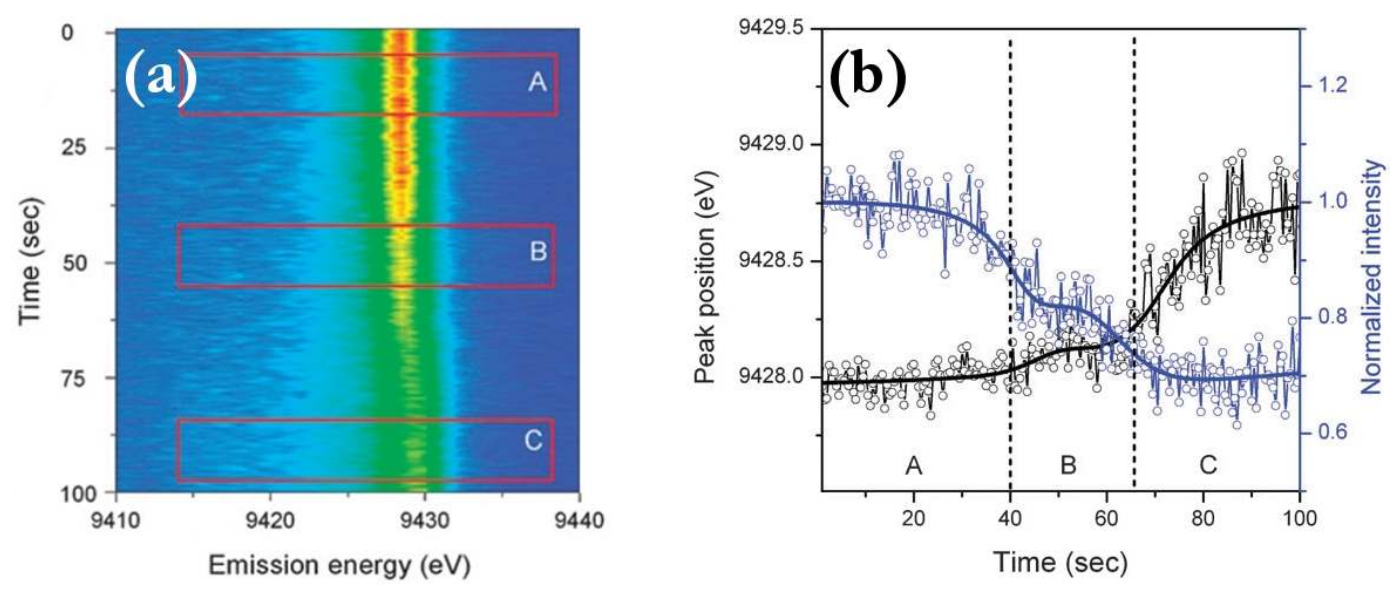

Figure II.6: Evolution of Pt $L \alpha_{1}$ HEROS spectra during decomposition in hydrogen of the platinum(II) acetylacetonate complex $\mathrm{Pt}(\mathrm{acac})_{2}$ at a temperature of $150{ }^{\circ} \mathrm{C} 60$. (a) The measured HEROS spectra as a function of time. (b) Temporal evolution of the position of the main spectral structure's peak (white line) as well as of fluorescence yield integrated over a narrow energy range centered at the peak. The symbols $\mathrm{A}$ and $\mathrm{C}$ in (a) and (b) mark time intervals before and after decomposition, respectively. In the time period marked with $\mathrm{B}$ an intermediate step in the starting complex' transition was observed. The plots were reproduced from Ref. 60]. 
Another time-resolved in situ study with HEROS was performed on a $\mathrm{Pt} / \mathrm{Al}_{2} \mathrm{O}_{3}$ catalyst during its reduction and reoxidation at $300{ }^{\circ} \mathrm{C}$ [68. In this work $\mathrm{Pt} L \alpha_{1}$ HEROS spectra were recorded one by one with acquisition time of $0.5 \mathrm{~s}$ at an incident beam energy fixed $10 \mathrm{eV}$ below $\mathrm{Pt} L_{3}$ edge binding energy. In order to obtain a satisfactory signal-to-noise ratio, the chemical reaction was initiated 120 times and for each cycle a series of HEROS spectra was recorded, which resulted in 2-hour total acquisition time. The obtained 120 sets of HEROS spectra as a function of time were next averaged. Starting and stopping the subsequent reduction-oxidation cycles was managed without opening the reactor containing the starting $\mathrm{Pt} / \mathrm{Al}_{2} \mathrm{O}_{3}$ catalyst, by switching the gas flowing through the reactor from $4 \% \mathrm{O}_{2}$ to $4 \% \mathrm{CO}$ and vice versa. Similarly to how it was done in previous time-resolved in situ HEROS on $\operatorname{Pt}(\operatorname{acac})_{2}$ [60, the measured HEROS spectra were integrated in the energy domain of the main spectral structure detected (off-resonant Pt $L \alpha_{1}$ asymmetric peak). Two narrow integration energy intervals were defined, one centered at $9.426 \mathrm{keV}$ and another at $9.427 \mathrm{keV}$. Thus obtained temporal dependence of total intensities from the two energy ranges of interest is presented in Fig. II.7(a). As shown, reduction of the starting

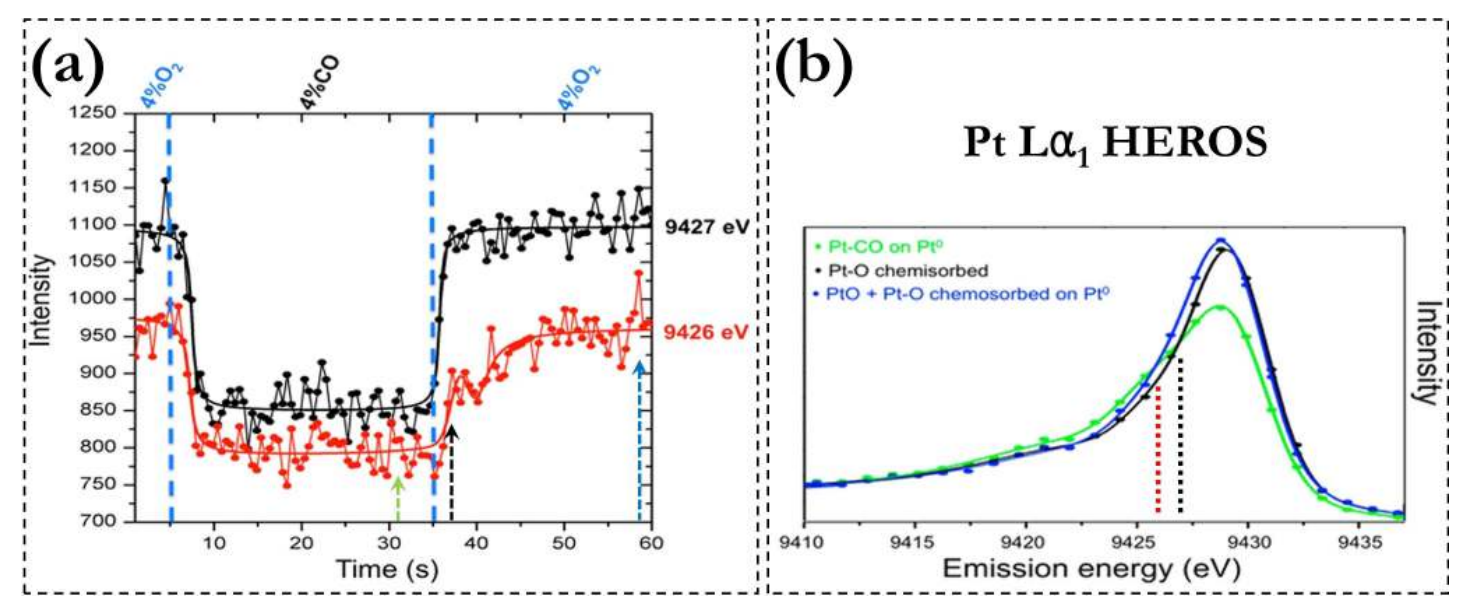

Figure II.7: The data measured with HEROS during reduction and reoxidation of $\mathrm{Pt} / \mathrm{Al}_{2} \mathrm{O}_{3}$ catalyst 68. (a) Evolution of the intensity integrated over two narrow energy ranges centered at $9.426 \mathrm{keV}$ and $9.427 \mathrm{keV}$. (b) Pt $L \alpha_{1}$ HEROS spectra measured in three moments during reoxidation, marked with dashed arrows in (a). The dashed lines in (b) indicate the two integration energy ranges. The figure was reproduced from Ref. [68].

complex Pt $/ \mathrm{Al}_{2} \mathrm{O}_{3}$ led to decrease in intensity of the off-resonant $\mathrm{Pt} L \alpha_{1}$ line, which means diminishing occupancy of the Pt $5 d$ orbital. Calculations performed with FEFF allowed to conclude that the decreasing intensity was caused by chemisorption of CO component on Pt atoms in atop position 69,70$]$. The temporal evolution of integrated 
intensity revealed formation of a metastable intermediate state during reoxidation but only for one of the integration energy intervals. Fig. II.7(b) presents Pt $L \alpha_{1}$ HEROS spectra measured before, after and in a transitional moment of the studied material reoxidation. The spectra differ mainly in the off-resonant $\mathrm{Pt} L \alpha_{1}$ line's intensity, but also in energy position and relative contribution of a small feature around $9.426 \mathrm{keV}$. From comparison of the HEROS spectra recorded after and in the time of reoxidation it was concluded that the reoxidized Pt catalyst contains effectively both metallic Pt species and oxidized ones (with a strong contribution from chemisorbed $\mathrm{O}$ ).

\section{$L_{3}$-edge HEROS-XAS of gaseous Xe}

Recent work shows that HEROS can be successfully applied to study the electronic structure of gaseous elements as well [61]. In this work a gaseous xenon sample was irradiated at the ID26 beamline of the European Synchrotron Radiation Facility (Grenoble, France) with a photon beam of energy $4.7589 \mathrm{keV}$, which is about $25 \mathrm{eV}$ below the Xe $L_{3}$ ionization threshold. The emitted radiation was detected by means of a Johansson-geometry-based in-vacuum spectrometer 38 in energy range centered at about $25 \mathrm{eV}$ below Xe $L \alpha_{1}$ fluorescence line energy with acquisition time of $5700 \mathrm{~s}$. From the FWHM of a Gaussian fit to the elastic photon scattering peak, experimental resolution of $0.76 \mathrm{eV}$ was found. In the measured HEROS spectrum, which is shown in Fig. II.8(a), $2 p_{3 / 2} \rightarrow 6 s, 5 d, 6 d$ resonances were observed followed by the characteristic decaying Lorentzian tail originating in the $2 p_{3 / 2} \rightarrow$ continuum excitations. The emis-
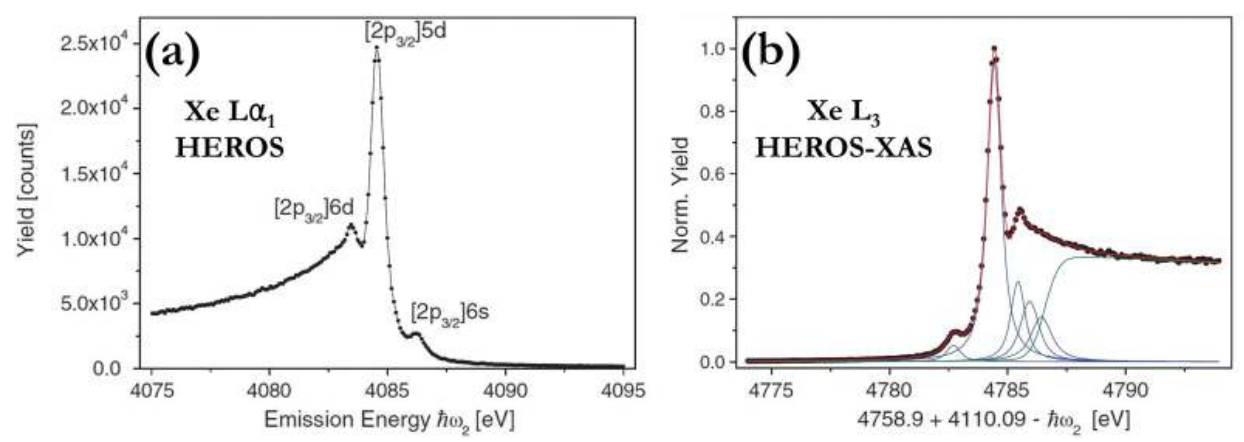

Figure II.8: Experimental spectroscopic data on gaseous xenon obtained with HEROS [61]. (a) Xe $L \alpha_{1}$ HEROS spectrum recorded at incident beam energy detuned $25 \mathrm{eV}$ below Xe $L_{3}$ edge binding energy. (b) Xe $L_{3}$ edge HEROS-XAS spectrum reconstructed from the spectrum in (a). The reconstruction was done based on the Kramers-Heisenberg formula derived by Tulkki and Åberg [44,49; the energy scale in (b) is determined by the RIXS energy conservation (see Section II.2 for more details). The plots were reproduced from Ref. [61]. 
sion data were next used to retrieve the Xe $L_{3}$ HEROS-XAS spectrum presented in Fig. II.8(b). In the obtained absorption spectrum five discrete states belonging to $d$ and $s$ - bands were observed followed by the continuum. The determined energies of the discrete states $6 s, 5 d, 6 d$ and $7 d$ as well as the $2 p_{3 / 2}$ ionization threshold were found to be in a fine agreement with previously published data. The determined relative occupancies of the states $6 s, 5 d$ and $6 d$ were also very consistent with the values reported in the literature. The HEROS-XAS spectrum was finally compared to the measured Xe $L_{3}$ HR-XAS spectrum and the same spectroscopic information was found.

\section{Mo $L_{3}$-edge HEROS-XAS for a nanolayered system at grazing emission conditions}

Applicability of HEROS in the soft X-rays' energy regime can be illustrated with the example of a study on the $L_{3}$ absorption edge of molybdenum atoms in a few-layer $\mathrm{MoSe}_{2}$ deposited on $\mathrm{SiO}_{2}$ [71]. The study was performed at the Phoenix I beamline of Swiss Light Source (Paul Scherrer Institute, Switzerland) using the von Hámos-geometrybased high-energy-resolution X-ray spectrometer of Fribourg [72. The studied sample was irradiated with an X-ray beam of energy $2.518 \mathrm{keV}$ (i.e., $3.6 \mathrm{eV}$ below Mo $L_{3}$ absorption edge binding energy) and the spectrometer was adjusted to cover Mo $L \alpha_{1,2}$ emission energy domain. In addition, the emitted radiation was detected at grazing
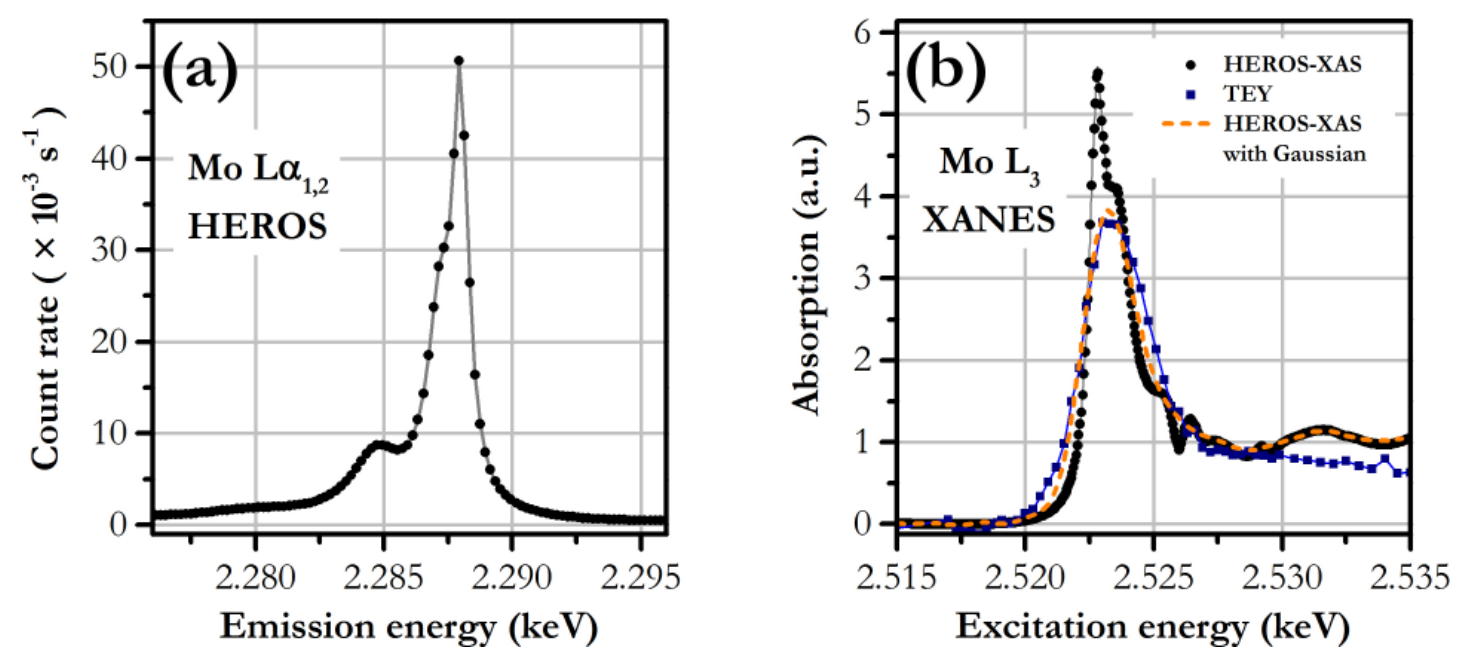

Figure II.9: Spectroscopic data on Mo for a tri-layer $\mathrm{MoSe}_{2}$ deposited on $\mathrm{SiO}_{2}$ [71]. (a) The Mo $L \alpha_{1,2}$ HEROS spectrum measured at an incident beam energy fixed $3.6 \mathrm{eV}$ below Mo $L_{3}$ ionization threshold. (b) Mo $L_{3}$ XANES obtained by reconstruction based on the data in (a) (HEROS-XAS) and the one measured with total electron yield (TEY) method. The dashed line is HEROS-XAS curve convolved with a Gaussian with FWHM of value $1.5 \mathrm{eV}$. 
exit conditions. Unlike grazing incidence setups, the grazing emission geometry has the advantage that the critical angle of total reflection does not change when tuning the incident photon energy across an absorption-edge and thus the probed depth-region remains the same. The measured HEROS spectrum is presented in Fig. II.9(a). Due to the only about $3 \mathrm{eV}$-separation of Mo energy levels $M_{5}$ and $M_{4}$, the measured spectrum is effectively a sum of overlapping signals from two decay channels: $M_{5} \rightarrow L_{3}$ and $M_{4} \rightarrow L_{3}$. Fig. II.9 (b) presents Mo $L_{3}$ HEROS-XAS spectrum compared to Mo $L_{3}$ XANES measured in the total electron yield (TEY) mode. As shown, the reconstructed spectrum exhibits very pronounced features not distinguishable in the TEY spectrum, apart from the white line. Applying blurring to the HEROS-XAS spectrum, by convolving it with a Gaussian of a $1.5 \mathrm{eV}-\mathrm{FWHM}$, results in a curve strongly converging with the TEY data up to about $2.530 \mathrm{keV}$. This finding suggests that both TEY and HEROS-XAS provide the same spectrum but the latter in a much higher energy resolution. 



\section{Chapter III \\ Self-absorption-free HEROS}

\section{III.1 Introduction}

X-ray absorption spectroscopy (XAS) and X-ray emission spectroscopy (XES) are widely used in the fields of physics, chemistry, medicine, biology and material sciences (see, e.g., Refs. 73 79]). It has been long established that conventional fluorescence mode XAS measurements bear an unwanted effect from the self-absorption process in the target material 80 . In view of the wide range of applications of XAS based techniques in different disciplines, considerable progress to circumvent the self-absorption and to account for its effect on XAS spectra measurements has been made. Nonetheless, in many scientific cases the self-absorption problem cannot be easily coped with because of the nature of the sample itself whose mass thickness may not be easily reduced either by thinning or diluting. One can state that mitigation of self-absorption has been and still is a topic of active research (see, e.g., Refs. 81 84]).

In the present study the high energy resolution off-resonant spectroscopy (HEROS) technique was used to investigate Ta $L_{3}$ absorption edge at a synchrotron. The offresonant Ta $L \alpha_{1}$ emission spectra measured with HEROS were used to calculate Ta $L_{3}$ edge XAS spectrum by means of Kramers-Heisenberg formula modified by Tulkki and Åberg [44, 49]. It was demonstrated that thus obtained HEROS-XAS spectra are free of self-absorption effect. This work was published in Physical Review Letters [1].

\section{III.2 Self-absorption in X-ray spectroscopy}

In the fluorescence mode XAS, with its typical setup outlined in Fig. III.1, the measured fluorescence yield $F Y$ as a function of the incident photon beam energy is affected by the self-absorption [80]. The self-absorption is a partial absorption of the 
photons penetrating the sample and the fluorescence escaping from it. It causes that the measured fluorescence yield is not in a linear dependence with the photoabsorption coefficient $\mu_{\mathrm{ph}}$ of the studied material. The self-absorption effect causes that the spectral structures appear weaker in the measured absorption spectra (see e.g. Ref. 85]). This effect is observed in both XANES and EXAFS region.

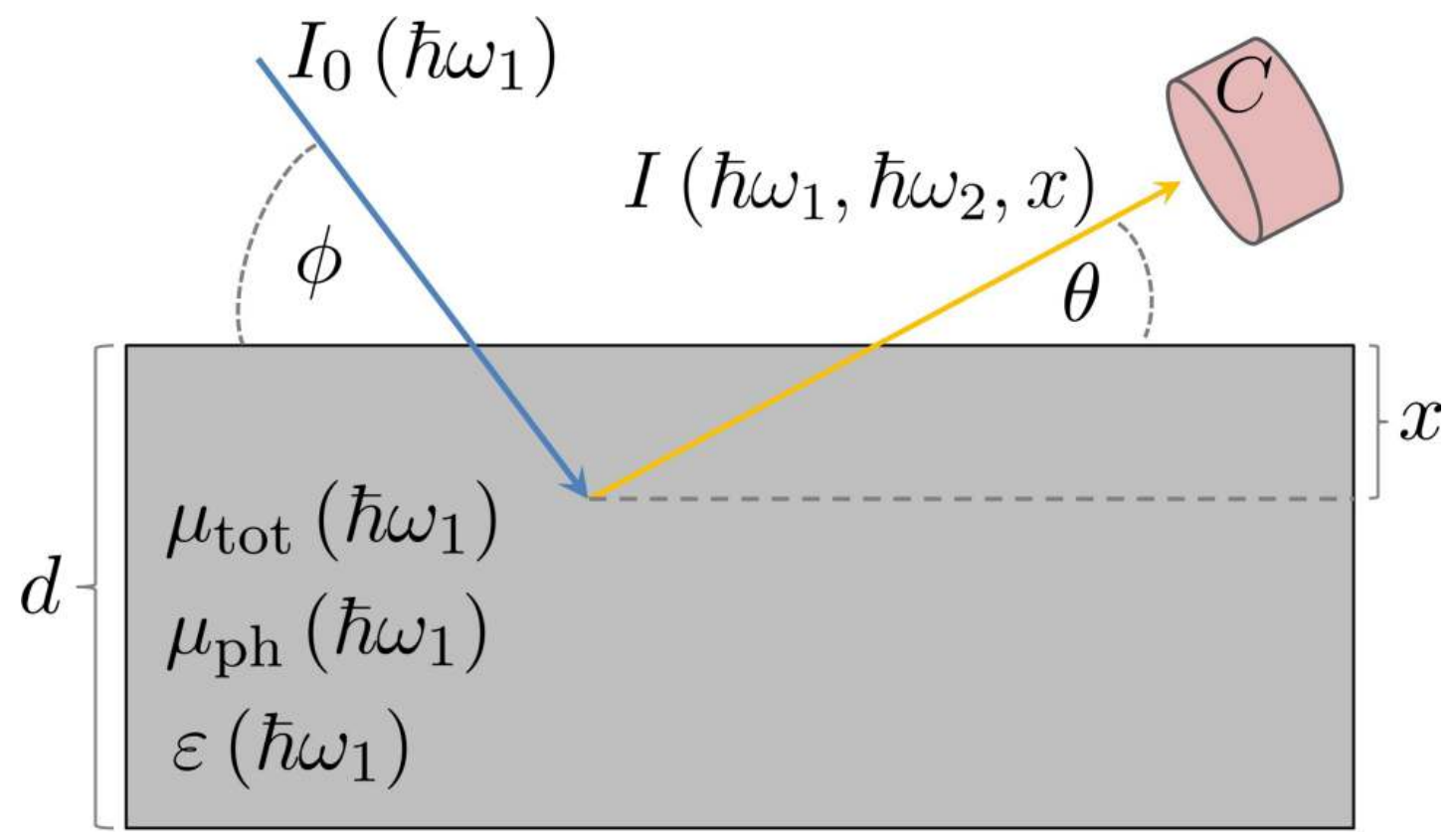

Figure III.1: Scheme of a typical fluorescence mode XAS experimental setup with assumed flat sample surface. The incident beam (blue arrow) of intensity $I_{0}$ and energy $\hbar \omega_{1}$ falls on the sample of thickness $d$ at an angle $\phi$. The fluorescence radiation (orange arrow) of energy $\hbar \omega_{2}$ induced at a depth $x$ escapes the sample at an angle $\theta$ and reaches the detecting system (in pink) with intensity I. The sample is made of a material characterized by the total linear attenuation coefficient $\mu_{\mathrm{tot}}\left(\hbar \omega_{1}\right)$, the linear photoabsorption coefficient $\mu_{\mathrm{ph}}\left(\hbar \omega_{1}\right)$ and the fluorescence efficiency $\varepsilon\left(\hbar \omega_{1}\right)$. The experimental constant $C$ associated to the detecting system depends on the detection efficiency and the covered solid angle.

Following analytical considerations of the fluorescence mode setup shown in Fig. III.1 one finds that the normalized yield of the fluorescence $F Y$ emitted at depth $x$ meets the relation 80,86

$$
\begin{aligned}
F Y\left(\hbar \omega_{1}, \hbar \omega_{2}, x\right) & =\frac{I\left(\hbar \omega_{1}, \hbar \omega_{2}, x\right)}{I_{0}\left(\hbar \omega_{1}\right)} \\
& =C \varepsilon\left(\hbar \omega_{1}\right) \mu_{\mathrm{ph}}\left(\hbar \omega_{1}\right) \frac{1}{\sin \phi} e^{-\left(\frac{\mu_{\mathrm{tot}}\left(\hbar \omega_{1}\right)}{\sin \phi}+\frac{\mu_{\mathrm{tot}}\left(\hbar \omega_{2}\right)}{\sin \theta}\right) x}
\end{aligned}
$$

where the meanings of the used symbols are explained in Fig. III.1. The extent to 
which the self-absorption affects the measured fluorescence yield is described by the term $\frac{1}{\sin \phi} \times \exp \left[-\left(\frac{\mu_{\mathrm{tot}}\left(\hbar \omega_{1}\right)}{\sin \phi}+\frac{\mu_{\mathrm{tot}}\left(\hbar \omega_{2}\right)}{\sin \theta}\right) x\right]$. It therefore varies with the incident photon energy, the energy of the detected fluorescence radiation and the geometry of the experiment. The fluorescence yield as a function of the sample thickness $d$ is described by the equation

$$
F Y\left(\hbar \omega_{1}, \hbar \omega_{2}, d\right)=C \frac{\varepsilon\left(\hbar \omega_{1}\right) \mu_{\mathrm{ph}}\left(\hbar \omega_{1}\right)}{\mu_{\mathrm{tot}}\left(\hbar \omega_{1}\right)+\mu_{\mathrm{tot}}\left(\hbar \omega_{2}\right) \frac{\sin \phi}{\sin \theta}}\left[1-e^{-\left(\frac{\mu_{\mathrm{tot}}\left(\hbar \omega_{1}\right)}{\sin \phi}+\frac{\mu_{\mathrm{tot}}\left(\hbar \omega_{2}\right)}{\sin \theta}\right) d}\right]
$$

which is found by integrating Eq. III.1 over $x$ varying from 0 to $d$.

Perhaps the most common approach to obtain fluorescence yield data free of the self-absorption effect is that proposed by Eisebitt et al. [80], further developed by Booth and Bridges [86] as well as Ablett et al. [87], independently. The authors applied to the measured XAS spectra a correction for the self-absorption effect based on the geometrical analysis described above. This approach, however, involves the use of the values for the studied material's total linear attenuation coefficient, while determining these values requires in principle XAS spectra already unaffected by the self-absorption. The effectiveness of the correction for the self-absorption effect can be seen in the Co $L_{3}$-edge absorption spectrum studied by Eisebitt et al. [80], which is presented in Fig. III.2. As shown, the fluorescence mode XAS spectra exhibit weaker white lines due to the self-absorption. The self-absorption-corrected FY absorption spectra are found to be in a good agreement with the EY data.

In the inverse partial fluorescence yield (IPFY) technique, reported by Achkar et al. [81, 82, the absorption edge under study is probed indirectly, by observing the normal fluorescence from the deexcitations to weaker bound electronic levels. The emitters of the normal fluorescence may be atoms of the studied element or another one. The authors showed that the inverse of the normal fluorescence yield is theoretically linearly proportional to the photoabsorption coefficient and free of the self-absorption effect. They supported their reasoning studying a single crystal of $\mathrm{La}_{1.475} \mathrm{Nd}_{0.4} \mathrm{Sr}_{0.125} \mathrm{CuO}_{4}$. The inverse of the $\mathrm{O} K \alpha \mathrm{PFY}$ spectrum recorded for the incident beam energy varying across $\mathrm{Cu} L_{2,3}$ and $\mathrm{Nd} M_{4,5}$ absorption edges provided self-absorption-free absorption spectra of the scanned electronic levels, as shown in Fig. III.3. 

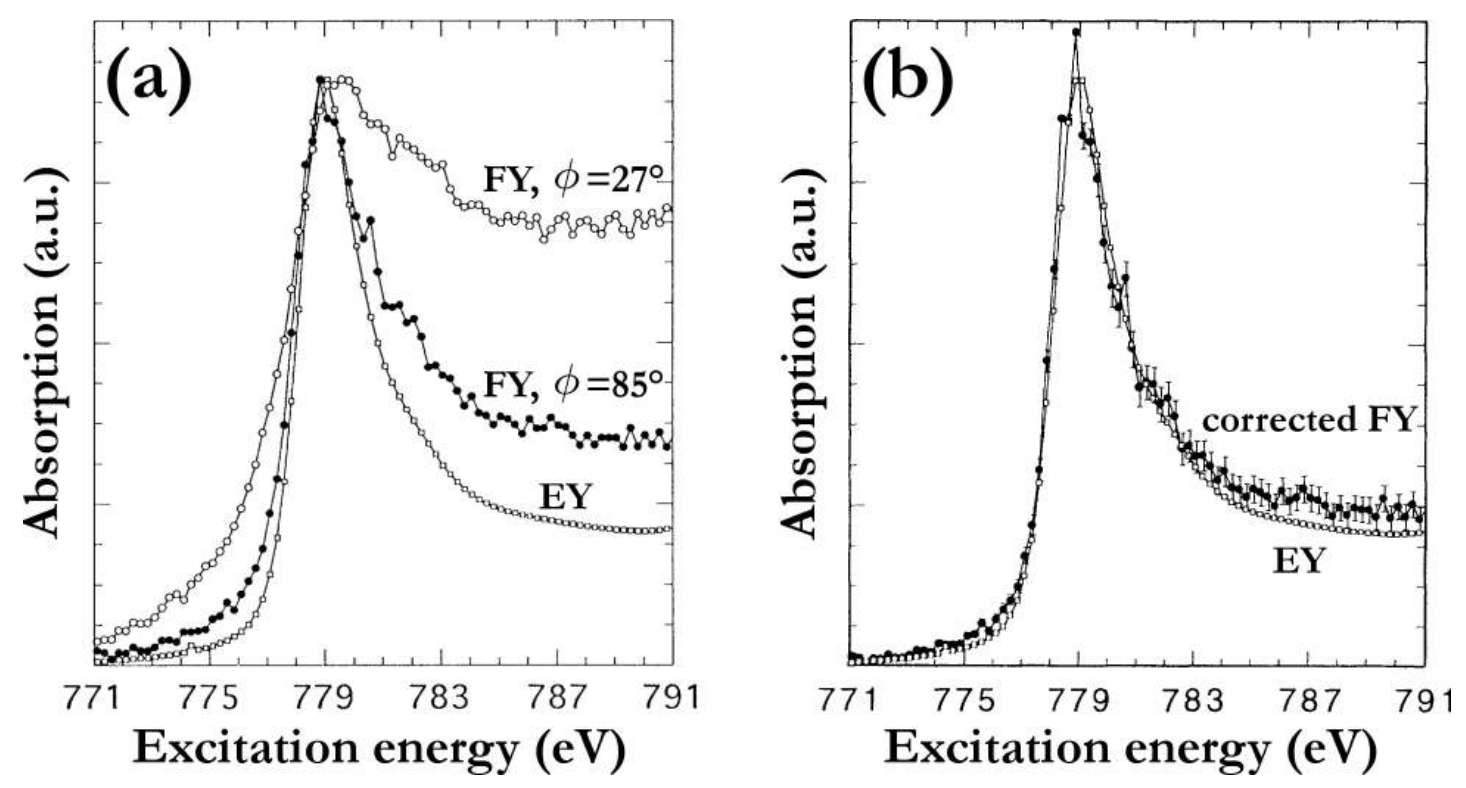

Figure III.2: (a) The Co $L_{3}$-edge absorption spectrum measured with the electron yield and the fluorescence yield for two incident angles: $27^{\circ}$ and $85^{\circ}$ [80]. (b) The Co $L_{3}$-edge FY absorption spectrum corrected for the self-absorption effect compared to the EY spectrum.
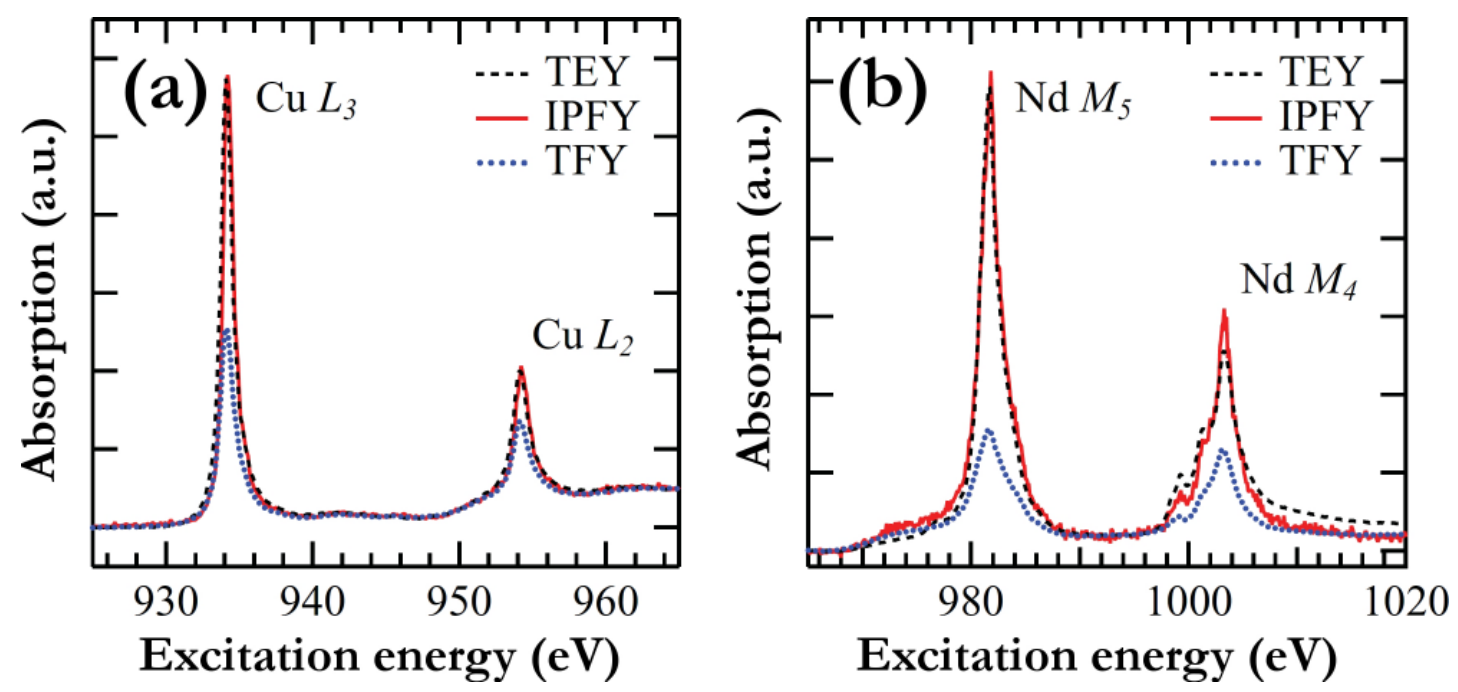

Figure III.3: Comparison of the absorption spectra of the $\mathrm{Cu} L_{2,3}$ (a) and $\mathrm{Nd}$ $M_{4,5}$ (b) edges measured with three techniques: total electron yield (TEY), total fluorescence yield (TFY) and inverse partial fluorescence yield (IPFY) 81]. The IPFY spectra, unlike the TFY ones, exhibit no self-absorption effect. 


\section{III.3 Experimental}

\section{III.3.1 Experimental setup}

The present work was performed at the SuperXAS beamline of the Swiss Light Source of the Paul Scherrer Institute, Switzerland (see Fig. III.4). The synchrotron's storage ring stores electrons of $2.4 \mathrm{GeV}$-energy circulating with a current of $400 \mathrm{~mA}$. SuperXAS is a bending magnet beamline and can deliver photons of energy ranging from 4.5 to $30 \mathrm{keV}$. The produced photon beam is collimated and passes through a double crystal monochromator. Two types of the monochromator crystals are available at the beamline: $\mathrm{Si}(111)$ reducing the beam's intrinsic energy resolution down to about $1.4 \times 10^{-4}$ and $\mathrm{Si}(311)$ allowing values of about $0.5 \times 10^{-4}$. The monochromatized beam is focused on the sample by means of a toroidally bent Rh mirror to spot sizes from $100 \times 100 \mu \mathrm{m}^{2}$ down to $5 \times 0.5 \mu \mathrm{m}^{2}$. Achievable fluxes on the target are of the order of $10^{12} \frac{\text { photon }}{\mathrm{s}}$.

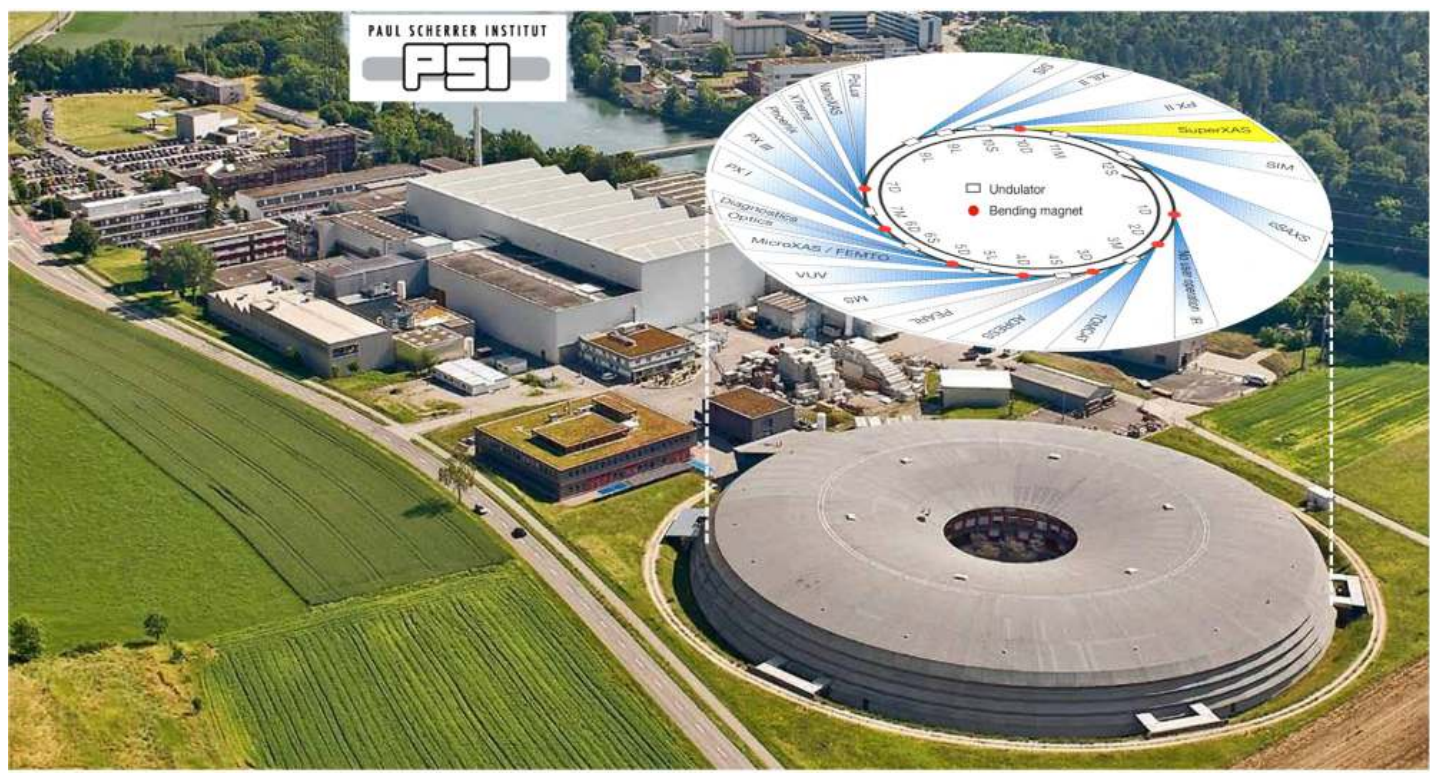

Figure III.4: Aerial view on the Swiss Light Source (SLS) located at the Paul Scherrer Institute (PSI) in Villigen, Switzerland. The measurements were carried out at the SuperXAS beamline (marked in yellow), one of 21 available at the facility.

In the present study the double $\mathrm{Si}(111)$ crystal monochromator was used and the incident beam's relative energy resolution of $1.4 \times 10^{-4}$ was achieved. The incident beam's photon flux was found to be $7-8 \times 10^{11} \frac{\text { photon }}{\mathrm{s}}$ and the spot size on the sample was $100 \times 100 \mu \mathrm{m}^{2}$. The measurements were done with the experimental setup pre- 


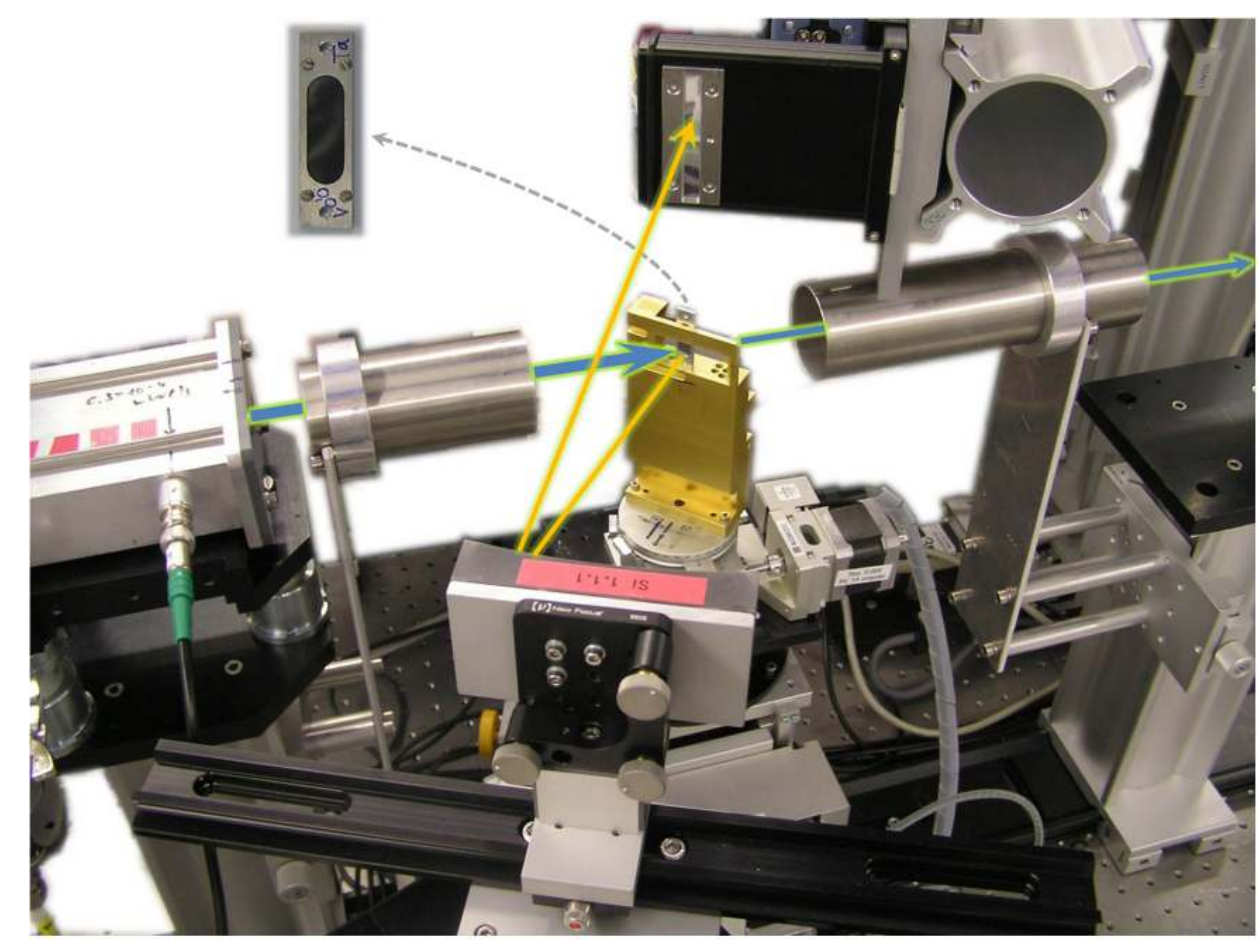

Figure III.5: The experimental setup showing the X-ray spectrometer and the ionization chamber placed upstream of the sample. The direction of the photons incident on and transmitted through the sample is shown by the blue arrow, while the path of the fluorescence radiation from the sample to the detector is outlined with the orange arrow. Not shown is a lead shielding that was used to reduce the unwanted signal from the background and the second helium ionization chamber placed downstream of the sample.

sented in Fig. III.5 at ambient conditions. Nine Ta metallic foils of nominal thicknesses in the range $0.5-50 \mu \mathrm{m}$ were irradiated at an incident angle of $45^{\circ}$. The Ta $L \alpha_{1,2}$ emission spectrum was detected by means of a wavelength-dispersive von-Hámos-geometrybased spectrometer composed of a cylindrically curved segmented-type $\mathrm{Si}(444)$ crystal 88 and the position-sensitive microstrip silicon MYTHEN detector [89]. Two 30-cm-long, helium filled, ionization chambers were placed along the beam direction upstream and downstream the sample to allow the FY normalization and transmission measurements. For each sample, the $L_{3}$ edge absorption spectrum was measured in the transmission and fluorescence mode simultaneously. The TFY and high-resolution XAS spectra were obtained from the $L \alpha_{1,2}$ XES data recorded for incident X-ray beam energies varied across the $L_{3}$ edge. The off-resonant emission spectrum was collected at a beam energy of $9.855 \mathrm{keV}$ (i.e., $26 \mathrm{eV}$ below the $L_{3}$ edge binding energy). The acquisition time for each XES spectrum was $10 \mathrm{~s}$ and $6000 \mathrm{~s}$ for the HEROS spectra. 


\section{III.3.2 Data analysis}

The raw experimental data, handled by the data acqusition system of SLS [90], were stored in text files (.TXT). They were accessed with different programming frameworks and software tools to retrieve and analyze the data relevant to the present work. This section presents a description of how were obtained the XAS (in both transmission mode and fluorescence mode) and the HEROS spectra for each Ta sample.

The energy calibration of the incident beam was done with the Ta $L_{3}$ absorption edge (see Fig. III.6(a)). The inflection point of the Ta $L_{3}$ edge XAS spectrum measured in transmission mode was assigned the value of $9.8811 \mathrm{keV}$ (taken from Ref. [91]), and the $0.3 \mathrm{eV}$-error on the incident beam energy was found. To calibrate the energy scale of the spectrometer, the incident beam energy was varied within the Ta $L \alpha_{1,2}$ emission energy domain and the elastically scattered photons were detected. Since the detector's pixel-to-pixel spatial resolving power (1280 independent $50 \mu \mathrm{m}$-pitch strips) was found to be beyond the total experimental resolution a binning of 4 was applied to all recorded emission spectra. The spectrometer was energy-calibrated with the elastic scattering peaks and the Ta $L \alpha_{1,2}$ emission lines (energies were taken from Ref. 92]), as presented in Fig. III.6(b). The energy calibration line was found by fitting a linear polynomial to the calibration data points. The uncertainty of the spectrometer energy calibration decreased linearly with increasing energy. For all the studied sample thicknesses, it remained in the range $2.4 \mathrm{eV}-1.3 \mathrm{eV}$ for energies from $8.085 \mathrm{keV}$ to $8.200 \mathrm{keV}$. Note, that because of different Ta $L_{3}$ edge binding energy values used during the data analysis the presented spectra are slightly shifted in the energy scale as compared to the ones reported in the article [1]. The average full width at half maximum (FWHM) experimental energy resolution of 1.25(6) eV was found by fitting a Gaussian to the elastic scattering peaks. The obtained FWHM values varied with the beam energy and the sample thickness in the $1.17 \mathrm{eV}$ to $1.3 \mathrm{eV}$ range.

In the transmission mode study, where the samples of thicknesses $d$ were irradiated at the same angle $\phi=45^{\circ}$, the measured incident beam intensity $I_{0}\left(\hbar \omega_{1}\right)$ and transmitted beam intensity $I_{\mathrm{t}}\left(\hbar \omega_{1}, d\right)$ were used to calculate the absorption spectra $\mu_{\text {tot }}\left(\hbar \omega_{1}, d\right)=-\ln \left[\frac{I_{\mathrm{t}}\left(\hbar \omega_{1}, d\right)}{I_{0}\left(\hbar \omega_{1}\right)}\right] \frac{\sin \phi}{d}$, according to the Bouguer-Lambert-Beer law. The obtained spectral curves were translated along the $\mu_{\text {tot }}$ axis so that their pre-edge regions fell to 0 (see Fig. III.6(a)). The total fluorescence yield spectra were obtained by integrating the XES data over the whole Ta $L \alpha_{1,2}$ energy domain $(8.045-8.250$ $\mathrm{keV})$. The partial fluorescence yield, high energy resolution XAS, spectra result from integrating the XES data within a $2 \mathrm{eV}$ energy window centered at the Ta $L \alpha_{1}$ fluo- 


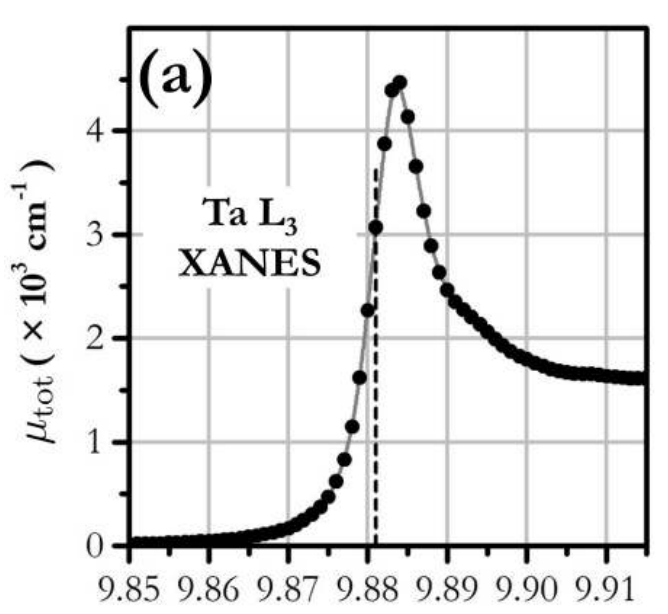

Incident beam energy $(\mathrm{keV})$

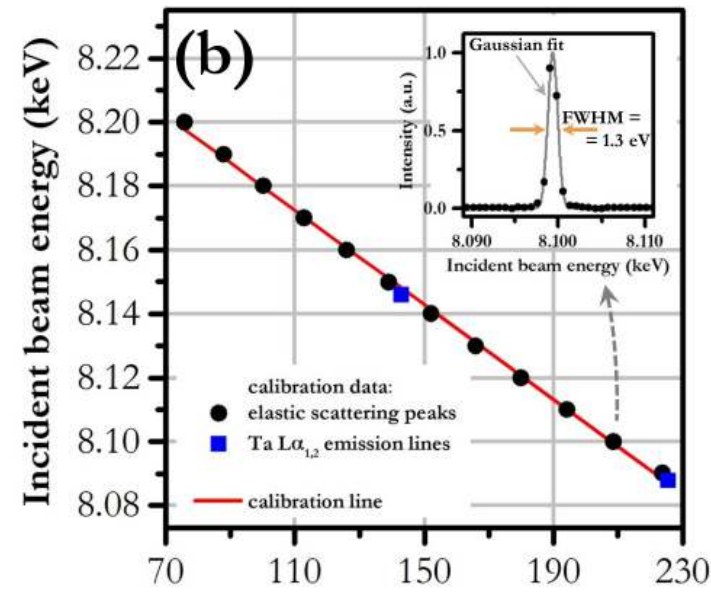

Strip number of the peak center

Figure III.6: (a) The Ta $L_{3}$ edge transmission mode XAS spectrum measured for the $1 \mu \mathrm{m}$ thick sample. The dashed line intersects the observed XANES at its inflection point to which an energy of $9.8811 \mathrm{keV}$ was assigned. (b) The data used for the energy calibration of the spectrometer during the measurements with the $1 \mu \mathrm{m}$ thick sample. The uncertainty of the emission energy increased linearly from $0.6 \mathrm{eV}$ to $1.7 \mathrm{eV}$ for the strips numbers from 75 to 225 . The inset shows an exemplary elastic scattering peak and its full width at half maximum (FWHM) of $1.3 \mathrm{eV}$.

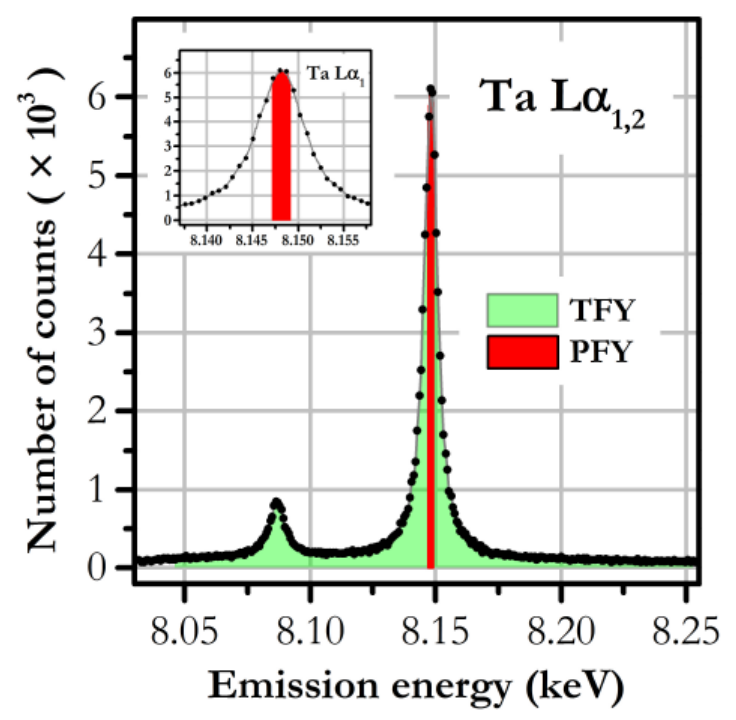

Figure III.7: Ta $L \alpha_{1,2}$ XES spectrum recorded at the incident beam energy tuned to $119 \mathrm{eV}$ above the Ta $L_{3}$ edge for the $1 \mu \mathrm{m}$ thick sample. The TFY and PFY spectra integration ranges are shown in green and red, respectively.

rescence line. The integration ranges for TFY and PFY spectra are presented in Fig. III.7. The flourescence mode XAS spectra were translated along the absorption axis so that the white line's tail fell to 0 and scaled to coincide at an excitation energy of 
$9.905 \mathrm{keV}$.

The strength of the HEROS signal depends on the sample thickness and the material concentration. Since different thicknesses were studied, a normalization of the experimental data was done before comparing the obtained HEROS spectra. First, all contributions to the measured signal coming from the background and the used experimental method (scattering, electronic noise in the detector) were described by a baseline and subtracted from the recorded data. The baseline was found by fitting a quadratic polynomial to the data points for which a zero HEROS signal is expected, as presented in Fig. III.8, Then all the HEROS spectra were scaled to coincide at an emission energy of about $8.086 \mathrm{keV}$. This procedure is based on the assumption that the sample thickness introduces only scaling to the overall HEROS yield (validity of this assumption is explained in Section III.4).
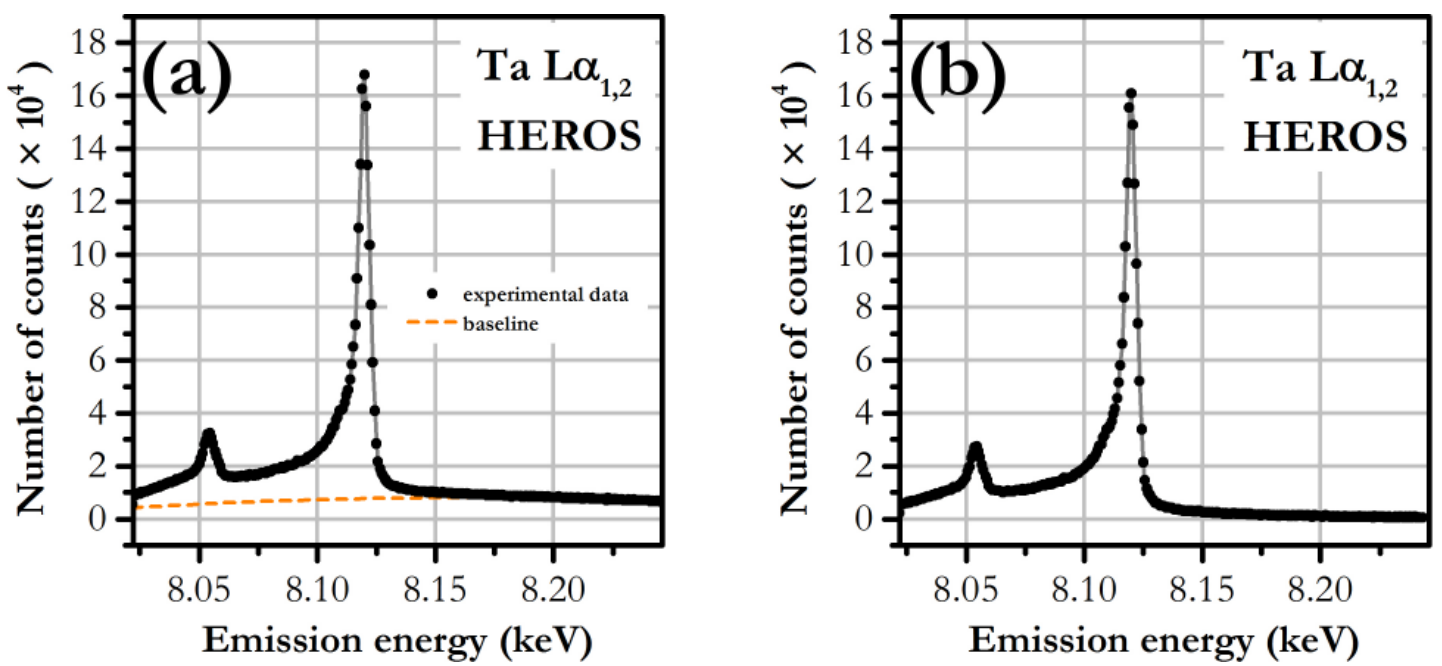

Figure III.8: (a) The Ta $L \alpha_{1,2}$ HEROS spectrum measured for the $1 \mu \mathrm{m}$ thick sample at the incident beam energy detuned to $26 \mathrm{eV}$ below the Ta $L_{3}$ edge with shown baseline. (b) The data from (a) with the subtracted baseline.

\section{III.4 Results and discussion}

The $L_{3}$-edge XAS spectra of elemental tantalum measured for different sample thicknesses in the transmission-mode, TFY, and high energy resolution are presented in Fig. III.9, In the transmission-mode spectra, plotted in Fig. III.9(a), the white line appears only for samples of thicknesses up to $20 \mu \mathrm{m}$ and decreases with increasing thickness. The decrease of the white line intensity was found to be accompanied by an $2 \mathrm{eV}$ increase of its FWHM. The spectra obtained for thicker samples are also char- 
acterized by a decrease of the overall spectral intensity and an apparent shift of the absorption edge energy with the sample thickness. The effect of the sample thickness on the transmission mode XAS spectra is well known and is named over-absorption or thickness effect 93] or incident beam self-absorption [94. It arises from different experimental factors whose contribution to the measured signal changes with the sample thickness. These factors may include the long tails of the incident beam's energy distribution function (where less attenuated X-rays give rise to a significant background), nonuniformity of the sample (uneven surface, internal pinholes), photons scattered to the detector without passing through the sample and others. All these unwanted contributions cause that the intensity of the photons transmitted through thicker samples is no longer proportional to the photoabsorption cross section as the photon energy is varied across the edge. The mentioned factors can be counteracted independently, however, the only way to considerably reduce the over-absorption is to use samples thin enough. Stern and Kim [95] recommend to use sample thicknesses $d$ satisfying the condition $\mu_{\max } d \leqslant 1$, where $\mu_{\max }$ stands for the maximum value of the absorption coefficient. In the present study this recommendation is complied with by only the 0.5 $\mu \mathrm{m}$ and $1 \mu \mathrm{m}$ thick Ta samples. The $\mu_{\max } d$ product calculated for the thickest one (i.e., $50 \mu \mathrm{m}$ thick) reaches a value of about 42 .

The measured high energy resolution and TFY XAS spectra of the Ta $L_{3}$ edge are depicted in Fig. III.9(b) and Fig. III.9(c), respectively. Self-absorption effect is predominantly reflected in the white line reduction and broadening. To a smaller extent they also cause distortions of the XANES peaks. The discussed differences in the absorption spectra are only observable for sample thicknesses up to $10 \mu \mathrm{m}$. Fig. III.9(d) shows the RIXS map recorded for the $1 \mu \mathrm{m}$ thick sample. The horizontal lines extending for excitation energies above $9.881 \mathrm{keV}$ are dominated by the Ta $L \alpha_{1}$ and $L \alpha_{2}$ emission lines. The two oblique features originate from the excitation of the $L_{3}$ photoelectrons to a sub-Fermi discrete state probed by the $L_{3} M_{5}$ and $L_{3} M_{4}$ decay channels.

The recorded HEROS spectra are presented in Fig. III.10(a). As shown, the effects on the spectral shape which are related to the sample thickness are almost blanked by the HEROS approach. The observed relative deviations, which for all the investigated samples do not exceed $4 \%$, are not related to the sample thickness but are due to the statistical fluctuations.

As reported by Tulkki and Åberg $[49$ the photon scattering cross section for the off-resonant excitation well below the ionization threshold is correlated to the density 

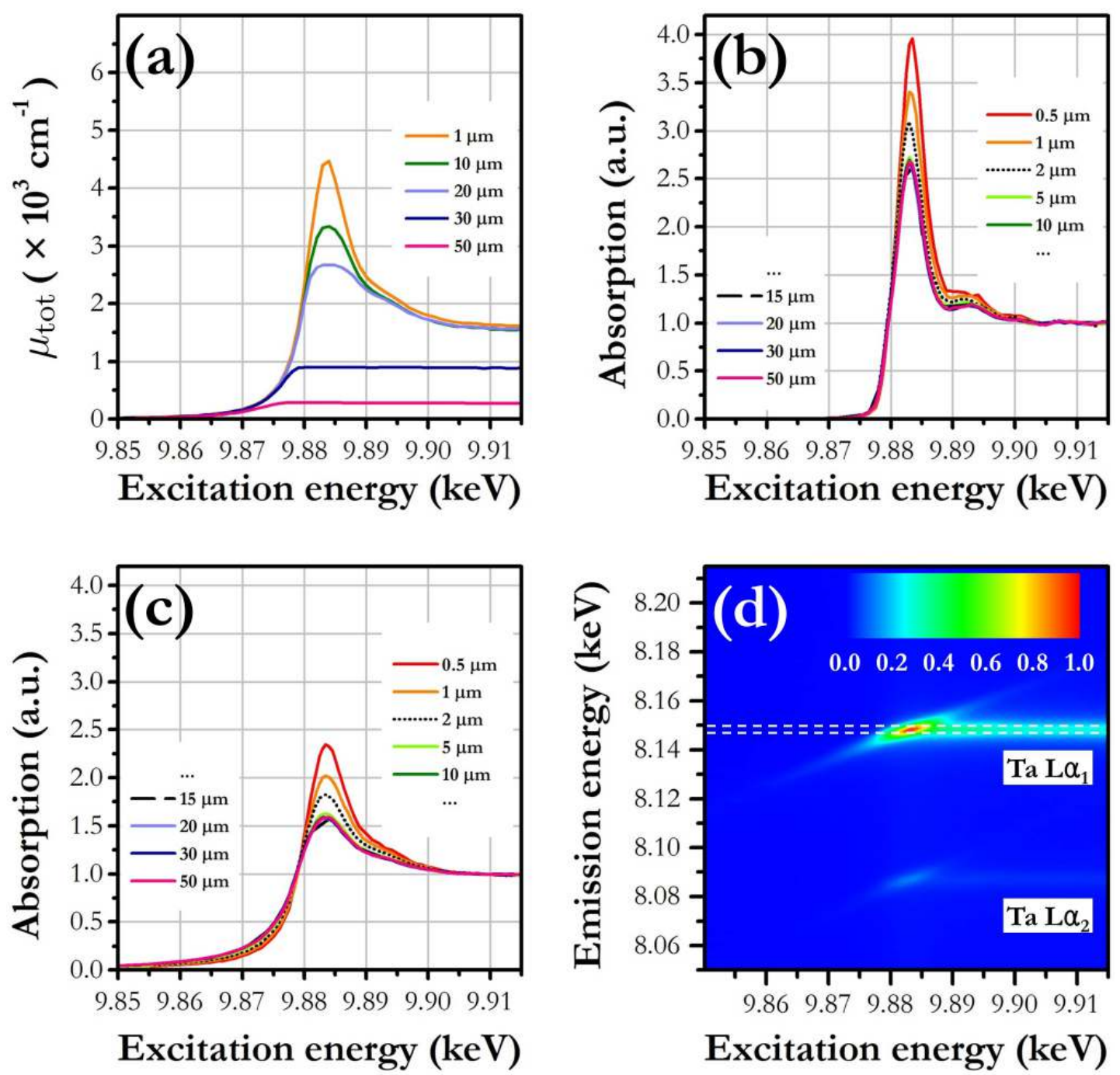

Figure III.9: Ta $L_{3}$ absorption edge $(9.881 \mathrm{keV})$ scanned with an X-ray beam of energy varying in the range $9.850-9.915 \mathrm{keV}$ for samples of different thicknesses [1]. The data were recorded both in transmission- (a) and fluorescence-mode in high energy resolution (b) and TFY (c). (d) RIXS plane recorded for the $1 \mu \mathrm{m}$ thick sample showing the normalized fluorescence yield as a function of energy of the incident and the emitted photons. High energy resolution XAS spectra in (b) were obtained by integrating the XES data over a $2 \mathrm{eV}$ integration window centered Ta $L \alpha_{1}\left(L_{3} M_{5}\right)$ fluorescence line, which is marked with the dashed lines in (d). Note that this energy interval is smaller than the initial state lifetime broadening of $4.68 \mathrm{eV}$ [96]. For the TFY spectra in (c) the integration range was extended onto the whole Ta $L \alpha_{1,2}\left(L_{3} M_{5,4}\right)$ energy domain $(8.045-8.250 \mathrm{keV})$. 

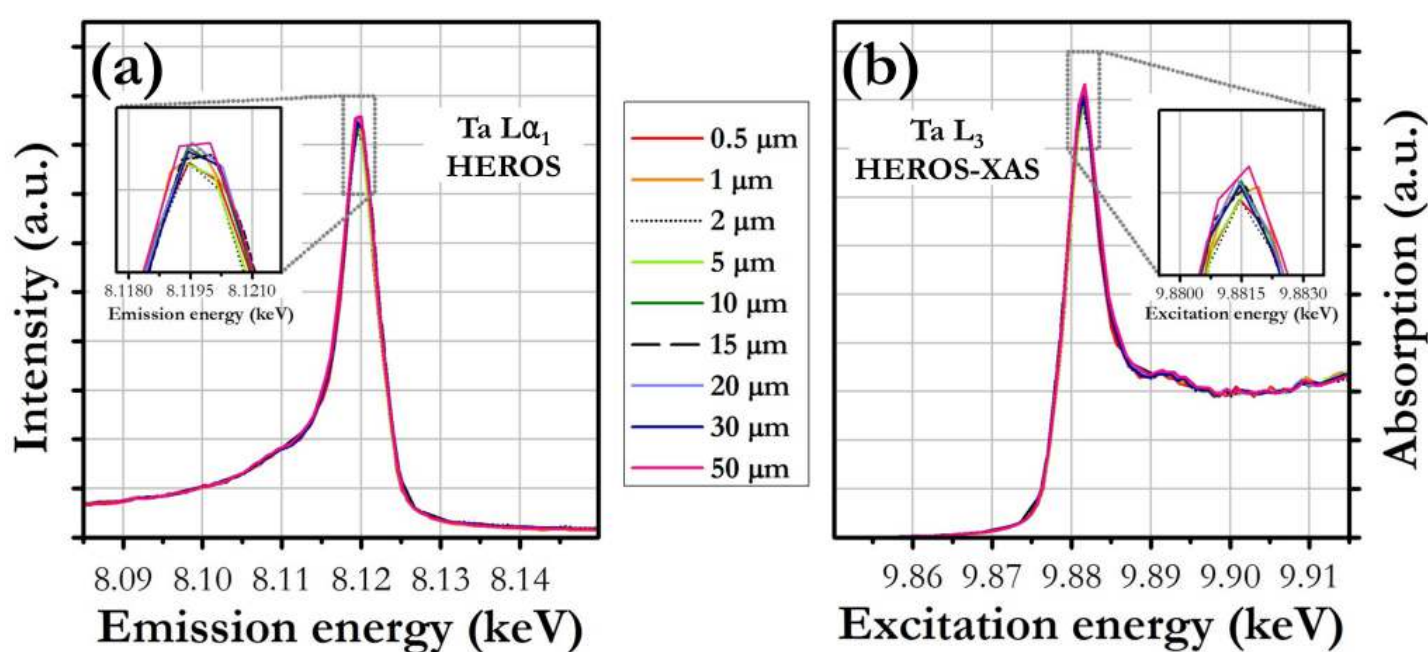

Excitation energy (keV)

Figure III.10: (a) HEROS spectra recorded for different sample thicknesses at an incident X-ray beam energy of $9.855 \mathrm{keV}$ (i.e. $26 \mathrm{eV}$ below Ta $L_{3}$ edge binding energy). (b) The reconstructed HEROS-XAS spectra corresponding to the Ta $L_{3}$ absorption edge. The reconstruction was done by means of Eq. III.3 (see further in the text). The HEROS spectra were scaled to coincide at the emission energy of $8.096 \mathrm{keV}$ in a) and the HEROS-XAS spectra at the excitation energy of 9.905 $\mathrm{keV}$ in (b). The insets show enlarged the scatter of the data at the top of the two peaks.

of unoccupied states. Assuming that the fluorescence yield is proportional to the scattering cross section and the oscillator strength distribution for electron excitation to the density of unoccupied states, one can reformulate the Tulkki and Åberg formula to retrieve the XAS data from the measured HEROS spectrum [60. The formula was adapted to the present study allowing calculation of the Ta $L_{3}$-edge absorption spectrum as a function of the excited photoelectron energy $E$, denoted by $I_{X A S}(E)$, based on the measured Ta $L \alpha_{1}$ HEROS data (shown in Fig. III.10(a)), denoted by $I_{X E S}\left(\hbar \omega_{2}\right)$. It has the following form [1]:

$$
\begin{aligned}
I_{X E S}\left(\hbar \omega_{2}\right)=\int_{0}^{\infty} & {\left[\frac{\hbar \omega_{2}}{\hbar \omega_{1}} \frac{\left(\left|E_{L_{3}}\right|-\left|E_{M_{5}}\right|\right)\left(E+\left|E_{L_{3}}\right|\right)}{\left(E+\left|E_{L_{3}}\right|-\hbar \omega_{1}\right)^{2}+\Gamma_{L_{3}}^{2} / 4}\right.} \\
& \left.\times I_{X A S}(E) \delta\left(\hbar \omega_{1}-\hbar \omega_{2}-\left|E_{M_{5}}\right|-E\right)\right] \mathrm{d} E,
\end{aligned}
$$

where $\Gamma_{L_{3}}$ stands for the initial state broadening, $\hbar \omega_{1}$ and $\hbar \omega_{2}$ the energies of the incident and the emitted photons, respectively. The initial and the final states' binding energies are denoted by $E_{L_{3}}$ and $E_{M_{5}}$, respectively. The final state broadening is omitted which results in substitution of the Lorentzian term in Eq. II.2 describing the final state's density with a Dirac delta function. The omission of the $M_{5}$ state broadening 
may seem arguable since its value of $1.61 \mathrm{eV}$ is comparable to that of the initial state, i.e. $4.68 \mathrm{eV}[96]$. However, it makes Eq. III.3 easily solvable for $I_{X A S}(E)$ and has a minor effect on the obtained results (introduces a small blurring to the calculated spectral curve). The values for $E_{L_{3}}$ and $E_{M_{5}}$ were taken from Ref. [91]. Finally, the $I_{X A S}(E)$ function retrieved from the HEROS data $I_{X E S}\left(\hbar \omega_{2}\right)$ by means of Eq. III.3 is proportional to the linear photoabsorption coefficient $\mu_{\mathrm{ph}}$ as a function of the excitation energy $\left(E+\left|E_{L_{3}}\right|\right)$, which is here named HEROS-XAS spectrum. Note that $\mu_{\mathrm{ph}}\left(E+\left|E_{L_{3}}\right|\right)=\mu_{\mathrm{ph}}\left(\hbar \omega_{1}-\hbar \omega_{2}+\left|E_{L_{3}}\right|-\left|E_{M_{5}}\right|\right)$ according to the energy conservation relation 49,54. The HEROS-XAS spectra reconstructed for all the studied sample thicknesses are presented in Fig. III.10(b). They appear independent of the sample thickness and thus of the self-absorption effect.

The fluorescence yield measured with a typical detection setup is described by Eq. III.2, with the symbols introduced in Fig. III.1. It can be used to study a relative difference of fluorescence yields detected for different sample thicknesses. Ratio of $F Y$ for sample thicknesses $d_{1}$ and $d_{2}$, which is expressed by the relation:

$$
\frac{F Y\left(\hbar \omega_{1}, \hbar \omega_{2}, d_{1}\right)}{F Y\left(\hbar \omega_{1}, \hbar \omega_{2}, d_{2}\right)}=\frac{1-e^{-\left(\frac{\mu_{\mathrm{tot}}\left(\hbar \omega_{1}\right)}{\sin \phi}+\frac{\mu_{\mathrm{tot}}\left(\hbar \omega_{2}\right)}{\sin \theta}\right) d_{1}}}{1-e^{-\left(\frac{\mu_{\mathrm{tot}}\left(\hbar \omega_{1}\right)}{\sin \phi}+\frac{\mu_{\mathrm{tot}}\left(\hbar \omega_{2}\right)}{\sin \theta}\right) d_{2}}}=\operatorname{Ratio}\left(\hbar \omega_{1}, \hbar \omega_{2}, d_{1}, d_{2}\right)
$$

was used to compare the self-absorption effect around the Ta $L_{3}$-edge in the conventional fluorescence XAS and HEROS methods. The $\mu_{\text {tot }}$ was obtained by scaling the transmission-mode XAS spectrum measured for the $0.5 \mu \mathrm{m}$ sample with the values of the total linear attenuation coefficient calculated from Ref. 97] assuming density of the elemental tantalum of $16.65 \frac{\mathrm{g}}{\mathrm{cm}^{3}}$. Thus obtained $\mu_{\text {tot }}$ as a function of the energy of the photons penetrating the Ta medium is plotted in the upper parts of Fig. III.11.

In the conventional fluorescence mode XAS the emitted radiation is detected and integrated within a fixed part of its spectrum and the incident beam energy is varied across a given absorption edge. In the present work the Ta $L_{3}$ edge is scanned and the emission from a $2 \mathrm{eV}$ energy window centered at the Ta $L \alpha_{1}$ emission line (for the high energy resolution XAS spectra) or the whole Ta $L \alpha_{1,2}$ energy range (for the TFY spectra) is detected and integrated. The ratios Ratio $\left(\hbar \omega_{1}, d_{1}, d_{2}\right)$ of thus measured fluorescence yields calculated for different sample thicknesses by means of Eq. III.4 are presented in Fig. III.11(a). As shown, the detected fluorescence yield depends on both the penetration depth of the incident photons (which depends on the incident beam energy and varies very strongly in the resonant regime) and the escape length of the induced fluorescence (which depends on the fluorescence radiation energy and varies slowly with the emission energy). As a result, thicker or more concentrated samples 

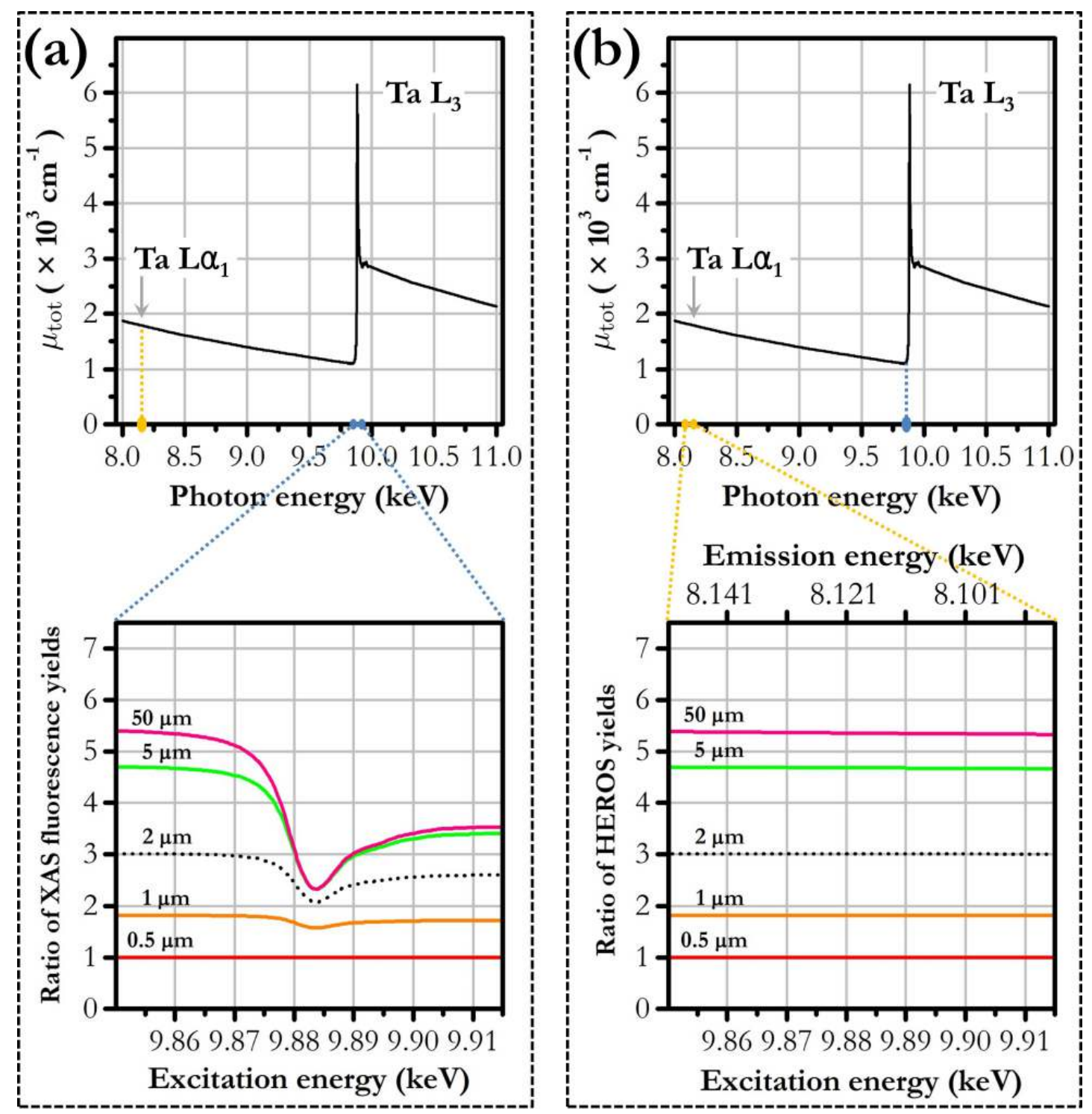

Figure III.11: Calculations based on Eq. III.4 showing the effects of the target thickness on the Ta $L_{3}$-edge in the conventional fluorescence-mode XAS (a) and in the HEROS (b), for $\phi=\theta=45^{\circ}$. The yield ratios were calculated with respect to the $0.5 \mu \mathrm{m}$ thick sample (i.e., $d_{2}=0.5 \mu \mathrm{m}$ ). In the XAS case the ratios Ratio $\left(\hbar \omega_{1}, \hbar \omega_{2}=8.146 \mathrm{keV}, d_{1}, d_{2}\right)$ were calculated for a fixed X-ray emission energy corresponding to the Ta $L \alpha_{1}$ line $(8.146 \mathrm{keV})$. In the HEROS case, the fluorescence yield ratios Ratio $\left(\hbar \omega_{1}=9.855 \mathrm{keV}, \hbar \omega_{2}, d_{1}, d_{2}\right)$ were first calculated. The calculations were performed for the beam energy used in the HEROS measurements, i.e. $26 \mathrm{eV}$ below the Ta $L_{3}$-edge binding energy. Then the energy scale of the $\mathrm{X}$-ray emission was converted to the excitation energy scale $\left(\left|E_{L_{3}}\right|+E\right)$ through the relation $\left(\left|E_{L_{3}}\right|+E\right)=\left|E_{L_{3}}\right|+9.855 \mathrm{keV}-\hbar \omega_{2}-\left|E_{M_{5}}\right|$ (see Eq. III.3). 
will provide stronger $F Y\left(\hbar \omega_{1}\right)$ signals, but will introduce stronger spectral distortions and reduction of the XANES peaks (see Fig. III.11(a)). Note, however, that these distortions are not as much due to the self-absorption of the emitted fluorescence radiation as due to the differences in the incident photon penetration depth as a function of the photon energy.

In contrast to the conventional fluorescence mode XAS, in the HEROS technique an emission spectrum is measured at a fixed off-resonant incident beam energy. The ratios Ratio $\left(\hbar \omega_{2}, d_{1}, d_{2}\right)$ calculated using Eq. III.4 for $\hbar \omega_{1}$ fixed $26 \mathrm{eV}$ below Ta $L_{3}$ edge binding energy and $\hbar \omega_{2}$ varying in the Ta $L \alpha_{1}$ energy range are presented in Fig. III.11(b) (lower plot, top and left axes). As shown, changing the target thickness, to a good approximation, introduces only scaling of the measured $F Y\left(\hbar \omega_{2}\right)$. Conversion of the measured HEROS spectra to HEROS-XAS spectra by means of Eq. III.3 yields absorption spectra whose shapes are independent of the target thickness (see Fig. III.11(b), lower plot, bottom and left axes).

\section{III.5 Conclusion}

In the present study the Ta $L_{3}$ absorption edge [1] was studied with high energy resolution off-resonant spectroscopy (HEROS) at a synchrotron. The absorption spectra measured in fluorescence mode suffer from the self-absorption effect which causes a reduction of the detected spectral structures, both in XANES and in EXAFS regions. The main contribution of the self-absorption effect to the conventional fluorescence mode XAS spectra arises from the photoabsorption coefficient strongly changing in the resonant regime. In HEROS an off-resonant emission spectrum is measured at an incident beam energy fixed below the given absorption edge binding energy. The impact of the self-absorption effect on the HEROS spectrum is reduced to only the probability of reabsorption of the produced fluorescence radiation escaping from the target which is usually nearly constant in the measured emission energy range. The HEROS spectrum contains information on the density of unoccupied states and can be converted to an absorption spectrum by means of the formula introduced by Kramers and Heisenberg [44] modified by Tulkki and Åberg [49].

To investigate the effect of the self-absorption on the spectra measured with HEROS, nine Ta metallic foils of nominal thicknesses in the range $0.5-50 \mu \mathrm{m}$ were studied. The measured Ta $L \alpha_{1}$ HEROS emission spectra and the reconstructed Ta $L_{3}$ HEROS-XAS absorption spectra were found to be independent of the target thickness and thus of the 
self-absorption effect. It was demonstrated that the HEROS method circumvents the problem of self-absorption effect allowing potentially the investigation of any strongly absorbing sample with fluorescence XAS. HEROS is thus an alternative to existing XAS techniques, in particular in cases where they are not applicable. It is the method of choice for single-shot XAS spectra measurements allowing extraction of a precise information on the electronic structure from XAS spectra which are free of self-absorption effect. 


\section{Chapter IV}

\section{Time-resolved chemical speciation with HEROS}

\section{IV.1 Introduction}

The ability of high energy resolution off-resonant spectroscopy (HEROS) to perform time-resolved studies on chemically dynamic systems has already been used to follow the time course of such chemical processes as oxidation, reduction and compound decomposition $60,68,98$. It has been shown that, despite a low fluorescence yield for the off-resonant excitations, HEROS allows observation of changes in the density of unoccupied states caused by the changing chemical environment of the probed atoms with a high temporal resolution reaching below $1 \mathrm{~s}$. Moreover, insensitivity to the self-absorption effect makes it a reliable tool to do a quantitative chemical speciation under reaction conditions.

In the present work the HEROS method was employed to study a silica supported $\mathrm{Ta}(\mathrm{V})$ bisalkyl catalyst at a synchrotron. The Ta $L \alpha_{1}$ HEROS spectra were measured during oxidation of the inactive starting complex and its form after activation in hydrogen. Based on the experimental data and theory-based calculations, it was shown that oxidation of the inactive and the active Ta catalyst leads to the formation of mono- and di-meric species on the $\mathrm{SiO}_{2}$ surface. The relative species' concentration was successfully retrieved as a function of time using the fingerprint HEROS spectra measured for the unoxidized and the oxidized catalyst. It allowed observation of a transition of the inactive catalyst from its unoxidized form to the oxidized one through an intermediate step. 


\section{IV.2 Experimental}

\section{IV.2.1 Experimental setup}

The measurements were carried out at the SuperXAS beamline of the Swiss Light Source of the Paul Scherrer Institute, Switzerland (see Fig. III.4). The collimated synchrotron beam was monochromatized by means of a double $\mathrm{Si}(111)$ crystal monochromator and focused with a toroidally bent Rh mirror to a $100 \times 100 \mu \mathrm{m}^{2}$-spot size on the target. First, a Ta foil was used as the target to perform energy calibration of the incident beam and the spectrometer. Then the investigated Ta complex was loaded into a quartz capillary reactor cell in a glove box and exposed to $20 \mathrm{ppm} \mathrm{O}_{2}$ at room temperature. Two silica supported Ta complexes were studied, Ta(V) bisalkyl complex (Complex 1) and Ta hydride (Complex 2):

$$
\begin{gathered}
\text { Complex 1: }\left[\left(\equiv \mathrm{SiO}_{2}\right) \mathrm{Ta}(=\mathrm{CH} t \mathrm{Bu})\left(\mathrm{CH}_{2} t \mathrm{Bu}\right)_{2}\right] \\
\text { Complex 2: }\left[\left(\equiv \mathrm{SiO}_{2}\right) \mathrm{TaH}_{3}\right]
\end{gathered}
$$

The quartz capillary reactor cell (see Fig. IV.1(a)) was mounted on the sample holder and connected to a remotely switchable gas system which allowed applying a gas flow through the target on line. Two gases were used: Ar to flush residual gases out of the reactor and $10 \% \mathrm{H}_{2} / \mathrm{He}$ to activate the Ta complex. The temperature of the Ta complex was adjusted with an air blower and a thermometer placed on two sides of the reactor (see Fig. IV.1(a)). The target was irradiated with a synchrotron X-ray beam of energy $9.863 \mathrm{keV}$ and $9.867 \mathrm{keV}$ for Complex 1 and Complex 2, respectively. The induced fluorescence was detected in the energy range around the Ta $L \alpha_{1}$ emission line (8.146 $\mathrm{keV}$ ) by means of a wavelength-dispersive von Hámos-type spectrometer consisting of two cylindrically curved segmented-type $\mathrm{Si}(444)$ crystals [88] and a two-dimensional PILATUS 100K detector [99] (see Fig. IV.1(b,c)). The radiation diffracted by the two crystals was directed onto two separate spots on the detector. The HEROS spectra were measured in the two regions of interest (ROIs) of the detector, and collected one by one with an acquisition time of $40 \mathrm{~s}$ each. From the full width at half maximum (FWHM) of a Gaussian fit to the elastic scattering peak the experimental resolution of $1.6 \mathrm{eV}$ was found. A 30-cm-long, helium filled, ionization chamber was placed upstream the target to allow the detected fluorescence yield normalization. 


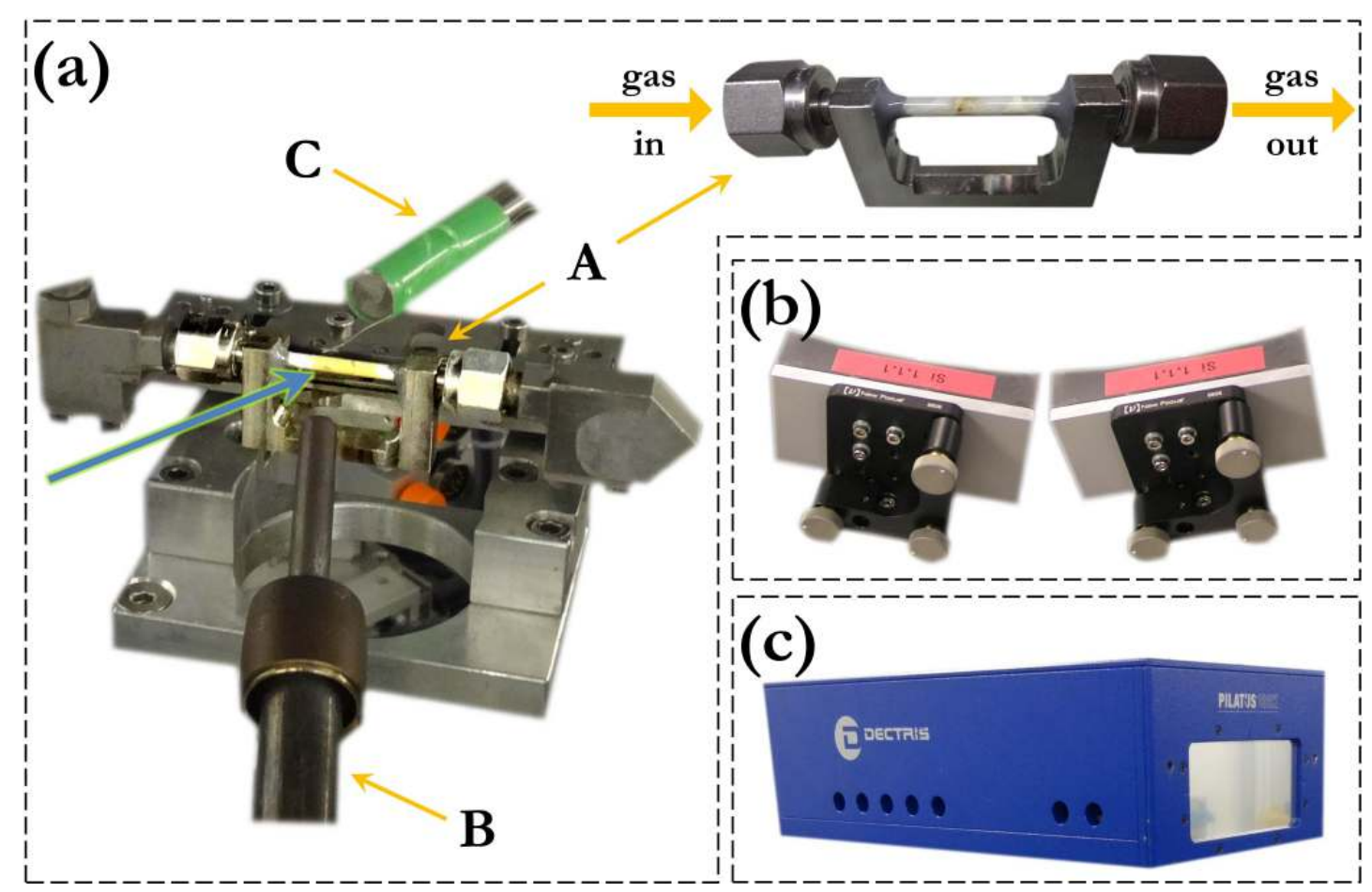

Figure IV.1: Elements of the used experimental setup. (a) Zoom on the target holder with the incident beam direction marked with a blue arrow. The meaning of the symbols is the following: A - connected to a gas system quartz capillary reactor cell containing the studied complex, B - blower with adjustable temperature of the blown air, $\mathrm{C}$ - thermometer. (b) Two Si(444) cylindrically curved segmented-type crystals [88. (c) Two-dimensional PILATUS 100K detector 99. The setup was shielded with lead and aluminum plates to reduce unwanted contributions to the signal coming from the background.

\section{IV.2.2 Data analysis}

Since a time-resolved chemical speciation with HEROS was attempted in this work, a precise energy calibration of the synchrotron beam and the used von Hámos spectrometer was of high importance. In this section the applied two-step energy calibration of the synchrotron beam and the spectrometer is described as well as the measured HEROS spectra analysis.

The synchrotron beam energy calibration is usually done with an absorption edge of a given element. In this approach, however, the determined absorption edge position depends on the spectroscopy method used and the nature of the target sample itself. The influence of the experimental setup on measured emission lines' positions is much more limited. In the present study the synchrotron beam energy calibration was therefore carried out in two steps. First, a Ta foil was used to measure the Ta $L_{3}$ 
edge absorption spectrum in the fluorescence mode. The first inflection point of the obtained spectral curve was assigned a value $9.8811 \mathrm{keV}$ [91]. The synchrotron beam energy was next varied in the Ta $L \alpha_{1,2}$ emission energy range with a step of $10 \mathrm{eV}$ and the elastically scattered photons were detected in the form of sharp peaks, in both regions of interest (ROIs) on the detector independently. The positions of the elastic scattering peaks and the corresponding incident beam energies were used to find the first step spectrometer calibration curve (a quadratic polynomial was assumed), as presented in Fig. IV.2(a). The obtained calibration curve was compared to the previously

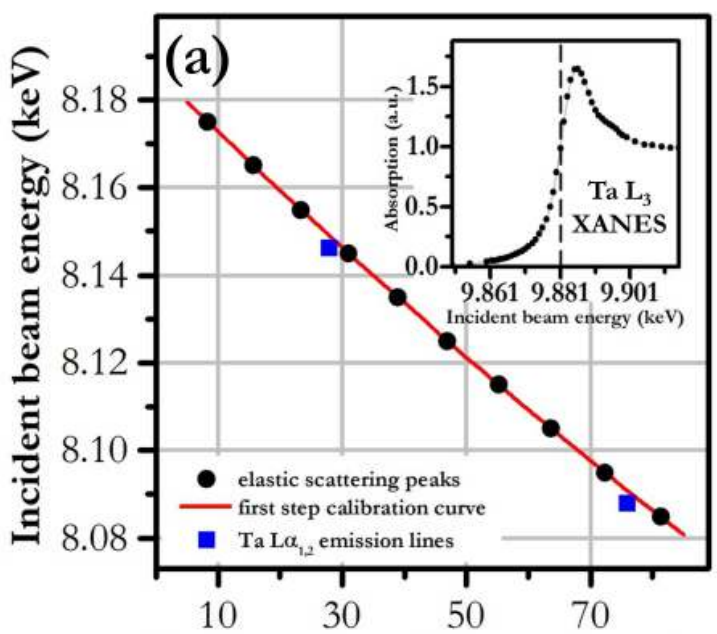

Pixel number of the peak center

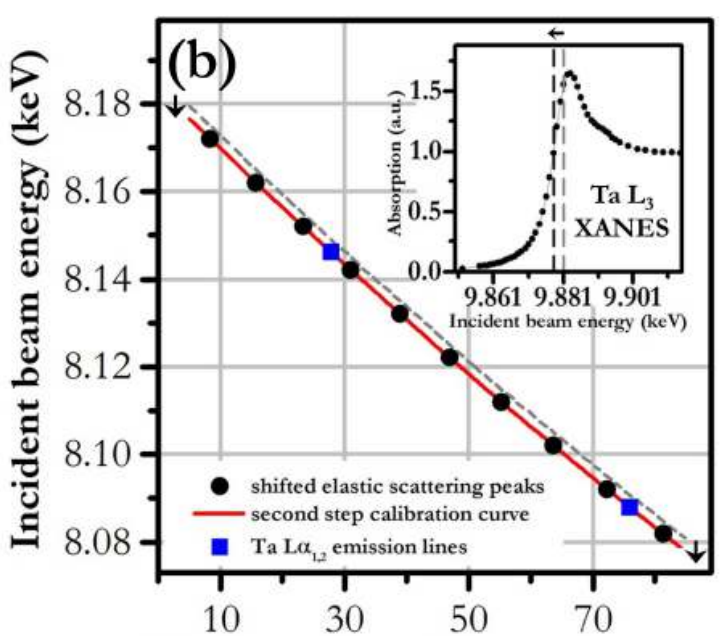

Pixel number of the peak center

Figure IV.2: Two-step energy calibration of the synchrotron beam and the spectrometer. In the first step (a) an inflection point of the measured Ta $L_{3}$ XAS spectral curve was assigned a value $9.8811 \mathrm{keV}$ [91] (see the inset) and the spectrometer was energy-calibrated with elastic scattering peaks. A shift of $2.9 \mathrm{eV}$ between the spectrometer calibration curve and the measured Ta $L \alpha_{1,2}$ emission lines' positions 92 was observed. In the second step (b) the new energy calibration was established by lowering the measured incident beam energies by $2.9 \mathrm{eV}$ as compared to the first step energy calibration.

measured Ta $L \alpha_{1,2}$ emission lines' positions (with their energies taken from Ref. [92]) and a relative energy shift of $2.9 \mathrm{eV}$ was found. In the second step, to keep the energy calibration consistent with the measured Ta $L \alpha_{1,2}$ emission lines' positions, a shift of $-2.9 \mathrm{eV}$ was introduced to the first step energy calibration of the synchrotron beam (see Fig. IV.2(b)). The incident beam energy uncertainty was found to be below 0.4 $\mathrm{eV}$. The error on the energy of the photons detected in both ROIs changed with their energy but did not exceed $0.5 \mathrm{eV}$ within the range $8.085-8.175 \mathrm{keV}$. The spectrometer energy resolution was found by fitting a Gaussian function to the elastic scattering 
peaks data. The average of the extracted full width at half maximum (FWHM) values was $1.6 \mathrm{eV}$ and $1.5 \mathrm{eV}$ for the two ROIs.

To estimate the contributions to the recorded HEROS signal coming from the background noise and the used experimental method (photon scattering, detector's electronic noise) a measurement was performed with the synchrotron beam directed onto a target-free spot on the reactor. Thus recorded signal was fitted with a quadratic polynomial and the obtained baseline was subtracted from all the measured HEROS spectra (see Fig. IV.3). The final spectra obtained in both ROIs were summed.
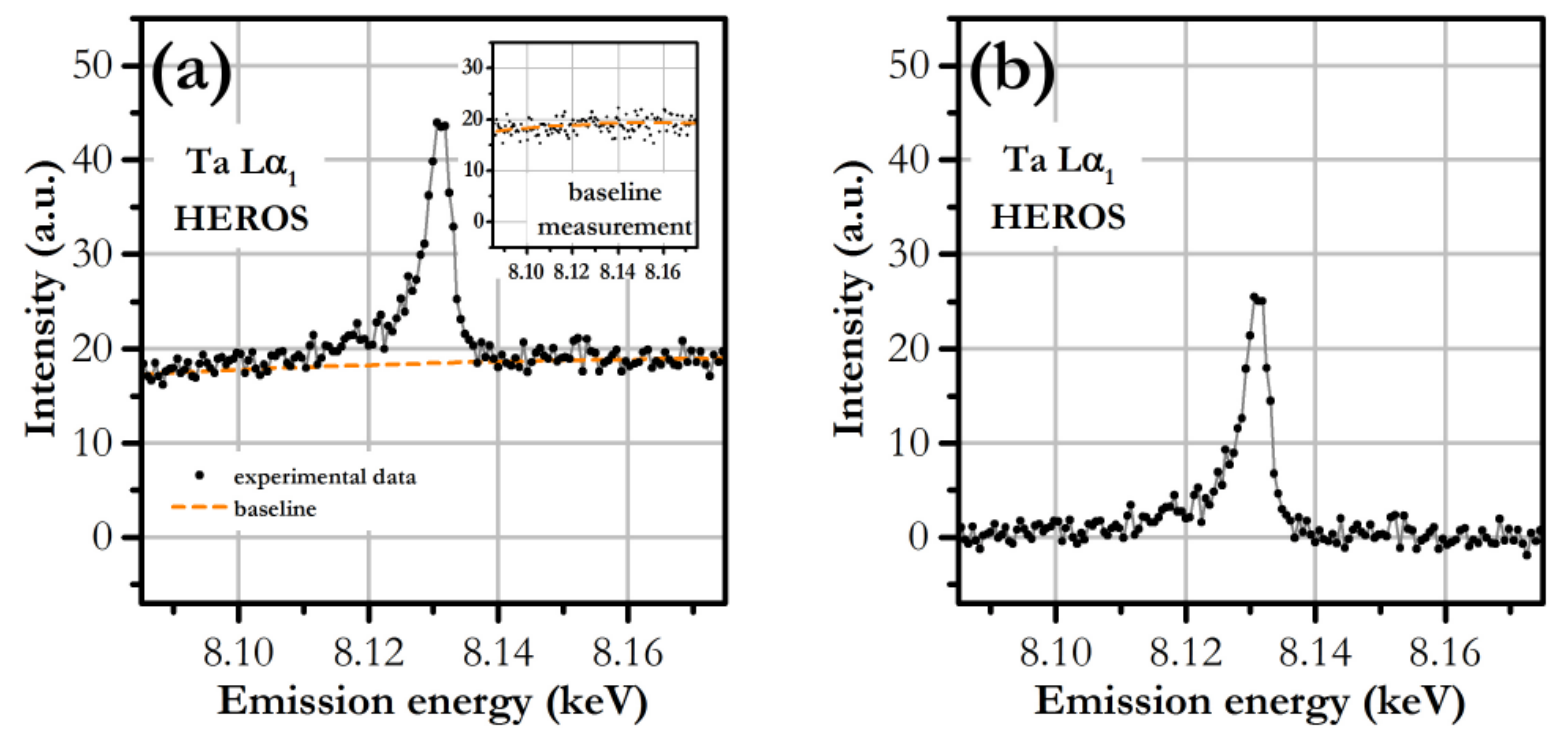

Figure IV.3: (a) The Ta $L \alpha_{1}$ HEROS spectrum recorded in one ROI at an incident beam energy of $9.867 \mathrm{keV}$ for Complex 1 with shown baseline. The inset presents a signal measured in the same ROI and at the same conditions but for a target-free spot on the reactor. The baseline was found by fitting a quadratic polynomial to the data recorded without the presence of the target Ta complex in the beam's field. (b) The data from (a) with the subtracted baseline.

The measured Ta $L \alpha_{1}$ HEROS spectra changed in time due to the changing chemical environment of the Ta atoms. Two reaction paths were followed: activation of Complex 1 to Complex 2 and oxidation of the latter, as well as direct oxidation of Complex 1. In Fig. IV.4(a) are shown the parameters whose temporal changes were studied. The relative chemical energy shifts were obtained from the positions of the off-resonant Ta $L \alpha_{1}$ line maxima. The intensity changes were determined by integrating the fluorescence yields in two emission energy ranges corresponding to two detected spectral structures. To investigate the temporal change in the concentration of Complex 1 and Complex 2 during their oxidation, their fingerprint HEROS spectra before and after oxidation were first measured. A linear combination of the fingerprint spec- 
tra was next fitted to each acquired HEROS spectrum (see Fig. IV.4(b)). The ratios of the extracted scaling coefficients allowed estimating the temporal evolution of the concentration of the two complexes during their oxidation.
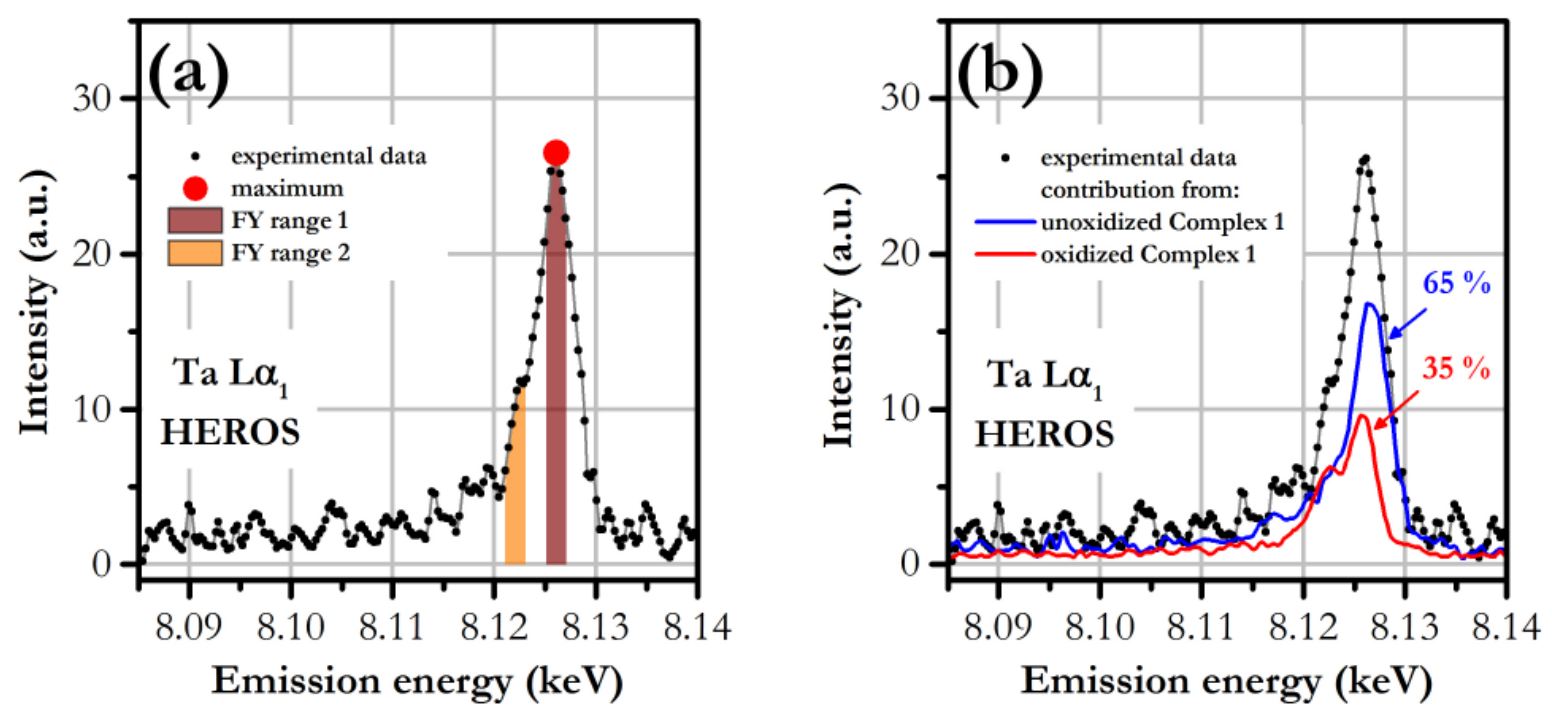

Figure IV.4: (a) One of the Ta $L \alpha_{1}$ HEROS spectra measured for Complex 1 during its oxidation. The two fluorescence yield (FY) integration ranges, $2 \mathrm{eV}$ wide and separated by $4 \mathrm{eV}$, correspond to two observed spectral features. The red dot indicates the off-resonant Ta $L \alpha_{1}$ line maximum. (b) The same spectrum as in (a) with shown contributions from the unoxidized and the oxidized Complex 1. The contributions, obtained by finding the best fit of the fingerprint spectra's linear combination to the measured HEROS spectra, reflect the relative concentration of the unoxidized and the oxidized Ta atoms. The presented HEROS spectrum was recorded when about $35 \%$ of the starting Complex 1 was already oxidized.

\section{IV.3 Calculation of XAS spectra with FEFF}

The independent particle theory describing XAS (see e.g. [100 102]) assumes that the potential determining the atomic orbitals is dominated by the nucleus' potential. The orbitals calculated under this assumption are approximate and can be corrected for the weak interaction between electrons. The independent particle approximation (IPA) allows to present the atom's wavefunction as a product of independent wavefunctions describing every orbital, which makes their calculation very efficient but ignores many important many-body effects. The approaches going beyond the independent particle approximation make use of the time-dependent density functional theory (TDDFT) 
or the Bethe-Salpeter equation (BSE) [103, 104]. However, they are usually based on simplified or semi-empirical models (see e.g. [100, 105, 106]), providing very often divergent results.

In the recent approach of Rehr et al. 100, 107, 108 the scattering of electromagnetic radiation on atomic electrons is described using the real-space Green's function (RSGF) formalism within quasiparticle picture (where the photoelectron is treated as a particle moving in a lossy inter-atomic potential). The authors express the absorption coefficient in terms of effective one particle Green's function corresponding to the intermediate and the final many-body states $[109,110]$. The Green's function is separated into two summands [11]: one associated with the absorbing atom (which is taken as the leading term) and another describing multiple scattering on the surrounding atoms (which is treated as a perturbation). Such a presentation of the Green's function leads to a form of the absorption coefficient similar to that obtained by Lee and Pendry [112]. It consists of two summands: one describing the intra-atomic contributions from the absorbing atom (i.e., the ones defined by the solid-state potential at the absorption site) and the multiple scattering term determining the fine structure.

The theoretical description developed by Rehr et al. is implemented in the FEFF software [107]. In the present work FEFF in the version 9.6 was used to calculate the $L_{3}$ edge XANES spectra of Ta atoms in different chemical environments. The program includes in the calculations to a good approximation effects of dominant many-body effects, such as the photoelectron-core hole interaction and the lifetime effects of the photoelectron and the core hole. However, the calculated spectrum may slightly vary depending on several input parameters. The full multiple scattering is computed within a sphere centered at the absorbing atom and having the radius specified by the parameter FMS (in ångströms) (see the FEFF's main window in Fig. IV.5). If the SCF card is activated, the self-consistent field method (also called Hartree-Fock method) is used to calculate the orbitals and the potentials. In this method different values of Coulomb potentials, electron charge distributions and Fermi energy are used in an iterative manner and the total energy of the system is calculated. If the total energy does not change any more between consecutive iterations, the last used values are applied to further calculations. The first parameter in the SCF card (called further simply $S C F$ parameter) determines the radius of the sphere (in ångströms) within which the calculated potentials are to be self-consistent with electron densities and Fermi energy. The EXCHANGE card contains two fields where an optional modification of the Fermi level and the spectral broadening can be introduced (in electronvolts). The calculated 


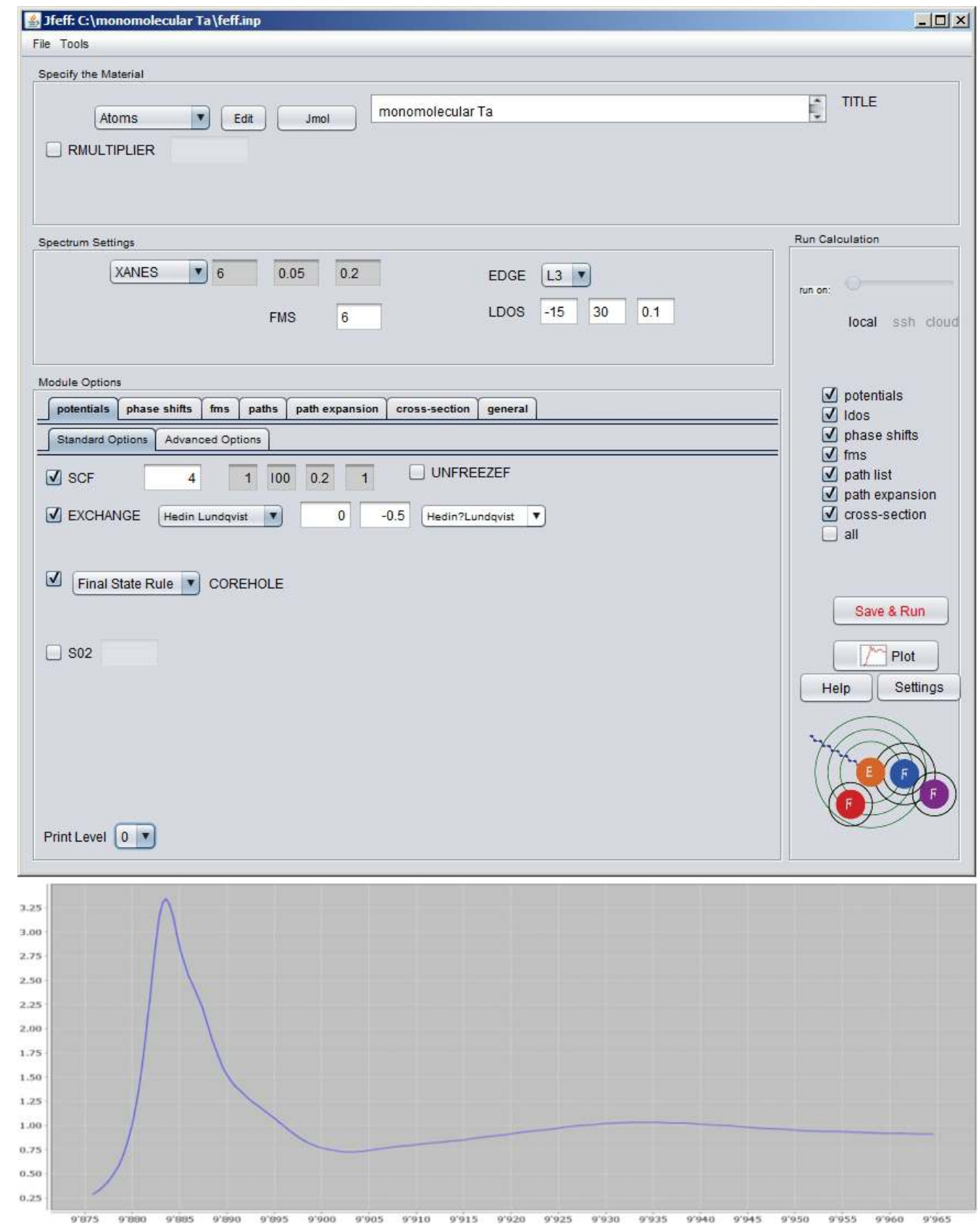

Figure IV.5: Screenshot showing the FEFF 9.6 program's main window and the plotting window with a calculated XANES. The shapes of the calculated spectral curves may vary depending on the input parameters: full multiple scattering (FMS), self-consistent field (SCF), exchange correlation potential (EXCHANGE) and the core hole treatment.

X-ray emission and absorption spectra depend on the fact whether the final states' wave functions are computed in the presence of the core hole potential or not. FEFF provides different treatments of the core hole state through the card COREHOLE. The 
three available options assume: absence of the core hole, screened potential of the core hole (within the random phase approximation, RPA) and final state rule (FSR). In the final state rule, which was introduced by von Barth and Grossmann [113], the electron excitation probabilities are calculated from wave functions obtained in the presence of the core hole potential, and for the calculations of the deexcitation probabilities no core hole potential is assumed. In the present work only FSR was used.

Calculation of XAS spectra with FEFF requires information on the spatial distribution of electric potential in the vicinity of the absorbing atom. For this reason, to run a XAS spectrum calculation one needs to specify an .INP file containing data which defines types of atoms and their configuration in a sample cluster. Such data is obtained experimentally and can be found in different databases available online, e.g. Crystallography Open Database [114]. Apart from XAS spectra, FEFF allows calculation of the density of unoccupied states. This feature was used to determine the most contributing states to the measured spectra.

\section{IV.4 Results and discussion}

The data measured within this work was published and can be found in Ref. [2]. The discussion held in this section is focused on experimental aspects of the study and only several chemistry related issues are addressed. The mentioned publication provides a more deeper chemistry-oriented analysis.

The Ta $L \alpha_{1}$ HEROS spectra measured for an incident beam energy of $9.863 \mathrm{keV}$ during oxidation of Complex 1 are presented in Fig. IV.6(a). The reaction took place at room temperature and it caused an increase in the fluorescence intensity as well as a shift of the detected spectral structure towards lower energies. In the case of Complex 2, the Ta $L \alpha_{1}$ HEROS spectra, which are shown in Fig. IV.6(b), were collected at incident beam energy of $9.867 \mathrm{keV}$. Complex 2 was obtained by activating Complex 1 in hydrogen which was achieved by exposing Complex 1 to $10 \% \mathrm{H}_{2} / \mathrm{He}$ gas mixture between $1300 \mathrm{~s}$ and $3200 \mathrm{~s}$ under temperature rising from $20{ }^{\circ} \mathrm{C}$ to $150{ }^{\circ} \mathrm{C}$. During activation, a slight gradual displacement of the detected spectral structure towards lower energies was observed. Further oxidation of Complex 2 led to a sudden spectral shift and an increase in intensity of the emitted fluorescence.

More precise analysis of temporal changes in the spectra measured during oxidation of Complex 1 is presented in Fig. IV.7. As shown, the spectral shift towards lower energies (Fig. IV.7(a)) did not occur in a continuous manner but in two steps, first by 
Temperature $\left({ }^{\circ} \mathrm{C}\right)$

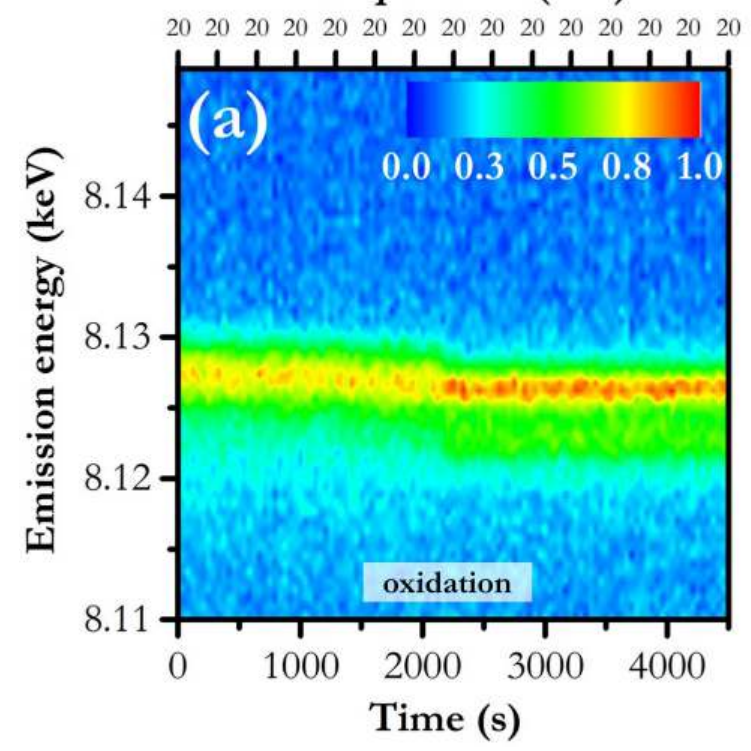

Temperature $\left({ }^{\circ} \mathrm{C}\right)$

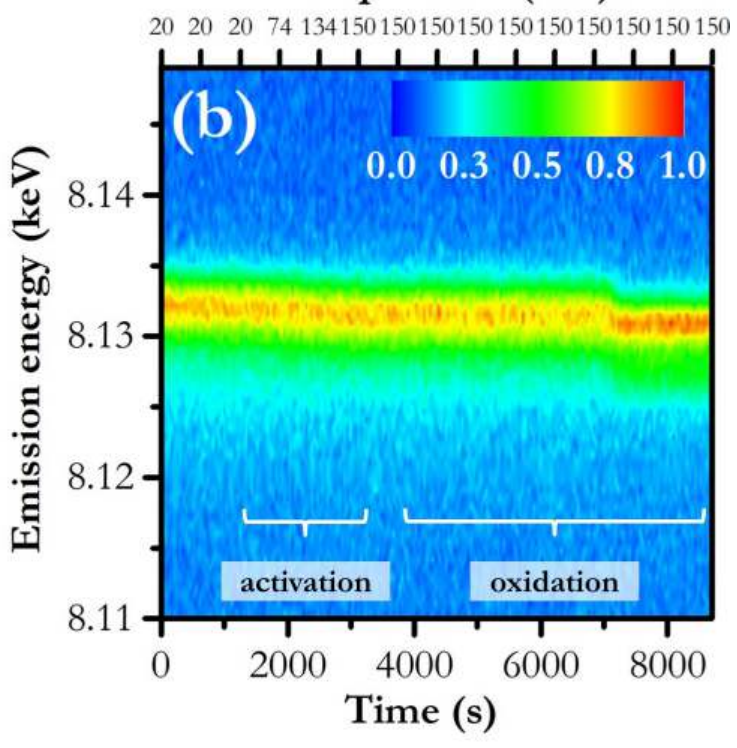

Figure IV.6: The measured Ta $L \alpha_{1}$ HEROS spectra as a function of time for Complex 1 (a) and Complex 2 (b). The spectra in (a) and (b) were recorded for an incident beam energy of $9.863 \mathrm{keV}$ and $9.867 \mathrm{keV}$, respectively (i.e. $18 \mathrm{eV}$ and $14 \mathrm{eV}$ below the Ta $L_{3}$ edge binding energy, respectively).
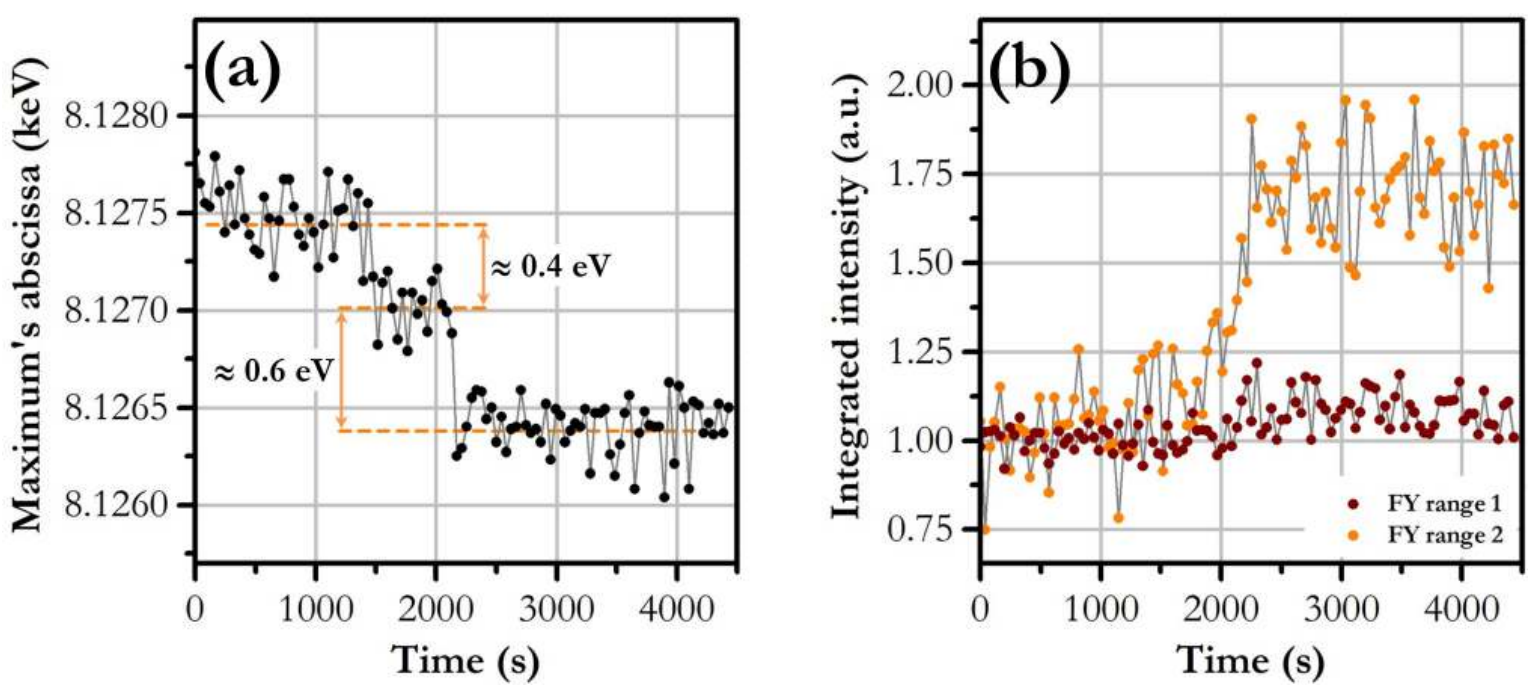

Figure IV.7: Variation of the off-resonant Ta $L \alpha_{1}$ line's position (a) and the fluorescence yield from two emission energy ranges (b) during oxidation of Complex 1. The emission energy range $F Y$ range 1 is centered at the main spectral feature's peak and $F Y$ range 2 is fixed $4 \mathrm{eV}$ below (for more details see Fig. IV.4(a)). The fluorescence yields integrated over the two emission energy ranges were scaled to 1 in the time interval $0-500 \mathrm{~s}$. The data in (a) suggests an intermediate chemical form of Complex 1 during its reaction with oxygen and the data in (b) shows the evolution of a second peak. 
about $0.4 \mathrm{eV}$ and next by about $0.6 \mathrm{eV}$. The detected shifts are bigger than the uncertainty introduced by the statistical fluctuations. This finding suggests that during oxidation Complex 1 passes through an intermediate form, which is consistent with further analysis. The evolution of the fluorescence yield integrated over two emission energy ranges (for more details see Fig. IV.4(a)) is shown in Fig. IV.7(b). The presented relative temporal changes of the two partial fluorescence yields show an overall growth of the fluorescence emission due to oxidation. However, while the main spectral feature's intensity is augmented by about $10 \%$, the fluorescence yield integrated over energy interval situated $4 \mathrm{eV}$ below the main spectral feature's peak grows by over 60 $\%$. This result indicates the evolution of another spectral structure on the low energy side of the main peak.

The evolution of the second peak in the HEROS spectra measured for Complex 1 during its oxidation suggests the formation of $\mathrm{Ta}=$ oxo dimeric surface species with octahedral coordination [115], which is consistent with calculations of Ta $L_{3}$ edge XAS spectra and off-resonant Ta $L \alpha_{1}$ XES spectra for a monomeric and a dimeric Ta species (see Fig. IV.8). The absorption spectra were computed using the FEFF program and the emission spectra were obtained using the Kramers-Heisenberg formula modified by Tulkki and Åberg [44, 49] with the result from FEFF as the input data. The XAS spectra in Fig. IV.8(a) show that Ta $L_{3}$ XANES is dominated by one peak in the case of monomeric species and by two peaks in the case of dimeric species. The electronic states that contribute most to the absorption spectra are in both cases the $5 d$ orbitals of Ta atoms. As shown in Fig. IV.8(b), there is a significant difference in the shape of the off-resonant XES spectra calculated for monomeric and dimeric Ta species, and it resides mainly in the presence of a doublet in the case of the latter. The performed calculations thus confirm that the evolution of the second peak in the Ta $L \alpha_{1}$ HEROS spectra measured during oxidation of Complex 1 is caused by formation of dimeric Ta species. However, the ratio of the two peaks' intensity is different for the spectrum calculated for a dimeric Ta species and the one measured for the oxidized Complex 1. This result suggests that both monomeric and dimeric Ta species are present in the sample after its oxidation.

Fig. IV.9 presents how the Ta $L \alpha_{1}$ HEROS spectra were changing during activation of Complex 1 leading to creation of Complex 2, and during oxidation of the latter. As shown in Fig. IV.9(a,b), the activation in hydrogen caused the off-resonant Ta $L \alpha_{1}$ line to move in a continuous way towards lower energies by about $0.5 \mathrm{eV}$. This continuous shift seems to have started at about $1300 \mathrm{~s}$, when the $10 \% \mathrm{H}_{2} / \mathrm{He}$ gas 


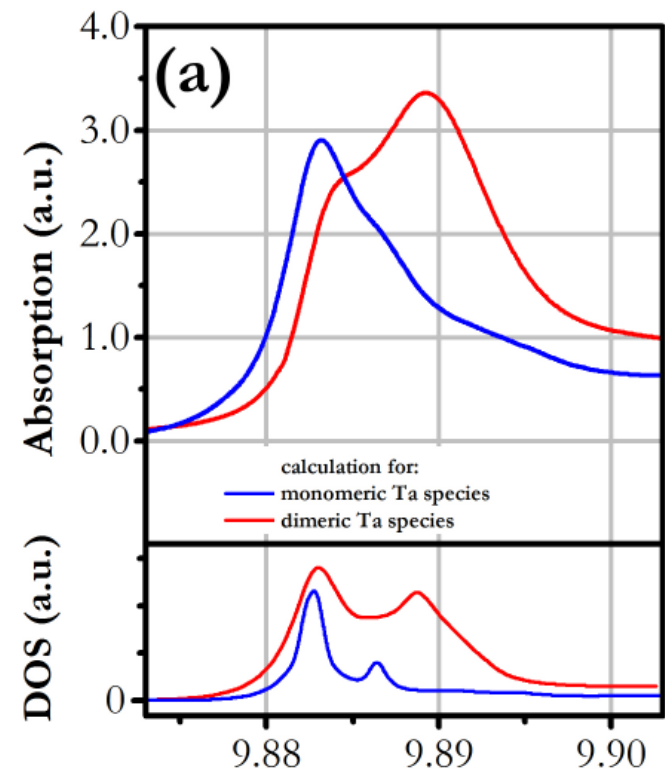

Excitation energy (keV)

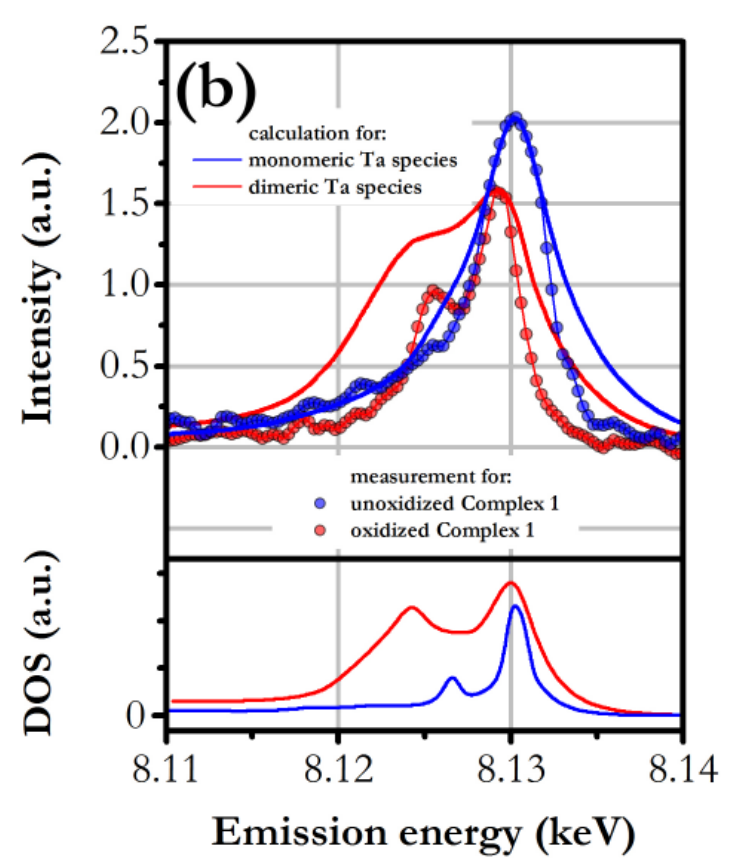

Figure IV.8: (a) The Ta $L_{3}$ edge XANES calculated with FEFF for a monomeric and a dimeric Ta species. The lower panel shows the distribution of the Ta atoms' $d$-states which are contributing the most to the absorption spectra. (b) Off-resonant Ta $L \alpha_{1}$ spectra calculated with the Kramers-Heisenberg formula modified by Tulkki and Åberg [44, 49] based on the XAS data from (a). The formula used was of the form of Eq. III.3 11. The data points come from the measurements of the fingerprint HEROS spectra for Complex 1 before and after its oxidation. The structures present in the calculated spectra are broader than the ones in the measured spectra because of a higher value of the final state broadening used in the calculations. The lower panel in (b) presents the density of unoccupied states from (a) converted to the emission energy scale by the RIXS energy conservation.

flow was engaged, and ended at about $2500 \mathrm{~s}$. Significant statistical fluctuations in the fluorescence intensity hinder accurate judgment on the temporal changes in the Ta $d$-states' occupancy. The main peak's fluorescence yield remained constant until about $2500 \mathrm{~s}$ after which a slight upward trend may be noticed. Much more pronounced changes are observable during oxidation of Complex 2, as presented in IV.9 (c,d). As a result of interaction with oxygen, the Ta $L \alpha_{1}$ HEROS spectra underwent a sudden shift towards lower energies by about $0.7 \mathrm{eV}$ with no intermediate step. The fluorescence intensity changes reveal a formation of another peak which is caused by formation of dimeric Ta species. The ratio of the two partial fluorescence yields after oxidation is, however, different than in the case of the oxidized Complex 1, which suggests relatively 

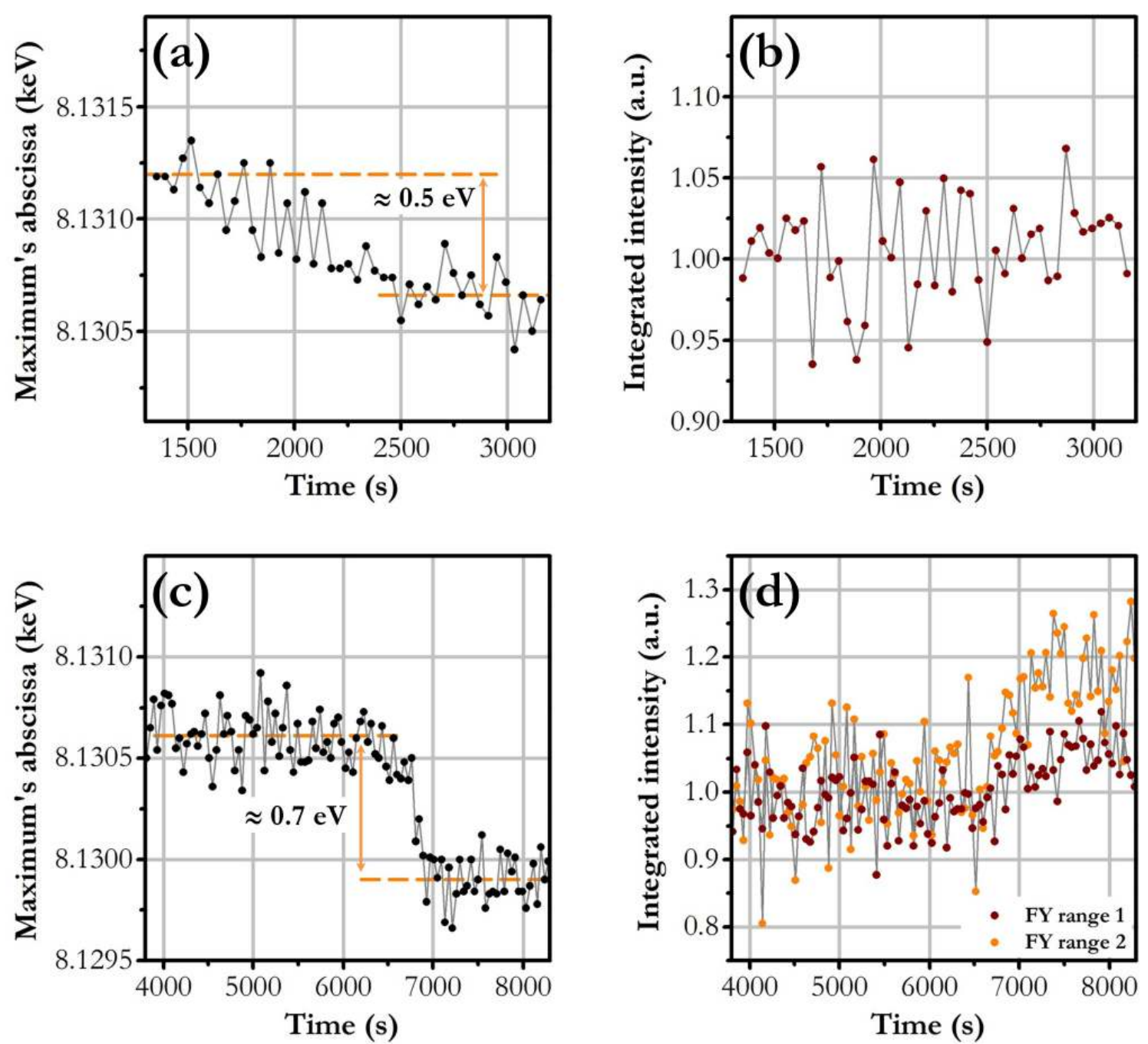

Figure IV.9: Temporal changes in the position of the Ta $L \alpha_{1}$ HEROS spectra and fluorescence yields integrated over two emission energy ranges during formation of Complex $2(a, b)$ and its oxidation $(c, d)$.

smaller contribution of $\mathrm{Ta}=$ oxo dimeric surface species to the measured spectra.

For both studied complexes the fingerprint Ta $L \alpha_{1}$ HEROS spectra were recorded before and after oxidation to determine temporal changes in the species' concentration. As can be seen in Fig. IV.10(a), during reaction of Complex 1 with oxygen only about $20 \%$ of the sample first turned into its oxidized form and the remaining $80 \%$ transformed afterwards. This finding is consistent with the result presented in Fig. IV.7(a). In the light of the apparent formation of dimeric Ta species during oxidation, one may suppose that the demonstrated step-wise transition is an effect of different reaction rates for oxidation and dimerization. Such a behavior was not observed in the case of Complex 2 oxidation, as shown in Fig. IV.10(b), where at about $6800 \mathrm{~s}$ all the sample was suddenly oxidized. 

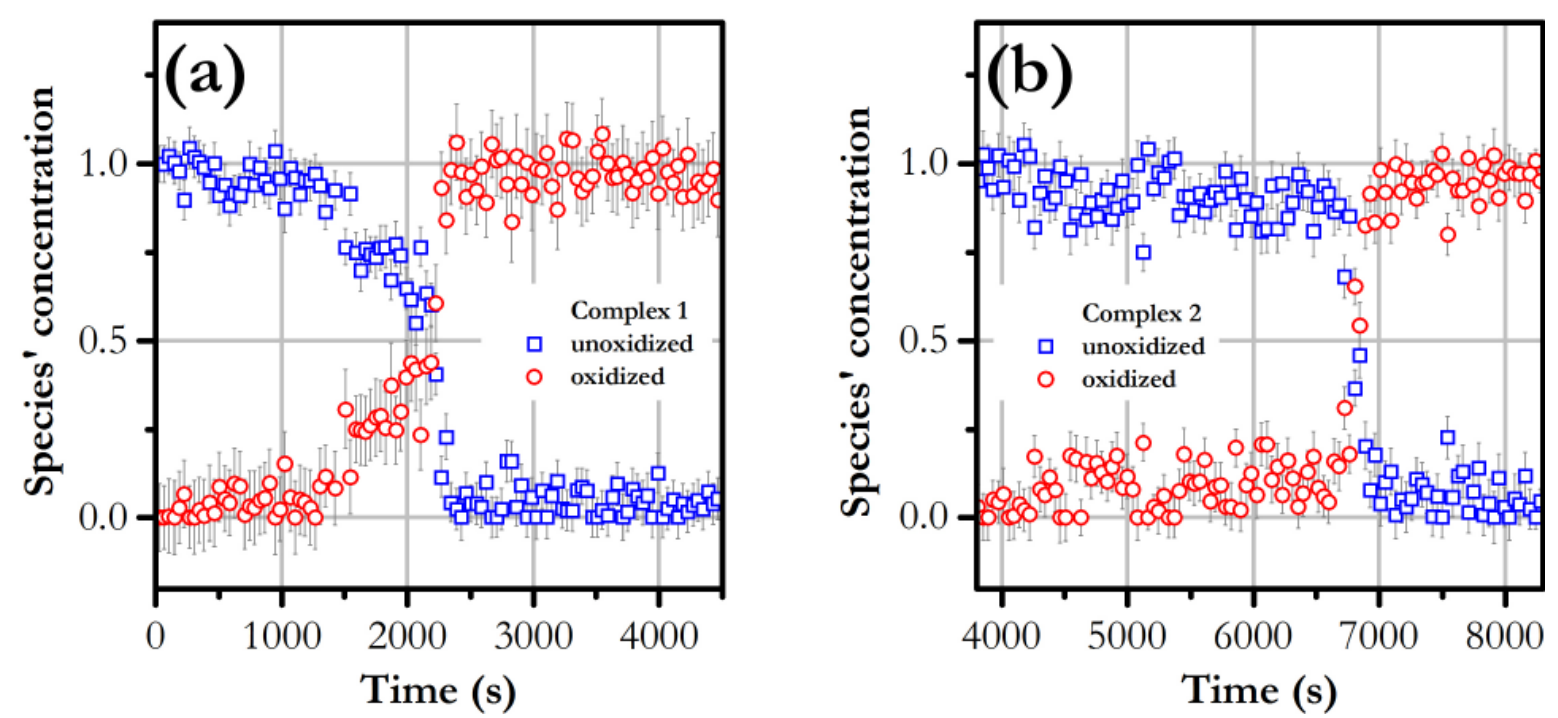

Figure IV.10: Relative concentration of Complex 1 [2] (a) and Complex 2 (b) as a function of time during oxidation. The step-wise character of the reaction in the case of Complex 1 was not observed for Complex 2.

\section{IV.5 Conclusion}

In the present work the HEROS method was used at a synchrotron to study temporal changes in the density of unoccupied states of Ta atoms in two different silica supported catalysts during their oxidation [2]. The catalysts studied were: inactive Ta(V) bisalkyl complex as well as Ta(V) bisalkyl complex activated in hydrogen. The active site in catalysis, postulated to be Ta hydride, was found to be very susceptible to oxygen and its detection was not reported in any earlier work. Analysis of Ta $L \alpha_{1}$ HEROS spectra measured with 40 s-time resolution showed that oxidation of both catalysts leads to formation of monomeric and dimeric Ta surface species. The catalysis was found to be irreversible. Calculations done with FEFF software 107 and KramersHeisenberg formula modified by Tulkki and Åberg [44, 49 revealed that the electronic states contributing most to the measured HEROS spectra come from the Ta $d$-band. The present work is therefore the first to depict the electronic structure of the $d$-orbitals (directly involved in the catalysis) of Ta grafted catalysts. 


\section{Chapter V}

\section{HEROS at X-ray free-electron laser facilities}

\section{V.1 Introduction}

This chapter deals with the application of HEROS at an X-ray free-electron laser (XFEL) facility. The goal of the study was to demonstrate the potential of the HEROS technique in determining the electronic structure of matter and tracking the electronic structural dynamics with femtosecond hard x-ray free electron laser pulses. Indeed, the single-shot capability of HEROS and its chemical sensitivity makes this technique an ideal probe for time-resolved X-ray experiments. Recent studies have shown that despite the high peak intensity of the X-ray pulses at XFELs the same electronic structure can be probed yielding experimental data consistent with those obtained at synchrotrons [116, 117]. In this perspective, the HEROS technique was applied to the investigation of the electronic structure of copper in different oxidation states. The present work focused on the case of $\mathrm{Cu}^{1+}$. The experimental HEROS spectra were compared to the ones for $\mathrm{Cu}^{0}$ and $\mathrm{Cu}^{2+}$ reported by Szlachetko et al. [3], and to calculations based on theoretical XAS spectra retrieved from FEFF 9.6 program 107 and reference XAS spectra.

\section{V.2 X-ray free-electron lasers}

At synchrotrons an electron beam is accelerated to the velocities close to the speed of light and is trapped in a storage ring. The electromagnetic radiation is emitted during the interaction of electrons with the magnetic field produced by the insertion devices: bending magnets, wigglers and undulators. At X-ray free-electron laser (XFEL) facil- 


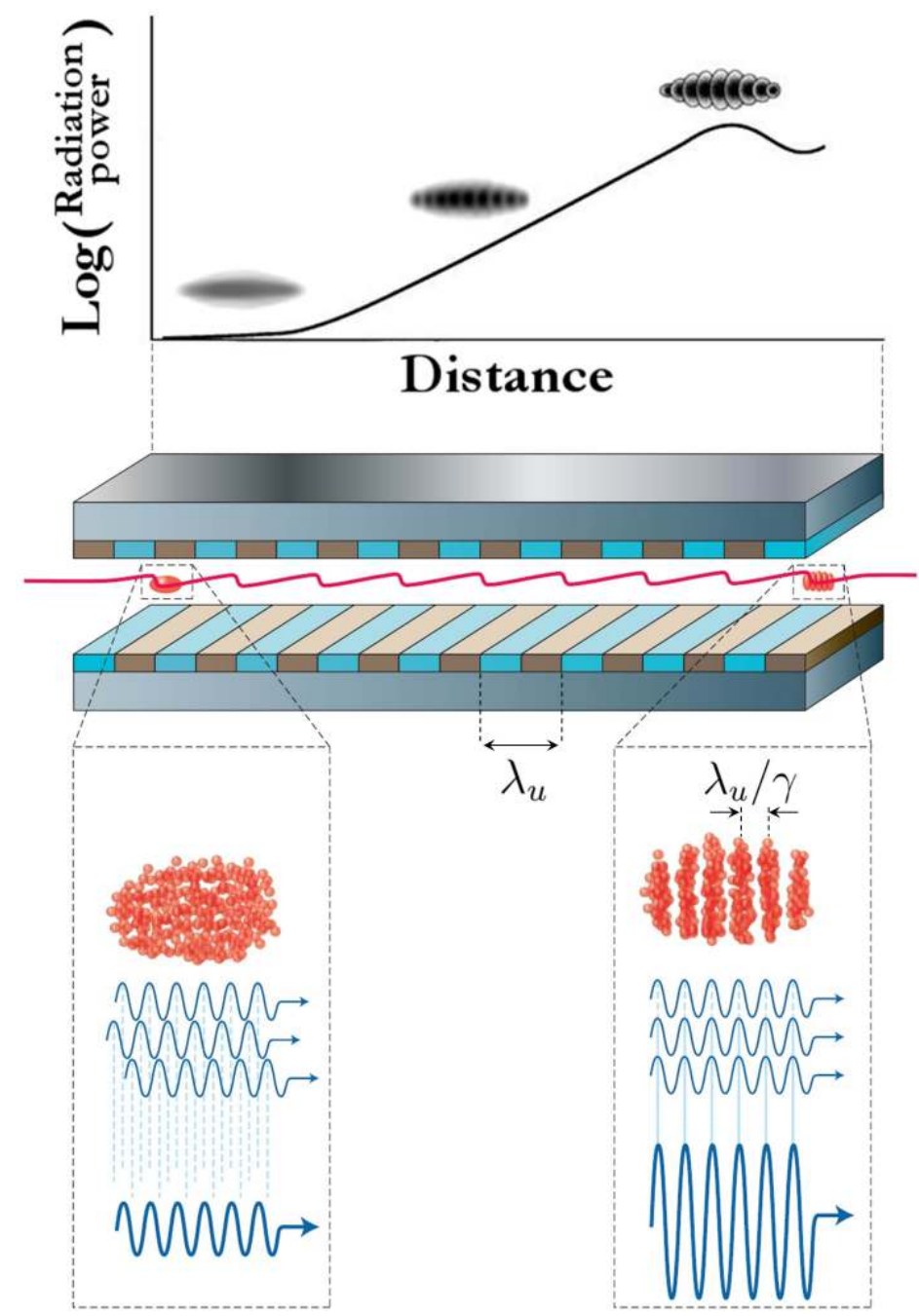

Figure V.1: (upper panel) The power of the emitted electromagnetic radiation as a function of the distance passed by the electron bunch in the undulator. The rapid exponential growth of the radiation power is caused by the formation of electron micro-bunches (lower panel). The microbunching and the electromagnetic radiation emission are mutually enhancing processes, hence the name self-amplified spontaneous emission (SASE). The illustrations were reproduced from Refs. [118, 119].

ities, the $4^{\text {th }}$ generation X-ray sources, a relativistic electron beam travels through an undulator whose length is typically of the order of hundreds to thousands of meters (i.e. 10 - 100 times more than for the undulators used at synchrotrons) [119. Due to the long undulators required, the XFELs are not equipped with storage rings and every electron bunch produced is dumped after passing through the undulator. During the long lasting interaction with the undulator's magnetic field, the electrons form micro-bunches separated by a distance of $\frac{\lambda_{u}}{\gamma}$, with undulator period $\lambda_{u}$ and electrons' Lorentz factor $\gamma$ (see Fig. V.1). The micro-bunches interfere constructively with the 
electromagnetic radiation they emit, which additionally enhances microbunching. Due to the mutual enhancement of the radiation production and micro-bunches formation this process is referred to as self-amplified spontaneous emission (SASE) 120,121.

The photon beam produced at XFELs consists of extremely bright and short X-ray pulses. As compared to synchrotron radiation, a typical XFEL produces $10^{-7}$ fewer pulses per second but each contains $10-10^{2}$ times more photons and has duration time up to $10^{4}$ times shorter (reaching below $1 \mathrm{fs}$ ). As a result an XFEL has an average brilliance (i.e., brilliance averaged over unit time of the machine's operation) comparable to that of a synchrotron, but its peak brilliance (i.e., brilliance of one pulse production) reaches far beyond capabilities of the $3^{\text {rd }}$ generation X-ray sources (Fig. V.2. . Using optics to focus a SASE beam allows to irradiate a small surface area with a

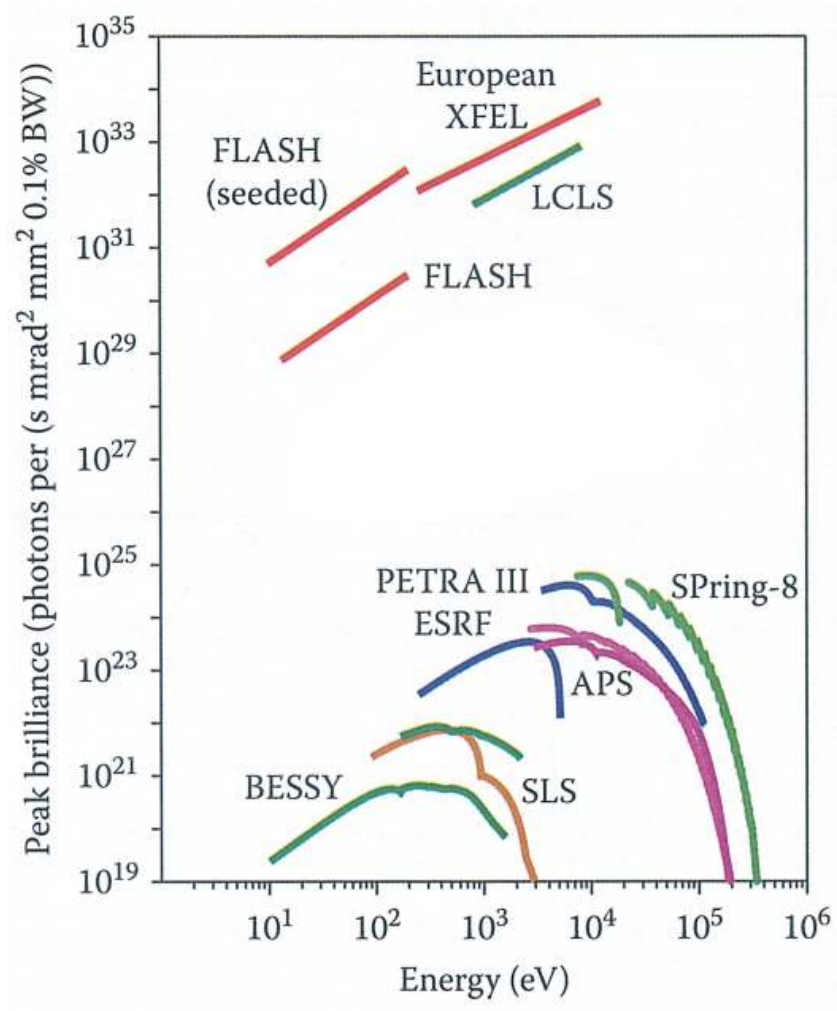

Figure V.2: Comparison of the peak brilliance between chosen $3^{\text {rd }}$ (BESSY, SLS, SPring-8, APS, ESRF, PETRA III) and $4^{\text {th }}$ (FLASH, LCLS, European XFEL) generation accelerator-based X-ray sources. The data was taken from Ref. 122 .

tremendous number of photons within the pulse duration [123, 124]. Achieveable values of the peak power density on a target are of the order of $10^{20} \frac{\mathrm{W}}{\mathrm{cm}^{2}}$ (thousands of $\frac{\text { photon }}{\mathrm{fs}_{\mathrm{s}} \times \AA^{2}}$ ) which is many orders of magnitude more than what synchrotrons can provide. The pure SASE X-ray beam has a longitudinal coherence similar to that of a synchrotron 
beam and is almost fully coherent in the transverse plane $[125,126]$. It has, however, a relatively large energy bandwidth (of the order of $10^{-3}$ ).

To reduce the energy bandwidth of the beam and improve its coherence, so called seeding is performed where a bright external laser beam (of the wavelength corresponding to the desired harmonics) is merged with the electron beam as it enters the undulator [127]. It makes the electrons to form micro-bunches much earlier and as a result enhances the production of coherent and monochromatic photons. This approach requires the use of a strong external source of monochromatic and coherent radiation, it allows therefore production of photons of energy limited to soft X-rays. To improve higher energy X-rays production the so called self-seeding is employed 128 130. In this approach, the undulator is split into two parts separated by a chicane which is composed of an X-ray monochromator and a bypass magnet system for the electron beam. The SASE photon beam leaves the first undulator, is monochromatized and enters the second undulator. The electron beam, once it leaves the first monochromator, is redirected from the photon propagation direction to bypass the monochromator and enters the second undulator. Since the interaction of X-rays with the monochromator delays the pulse by up to $10 \mathrm{ps}$, the bypass system length has to be well adjusted so the electron pulse enters the second undulator together with the monochromatized photon pulse. Further propagation of electron pulses interfering with seeding photons leads to an amplified production of highly monochromatic and fully coherent X-rays. As shown in Fig. V.3(b,c), self-seeding of an XFEL beam considerably narrows down its energy bandwidth. The self-seeded XFEL beam has an energy bandwidth comparable to that of a synchrotron but its peak brilliance is up to $10^{10}$ times higher.
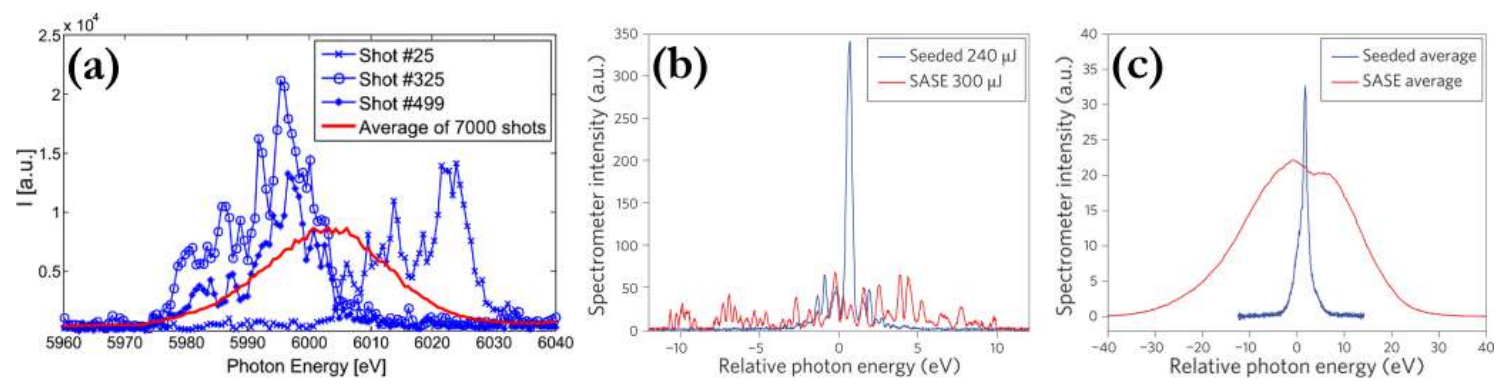

Figure V.3: (a) Spectral profiles of three single X-ray pulses measured at X-ray Pump Probe instrument of LCLS showing variations of the photon energy caused by the electron energy jitter. (b,c) The effect of the self-seeding on the X-ray beam energy bandwidth examined at LCLS. Note the larger spectral bandwidth of the averaged spectra with respect to the single-shot spectra caused mainly by the electron energy jitter. The plots were reproduced from Refs. [130,131]. 
One of the best known factors hindering the photon beam quality at XFELs is the pulse-to-pulse electron beam energy instability, also known as electron energy jitter [132]. It results from deviations of the phase in radio frequency cavities used to accelerate electron bunches. The electron energy jitter introduces variations to the photon energy (see Fig. V.3(a)) and, since it causes most of the electron bunches to be off the resonance, decreases the average brilliance of the produced X-ray beam. Reducing the jitter may potentially increase SASE and self-seeded XFEL beam average brilliance and reduce its energy bandwidth by a factor of two.

The extremely high photon fluxes that are achievable open the way to studies of $\mathrm{x}$-ray nonlinear processes and those of very low cross sections, such as double-core hole creation [133, 134], two-photon absorption [135], amplified spontaneous X-ray emission [136, 137], plasma creation [138 and X-ray-laser wave mixing [139]. The ultrashort X-ray pulses in combination with X-ray spectroscopy methods allow to perform time-resolved studies on femtosecond-long molecular processes, e.g., photo-excited spin transitions [140] or hot electron-mediated photocatalysis [141, 142].

\section{V.3 Experimental}

\section{V.3.1 CXI instrument at LCLS}

The Linac coherent light source (LCLS) is an XFEL located at SLAC National Accelerator Laboratory in Menlo Park, California, USA. It occupies about a $1 \mathrm{~km}$ long fragment of the tunnel formerly used by the SLAC linear accelerator and extends to two underground experimental stations (Fig. V.4). It starts with an electron photoinjector which forms electron bunches of charges of up to $250 \mathrm{pC}$ and injects them into the linac at the energy of up to $135 \mathrm{MeV}$ [143,144. The linac consists of three straight sections separated by two magnetic chicane bunch compressors. The electron bunches are accelerated in the straight sections and undergo compression in the chicanes. They leave the linac with the energy of up to $15.4 \mathrm{GeV}$ and the bunch length of down to 2 microns (sub-10 fs pulse duration). After the electron beam passes through the diagnostics section, where its different parameters are measured and where it is subjected to focusing, it enters $130 \mathrm{~m}$ long undulator where the final X-ray emission occurs. The produced X-ray beam - similar to the electron one - consists of pulses, each having up to $4.7 \mathrm{~mJ}$ of energy and down to below $5 \mathrm{fs}$ duration. The photon beam energy available at LCLS ranges from 0.25 to $10.5 \mathrm{keV}$. The machine can operate at up to 120 
$\mathrm{Hz}$ repetition rate.

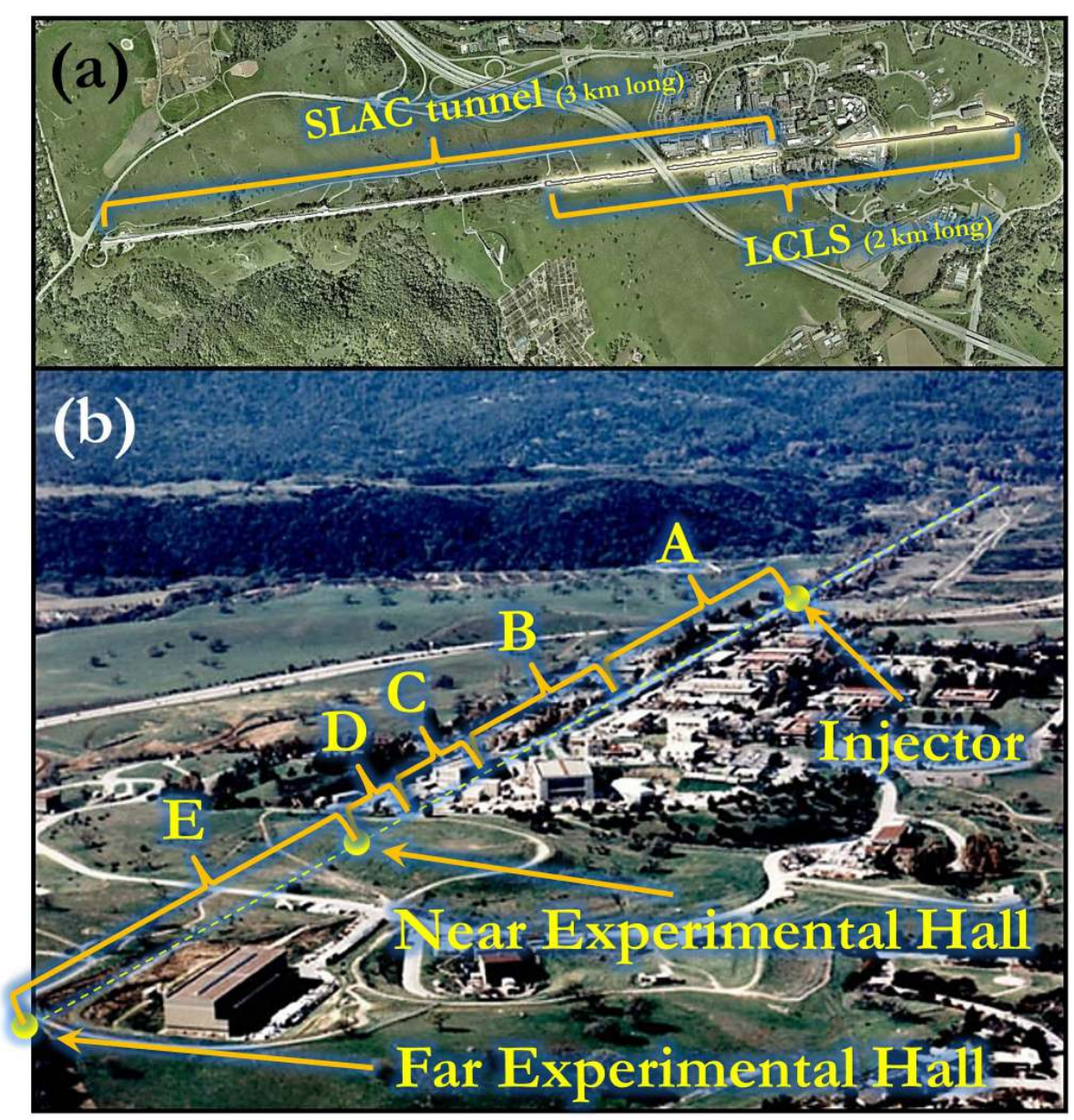

Figure V.4: (a) Aerial view of SLAC showing the proportions of LCLS with respect to the whole site. (b) View on LCLS with main modules marked. The meaning of the symbols used is following: A - linac, B - electron beam transport line (with diagnostics and focusing magnets), C - undulator, D - Front End Enclosure with X-ray optics (see Fig. V.5 for more details), E - X-ray beam transport line. The illustrations were taken from Refs. [145, 146].

The XFEL photon beam is characterized by a nominal peak brilliance of $20 \times 10^{32}$ $\frac{\text { photon }}{\mathrm{s}^{\prime} \mathrm{mm}^{2} \times \mathrm{mrad}^{2} \times 0.1 \% \mathrm{BW}}$ and an energy bandwidth of about $0.2 \%$ which can be narrowed down over 10 times in the self-seeding mode. The electron pulse charge influences both the number of photons contained in one X-ray shot and the photon pulse duration [147]. In the high charge mode (the order of $1 \mathrm{nC}$ ) one photon pulse has a duration of down to $80 \mathrm{fs}$ and contains typically $10^{12}$ photons. In the low charge mode (the order of $10 \mathrm{pC}$ ) the photon pulse duration can reach several femtoseconds and number of photons in a pulse decreases by a factor of 10. The X-ray pulses are directed to the experimental stations through the offset mirror system installed in the Front End Enclosure (FEE) 
(see Fig. V.5).

At LCLS there are six experimental stations with equipment optimized for different areas of research [148]. The Atomic, Molecular \& Optical Science (AMO) instrument located in the Near Experimental Hall is dedicated to study of extremely intense X-ray pulses with atoms and molecules. The research done at Soft X-ray Materials Science (SXR) instrument is focused on the experiments that involve scattering of soft X-rays. The pump-probe experiments are performed at X-ray Pump Probe (XPP) instrument which is equipped with a fast optical laser. The X-ray Correlation Spectroscopy (XCS) instrument installed in the Far Experimental Hall allows study on the condensed matter systems dynamics. The Coherent X-ray Imaging (CXI) instrument is specialized in imaging nano-structures with sub-nano resolution. The farthest station, Matter in Extreme Conditions (MEC) instrument, grants access to X-ray studies on matter at over 10 thousand Kelvin temperature and 10 milion bar pressure.

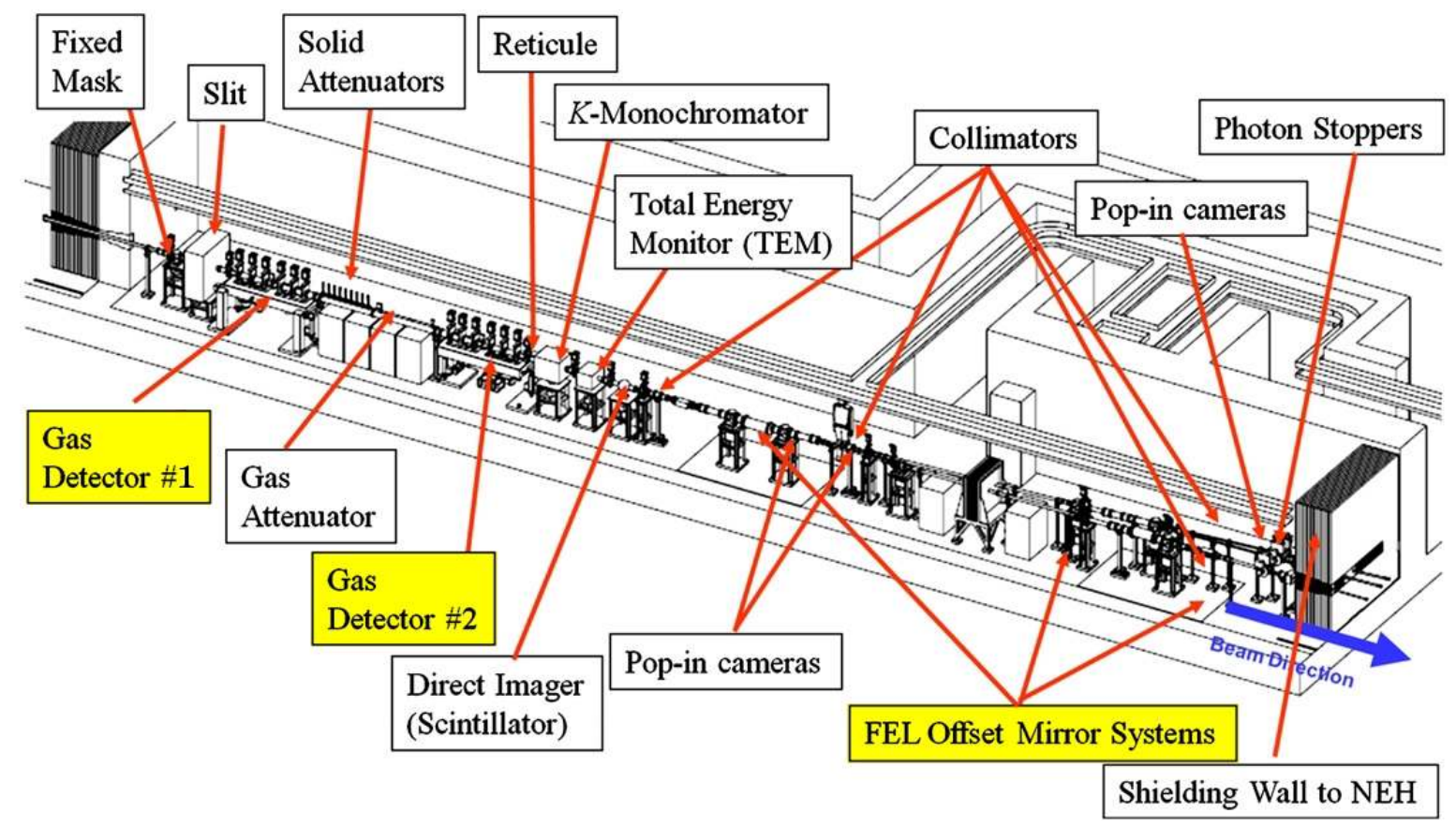

Figure V.5: Front End Enclosure (FEE) with the X-ray optics and diagnostics equipment. As shown the gas detector monitoring the photon pulse energy is installed before the offset mirror system which directs the beam to the experimental stations. The figure was reproduced from Ref. [149].

\section{V.3.2 Experimental setup}

The present experiment was performed at the CXI instrument which allowed the use of $\mathrm{X}$-rays of the required energy (about $9000 \mathrm{eV}$ ) and contained enough room to install the 
von Hámos spectrometer [150]. The X-ray beam delivered to the sample passed through the LCLS Front End Enclosure mirror and the CXI station's focusing Kirkpatrick-Baez mirror system which decreased its original intensity by 65 to $76 \%$. The target sample $\left(\mathrm{Cu}, \mathrm{Cu}_{2} \mathrm{O}\right.$ or $\mathrm{CuO}$ ) was irradiated at an angle of $45^{\circ}$ (see Fig. V.6) with X-rays of energy $8.967 \mathrm{keV}$, i.e., $12 \mathrm{eV}$ below the $\mathrm{Cu} K$-edge binding energy. Since the application

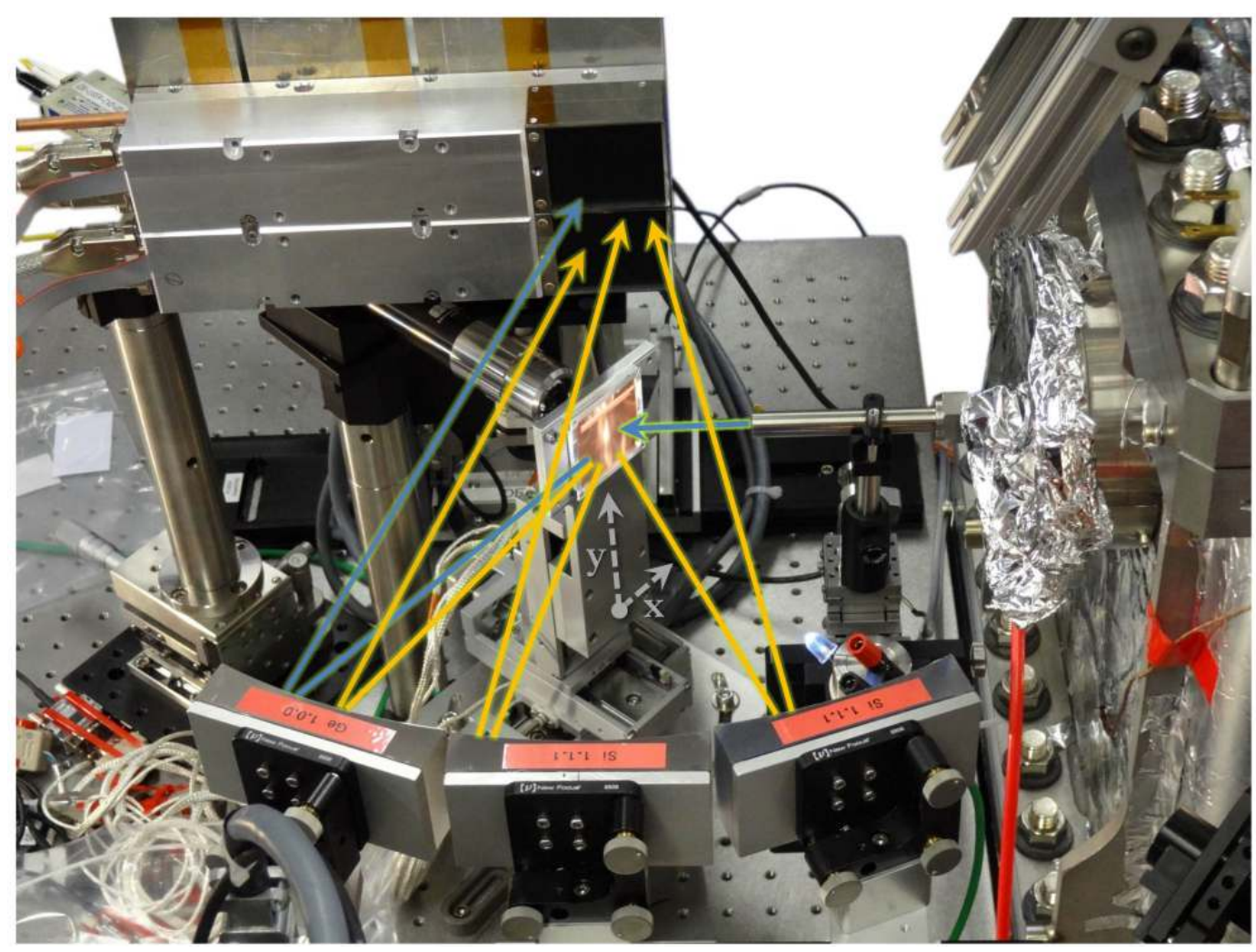

Figure V.6: The illustration of the experimental setup. The blue arrows symbolize the incident X-ray beam and the elastically scattered photons, the orange arrows show the path of the fluorescent radiation produced in the sample. Note that the $\mathrm{Ge}(800)$ crystal was used to detect both the elastically scattered photons and the $\mathrm{Cu} K \beta$ fluorescence. The target was moved along the $\mathrm{x}$ - and y-axis to ensure each shot the same target conditions. Not presented is the shielding that was used to reduce the background signal.

of the HEROS technique requires a highly monochromatic X-ray beam, the XFEL was operated in the self-seeding mode which allowed narrowing the beam energy bandwidth down to about $1.7 \mathrm{eV}$. The fluorescence emitted from the sample was detected by means of a wavelength-dispersive von Hámos spectrometer composed of three segmented-type crystals [88] with $25 \mathrm{~cm}$-radius of curvature and two combined 2-dimensional $140 \mathrm{~K}$ CSPAD detectors each consisting of two pads [151]. Two Si(444) crystals were used to detect the fluorescence in the $\mathrm{Cu} K \alpha_{1,2}$ lines energy domain $(7.980-8.060 \mathrm{keV})$. The 
remaining one, $\mathrm{Ge}(800)$, was adjusted to diffract the elastically scattered X-rays which were used to determine the incident beam energy and the experimental resolution, as well as the $\mathrm{Cu} K \beta$ fluorescence. The whole setup was arranged in a way allowing detection of the radiation diffracted at a Bragg angle of about $80^{\circ}$ on different spots on the detectors.

To avoid too high fluxes on the sample the target was moved away from the incident beam's focal point and the beam's spot size on the sample was found to be $10 \times 10$ $\mu \mathrm{m}^{2}$. The XFEL produced X-ray pulses with 30 fs-pulse duration and approximately $0.7 \mathrm{~mJ}$-pulse energy at the repetition rate of $120 \mathrm{~Hz}$. The X-ray peak flux which was found to be of the order of $10^{-1} \frac{\text { photon }}{\mathrm{fs} \times \AA^{2}}$ was still high enough to scorch the sample's surface. The target was therefore put in oscillatory motion along the x-axis (see Fig. V.6 at a speed of $0.5 \frac{\mathrm{mm}}{\mathrm{s}}$ and displaced along the y-axis once one row of burned spots was completed.

\section{V.3.3 Data acquisition}

The apparatus available at LCLS for data acquisition is very diverse 144, 152. In this section are mentioned only devices acquiring data relevant to the present work, which are: the values of the electron bunch charge and length, electron energy, photon pulse energy, sample holder motors' position as well as the spectrometer 2D detectors' readings. The electron bunch charge was measured with a Faraday cup installed in the injector and the toroidal charge monitors placed in different points along the XFEL [143]. The information on the electron bunch length and duration was obtained by means of an X-band RF transverse cavity located downstream of the undulator 153 155. The electron bunch, once it exited the undulator, was transversely deflected by the RF cavity. The vertical size of the tilted bunch depends on its longitudinal size and can be measured with a fluorescent screen. However, before the electron bunch was directed onto a screen, it was bent in a dipole magnet to enable electron energy measurement. With the final reading from the fluorescent screen the information on the electron bunch length (and duration) and the transverse electron energy profile was extracted. The X-ray pulse energy was measured in an nonintrusive way by means of a $\mathrm{N}_{2}$ gas detector 156. While passing through the gas, the pulse ionized part of the $\mathrm{N}_{2}$ atoms which next recombined and produced UV radiation. The UV emission yield was measured and converted to the photon pulse energy. There was no means available for a direct photon pulse duration measurement. It was assumed that it was equal to the electron pulse duration, however, certain studies show that the photon 
pulse can be even two times shorter (see e.g. Ref. [157]). The two-axes sample holder position was controlled with two stepper motors. The fluorescence signal produced in the studied samples was detected by a wavelength-dispersive spectrometer equipped with two combined 2-dimensional 140K CSPAD detectors 151.

The LCLS Timing System is responsible for a synchronous operation of all the apparatus and software working at LCLS [158, 159]. One of its subsystems, Timing Event System, generates and sends signals, timing triggers, to the on-line Data Acquisition (DAQ) system which is designed for the experimental data acquisition and storage [160]. Thanks to the highly precise trigger distribution the data from all the diagnostics detectors connected to the system are read out for each XFEL pulse separately and saved in XTC files. As a result, the data in the XTC files is organized in records, also called events, each containing an XFEL pulse ordering number and corresponding detectors' readings. Some of the detectors, including the ones reading the motors' positions, are not read out for each event but with a given frequency. To match their readings to subsequent events' times, interpolation is done.

The XTC file format is designed for a quick data storage event-by-event but performing analysis on a subset of events takes relatively a lot of time. In one XTC file is recorded data from one run and once writing to one file is completed, its translation to HDF5 file is started. The HDF5 is an indexed file format which allows much more efficient access to the addressed events [161]. It also requires much less disk space but it still needs almost 600 kilobytes per event or equivalently 40 gigabytes for 10 minutes of acquisition at the repetition rate of $120 \mathrm{~Hz}$.

\section{V.3.4 Data analysis}

\section{Events selection}

The experimental data in the HDF5 files were accessed with the Python programming framework [162]. Appendix B presents a Python module that was developed to access the data relevant to the present work. Additional dedicated programs were written to search for the events meeting preset conditions and process their data.

Fig. V.7 (a,b) present how the electron energy and photon pulse energy were jittering during the exemplary 10-minute run with a $\mathrm{Cu}$ sample. Most of the events contained data from either pure SASE pulses or a mixture of the SASE and self-seeded ones. Since in the present study a well defined incident X-ray beam energy was necessary only data for the well defined self-seeded pulses were considered in the analysis. 


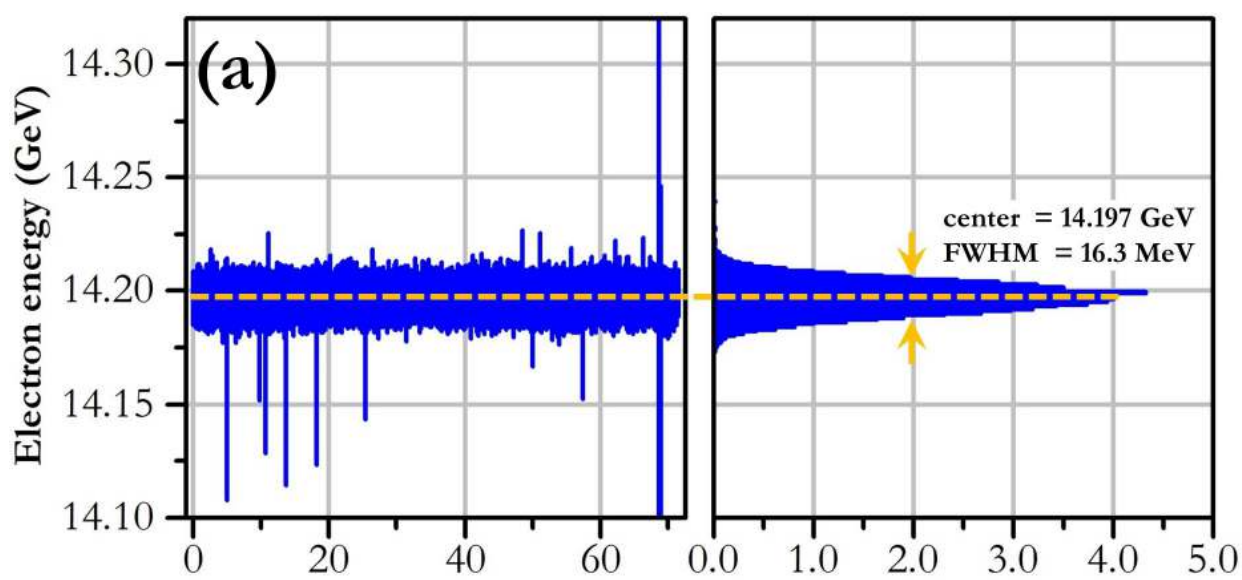

Event ordering number $\left(\times 10^{3}\right) \quad$ Number of events $\left(\times 10^{3}\right)$

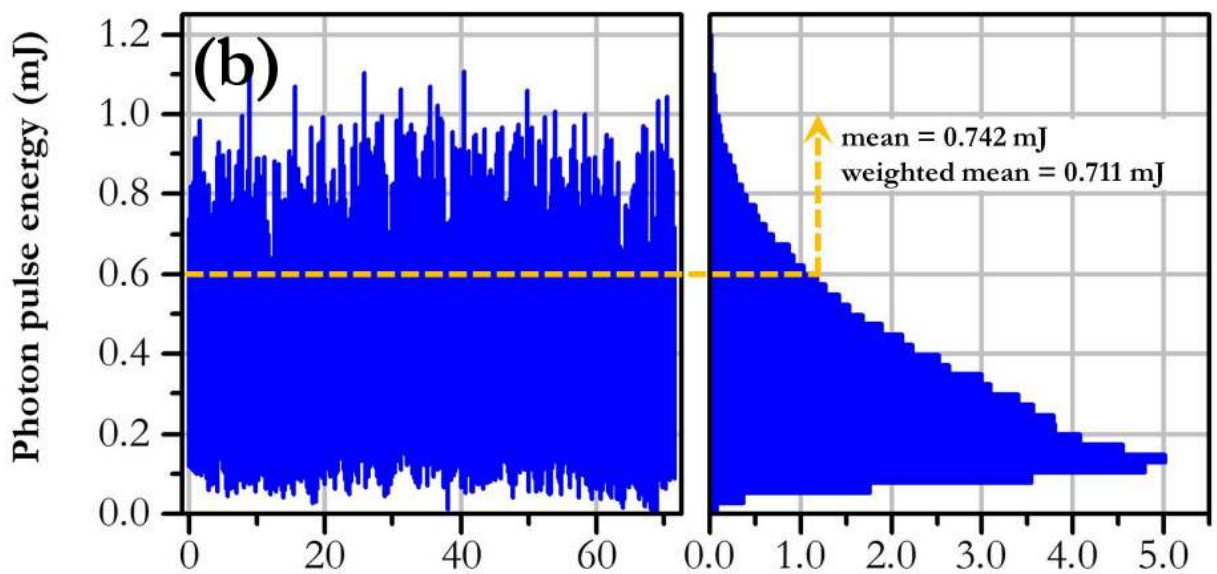

Event ordering number $\left(\times 10^{3}\right) \quad$ Number of events $\left(\times 10^{3}\right)$

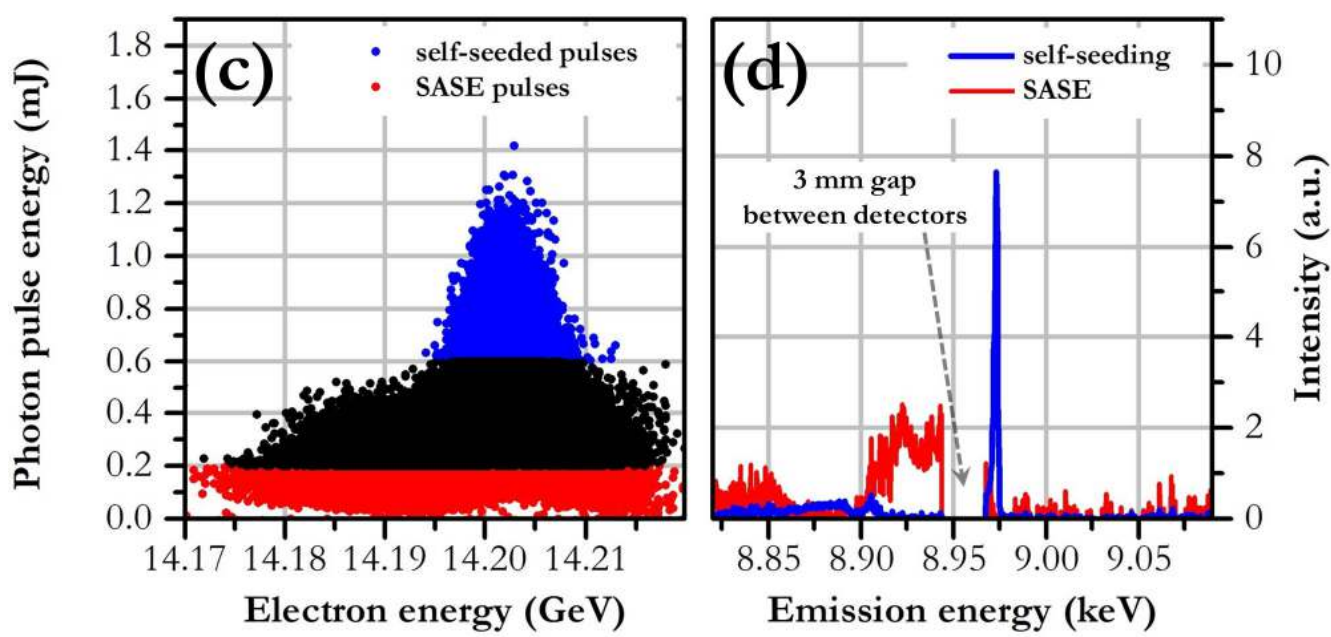

Figure V.7: The pulse-to-pulse electron energy jitter of about $0.1 \%$ (a), and the over $90 \%$ variation in the photon pulse energy due to self-seeding (b). (c) The correlation between the electron energy and the photon pulse energy for the SASE and self-seeded pulses. (d) The average spectrometer recording for the SASE pulses, with a visible broad distribution of X-ray energies, and the selfseeded ones, with a strong peak corresponding to the elastic photon scattering. 
Finding them among all the recorded events can be easily achieved if one understands how the self-seeding performance is reflected in the beam diagnostics data. As can be seen in Fig. V.7 (c), there is a correlation between the electron energy and the photon pulse energy. The well self-seeded electron pulses produce bright photon pulses and are close in energy, whereas the X-ray pulses coming from the SASE are expected to have relatively low energies. This statement is supported by the spectrometer recordings presented in Fig. V.7(d) showing the average spectra of two groups of X-ray pulses: those having the energy exceeding $0.6 \mathrm{~mJ}$ and the ones with not more than $0.2 \mathrm{~mJ}$ energy. As can be seen, the high-energy photon pulses have one well defined spectral component indicating that in their cases the self-seeding was successful. The spectra contain also a weak signal from the $\mathrm{Cu} K \beta$ emission (a small peak around $8.906 \mathrm{keV}$ ) as well as from the off-resonant X-ray scattering on the $\mathrm{Cu} K$-shell electrons.
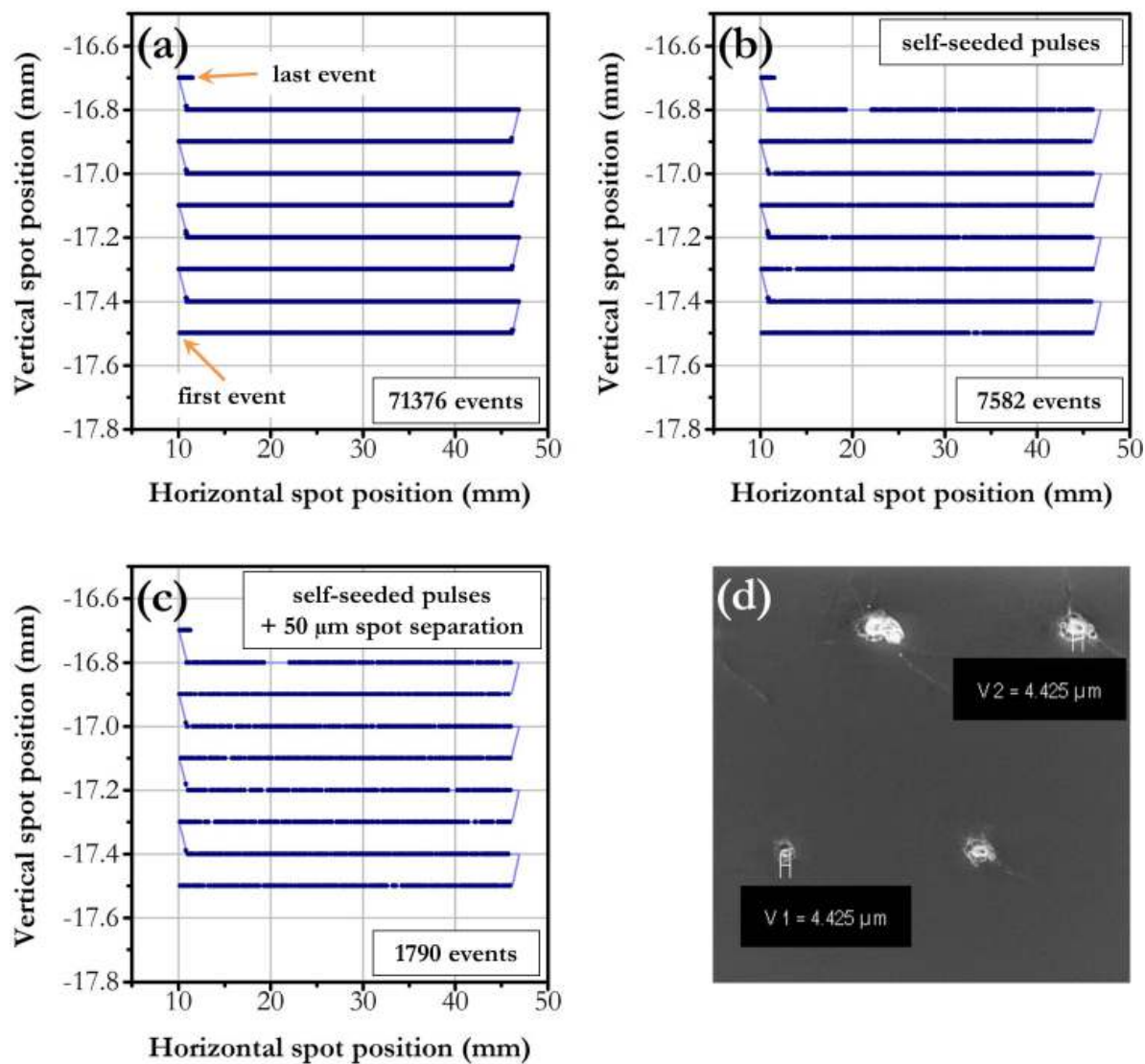

Figure V.8: The distribution of the spots on the sample during the run with the elemental $\mathrm{Cu}$ target. From among all the events recorded (a), those with the self-seeded pulses account for about $10 \%$ (b) and the fraction of those with additionally well separated spots remains at the level of several \% (c). (d) Fragment of the sample's surface imaged with a scanning electron microscope. The spot size was found to be within several micrometers. 
Since the very intense self-seeded pulses burned holes in the samples (i.e., destroyed the target), another step was taken during the event selection ensuring that every spot was not hit by two subsequent self-seeded pulses. It was realized by selecting among the events with the photon pulse energy exceeding $0.6 \mathrm{~mJ}$ only those with a spot separation of at least $50 \mu \mathrm{m}$ from the previously recorded one. As can be seen in Fig. V.8, the final number of events meeting the criteria relevant to the present study is a small fraction of the total amount of the acquired events.

\section{Processing data of the $2 \mathrm{D}$ detectors}

To obtain the final X-ray spectra, the detectors' data for the selected events were summed and processed in the way described in this section. This included corrections for the pedestal, common mode and the flat field, conversion from the pixel readout values to the number of the photons detected, definition of the regions of interest (ROIs) with data projection onto the dispersive axis and subtraction of the $\mathrm{Cu} K \alpha_{1,2}$ fluorescence signal.

The HDF5 data files contain the detectors' readings with preapplied corrections for the pedestal and the so called common mode. The pedestal (also referred to as dark rate or dark current) is an additional input produced by the readout electronics not related to the measured signal. The pedestal value is constant for each strip (channel) of the detector and does not depend on the readings from other strips. The common mode is an enhancement of the readout coming from environmental factors, such as the pick-up current or variations of the reference ground caused by the power supply. It affects synchronously a group of neigbouring channels.

Based on the readout values among the pixels it has been established that the value of 26.5 ADU corresponds to a detection of one photon and the pixels returning values below 13.25 ADU did not register any radiation absorption (see Fig. V.9). Using these values the detectors' readings were converted to matrices of the detected $\mathrm{X}$-rays distribution. Next three ROIs on the detector were defined, $\mathrm{ROI}_{0}$ recording the radiation diffracted by the $\mathrm{Ge}(800)$ crystal and $\mathrm{ROI}_{1}$ and $\mathrm{ROI}_{2}$ recording the signal from the two $\mathrm{Si}(444)$ crystals. The data from ROIs projected on the dispersive axis included a signal distorted by the periodically changing pixel-to-pixel sensitivity, as can be seen in Fig. V.10(a). Normalization of the ROIs data to the pixel gain was done with the flat field curve which is an average response of one strip of uniformly illuminated pixels. The flat field curve was found by averaging the two lines obtained by projection on the dispersive axis the values of two bands of pixels adjacent to a given 


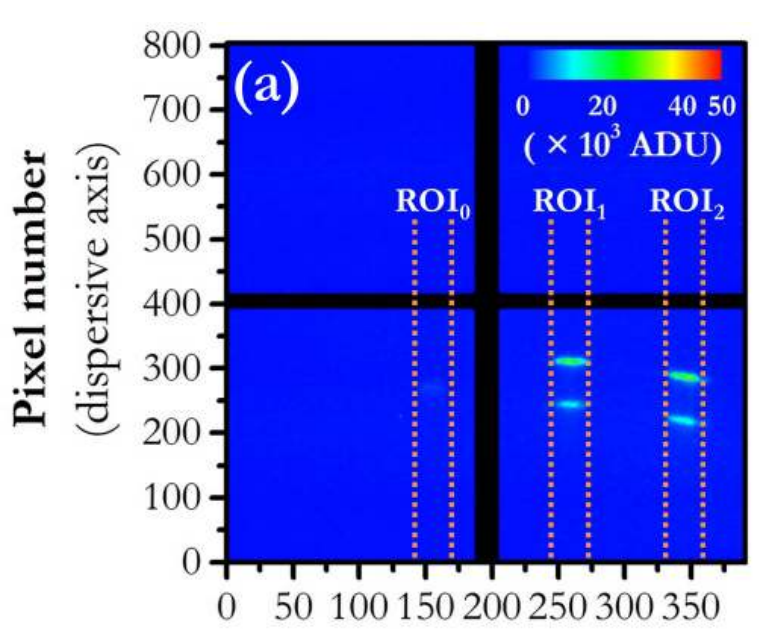

Pixel number

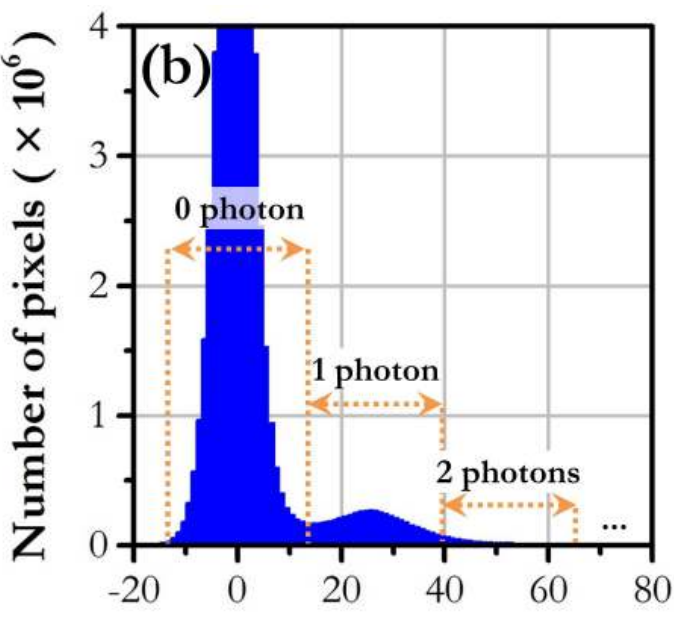

Pixel readout (ADU)

Figure V.9: (a) Sum of the detectors' readings for 269 pulses during the $\mathrm{Cu}$ $K \alpha_{1,2}$ measurement with the three ROIs marked with vertical dotted lines. In black are shown: the vertical 3-mm gap between the detectors and the horizontal 5-mm gap between the two pads constituting each detector. (b) Histogram showing the distribution of the readout values among the pixels (within the events summed in (a)).
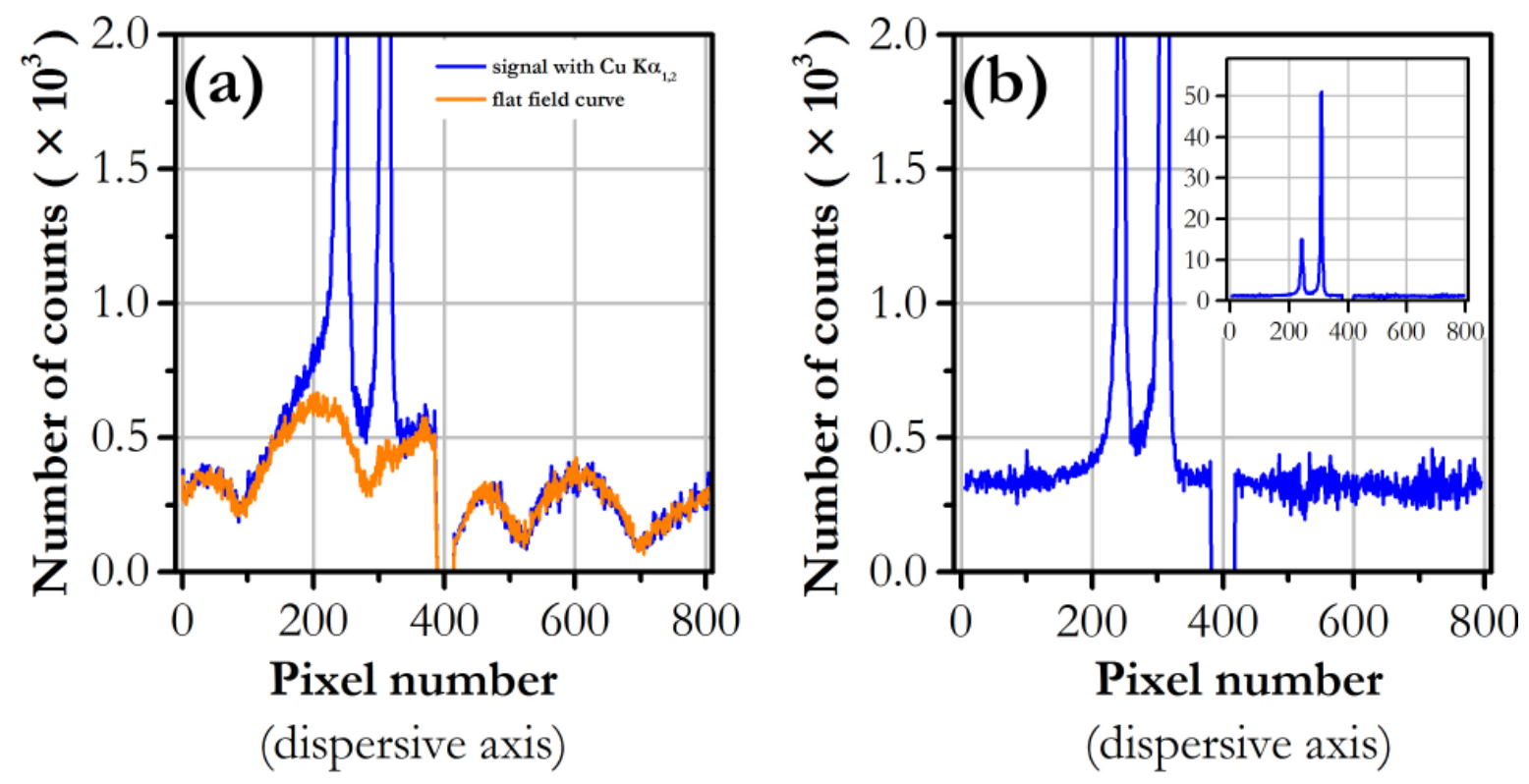

Figure V.10: (a) The projected $\mathrm{ROI}_{1}$ signal from the detectors' readings in Fig. $\mathrm{V} .9$ (a) and the flat field curve. (b) The flat-field-corrected $\mathrm{Cu} K \alpha_{1,2}$ signal from (a) (see the inset for the full scale). It was used for the energy calibration of the HEROS spectra recorded in $\mathrm{ROI}_{1}$.

ROI, one to the left and one to the right. The projected ROI values were divided by the flat field curve and multiplied by its mean, yielding finally spectroscopic data free of 
the effects of the used method (see Fig. V.10(b)). The flat-fielded data from all three ROIs were next binned to decrease the statistical intensity fluctuations. The dispersive axis scale in $\mathrm{ROI}_{1}$ and $\mathrm{ROI}_{2}$ was calibrated independently with the $\mathrm{Cu} K \alpha_{1,2}$ emission lines detected for the incident photon energy set above the $\mathrm{Cu} K$-edge binding energy $(8.979 \mathrm{keV})$. The calibration of the energy scale in $\mathrm{ROI}_{0}$ was done with the elastic scattering peak (see Section V.4 for more details) and the $\mathrm{Cu} K \beta$ emission line.

Fig. V.11 presents the average emission spectra detected in $\mathrm{ROI}_{1}$ for the metallic $\mathrm{Cu}$ for three groups of events: two containing the events with the lowest self-seeding performance, and one with the well self-seeded pulses. As illustrated, part of the SASE pulses had sufficiently high electron energies to induce in the sample fluorescence involving $\mathrm{Cu} K L_{3}$ and $K L_{2}$ electron transitions. Surprisingly, the spectra recorded for pulses with the highest self-seeding performance were found to contain, in addition to the expected HEROS signal, a normal $\mathrm{Cu} K \alpha_{1,2}$ fluorescence. This indicates that the self-seeding, having a magnifying effect on the monochromaticity of the produced X-ray pulses, leaves a weak but broad spectral component characteristic for the SASE radiation. Due to the relatively high cross section of the resonant X-ray scattering on the $\mathrm{Cu} K$-shell electrons, the weak SASE contamination among the selected events contributed significantly to the measured in $\mathrm{ROI}_{1}$ and $\mathrm{ROI}_{2}$ HEROS signal in the form of the $\mathrm{Cu} K \alpha_{1,2}$ emission lines. These contributions were rescaled and subtracted from the measured signal, in both ROIs independently. Finally, the HEROS spectra obtained from $\mathrm{ROI}_{1}$ and $\mathrm{ROI}_{2}$ were summed.

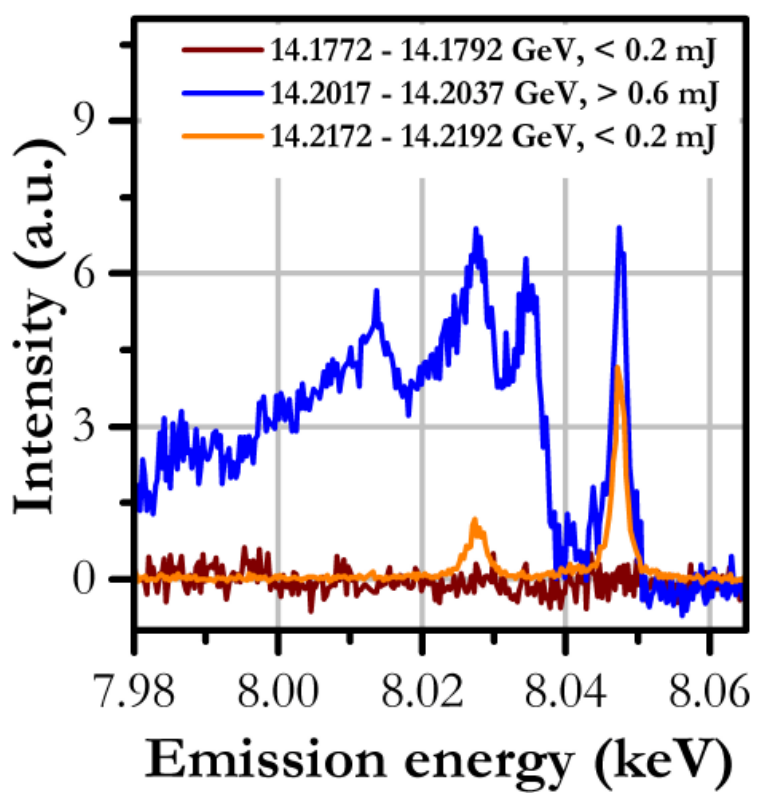

Figure V.11: The average emission spectra measured in $\mathrm{ROI}_{1}$ for three groups of events differing in the electron energy and the photon pulse energy. 


\section{V.4 Results and discussion}

The HEROS spectrum measured for the elemental $\mathrm{Cu}$ sample at the incident beam energy of $8.967 \mathrm{keV}$, which is $12 \mathrm{eV}$ below the $\mathrm{Cu} K$-shell binding energy, is shown in Fig. V.12, The spectrum was recorded for 2000 self-seeded pulses. As demonstrated in Ref. [3], the fluctuations of the incident photon beam intensity influence only the total yield of the HEROS spectra (i.e., the area under the measured curve), leaving the spectral shape unaffected. As a result, the detectors' readings summed for the selected self-seeded pulses did not need any normalization for the photon pulse energy jitter.

The presented spectrum is characterized by a significant rise in intensity below $8.040 \mathrm{keV}$ which slowly decreases towards the lower energies. The obtained spectral structure contains several resonances. To understand their origin, Tulkki and Åberg [49] formalism-based calculations were performed yielding the off-resonant emission spectra presented in Fig. V.12, The following formula was used:

$$
\begin{aligned}
I_{X E S}\left(\hbar \omega_{2}\right)=\sum_{\text {final }=2 p_{3 / 2}, 2 p_{1 / 2}} \int & \frac{\hbar \omega_{2}}{\hbar \omega_{1}} \frac{E_{\text {final } \rightarrow 1 s} E_{\text {exc }}}{\left(E_{\text {exc }}-\hbar \omega_{1}\right)^{2}+\Gamma_{1 s}^{2} / 4} \\
& \times \frac{\Gamma_{\text {final }} /(2 \pi)}{\left(\hbar \omega_{1}-\hbar \omega_{2}+E_{\text {final } \rightarrow 1 s}-E_{\text {exc }}\right)^{2}+\Gamma_{\text {final }}^{2} / 4} \\
& \left.\times \frac{g_{\text {final } \leftrightarrow 1 s}}{g_{2 p_{3 / 2} \leftrightarrow 1 s}} I_{X A S}\left(E_{\text {exc }}\right)\right] \mathrm{d} E_{\text {exc }}
\end{aligned}
$$

with the incident photon energy $\hbar \omega_{1}$, the emission spectrum $I_{X E S}\left(\hbar \omega_{2}\right)$, the absorption spectrum as a function of the excitation energy $I_{X A S}\left(E_{\text {exc }}\right)$, initial and final states broadening $\Gamma_{1 s}$ and $\Gamma_{\text {final }}$, the emission line energy $E_{\text {final } \rightarrow 1 s}$ and final-to- $1 s$ state transition oscillator strength $g_{\text {final } \leftrightarrow 1 s}$. Due to a relatively small separation of the $\mathrm{Cu}$ $2 p_{3 / 2}$ and $2 p_{1 / 2}$ states' binding energies, two decay channels contribute to the measured spectra, i.e. $2 p_{3 / 2} \rightarrow 1 s$ and $2 p_{1 / 2} \rightarrow 1 s$. Therefore summation is done over two final states involved, $2 p_{3 / 2}$ and $2 p_{1 / 2}$. The emission lines' energies $\left(E_{2 p_{3 / 2} \rightarrow 1 s}\right.$ and $\left.E_{2 p_{1 / 2} \rightarrow 1 s}\right)$ were taken from Ref. [92] and the initial and final states' broadenings $\left(\Gamma_{1 s}, \Gamma_{2 p_{3 / 2}}\right.$ and $\Gamma_{2 p_{1 / 2}}$ ) from Ref. [96. The value of the oscillator strengths' ratio $g_{2 p_{1 / 2} \leftrightarrow 1 s} / g_{2 p_{3 / 2} \leftrightarrow 1 s}$ used in calculations was 0.51 .

The $I_{X A S}\left(E_{\text {exc }}\right)$ data was obtained from two different sources. The data used as reference was a high energy resolution $\mathrm{Cu} K$-edge XAS spectrum measured at a synchrotron (published in Ref. [163]). The off-resonant emission spectrum, obtained by applying the reference $I_{X A S}\left(E_{e x c}\right)$ data to Eq. V.1, is presented in Fig. V.12(a) as a pink line. The experimental data compared to the reference one, apart from the differ- 

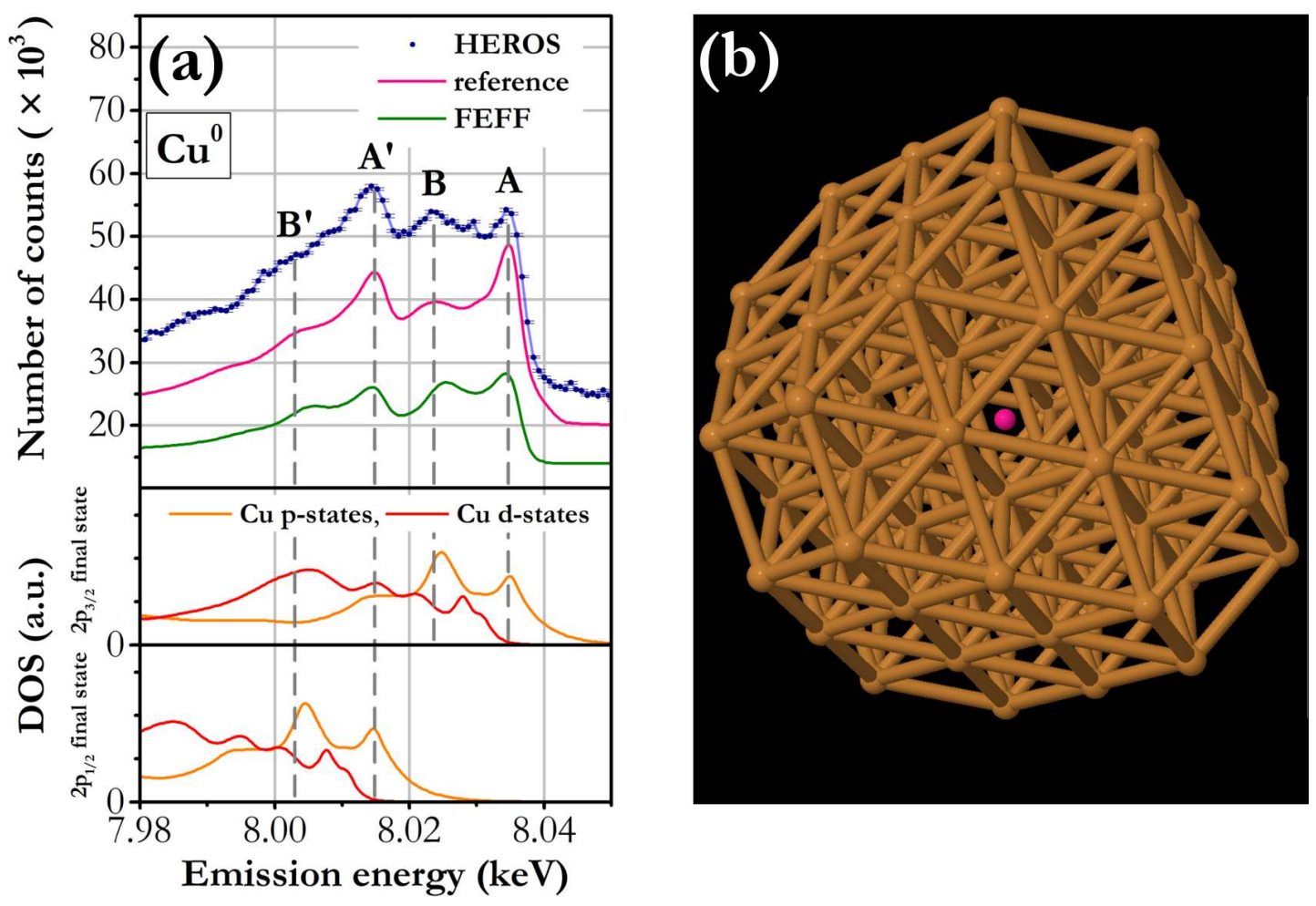

Figure V.12: (a) The HEROS spectrum obtained for the $\mathrm{Cu}$ foil 3 compared to the calculations based on the reference XAS spectra (in pink) and the theoretical XAS spectra (by FEFF; in green). The lower panels show the density of the most contributing unoccupied states (by FEFF) as a function of the energy of the emitted photons. (b) Project of the Cu crystal fragment used in calculations with FEFF. The spectrum presented in (a) was calculated for the absorbing $\mathrm{Cu}$ atom located in the center of the structure (in pink) and surrounded by the spectator $\mathrm{Cu}$ atoms (in orange).

ences in the obtained structures' intensities, exhibits the same spectral features. This demonstrates that the same electronic structure can be successfully studied both with XAS at a synchrotron and with HEROS at an XFEL. According to the published XAS data interpretation [164 165, the detected resonances $\mathrm{A}$ and $\mathrm{B}$ are due to the excitation of the $1 s$ electrons to the unoccupied $4 p$ states as well as to multiple photoelectrons' scattering probed by photons emitted in the $2 p_{3 / 2} \rightarrow 1 s$ core-core deexcitation. The same excitation channels are reflected in the resonances A' and B'. They are, however, induced by the $2 p_{1 / 2} \rightarrow 1 s$ decay channel and thus are shifted towards the low-energy side by $20 \mathrm{eV}$, which is the difference between the binding energies of the $\mathrm{Cu} 2 p_{3 / 2}$ and $2 p_{1 / 2}$ states.

The second $I_{X A S}\left(E_{\text {exc }}\right)$ data used in the calculations was the $\mathrm{Cu} K$-edge absorption spectrum computed with the FEFF 9.6 program. The used input parameters were: the 
full multiple scattering (FMS) factor of 8.0 and the self-consistent field (SCF) factor of 6.0. The off-resonant emission spectrum calculated from the FEFF's absorption spectrum by means of Eq. V.1 is shown in Fig. V.12(a) as a green line. The blurring of the incident beam energy $\hbar \omega_{1}$ was applied to the calculated emission spectrum with the beam's spectral profile described by a Gaussian function with a FWHM of $1.7 \mathrm{eV}$. The theoretical spectrum is characterized by the same resonances as the ones observed in the experimental data. Their origin can be determined based on the density of unoccupied states which is plotted in the lower panels in Fig. V.12(a) as a function of the energy of the photons emitted in the two decay channels. As shown, the observed spectral features relate mainly to the excitations from $1 s$ to the unoccupied $p$-states. Their shape cannot be, however, fully explained without engaging the unoccupied $d$ states. For example, if the structure B' was originating from only the $1 s \rightarrow p$ excitation, it would appear much narrower. In fact, this structure reflects the intensity of both the $2 p_{1 / 2} \rightarrow 1 s$ photons probing $1 s \rightarrow p$ transition and the $2 p_{3 / 2} \rightarrow 1 s$ photons probing the $1 s \rightarrow d$ transition.

The HEROS spectra measured for the $\mathrm{Cu}_{2} \mathrm{O}$ and $\mathrm{CuO}$ samples as well as the calculated data are shown in Fig. V.13. The experimental data correspond to 1237 and 1000 self-seeded pulses in case of $\mathrm{Cu}_{2} \mathrm{O}$ and $\mathrm{CuO}$, respectively. The incident beam energy and the average energy of the photon pulses arriving at the samples were the same as during the measurements on the $\mathrm{Cu}$ sample (i.e., $8.967 \mathrm{keV}$ and $0.17-0.25$ mJ, respectively). The HEROS signals recorded for the copper oxides are weaker than in the case of the elemental $\mathrm{Cu}$ measurements mainly due to the lower concentration of the copper atoms. They are characterized by similar broad structures below $8.040 \mathrm{keV}$ diminishing towards the low-energy side and containing similar set of resonances. The resonances detected in the $\mathrm{Cu}_{2} \mathrm{O}$ spectrum may not be, however, easily seen because of the low statistics. Noteworthy are the multiple photoelectrons' scattering resonances $\mathrm{B}_{2}$ and $\mathrm{B}_{2}$ in the $\mathrm{CuO}$ spectrum which appear much stronger than for other samples. The origin of the $\mathrm{B}_{1}$ structure in the $\mathrm{Cu}_{2} \mathrm{O}$ spectrum is not yet fully understood. The reference and the theoretical off-resonant spectra contain similar structures yet differing from the experimental data in the intensity. In case of the copper oxides additional contribution to the density of unoccupied states is given by the $p$-states of the $\mathrm{O}$ atoms. As shown in the lower panels in Fig. V.13, they mix with the copper states forming the so called hybridized states. This results in an additional excitation path involved in the detected fluorescence, the excitation of $\mathrm{Cu} 1 s$ electrons to the $\mathrm{O} p$-states.

As demonstrated above, HEROS is a tool employable at an XFEL to study the 

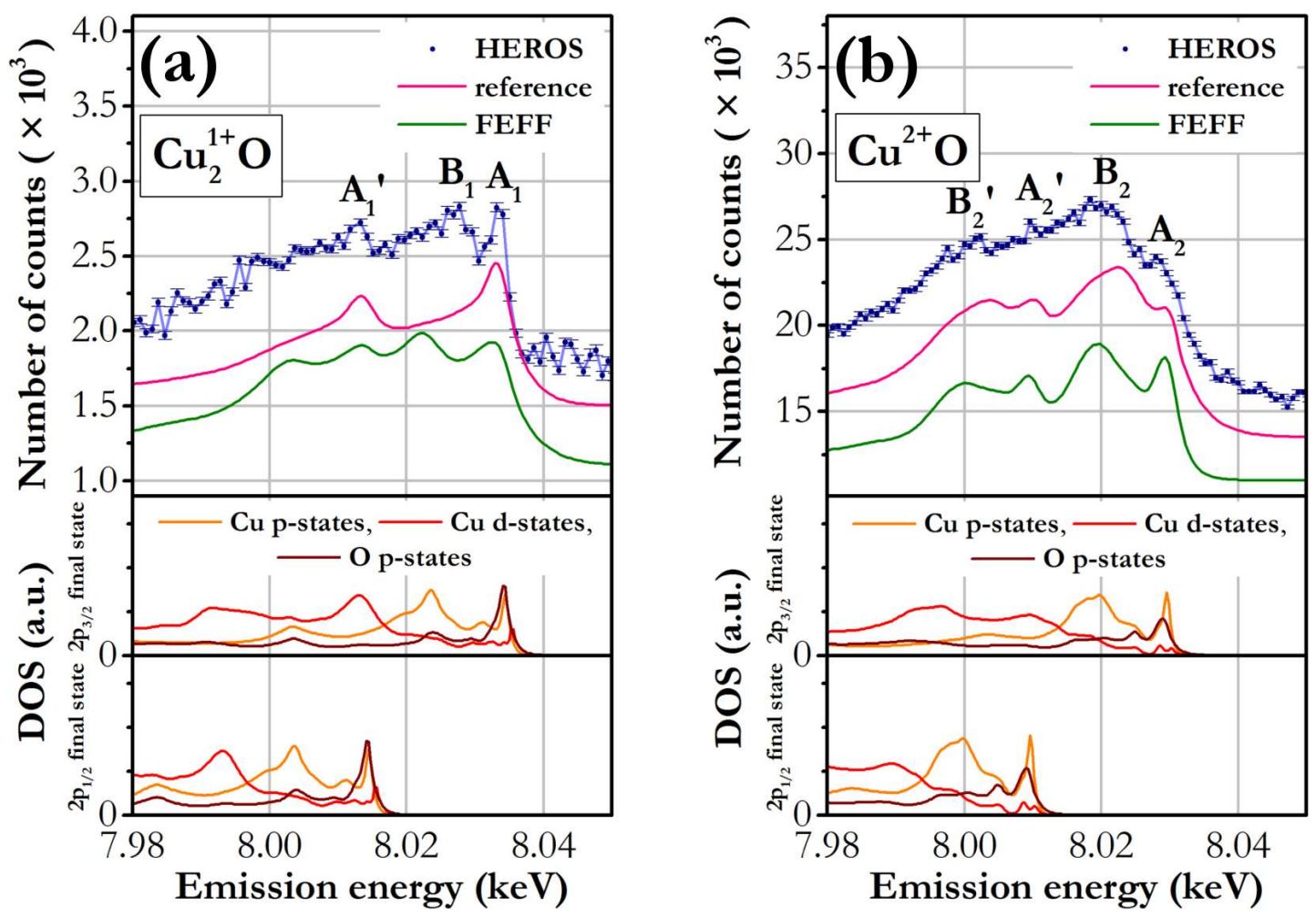

Figure V.13: The results obtained for the $\mathrm{Cu}_{2} \mathrm{O}(\mathrm{a})$ and the $\mathrm{CuO}$ [3] (b) copper oxides. Note additional O $p$-states contributing to the off-resonant emission spectra.

density of the unoccupied states sensitive to the chemical environment of the scattering atom. Further, this technique has another advantage strengthening its capability for the chemical speciation. As explained in Chapter II] photons detected in a HEROS measurement are produced in a resonant inelastic X-ray scattering (RIXS) process and their energy $\hbar \omega_{2}$ fulfills the relation $\hbar \omega_{2}=\hbar \omega_{1}-E_{\text {final }}-E$, with the incident photon energy $\hbar \omega_{1}$, final state binding energy $E_{\text {final }}$ and the energy of the excited photoelectron $E$. As a result, the HEROS signal is sensitive not only to the density of the unoccupied states (characterized by the energy $E$ ) but to the final state binding energy $E_{\text {final }}$ as well.

The electronic states are known to be shifted in energy due to solid and chemical effects. As depicted in Fig. V.14 the measured Cu HEROS spectra shift towards lower energies with increasing oxidation state. The observed chemical shifts of $-2.2 \mathrm{eV}$ for $\mathrm{Cu}^{1+}$ and $-5.4 \mathrm{eV}$ for $\mathrm{Cu}^{2+}$, are much more pronounced than the shifts of the $K \alpha_{1}$ emission line reported by J. Kawai and Y. Nihei [166].

The edge of the measured HEROS spectrum, here denoted as $E_{\text {cut-off }}$, is determined 
by the energy conservation and has a value of:

$$
E_{\text {cut-off }}=\hbar \omega_{1}+E_{\text {final } \rightarrow \text { initial }}-E_{\text {initial }} .
$$

In the present case the HEROS spectra contain two overlapping signals coming from the $2 p_{3 / 2} \rightarrow 1 s\left(K \alpha_{1}\right)$ and $2 p_{1 / 2} \rightarrow 1 s\left(K \alpha_{2}\right)$ decay channels. The edges marked in Fig. V.14(a) with dashed lines show the cutoffs of the $2 p_{3 / 2} \rightarrow 1 s$ signal, and their positions are thus described by the relation $E_{\text {cut-off }}=\hbar \omega_{1}+E_{2 p_{3 / 2} \rightarrow 1 s}-E_{1 s}$. The measured value $E_{\text {cut-off }}$ was used to determine the incident beam energy $\hbar \omega_{1}=E_{\text {cut-off }}-E_{2 p_{3 / 2} \rightarrow 1 s}+E_{1 s}$. The shift $\Delta E_{\text {cut-off }}$ for the different oxidation states $x$, expressed by

$$
\Delta E_{\text {cut-off }}=\left(E_{\mathrm{Cu}^{0}}-E_{\mathrm{Cu}^{x}}\right)_{2 p_{3 / 2} \rightarrow 1 s}-\left(E_{\mathrm{Cu}^{0}}-E_{\mathrm{Cu}^{x}}\right)_{1 s}
$$

depends not only on the change of the emission line energy but also of the absorption edge energy. The $\Delta E_{\text {cut-off }}$ of $-5.4(5) \mathrm{eV}$ found for the $\mathrm{CuO}$ compound is close to the value of $-4.4(5) \mathrm{eV}$ for the $\mathrm{Cu} 1$ s-edge binding energy measured at a synchrotron [167].
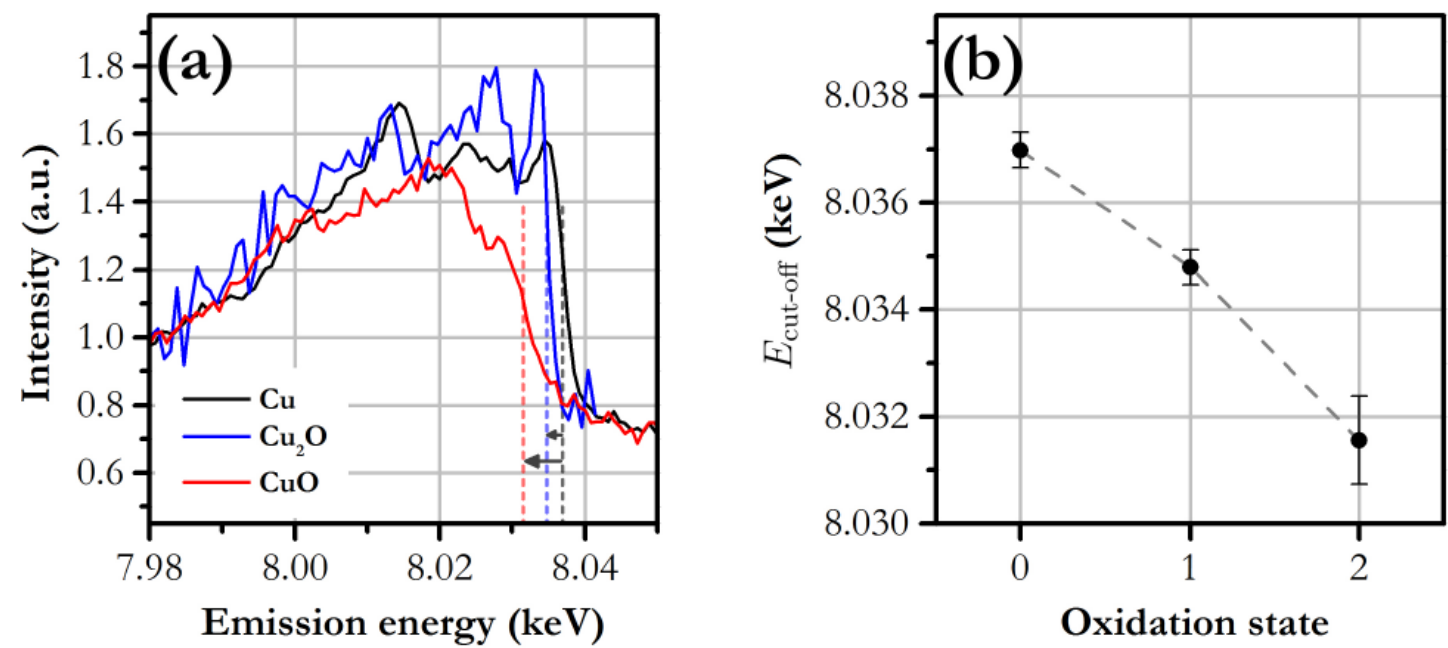

Figure V.14: (a) The measured HEROS spectra for the $\mathrm{Cu}^{0}, \mathrm{Cu}_{2}^{1+} \mathrm{O}$ and $\mathrm{Cu}^{2+} \mathrm{O}$ samples. For the sake of comparison the spectra were normalized to 1 at 7.980 $\mathrm{keV}$. The dashed lines intersect the experimental curves at their first inflection points. (b) The obtained $E_{\text {cut-off }}$ values as a function of the $\mathrm{Cu}$ oxidation state.

\section{V.5 Conclusion}

In this work the high energy resolution off-resonant spectroscopy (HEROS) was used for the first time at a $4^{\text {th }}$ generation radiation source, an X-ray free-electron laser (LCLS, Menlo Park, California, USA), to study the unoccupied electronic states of the $\mathrm{Cu}$ 
atoms. The obtained results for $\mathrm{Cu}_{2}^{1+} \mathrm{O}$ were compared to data reported for $\mathrm{Cu}^{0}$ and $\mathrm{Cu}^{2+} \mathrm{O}$ reported by Szlachetko et al. [3]. Since this technique requires a well defined energy of the incident photon beam the machine was operated in the self-seeding mode. Thanks to the single-shot feature of HEROS, the intensity of the incident XFEL pulses influenced only the overall HEROS signal yield, leaving the shape of the measured spectra unaffected.

The measured HEROS spectra delivered information on the density of the $\mathrm{Cu}$ atoms' unoccupied states for the three $\mathrm{Cu}$ oxidation states. Based on the comparison of the experimental data to the reference and the theoretical data, it was established that the spectral features originate mainly from the $1 s \rightarrow p$ and $1 s \rightarrow d$ electronic excitations probed by two decay channels, namely $2 p_{3 / 2} \rightarrow 1 s\left(K \alpha_{1}\right)$ and $2 p_{1 / 2} \rightarrow 1 s\left(K \alpha_{2}\right)$. In the case of the copper oxides the electronic transitions to the hybridized states consisting of the $\mathrm{Cu} p$ - and $d$-states as well as the $\mathrm{O} p$-states were probed. Furthermore, energy shifts of the HEROS spectra with the oxidation state of the probed $\mathrm{Cu}$ atoms were observed. In conclusion, the present study demonstrated that the HEROS technique at an XFEL provides detailed electronic and structural information, and thus has the potential for single-shot spectroscopic studies of structure dynamics on femtosecond time-scales. 



\section{List of figures}

I.1 $\quad$ Most intense $K, L$ and $M$ X-ray transitions. . . . . . . . . . . . . . . . 4

I.2 Total cross section $\sigma_{\text {tot }}$ for interaction of photons with Ta atoms $(Z=73)$ plotted as a function of the incident photon energy $\hbar \omega_{1}$. . . . . . . . . 5

I.3 High-resolution $K$ X-ray emission spectrum of $\mathrm{Cu}$ from a $\mathrm{CuO}$ oxide sample. . . . . . . . . . . . . . . . 8

I.4 (a) An outline of the XAS methods' experimental setups. (b) The $K$ edge XAS spectrum of Fe atoms in a celadon ceramic measured in fluorescence mode. . . . . . . . . . . . . . . . . . . . . . . . . . . . . . . . 11

I.5 (a) Spectrum of an X-ray beam produced with an X-ray tube with $\mathrm{Cu}$ anode operated at a voltage of $20 \mathrm{kV}$. (b) Comparison of spectral brilliances of different X-ray sources. . . . . . . . . . . . . . . . . 14

II.1 Nonresonant and resonant inelastic scattering of X-rays on atomic elec-

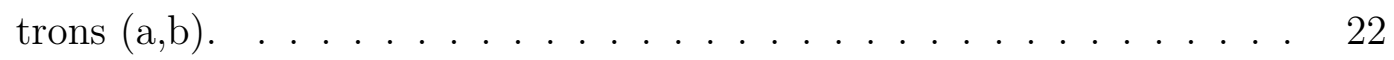

II.2 Schematic of the off-resonant X-ray scattering (a,b). . . . . . . . . . . . 25

II.3 3D RXES plane and sections through it $(\mathrm{a}, \mathrm{b}, \mathrm{c}, \mathrm{d}) . \quad \ldots$. . . . . . . . . . 27

II.4 3D RXES plane with the energy transfer scale and sections through it

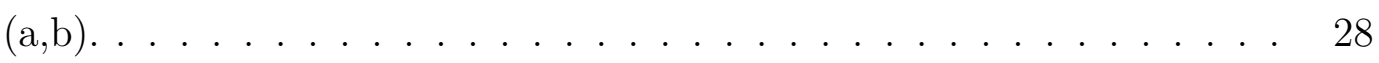

II.5 Measurements on the $\mathrm{CuO}$ compound performed by Hayashi et al. (a,b). 32

II.6 Evolution of $\mathrm{Pt} L \alpha_{1}$ HEROS spectra during decomposition in hydrogen of the platinum(II) acetylacetonate complex $\mathrm{Pt}(\mathrm{acac})_{2}$ at a temperature of $150{ }^{\circ} \mathrm{C}(\mathrm{a}, \mathrm{b}) . \ldots \ldots \ldots \ldots \ldots$

II.7 The data measured with HEROS during reduction and reoxidation of $\mathrm{Pt} / \mathrm{Al}_{2} \mathrm{O}_{3}$ catalyst $(\mathrm{a}, \mathrm{b}) . \ldots \ldots . \ldots . . \ldots 34$

II.8 Experimental spectroscopic data on gaseous xenon obtained with HEROS

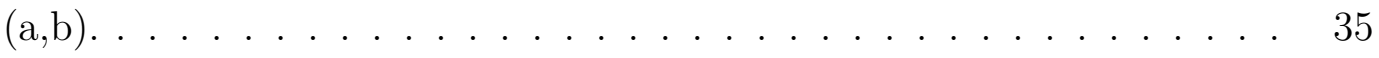


III.1 Scheme of a typical fluorescence mode XAS experimental setup with assumed flat sample surface. . . . . . . . . . . . . . . . . . . . . . . . 40

III.2 (a) The Co $L_{3}$-edge absorption spectrum measured with the electron yield and the fluorescence yield for two incident angles: $27^{\circ}$ and $85^{\circ}$. (b) The Co $L_{3}$-edge FY absorption spectrum corrected for the selfabsorption effect compared to the EY spectrum. . . . . . . . . . . . . . 42

III.3 Comparison of the absorption spectra of the $\mathrm{Cu} L_{2,3}$ (a) and $\mathrm{Nd} M_{4,5}$ (b) edges measured with three techniques: total electron yield (TEY), total fluorescence yield (TFY) and inverse partial fluorescence yield (IPFY). $\quad 42$

III.4 Aerial view on the Swiss Light Source (SLS) located at the Paul Scherrer Institute (PSI) in Villigen, Switzerland. . . . . . . . . . . . . . . . . 43

III.5 The experimental setup showing the X-ray spectrometer and the ionization chamber placed upstream of the sample. . . . . . . . . . . . . . . . 44

III.6 (a) The Ta $L_{3}$ edge transmission mode XAS spectrum measured for the $1 \mu \mathrm{m}$ thick sample. (b) The data used for the energy calibration of the spectrometer during the measurements with the $1 \mu \mathrm{m}$ thick sample. . . 46

III.7 Ta $L \alpha_{1,2}$ XES spectrum recorded at the incident beam energy tuned to $119 \mathrm{eV}$ above the Ta $L_{3}$ edge for the $1 \mu \mathrm{m}$ thick sample. . . . . . . . . 46

III.8 (a) The Ta $L \alpha_{1,2}$ HEROS spectrum measured for the $1 \mu \mathrm{m}$ thick sample \begin{tabular}{|c|}
\hline at the incident beam energy detuned to $26 \mathrm{eV}$ below the Ta $L_{3}$ edge with \\
\hline
\end{tabular} shown baseline. (b) The data from (a) with the subtracted baseline. . . 47

III.9 Ta $L_{3}$ absorption edge $(9.881 \mathrm{keV})$ scanned with an X-ray beam of energy varying in the range $9.850-9.915 \mathrm{keV}$ for samples of different thicknesses $(\mathrm{a}, \mathrm{b}, \mathrm{c}, \mathrm{d}) . \ldots \ldots \ldots \ldots \ldots \ldots$

III.10 (a) HEROS spectra recorded for different sample thicknesses at an inci-

\begin{tabular}{|c|}
\hline dent X-ray beam energy of $9.855 \mathrm{keV}$ (i.e. $26 \mathrm{eV}$ below Ta $L_{3}$ edge bind- \\
\hline ing energy). (b) The reconstructed HEROS-XAS spectra corresponding \\
\hline
\end{tabular}
to the Ta $L_{3}$ absorption edge. . . . . . . . . . . . . . . . . . . . . . . . 50

III.11 Calculations based on Eq. [III.4 showing the effects of the target thick\begin{tabular}{|c|}
\hline ness on the Ta $L_{3}$-edge in the conventional fluorescence-mode XAS (a) \\
\hline
\end{tabular} and in the HEROS (b), for $\phi=\theta=45^{\circ}$. . . . . . . . . . . . . 52

IV.1 Elements of the used experimental setup $(\mathrm{a}, \mathrm{b}, \mathrm{c}) . \ldots \ldots$. . . . . . . . 57 
IV.2 Two-step energy calibration of the synchrotron beam and the spectrometer $(\mathrm{a}, \mathrm{b}) . \ldots \ldots \ldots \ldots \ldots$

IV.3 (a) The Ta $L \alpha_{1}$ HEROS spectrum recorded in one ROI at an incident beam energy of $9.867 \mathrm{keV}$ for Complex 1 with shown baseline. (b) The data from (a) with the subtracted baseline. . . . . . . . . . . . . . 59

IV.4 (a) One of the Ta $L \alpha_{1}$ HEROS spectra measured for Complex 1 during its oxidation. (b) The same spectrum as in (a) with shown contributions from the unoxidized and the oxidized Complex 1. . . . . . . . . . . . . 60

IV.5 Screenshot showing the FEFF 9.6 program's main window and the plotting window with a calculated XANES. . . . . . . . . . . . . . . 62

IV.6 The measured Ta $L \alpha_{1}$ HEROS spectra as a function of time for Complex 1 (a) and Complex 2(b). . . . . . . . . . . . . . 64

IV.7 Variation of the off-resonant Ta $L \alpha_{1}$ line's position (a) and the fluorescence yield from two emission energy ranges (b) during oxidation of

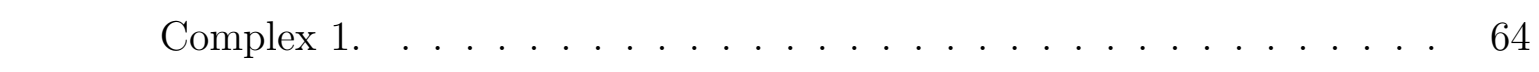

IV.8 (a) The Ta $L_{3}$ edge XANES calculated with FEFF for a monomeric and a dimeric Ta species. (b) Off-resonant Ta $L \alpha_{1}$ spectra calculated with the Kramers-Heisenberg formula modified by Tulkki and Åberg. . . . . 66

IV.9 Temporal changes in the position of the Ta $L \alpha_{1}$ HEROS spectra and fluorescence yields integrated over two emission energy ranges during

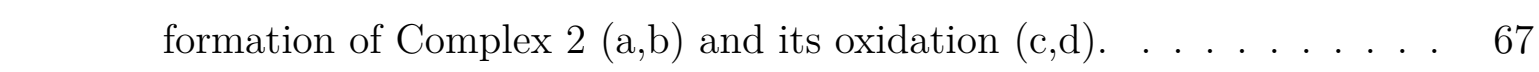

IV.10 Relative concentration of Complex 1 (a) and Complex 2 (b) as a function of time during oxidation. . . . . . . . . . . . . . . . . .

V.1 (upper panel) The power of the emitted electromagnetic radiation as a function of the distance passed by the electron bunch in the undulator. The rapid exponential growth of the radiation power is caused by the formation of electron micro-bunches (lower panel). . . . . . . . . . . 70

V.2 Comparison of the peak brilliance between chosen $3^{\text {rd }}$ (BESSY, SLS, SPring-8, APS, ESRF, PETRA III) and $4^{\text {th }}$ (FLASH, LCLS, European XFEL) generation accelerator-based X-ray sources. . . . . . . . . . . . 71

V.3 (a) Spectral profiles of three single X-ray pulses measured at X-ray Pump Probe instrument of LCLS showing variations of the photon energy caused by the electron energy jitter. (b,c) The effect of the self-seeding on the X-ray beam energy bandwidth examined at LCLS. . 
V.4 (a) Aerial view of SLAC showing the proportions of LCLS with respect to the whole site. (b) View on LCLS with main modules marked. . . . 74

V.5 Front End Enclosure (FEE) with the X-ray optics and diagnostics equipment. . . . . . . . . . . . . . . . . . . . 75

V.6 The illustration of the experimental setup. . . . . . . . . . . . . . . . . 76

V.7 Characteristics of the electron and the photon beam at LCLS (a,b,c,d). $\quad 79$

V.8 The distribution of the spots on the sample during the run with the elemental $\mathrm{Cu}$ target $(\mathrm{a}, \mathrm{b}, \mathrm{c}, \mathrm{d}) . \ldots \ldots$. . . . . . . . . . 80

V.9 (a) Sum of the detectors' readings for 269 pulses during the $\mathrm{Cu} K \alpha_{1,2}$ measurement with the three ROIs marked with vertical dotted lines. (b) Histogram showing the distribution of the readout values among the pixels (within the events summed in (a)). . . . . . . . . . . . . 82

V.10 (a) The projected $\mathrm{ROI}_{1}$ signal from the detectors' readings in Fig. V.9(a) and the flat field curve. (b) The flat-field-corrected $\mathrm{Cu} K \alpha_{1,2}$ signal from (a). . . . . . . . . . . . . . . . . . . 82

V.11 The average emission spectra measured in $\mathrm{ROI}_{1}$ for three groups of events differing in the electron energy and the photon pulse energy. . . 83

V.12 (a) The HEROS spectrum obtained for the $\mathrm{Cu}$ foil compared to the calculations based on the reference XAS spectra (in pink) and the theoretical XAS spectra (by FEFF; in green). (b) Project of the Cu crystal fragment used in calculations with FEFF. . . . . . . . . . . . . . . . . 85

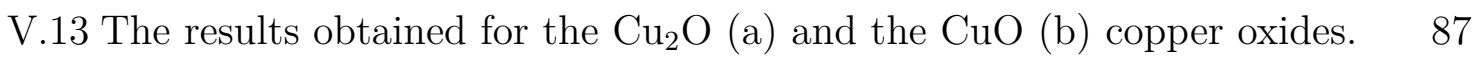

V.14 (a) The measured HEROS spectra for the $\mathrm{Cu}^{0}, \mathrm{Cu}_{2}^{1+} \mathrm{O}$ and $\mathrm{Cu}^{2+} \mathrm{O}$ samples. (b) The obtained $E_{\text {cut-off values as a function of the } \mathrm{Cu} \text { oxidation }}$ state. . . . . . . . . . . . . . . . . . . 88 


\section{List of tables}

I.1 Correspondence between atomic levels, IUPAC subshell notations and associated orbitals. . . . . . . . . . . . . . . . . . . 3

I.2 Comparison of useful energy ranges and resolutions between different types of X-ray energy-dispersive detectors and a Bragg-type crystal spectrometer. . . . . . . . . . . . . . . . . . . . . . . 19 



\section{References}

[1] W. Błachucki, J. Szlachetko, J. Hoszowska, J.-Cl. Dousse, Y. Kayser, M. Nachtegaal, J. Sá, "High Energy Resolution Off-Resonant Spectroscopy for X-Ray Absorption Spectra Free of Self-Absorption Effects," Physical Review Letters, vol. 112, no. 173003, 2014, http://dx.doi.org/10.1103/PhysRevLett.112.173003

[2] W. Błachucki, J. Szlachetko, Y. Kayser, J.-Cl. Dousse, J. Hoszowska, D. L. A. Fernandes, J. Sá, "Study of the reactivity of silica supported tantalum catalysts with oxygen followed by in situ HEROS," Physical Chemistry Chemical Physics, vol. 17, pp. 18262 - 18 264, 2015, http://dx.doi.org/10.1039/c5cp02950c

[3] J. Szlachetko et al., "The electronic structure of matter probed with a single femtosecond hard x-ray pulse," Structural Dynamics, vol. 1, no. 021101, 2014, http://dx.doi.org/10.1063/1.4868260

[4] R. Jenkins, X-Ray Fluorescence Spectrometry, 2nd Edition. John Wiley \& Sons, 1999, ISBN: 978-0-471-29942-4.

[5] R. L. Johnson, H. Schmidt-Böcking, B. F. Sonntag, Ed., Proceedings of the The 17th international conference on x-ray and inner-shell processes, vol. 389, 1997, ISBN: 1-56396-563-1, http://scitation.aip.org/content/aip/ proceeding/aipcp/389 [Accessed: 27 July 2015].

[6] A. K. Wróblewski, Historia fizyki. Wydawnictwo Naukowe PWN, 2006, ch. Fizyka około roku 1900, Fizyka atomu i droga do mechaniki kwantowej, Wyd. 1, Warszawa, ISBN: 978-83-01-14635-1.

[7] R. Jenkins, R. Manne, R. Robin, C. Senemaud, "IUPAC - nomenclature system for x-ray spectroscopy," X-Ray Spectrometry, vol. 20, pp. 149 - 155, 1991, http://dx.doi.org/10.1002/xrs.1300200308

[8] J. Yano, V. K. Yachandra, "Evaluation of Photonuclear Reaction Data on Tantalum-181 up to 140MeV," Journal of Nuclear Science and Technology, vol. 35, pp. 685 - 691, 1998, http://dx.doi.org/10.1080/18811248.1998. 9733928

[9] M. J. Berger, J. H. Hubbell, S. M. Seltzer, J. Chang, J. S. Coursey, R. Sukumar, D. S. Zucker, K. Olsen, "XCOM: Photon Cross Section Database," National Institute of Standards and Technology, Gaithersburg, MD, 2010, http://physics.nist.gov/xcom [Accessed: 7 August 2015].

[10] D. S. Urch, "X-Ray emission spectroscopy," Quarterly Reviews, Chemical Society, vol. 25, pp. 343 - 364, 1971, http://dx.doi.org/10.1039/QR9712500343

[11] U. Bergmann, P. Glatzel, "X-ray emission spectroscopy," Photosynthesis Research, vol. 102, pp. 255 - 266, 2009, http://dx.doi.org/10.1007/s11120-009-9483-6

[12] U. Bergmann, C.R. Horne, T.J. Collins, J.M. Workman, S.P. Cramer, "Chemical dependence of interatomic X-ray transition energies and intensities - a study of Mn $K \beta^{\prime \prime}$ and $K \beta_{2,5}$ spectra," Chemical Physics Letters, vol. 302, pp. 119 - 124, 1999, http://dx.doi.org/10.1016/S0009-2614(99)00095-0

[13] V. A. Safonov et al., "Valence-to-Core X-ray Emission Spectroscopy Identification of Carbide Compounds in Nanocrystalline Cr Coatings Deposited from Cr(III) Electrolytes Containing Organic Substances," Journal of Physical Chemistry B, vol. 110, pp. 23192 - 23 196, 2006, http://dx.doi.org/10.1021/jp064569j

[14] C. J. Pollock, S. DeBeer, "Valence-to-Core X-ray Emission Spectroscopy: A Sensitive Probe of the Nature of a Bound Ligand," Journal of the American Chemical Society, vol. 133, pp. 5594 - 5601, 2011, http://dx.doi. org/10.1021/ja200560z 
[15] C. J. Milne, T. J. Penfold, M. Chergui, "Recent experimental and theoretical developments in time-resolved X-ray spectroscopies," Coordination Chemistry Reviews, vol. 277-278, pp. 44-68, 2014, http://dx.doi.org/10.1016/ j.ccr.2014.02.013

[16] F. W. Lytle, "X-ray absorption spectroscopy," Berichte der Bunsengesellschaft für physikalische Chemie, vol. 91, pp. 1251 - 1257, 1987, http://dx.doi.org/10.1002/bbpc.19870911134

[17] J. Yano, V. K. Yachandra, "X-ray absorption spectroscopy," Photosynthesis Research, vol. 102, pp. 241 - 254, 2009, http://dx.doi.org/10.1007/s11120-009-9473-8

[18] M. Hidaka, H. Horiuchi, K. Ohashi, R. P. Wijesundera, L. S. R. Kumara, Nark Eon Sung, "Local structures and electronic band states of $\alpha-\mathrm{Fe}_{2} \mathrm{O}_{3}$ polycrystalline particles included in the red-color overglazes and the transparent glazes of the Kakiemon-style porcelains by means of X-ray absorption spectra (П)," Cerâmica, vol. 55, pp. 223 - 232, 2009, http://dx.doi.org/10.1590/S0366-69132009000300001

[19] J. Jaklevic, J. A. Kirby, M. P. Klein, A. S. Robertson, G. S. Brown, P. Eisenberger, "Fluorescence detection of exafs: Sensitivity enhancement for dilute species and thin films," Solid State Communications, vol. 23, pp. 679 - 682, 1977, http://dx.doi.org/10.1016/0038-1098(77)90548-8

[20] W. Gudat, C. Kunz, "Close Similarity between Photoelectric Yield and Photoabsorption Spectra in the Soft-XRay Range," Physical Review Letters, vol. 29, p. 169, 1972, http://dx.doi.org/10.1103/PhysRevLett.29.169

[21] P. Eisenberger, P. M. Platzman, H. Winick, "X-Ray Resonant Raman Scattering: Observation of Characteristic Radiation Narrower than the Lifetime Width," Physical Review Letters, vol. 36, p. 623, 1976, http://dx.doi. org/10.1103/PhysRevLett.36.623

[22] K. Hämäläinen, D. P. Siddons, J. B. Hastings, L. E. Berman, "Elimination of the inner-shell lifetime broadening in x-ray-absorption spectroscopy," Physical Review Letters, vol. 67, p. 2850, 1991, http://dx.doi.org/10.1103/ PhysRevLett.67.2850

[23] F. Reinhardt et al., "Evaluation of High-Resolution X-ray Absorption and Emission Spectroscopy for the Chemical Speciation of Binary Titanium Compounds," Analytical Chemistry, vol. 81, pp. 1770 - 1776, 2009, http: //dx.doi.org/10.1021/ac8018069

[24] A. Kotani, S. Shin, "Resonant inelastic x-ray scattering spectra for electrons in solids," Reviews of Modern Physics, vol. 73, p. 203, 2001, http://dx.doi.org/10.1103/RevModPhys.73.203

[25] P. Glatzel et al., "Hard x-ray photon-in-photon-out spectroscopy with lifetime resolution - of XAS, XES, RIXSS and HERFD," AIP Conference Proceedings, vol. 879, p. 1731, 2007, http://dx.doi.org/10.1063/1.2436402

[26] J. Singh, C. Lamberti, J. A. van Bokhoven, "Advanced X-ray absorption and emission spectroscopy: in situ catalytic studies," Chemical Society Reviews, vol. 39, pp. 4754 - 4766, 2010, http://dx.doi.org/10.1039/ C0CS00054J

[27] A. Erbil, G. S. Cargill III, R. Frahm, R. F. Boehme, "Total-electron-yield current measurements for near-surface extended x-ray-absorption fine structure," Physical Review B, vol. 37, p. 2450, 1988, http://dx.doi.org/10. 1103/PhysRevB.37.2450

[28] Synchrotron Radiation in Chemistry and Biology I. Springer Berlin Heidelberg, 1988, vol. 145, ch. XANES in condensed systems, pp. 29 - 67, http://dx.doi.org/10.1007/BFb0111235

[29] H. Wende, "Recent advances in x-ray absorption spectroscopy," Reports on Progress in Physics, vol. 67, pp. 2105 - 2181, 2004, http://dx.doi.org/10.1088/0034-4885/67/12/R01

[30] H. Ebel, "X-ray Tube Spectra," X-Ray Spectrometry, vol. 28, pp. 255 - 266, 1999, http://dx.doi.org/10.1002/ (SICI)1097-4539(199907/08)28:4<255::AID-XRS347>3.0.CO;2-Y

[31] A. C. Thompson et al., "X-Ray Data Booklet," Lawrence Berkeley National Laboratory, Berkeley, USA, 2009, http://xdb.lbl.gov/ [Accessed: 31 July 2015].

[32] R. Jenkins, X-Ray Fluorescence Spectrometry, 2nd Edition. John Wiley \& Sons, 1999, ch. Instrumentation for X-ray spectrometry, ISBN: 978-0-471-29942-4. 
[33] K. P. Severin, Energy Dispersive Spectrometry of Common Rock Forming Minerals. Springer Netherlands, 2004, ch. Energy Dispersive Spectrometry, http://dx.doi.org/10.1007/978-1-4020-2841-0_1

[34] J. Sá, Ed., High-resolution XAS/XES: analyzing electronic structures of catalysts. CRC Press, 2014, ch. Crystal spectrometers, ISBN 978-1-4665-9298-8.

[35] H. H. Johann, "Die Erzeugung lichtstarker Röntgenspektren mit Hilfe von Konkavkristallen," Zeitschrift für Physik, vol. 69, pp. 185 - 206, 1931, http://dx.doi.org/10.1007/BF01798121

[36] T. Johansson, "Über ein neuartiges, genau fokussierendes Röntgenspektrometer," Zeitschrift für Physik, vol. 69, pp. 507 - 528, 1933, http://dx.doi.org/10.1007/BF01342254

[37] L. von Hámos, "Röntgenspektroskopie und Abbildung mittels gekrümmter Kristallreflektoren," Naturwissenschaften, vol. 20, pp. 705 - 706, 1932, http://dx.doi.org/10.1007/BF01494468

[38] M. Kavčič, M. Budnar, A. Mühleisen, F. Gasser, M. Žitnik, K. Bučar, R. Bohinc, "Design and performance of a versatile curved-crystal spectrometer for high-resolution spectroscopy in the tender x-ray range," Review of Scientific Instruments, vol. 83, no. 033113, 2012, http://dx.doi.org/10.1063/1.3697862

[39] M. Sánchez del Río, "X-ray Oriented Programs (XOP)," http://www.esrf.eu/computing/scientific/xop2.1

[40] C. Vettier, "Resonant elastic X-ray scattering: Where from? where to?" The European Physical Journal Special Topics, vol. 208, pp. 3 - 14, 2012, http://dx.doi.org/10.1140/epjst/e2012-01602-7

[41] J. Fink, E. Schierle, E. Weschke, J. Geck, "Resonant elastic soft x-ray scattering," Reports on Progress in Physics, vol. 76, no. 056502, 2013, http://dx.doi.org/10.1088/0034-4885/76/5/056502

[42] L. J. P. Ament, M. van Veenendaal, T. P. Devereaux, J. P. Hill, J. van den Brink, "Resonant inelastic xray scattering studies of elementary excitations," Reviews of Modern Physics, vol. 83, p. 705, 2011, http: //dx.doi.org/10.1103/RevModPhys.83.705

[43] M. Simon, T. Schmitt, Ed., Special issue on Progress In Resonant Inelastic X-ray scattering, 2013, vol. 188, J. Electron Spectrosc. Rel. Phenom., ISSN 0368-2048.

[44] H. A. Kramers, W. Heisenberg, "Über die Streuung von Strahlung durch Atome," Zeitschrift für Physik, vol. 31, pp. 681 - 708, 1925, http://dx.doi.org/10.1007/BF02980624

[45] P. A. M. Dirac, "The Quantum Theory of Dispersion," Proceedings of the Royal Society of London A, vol. 114, pp. $710-728,1927$, http://dx.doi.org/10.1098/rspa.1927.0071

[46] W. P. Healy, "A generalization of the Kramers-Heisenberg dispersion formula," Physical Review A, vol. 16, p. 1568, 1977, http://dx.doi.org/10.1103/PhysRevA.16.1568

[47] W. P. Healy, R. G. Woolley, "On the derivation of the Kramers-Heisenberg dispersion formula from non-relativistic quantum electrodynamics," Journal of Physics B: Atomic and Molecular Physics, vol. 11, p. 1131, 1978, http://dx.doi.org/10.1088/0022-3700/11/7/013

[48] J. Tulkki, T. Åberg, "Statistical theory of electronic Raman resonance scattering by oriented atoms," Journal of Physics B: Atomic and Molecular Physics, vol. 13, pp. 3341 - 3360, 1980, http://dx.doi.org/10.1088/ $0022-3700 / 13 / 17 / 013$

[49] J. Tulkki, T. Åberg, "Behaviour of Raman resonance scattering across the K X-ray absorption edge," Journal of Physics B: Atomic and Molecular Physics, vol. 15, pp. L435 - L440, 1982, http://dx.doi.org/10.1088/ 0022-3700/15/13/004.

[50] E. Fermi, Nuclear Physics. University of Chicago Press, 1950, Compiled by: J. Orear, A. H. Rosenfeld, R. A. Schluter.

[51] C. J. Sparks, Jr., "Inelastic Resonance Emission of X Rays: Anomalous Scattering Associated with Anomalous Dispersion," Physical Review Letters, vol. 33, p. 262, 1974, http://dx.doi.org/10.1103/PhysRevLett.33.262

[52] P. Suortti, V. Eteläniemi, K. Hämäläinen, S. Manninen, "FINE STRUCTURE OF RESONANT RAMAN SCATTERING," Journal de Physique Colloques, vol. 48, pp. C9-831 - C9-834, 1987, http://dx.doi.org/10.1051/ jphyscol:19879147 
[53] V. Eteläniemi, K. Hämäläinen, S. Manninen, P. Suortti, "XANES spectroscopy using high-resolution resonant Raman scattering: application to holmium," Journal of Physics: Condensed Matter, vol. 4, pp. 879 - 886, 1992, http://dx.doi.org/10.1088/0953-8984/4/3/027

[54] H. Hayashi, R. Takeda, Y. Udagawa, T. Nakamura, H. Miyagawa, H. Shoji, S. Nanao, N. Kawamura, "Lifetimebroadening-suppressed/free XANES spectroscopy by high-resolution resonant inelastic x-ray scattering," Physical Review B, vol. 68, no. 045122, 2003, http://dx.doi.org/10.1103/PhysRevB.68.045122

[55] H. Hayashi, R. Takeda, Y. Udagawa, T. Nakamura, H. Miyagawa, H. Shoji, S. Nanao, N. Kawamura, "Lifetimebroadening-removed XANES spectroscopy by high-resolution resonant inelastic x-ray scattering," Physica Scripta, vol. T115, pp. 1094 - 1096, 2005, http://dx.doi.org/10.1238/Physica.Topical.115a01094

[56] J. Szlachetko, J.-Cl. Dousse, J. Hoszowska, M. Pajek, R. Barrett, M. Berset, K. Fennane, A. Kubala-Kukus, M. Szlachetko, "High-Resolution Study of X-Ray Resonant Raman Scattering at the K Edge of Silicon," Physical Review Letters, vol. 97, no. 073001, 2006, http://dx.doi.org/10.1103/PhysRevLett.97.073001

[57] J. Szlachetko, J.-Cl. Dousse, M. Berset, K. Fennane, M. Szlachetko, J. Hoszowska, R. Barrett, M. Pajek, and A. Kubala-Kukus, "High-resolution study of the x-ray resonant Raman scattering process around the 1s absorption edge for aluminium, silicon, and their oxides," Physical Review A, vol. 75, no. 022512, 2007, http://dx.doi.org/10.1103/PhysRevA.75.022512

[58] D. T. Bowron, M. H. Krisch, A. C. Barnes, J. L. Finney, A. Kaprolat, M. Lorenzen, "X-ray-Raman scattering from the oxygen K edge in liquid and solid $\mathrm{H}_{2} \mathrm{O}$," Physical Review B, vol. 62, p. R9223, 2000, http://dx.doi. org/10.1103/PhysRevB.62.R9223

[59] D. Sokaras et al., "A high resolution and large solid angle x-ray Raman spectroscopy end-station at the Stanford Synchrotron Radiation Lightsource," Review of Scientific Instruments, vol. 83, no. 043112, 2012, http://dx. doi.org/10.1063/1.4704458

[60] J. Szlachetko et al., "High energy resolution off-resonant spectroscopy at sub-second time resolution: $\left(\mathrm{Pt}(\mathrm{acac})_{2}\right)$ decomposition," Chemical Communications, vol. 48, pp. 10898 - 10900, 2012, http://dx.doi.org/10.1039/ C2CC35086F

[61] M. Kavčič, M. Žitnik, K. Bučar, A. Mihelič, B. Marolt, J. Szlachetko, P. Glatzel, K. Kvashnina, "Hard x-ray absorption spectroscopy for pulsed sources," Physical Review B, vol. 87, no. 075106, 2013, http://dx.doi. org/10.1103/PhysRevB.87.075106

[62] J. Sá, Ed., High-resolution XAS/XES: analyzing electronic structures of catalysts. CRC Press, 2014, ch. Techniques: RXES, HR-XAS, HEROS, GIXRF, and GEXRF, ISBN 978-1-4665-9298-8.

[63] P. Carra, M. Fabrizio, B. T. Thole, "High Resolution X-Ray Resonant Raman Scattering," Physical Review Letters, vol. 74, p. 3700, 1995, http://dx.doi.org/10.1103/PhysRevLett.74.3700

[64] P. W. Loeffen, R. F. Pettifer, S. Müllender, M. A. van Veenendaal, J. Röhler, D. S. Sivia, "Deconvolution of lifetime broadening at rare-earth $\mathrm{L}_{I I I}$ edges compared to resonant inelastic x-ray scattering measurements," Physical Review B, vol. 54, p. 14877, 1996, http://dx.doi.org/10.1103/PhysRevB.54.14877

[65] A. Kotani, K.O. Kvashnina, S.M. Butorin, P. Glatzel, "A new method of directly determining the core-hole effect in the Ce $\mathrm{L}_{3}$ XAS of mixed valence Ce compounds-An application of resonant X-ray emission spectroscopy," Journal of Electron Spectroscopy and Related Phenomena, vol. 184, pp. 210 - 215, 2011, http://dx.doi.org/ 10.1016/j.elspec.2010.12.028

[66] A. Kotani, K. O. Kvashnina, P. Glatzel, J. C. Parlebas, G. Schmerber, "Single Impurity Anderson Model versus Density Functional Theory for Describing $\mathrm{Ce}_{3}$ X-Ray Absorption Spectra of $\mathrm{CeFe}_{2}$ : Resolution of a Recent Controversy," Physical Review Letters, vol. 108, no. 036403, 2012, http://dx.doi.org/10.1103/PhysRevLett. 108.036403

[67] S. G. Fiddy et al., "Particle development and characterisation in $\mathrm{Pt}(\mathrm{acac})_{2}$ and $\mathrm{Pt}(\mathrm{acac})_{2} / \mathrm{GeBu}_{4}$ derived catalysts supported upon porous and mesoporous $\mathrm{SiO}_{2}$ : effect of reductive environment, and support structure," Physical Chemistry Chemical Physics, vol. 4, pp. 827 - 834, 2002, http://dx.doi.org/10.1039/B108545J 
[68] J. Szlachetko, D. Ferri, V. Marchionni, A. Kambolis, O. V. Safonova, C. J. Milne, O. Kröcher, M. Nachtegaal, J. Sá, "Subsecond and in Situ Chemical Speciation of $\mathrm{Pt} / \mathrm{Al}_{2} \mathrm{O}_{3}$ during Oxidation-Reduction Cycles Monitored by High-Energy Resolution Off-Resonant X-ray Spectroscopy," Journal of the American Chemical Society, vol. 135, pp. 19071 - 19 074, 2013, http://dx.doi.org/10.1021/ja410146c

[69] Z.-P. Liu, P. Hu, "CO Oxidation and NO Reduction on Metal Surfaces: Density Functional Theory Investigations," Topics in Catalysis, vol. 28, pp. 71 - 78, 2004, http://dx.doi.org/10.1023/B:TOCA.0000024335.88459.81

[70] C. J. Zhang, P. Hu, "CO Oxidation on $\mathrm{Pd}(100)$ and $\mathrm{Pd}(111)$ : A Comparative Study of Reaction Pathways and Reactivity at Low and Medium Coverages," Journal of the American Chemical Society, vol. 123, pp. 1166 1172, 2001, http://dx.doi.org/10.1021/ja002432f

[71] J. Hoszowska, W. Cao, W. Błachucki, M.-W. Chen, J.-Cl. Dousse, Y. Kayser, A. Kis, D. Krasnozhon, J. Szlachetko, "Probing the electronic structure of nanolayered systems with the synchrotron radiation based highresolution GEXRF-RIXS-XAS technique," in Book of abstracts of The 15th International Conference on Total Reflection X-Ray Fluorescence Analysis and Related Methods (TXRF2013), 2013, Osaka, Japan, 2013, p. 8.

[72] J. Hoszowska, J.-Cl. Dousse, J. Kern, Ch. Rhême, "High-resolution von Hamos crystal X-ray spectrometer," Nuclear Instruments and Methods in Physics Research Section A, vol. 376, p. 129, 1996, http://dx.doi.org/ 10.1016/0168-9002(96)00262-8.

[73] A. Warland, C. Antoniak, M. Darbandi, C. Weis, J. Landers, W. Keune, H. Wende, "Effect of silica capping on the oxidation of $\mathrm{Fe}_{3} \mathrm{O}_{4}$ nanoparticles in dispersion revealed by x-ray absorption spectroscopy," Physical Review B, vol. 85, no. 235113, 2012, http://dx.doi.org/10.1103/PhysRevB.85.235113

[74] S. Landsberger, C. Brabec, B. Canion, J. Hashem, C. Lu, D. Millsap, G. George, "Determination of ${ }^{226}$ Ra, ${ }^{228} \mathrm{Ra}$ and ${ }^{210} \mathrm{~Pb}$ in NORM products from oil and gas exploration: Problems in activity underestimation due to the presence of metals and self-absorption of photons," Journal of Environmental Radioactivity, vol. 125, pp. 23 - 26, 2013, http://dx.doi.org/10.1016/j.jenvrad.2013.02.012

[75] M. Gräfe, E. Donner, R. N. Collins, E. Lombi, "Speciation of metal(loid)s in environmental samples by Xray absorption spectroscopy: A critical review," Analytica Chimica Acta, vol. 822, pp. 1 - 22, 2014, http: //dx.doi.org/10.1016/j.aca.2014.02.044

[76] R. Ortega, A. Carmona, I. Llorens, P. L. Solari, "X-ray absorption spectroscopy of biological samples. A tutorial," Journal of Analytical Atomic Spectrometry, vol. 27, pp. 2054 - 2065, 2012, http://dx.doi.org/10.1039/ C2JA30224A

[77] S. Bordiga, E. Groppo, G. Agostini, J. A. van Bokhoven, C. Lamberti, "Reactivity of Surface Species in Heterogeneous Catalysts Probed by In Situ X-ray Absorption Techniques," Chemical Reviews, vol. 113, pp. 1736 1850, 2013, http://dx.doi.org/10.1021/cr2000898

[78] X. Chen et al., "Properties of Disorder-Engineered Black Titanium Dioxide Nanoparticles through Hydrogenation," Scientific Reports, vol. 3, no. 1510, 2013, http://dx.doi.org/10.1038/srep01510

[79] R. Mitzner et al., "L-Edge X-ray Absorption Spectroscopy of Dilute Systems Relevant to Metalloproteins Using an X-ray Free-Electron Laser," Journal of Physical Chemistry Letters, vol. 4, pp. 3641 - 3647, 2013, http: //dx.doi.org/10.1021/jz401837f

[80] S. Eisebitt, T. Böske, J.-E. Rubensson, W. Eberhardt, "Determination of absorption coefficients for concentrated samples by fluorescence detection," Physical Review B, vol. 47, p. 14103, 1993, http://dx.doi.org/10.1103/ PhysRevB.47.14103

[81] A. J. Achkar, T. Z. Regier, H. Wadati, Y.-J. Kim, H. Zhang, D. G. Hawthorn, "Bulk sensitive x-ray absorption spectroscopy free of self-absorption effects," Physical Review B, vol. 83, no. 081106(R), 2011, http://dx.doi. org/10.1103/PhysRevB.83.081106

[82] A. J. Achkar, T. Z. Regier, E. J. Monkman, K. M. Shen, D. G. Hawthorn, "Determination of total x-ray absorption coefficient using non-resonant x-ray emission," Scientific Reports, vol. 1, no. 182, 2011, http://dx.doi.org/ 10.1038/srep00182 
[83] E. F. Aziz, M. H. Rittmann-Frank, K. M. Lange, S. Bonhommeau, M. Chergui, "Charge transfer to solvent identified using dark channel fluorescence-yield L-edge spectroscopy," Nature Chemistry, vol. 2, pp. 853 857, 2010, http://dx.doi.org/10.1038/nchem.768

[84] F. M. F. de Groot, "Dips and peaks in fluorescence yield X-ray absorption are due to state-dependent decay," Nature Chemistry, vol. 4, pp. 766 - 767, 2012, http://dx.doi.org/10.1038/nchem.1431

[85] I. J. Pickering, R. C. Prince, T. Divers, G. N. George, "Sulfur K-edge X-ray absorption spectroscopy for determining the chemical speciation of sulfur in biological systems," FEBS Letters, vol. 441, pp. $11-14,1998$, http://dx.doi.org/10.1016/S0014-5793(98)01402-1

[86] C. H. Booth, F. Bridges, "Improved self-absorption correction for fluorescence measurements of extended xray absorption fine-structure," Physica Scripta, vol. T115, pp. 202 - 204, 2005, http://dx.doi.org/10.1238/ Physica.Topical.115a00202

[87] J. M. Ablett, J. C. Woicik, C. C. Kao, "New Correction Procedure for X-Ray Spectroscopic Fluorescence Data: Simulations and Experiments," in Advances in X-Ray Analysis: Proceedings of the Annual Conference On Application of X-ray Analysis, Denver, 2004, vol. 48. IEEE, New York, 2005, p. 266, http://www.icdd. com/resources/axa/VOL48/V48_36.pdf [Accessed: 06 May 2015].

[88] J. Szlachetko et al., "A von Hamos x-ray spectrometer based on a segmented-type diffraction crystal for singleshot x-ray emission spectroscopy and time-resolved resonant inelastic x-ray scattering studies," Review of Scientific Instruments, vol. 83, no. 103105, 2012, http://dx.doi.org/10.1063/1.4756691

[89] A. Bergamaschi et al., "The MYTHEN detector for X-ray powder diffraction experiments at the Swiss Light Source," Journal of Synchrotron Radiation, vol. 17, pp. 653 - 668, 2010, http://dx.doi.org/10.1107/ S0909049510026051

[90] S. Hunt et al., "THE CONTROL AND DATA ACQUISITION SYSTEM OF THE SWISS LIGHT SOURCE," in Presented at the International Conference on Accelerator and Large Experimental Physics Control Systems, 1999, Trieste, Italy, 1999, http://accelconf.web.cern.ch/AccelConf/ica99/papers/ma1i01.pdf] [Accessed: 13 May 2015].

[91] J. A. Bearden, A. F. Burr, "Reevaluation of X-Ray Atomic Energy Levels," Reviews of Modern Physics, vol. 39, p. 125, 1967, http://dx.doi.org/10.1103/RevModPhys.39.125

[92] R. D. Deslattes, E. G. Kessler, Jr., P. Indelicato, L. de Billy, E. Lindroth, J. Anton, "X-ray transition energies: new approach to a comprehensive evaluation," Reviews of Modern Physics, vol. 75, p. 35, 2003, http://dx. doi.org/10.1103/RevModPhys.75.35

[93] L. G. Parratt, C. F. Hempstead, E. L. Jossem, " "Thickness Effect" in Absorption Spectra near Absorption Edges," Physical Review, vol. 105, p. 1228, 1957, http://dx.doi.org/10.1103/PhysRev.105.1228

[94] M. Bianchini, P. Glatzel, "A tool to plan photon-in/photon-out experiments: count rates, dips and selfabsorption," Journal of Synchrotron Radiation, vol. 19, pp. 911 - 919, 2012, http://dx.doi.org/10.1107/ S0909049512038551

[95] E. A. Stern, K. Kim, "Thickness effect on the extended-x-ray-absorption-fine-structure amplitude," Physical Review B, vol. 23, p. 3781, 1981, http://dx.doi.org/10.1103/PhysRevB.23.3781

[96] J. L. Campbell, T. Papp, "WIDTHS OF THE ATOMIC K - N7 LEVELS," Atomic Data and Nuclear Data Tables, vol. 77, pp. 1 - 56, 2001, http://dx.doi.org/10.1006/adnd.2000.0848

[97] J. H. Hubbell, S. M. Seltzer, "Tables of X-Ray Mass Attenuation Coefficients and Mass Energy-Absorption Coefficients," National Institute of Standards and Technology, Gaithersburg, MD, 2004, http://physics.nist. gov/xaamdi [Accessed: 2 December 2013].

[98] J. Szlachetko, J. Sá, M. Nachtegaal, U. Hartfelder, J.-Cl. Dousse, J. Hoszowska, D. L. A. Fernandes, H. Shi, C. Stampfl, "Real Time Determination of the Electronic Structure of Unstable Reaction Intermediates during $\mathrm{Au}_{2} \mathrm{O}_{3}$ Reduction," Journal of Physical Chemistry Letters, vol. 5, pp. 80 - 84, 2014, http://dx.doi.org/10. $1021 / \mathrm{jz} 402309 \mathrm{~s}$ 
[99] Ch. Broennimann et al., "The PILATUS 1M detector," Journal of Synchrotron Radiation, vol. 13, pp. 120 - 130 , 2006, http://dx.doi.org/10.1107/S0909049505038665

[100] J. J. Rehr, R. C. Albers, "Theoretical approaches to x-ray absorption fine structure," Reviews of Modern Physics, vol. 72, p. 621, 2000, http://dx.doi.org/10.1103/RevModPhys.72.621

[101] T. Fujikawa, N. Yiwata, "A new approach to full multiple-scattering XAFS calculation," Surface Science, vol. 357 - 358, pp. 60 - 64, 1996, http://dx.doi.org/10.1016/0039-6028(96)00058-1

[102] C. R. Natoli, D. K. Misemer, S. Doniach, F. W. Kutzler, "First-principles calculation of x-ray absorption-edge structure in molecular clusters," Physical Review A, vol. 22, p. 1104, 1980, http://dx.doi.org/10.1103/ PhysRevA.22.1104

[103] J. A. Soininen, E. L. Shirley, "Scheme to calculate core hole-electron interactions in solids," Physical Review B, vol. 64, no. 165112, 2001, http://dx.doi.org/10.1103/PhysRevB.64.165112

[104] A. L. Ankudinov, Y. Takimoto, J. J. Rehr, "Combined Bethe-Saltpeter equations and time-dependent densityfunctional theory approach for x-ray absorption calculations," Physical Review B, vol. 71, no. 165110, 2005, http://dx.doi.org/10.1103/PhysRevB.71.165110

[105] W. von der Linden, P. Horsch, "Precise quasiparticle energies and Hartree-Fock bands of semiconductors and insulators," Physical Review B, vol. 37, p. 8351, 1988, http://dx.doi.org/10.1103/PhysRevB.37.8351

[106] E. E. Krasovskii, W. Schattke, V. N. Strocov, R. Claessen, "Unoccupied band structure of $\mathrm{NbSe}_{2}$ by very lowenergy electron diffraction: Experiment and theory," Physical Review B, vol. 66, no. 235403, 2002, http: //dx.doi.org/10.1103/PhysRevB.66.235403

[107] J. J. Rehr, J. J. Kas, F. D. Vila, M. P. Prange, K. Jorissen, "Parameter-free calculations of x-ray spectra with FEFF9," Physical Chemistry Chemical Physics, vol. 12, pp. 5503 - 5513, 2010, http://dx.doi.org/10.1039/ B926434E

[108] L. Campbell, L. Hedin, J. J. Rehr, W. Bardyszewski, "Interference between extrinsic and intrinsic losses in xray absorption fine structure," Physical Review B, vol. 65, no. 064107, 2002, http://dx.doi.org/10.1103/ PhysRevB.65.064107

[109] J. J. Kas, J. J. Rehr, J. A. Soininen, P. Glatzel, "Real-space Green's function approach to resonant inelastic x-ray scattering," Physical Review B, vol. 83, no. 235114, 2011, http://dx.doi.org/10.1103/PhysRevB.83.235114

[110] T. Fujikawa., T. Konishi, T. Fukamachi, "A first-principle approach to X-ray scattering from solids," Journal of Electron Spectroscopy and Related Phenomena, vol. 134, pp. 195 - 206, 2004, http://dx.doi.org/10.1016/j. elspec.2003.11.002

[111] A. L. Ankudinov, J. J. Rehr, "Relativistic calculations of spin-dependent x-ray-absorption spectra," Physical Review B, vol. 56, p. R1712, 1997, http://dx.doi.org/10.1103/PhysRevB.56.R1712

[112] P. A. Lee, J. B. Pendry, "Theory of the extended x-ray absorption fine structure," Physical Review B, vol. 11, p. 2795, 2002, http://dx.doi.org/10.1103/PhysRevB.11.2795

[113] U. von Barth, G. Grossmann, "Dynamical effects in x-ray spectra and the final-state rule," Physical Review B, vol. 25, p. 5150, 1982, http://dx.doi.org/10.1103/PhysRevB.25.5150

[114] http://www.crystallography.net/[Accessed: 27 June 2015].

[115] R. N. Kapoor, F. Cervantes-Lee, C. F. Campana, C. Haltiwanger, K. Abney, K. H. Pannell, "Synthesis, Structural and Spectroscopic Characterization, Catalytic Properties, and Thermal Transformations of New Cyclic Diand Trisiloxanediolato Tantalum Complexes," Inorganic Chemistry, vol. 45, pp. 2203 - 2208, 2006, http: //dx.doi.org/10.1021/ic051274w

[116] R. Alonso-Mori et al., "Energy-dispersive X-ray emission spectroscopy using an X-ray free-electron laser in a shot-by-shot mode," in Proceedings of the National Academy of Sciences of the United States of America, H. B. Gray, Ed., 2012, pp. 19103 - 19 107, http://dx.doi.org/10.1073/pnas.1211384109 
[117] J. Kern et al., "Simultaneous femtosecond X-ray spectroscopy and diffraction of photosystem II at room temperature," Science, vol. 340, pp. 491 - 495, 2013, http://dx.doi.org/10.1126/science.1234273

[118] B. Sonntag, "VUV and X-ray free-electron lasers," Nuclear Instruments and Methods in Physics Research A, vol. 467 - 468, pp. 8 - 15, 2001, http://dx.doi.org/10.1016/S0168-9002(01)00210-8

[119] B. W. J. McNeil, N. R. Thompson, "X-ray free-electron lasers," Nature Photonics, vol. 4, pp. 814 - 821, 2010, http://dx.doi.org/10.1038/nphoton.2010.239

[120] Ya. S. Derbenev, A. M. Kondratenko, E. L. Saldin, "On the possibility of using a free electron laser for polarization of electrons in storage rings," Nuclear Instruments and Methods in Physics Research, vol. 193, pp. 415 421, 1982, http://dx.doi.org/10.1016/0029-554X(82)90233-6

[121] J. B. Murphy, C. Pellegrini, "Free electron lasers for the XUV spectral region," Nuclear Instruments and Methods in Physics Research A, vol. 237, pp. 159 - 167, 1985.

[122] W. Ackermann et al., "Operation of a free-electron laser from the extreme ultraviolet to the water window," Nature Photonics, vol. 1, pp. 336 - 342, 2007, http://dx.doi.org/10.1038/nphoton.2007.76

[123] H. Yumoto et al., "Focusing of X-ray free-electron laser pulses with reflective optics," Nature Photonics, vol. 7 , pp. 43 - 47, 2013, http://dx.doi.org/10.1038/nphoton.2012.306

[124] H. Mimura et al., "Generation of $10^{20} \mathrm{~W} \mathrm{~cm}^{-2}$ hard X-ray laser pulses with two-stage reflective focusing system," Nature Communications, vol. 5, no. 3539, 2014, http://dx.doi.org/10.1038/ncomms4539

[125] Z. Huang, "Brightness and Coherence of Synchrotron Radiation and FELs," SLAC Publication, no. SLAC-PUB15449, 2013, http://slac.stanford.edu/pubs/slacpubs/15250/slac-pub-15449.pdf] [Accessed: 11 March 2015]

[126] F. Lehmkühler et al., "Single Shot Coherence Properties of the Free-Electron Laser SACLA in the Hard X-ray Regime," Scientific Reports, vol. 4, no. 5234, 2014, http://dx.doi.org/10.1038/srep05234

[127] L. H. Yu, "Generation of intense uv radiation by subharmonically seeded single-pass free-electron lasers," Physical Review A, vol. 44, pp. 5178 - 5193, 1991, http://dx.doi.org/10.1103/PhysRevA.44.5178

[128] J. Feldhaus, E. L. Saldinb, J. R. Schneidera, E. A. Schneidmillerb, M. V. Yurkovc, "Possible application of X-ray optical elements for reducing the spectral bandwidth of an X-ray SASE FEL," Optics Communication, vol. 140, pp. 341 - 352, 1997, http://dx.doi.org/10.1016/S0030-4018(97)00163-6

[129] E. L. Saldina, E. A. Schneidmillera, Yu. V. Shvyd'kob, M. V. Yurkovc, "X-ray FEL with a meV bandwidth," Nuclear Instruments and Methods in Physics Research A, vol. 475, pp. 357 - 362, 2001, http://dx.doi.org/ 10.1016/S0168-9002(01)01539-X

[130] J. Amann et al., "Demonstration of self-seeding in a hard-X-ray free-electron laser," Nature Photonics, vol. 6, pp. 693 - 698, 2012, http://dx.doi.org/10.1038/nphoton.2012.180

[131] P. Karvinen et al., "Single-shot analysis of hard x-ray laser radiation using a noninvasive grating spectrometer," Optics Letters, vol. 37, pp. 5073 - 5075, 2012, http://dx.doi.org/10.1364/OL.37.005073

[132] J. Welch, F.-J. Decker, J. Hastings, Z. Huang, A. Lutman, M. Messerschmidt, J. L. Turner, "COMPARISON OF HARD X-RAY SELF-SEEDING WITH SASE AFTER A MONOCHROMATOR AT LCLS," in Proceedings of the 34th International Free-Electron Laser Conference, T. Tanaka, V. RW Schaa, Ed., 2013, pp. 217 220, https://accelconf.web.cern.ch/accelconf/FEL2012/papers/tuob04.pdf [Accessed: 20 March 2015].

[133] L. Young et al., "Femtosecond electronic response of atoms to ultra-intense X-rays," Nature, vol. 466, pp. 56 61, 2010, http://dx.doi.org/10.1038/nature09177

[134] K. Tamasaku et al., "Double Core-Hole Creation by Sequential Attosecond Photoionization," Physical Review Letters, vol. 111, 2011, http://dx.doi.org/10.1103/PhysRevLett.111.043001

[135] K. Tamasaku et al., "X-ray two-photon absorption competing against single and sequential multiphoton processes," Nature Photonics, vol. 8, pp. 313 - 316, 2014, http://dx.doi.org/10.1038/nphoton.2014.10

[136] N. Rohringer et al., "Atomic inner-shell X-ray laser at 1.46 nanometres pumped by an X-ray free-electron laser," Nature, vol. 481, pp. 488 - 491, 2012, http://dx.doi.org/10.1038/nature10721 
[137] M. Beye et al., "Stimulated X-ray emission for materials science," Nature, vol. 501, pp. 191 - 194, 2013, http: //dx.doi.org/10.1038/nature12449.

[138] S. M. Vinko et al., "Creation and diagnosis of a solid-density plasma with an X-ray free-electron laser," Nature, vol. 482 , pp. 59 - 62, 2012, http://dx.doi.org/10.1038/nature10746

[139] T. E. Glover et al., "X-ray and optical wave mixing," Nature, vol. 488, pp. 603 - 608, 2012, http://dx.doi.org/ $10.1038 /$ nature11340

[140] H. T. Lemke et al., "Femtosecond X-ray Absorption Spectroscopy at a Hard X-ray Free Electron Laser: Application to Spin Crossover Dynamics," Journal of Physical Chemistry A, vol. 117, pp. 735 - 740, 2013, http://dx.doi.org/10.1021/jp312559h

[141] M. Beye et al., "Selective Ultrafast Probing of Transient Hot Chemisorbed and Precursor States of CO on Ru(0001)," Physical Review Letters, vol. 110, no. 186101, 2013, http://dx.doi.org/10.1103/PhysRevLett. 110.186101

[142] M. Dell'Angela et al., "Real-Time Observation of Surface Bond Breaking with an X-ray Laser," Science, vol. 339, pp. 1302 - 1305, 2013, http://dx.doi.org/10.1126/science.1231711

[143] R. Akre et al., "Commissioning the Linac Coherent Light Source injector," Physical Review ST Accelerators and Beams, vol. 11, no. 030703, 2008, http://dx.doi.org/10.1103/PhysRevSTAB.11.030703

[144] H. Loos, "LCLS Accelerator Operation and Measurement of Electron Beam Parameters Relevant for the X-ray Beam," SLAC Publication, no. SLAC-PUB-15422, 2013, http://www.slac.stanford.edu/cgi-wrap/getdoc/ slac-pub-15422.pdf [Accessed: 16 March 2015].

[145] http://cdn.phys.org/newman/gfx/news/hires/2012/gcgetdh.jpg [Accessed: 16 March 2015].

[146] http://www.fnal.gov/pub/ferminews/ferminews03-12-01/slac.jpg [Accessed: 16 March 2015].

[147] Y. Ding et al., "Measurements and Simulations of Ultralow Emittance and Ultrashort Electron Beams in the Linac Coherent Light Source," Physical Review Letters, vol. 102, no. 254801, 2009, http://dx.doi.org/10. 1103/PhysRevLett.102.254801

[148] https://portal.slac.stanford.edu/sites/lcls_public/instruments/Pages/default.aspx [Accessed: 17 March 2015].

[149] S. Moeller et al., "Photon beamlines and diagnostics at LCLS," Nuclear Instruments and Methods in Physics Research A, vol. 635, pp. S6 - S11, 2011, http://dx.doi.org/10.1016/j.nima.2010.10.125

[150] S. Boutet, G. J. Williams, "The Coherent X-ray Imaging (CXI) instrument at the Linac Coherent Light Source (LCLS)," New Journal of Physics, vol. 12, no. 035024, 2010, http://dx.doi.org/10.1088/1367-2630/12/3/ 035024

[151] S. Herrmann et al., "CSPAD-140k: A versatile detector for LCLS experiments," Nuclear Instruments and Methods in Physics Research Section A, vol. 718, pp. 550 - 553, 2013, http://dx.doi.org/10.1016/j.nima.2013.01.057

[152] J. Frisch et al., "Beam Measurements at LCLS," SLAC Publication, no. SLAC-PUB-15018, 2012, http://slac. stanford.edu/pubs/slacpubs/15000/slac-pub-15018.pdf [Accessed: 24 March 2015].

[153] D. Xiang, Y. Ding, "Longitudinal-to-Transverse Mapping for Femtosecond Electron Bunch Length Measurement," SLAC Publication, no. SLAC-PUB-14100, 2010, http://slac.stanford.edu/pubs/slacpubs/14000/ slac-pub-14100.pdf [Accessed: 24 March 2015].

[154] C. Behrens et al., "Few-femtosecond time-resolved measurements of X-ray free-electron lasers," Nature Communications, vol. 5, no. 3762, 2014, http://dx.doi.org/10.1038/ncomms4762

[155] Y. Ding et al., "Results from the LCLS X-Band Transverse Deflector with Femtosecond Temporal Resolution," SLAC Publication, no. SLAC-PUB-16105, 2014, http://slac.stanford.edu/pubs/slacpubs/16000/ slac-pub-16105.pdf [Accessed: 24 March 2015].

[156] S. P. Hau-Riege, R. M. Bionta, D. D. Ryutov, J. Krzywinski, "Measurement of x-ray free-electron-laser pulse energies by photoluminescence in nitrogen gas," Journal of Applied Physics, vol. 103, no. 053306, 2008, http://dx.doi.org/10.1063/1.2844478 
[157] S. Düsterer et al., "Femtosecond x-ray pulse length characterization at the Linac Coherent Light Source freeelectron laser," New Journal of Physics, vol. 13, no. 093024, 2008, http://dx.doi.org/10.1088/1367-2630/13/ $9 / 093024$

[158] P. Krejcik et al., "Timing and Synchronization at the LCLS," SLAC Publication, no. SLAC-PUB-12593, 2007, http://www.slac.stanford.edu/cgi-wrap/getdoc/slac-pub-12593.pdf [Accessed: 25 March 2015].

[159] J. Dusatko, S. Allison, M. Browne, P. Krejcik, "THE LCLS TIMNG EVENT SYSTEM," in Proceedings of BIW10, C. Dillingham, J. Chew, Ed., 2010, pp. 379 - 383, https://accelconf.web.cern.ch/accelconf/BIW2010/papers/ tupsm083.pdf [Accessed: 25 March 2015].

[160] https://confluence.slac.stanford.edu/display/PSDM/LCLS+Data+Analysis [Accessed: 25 March 2015].

[161] http://www.hdfgroup.org/HDF5 [Accessed: 25 March 2015].

[162] https://www.python.org [Accessed: 25 March 2015].

[163] A. Gaur, B. D. Shrivastava, S. K. Joshi, "Copper K-edge XANES of $\mathrm{Cu}(\mathrm{I})$ and $\mathrm{Cu}(\mathrm{II})$ oxide mixtures," Journal of Physics: Conference Series, vol. 190, no. 012084, 2009, http://dx.doi.org/10.1088/1742-6596/190/1/012084

[164] G. N. Greaves, P. J. Durham, G. Diakun, P. Quinn, "Near-edge X-ray absorption spectra for metallic Cu and Mn," Nature, vol. 294, pp. 139 - 142, 1981, http://dx.doi.org/10.1038/294139a0

[165] S. Bocharov, Th. Kirchner, G. Dräger, O. Šipr, and A. Šimůnek, "Dipole and quadrupole contributions to polarized $\mathrm{Cu}$ K x-ray absorption near-edge structure spectra of CuO," Physical Review B, vol. 63, no. 045104, 2001, http://dx.doi.org/10.1103/PhysRevB.63.045104

[166] J. Kawai, Y. Nihei, "Charge transfer effects on the chemical shift and the line width of the CuKa X-ray flourescence spectra of copper oxides," Solid State Communications, vol. 70, pp. 567 - 571, 1989, http://dx.doi.org/10. 1016/0038-1098(89)90951-4

[167] L. A. Grunes, "Study of the K edges of 3d transition metals in pure and oxide form by x-ray-absorption spectroscopy," Physical Review B, vol. 27, p. 2111, 1983, http://dx.doi.org/10.1103/PhysRevB.27.2111 
Appendices 



\section{A Reconstruction algorithms with Mathematica}

The presented codes were used to reconstruct off-resonant XES spectra from XANES data or vice versa. They were made with Wolfram Mathematica computing software in version 8.0.4 installed on a 64-bit Windows 7 operating system. The presented algorithms are implementations of the Kramers-Heisenerg formula modified by Tulkki and Åberg [44 49] (see Eq. II.2 assuming proportionality between the fluorescence yield and the scattering cross section as well as between the photoabsorption coefficient and the initial state-to-continuum transition oscillator strength.

Different numerical approaches were developed to optimize the calculations and to allow for cross checking of the obtained results. Only selected functions are presented below to outline the methods used. The versions of the written codes differ in e.g., treating the final state lifetime broadening, which in some cases is negligibly small. In such cases, neglecting the final state width dramatically shortens the computation time and causes typically insignificant blurring of the calculated absorption spectral curves and sharpening of the calculated emission spectral curves.

The main input data required to run the computation are XASSpectrum or XESSpectrum for calculation of an emission spectrum or an absorption spectrum, respectively. They need to be lists consisting of two-coordinate data points - first coordinate for the energy and another for the absorption or the intensity. The symbols $E 1, E i, \Gamma i, E f$ and $\Gamma f$ refer to $\hbar \omega_{1},\left|E_{i}\right|, \Gamma_{i},\left|E_{f}\right|$ and $\Gamma_{f}$, respectively.

Reconstruction of off-resonant XES spectra based on XANES data

In the function presented below the final state lifetime broadening is neglected which allows replacing the Lorentzian in Eq. II.2 centered at $\hbar \omega_{1}-\hbar \omega_{2}-\left|E_{f}\right|-E$ with Dirac delta $\delta\left(\hbar \omega_{1}-\hbar \omega_{2}-\left|E_{f}\right|-E\right)$. It reduces the integral to an easily operable algebraic expression and makes calculation of the emission spectrum immediate.

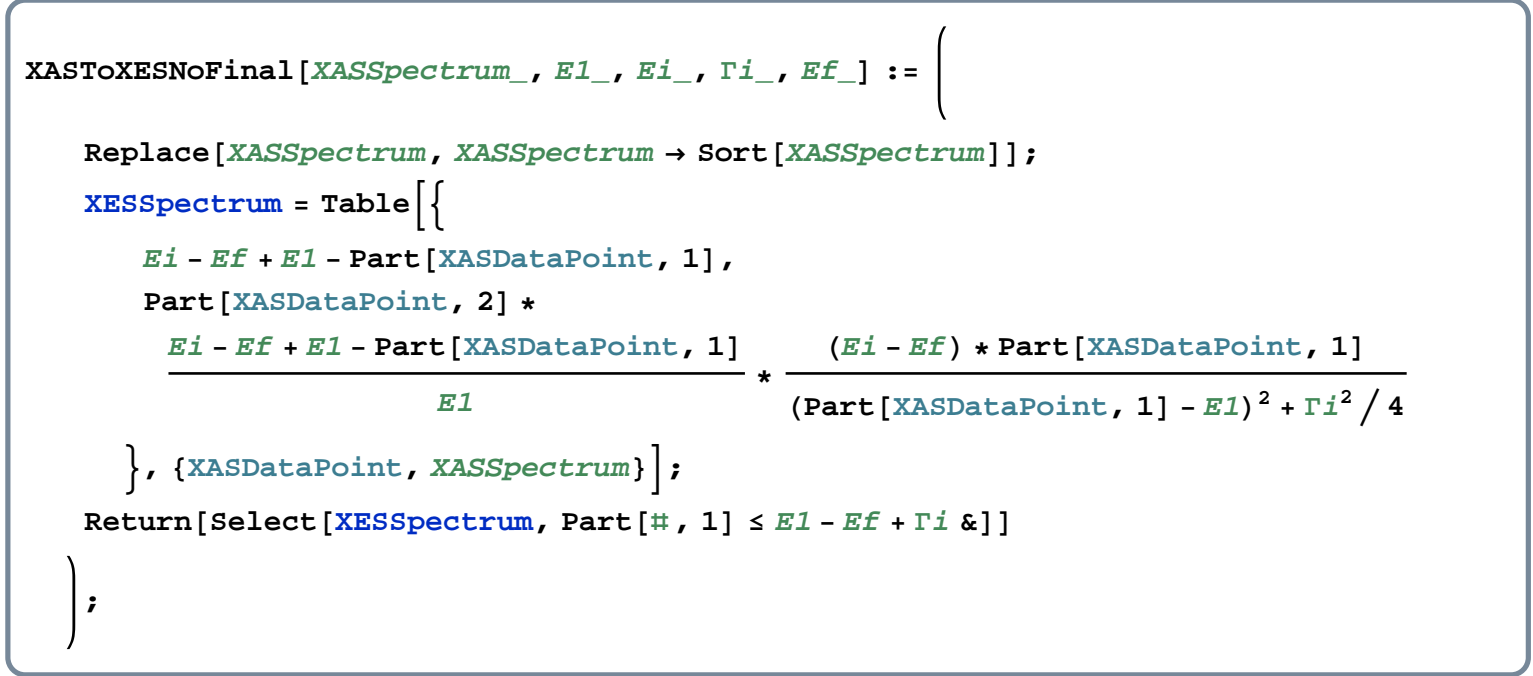

In the following code the final state lifetime broadening $\Gamma_{f}$ is taken into account. It involves computation of an integral which increases the computation time typically up to few minutes.

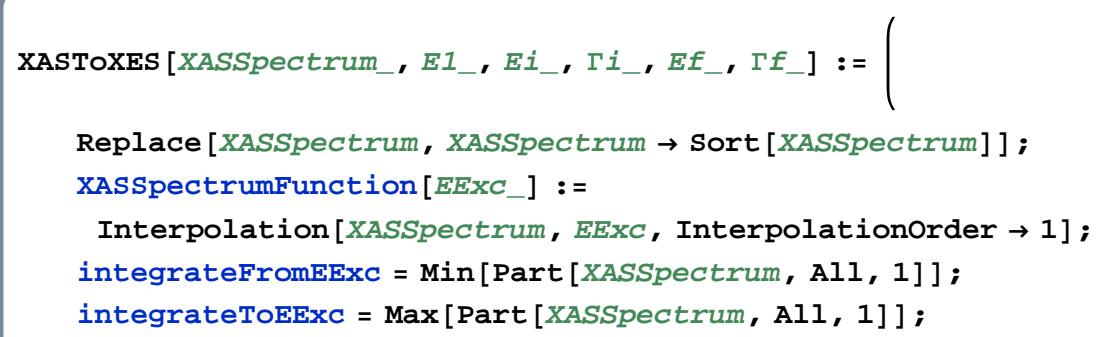




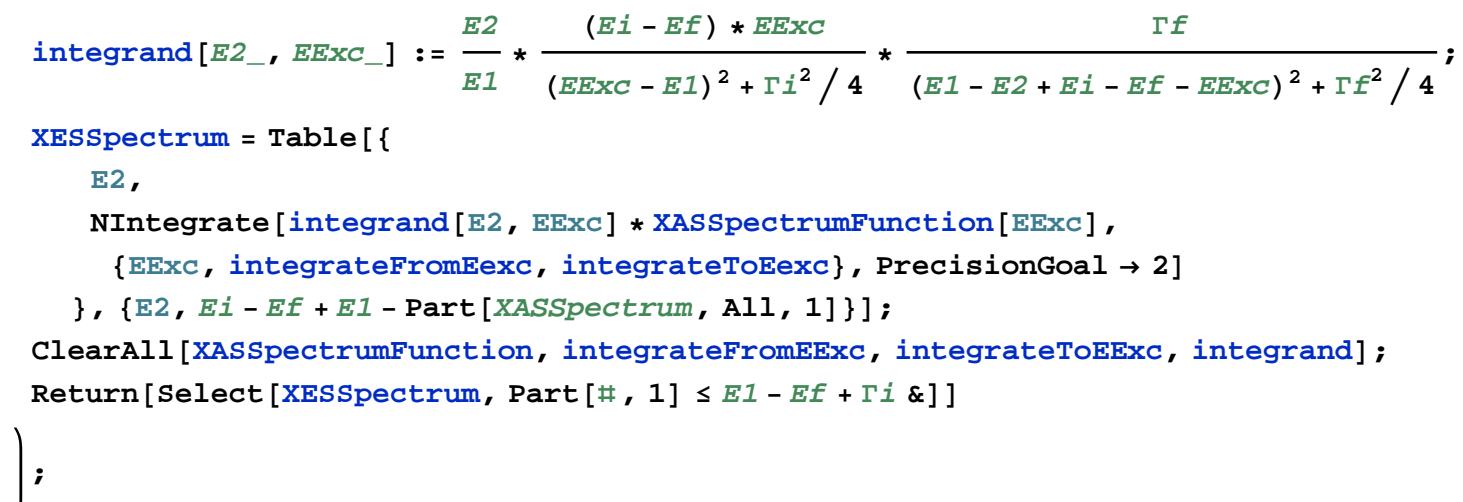

Reconstruction of XANES based on off-resonant XES data

The function below does not account for the final state lifetime broadening. Similarly as in the case of XASTOXESNoFinal, the computation is very short. The XANES obtained with the XESTOXASNoFinal function is what Hayashi et al. refer to as lifetime-broadening-suppressed XANES (LBS-XANES) 54 55.

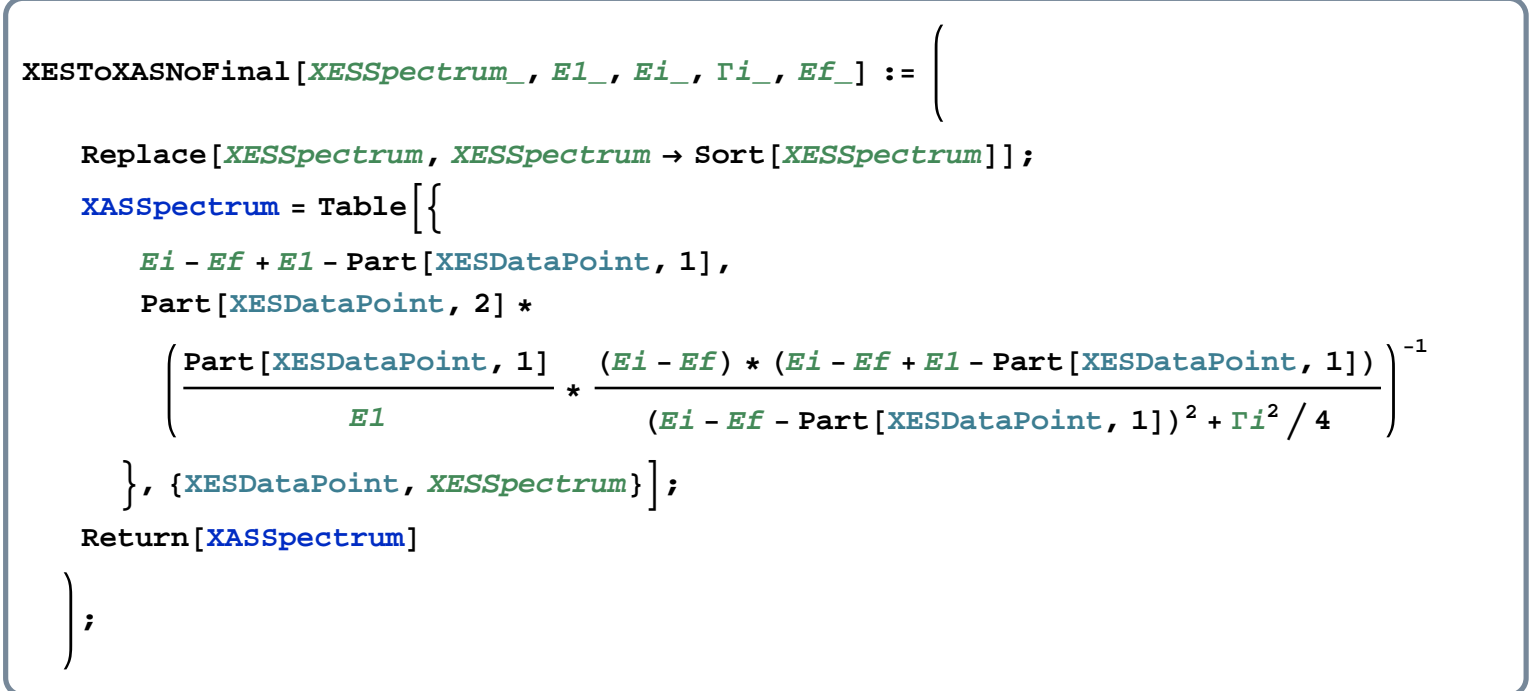

Calculation of an absorption spectrum using the off-resonant XES data including the final state lifetime broadening involves solving a Fredholm equation of the first kind. The spectrum calculated with the function below is a numerical approximation of the solution and its exactness is higher for bigger number of the input XES data points and for better statistics of the recorded emission spectral data. In the calculation done with XESToXAS system of many equations is solved (the computation time grows quadratically with the number of input data points) which makes the computation quite long (typically up to tens of minutes). The algorithm fails to compute correct absorption spectrum, if the provided XES data is of low statistics. The spectrum calculated with the following code is called by Hayashi et al. lifetimebroadening-free XANES (LBF-XANES) [54].

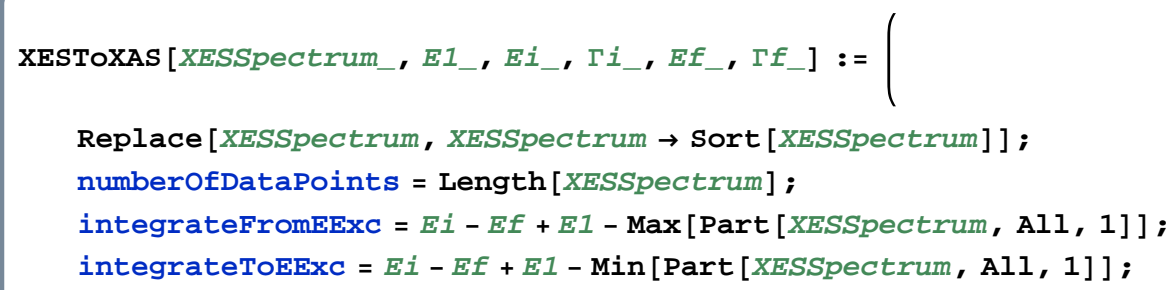




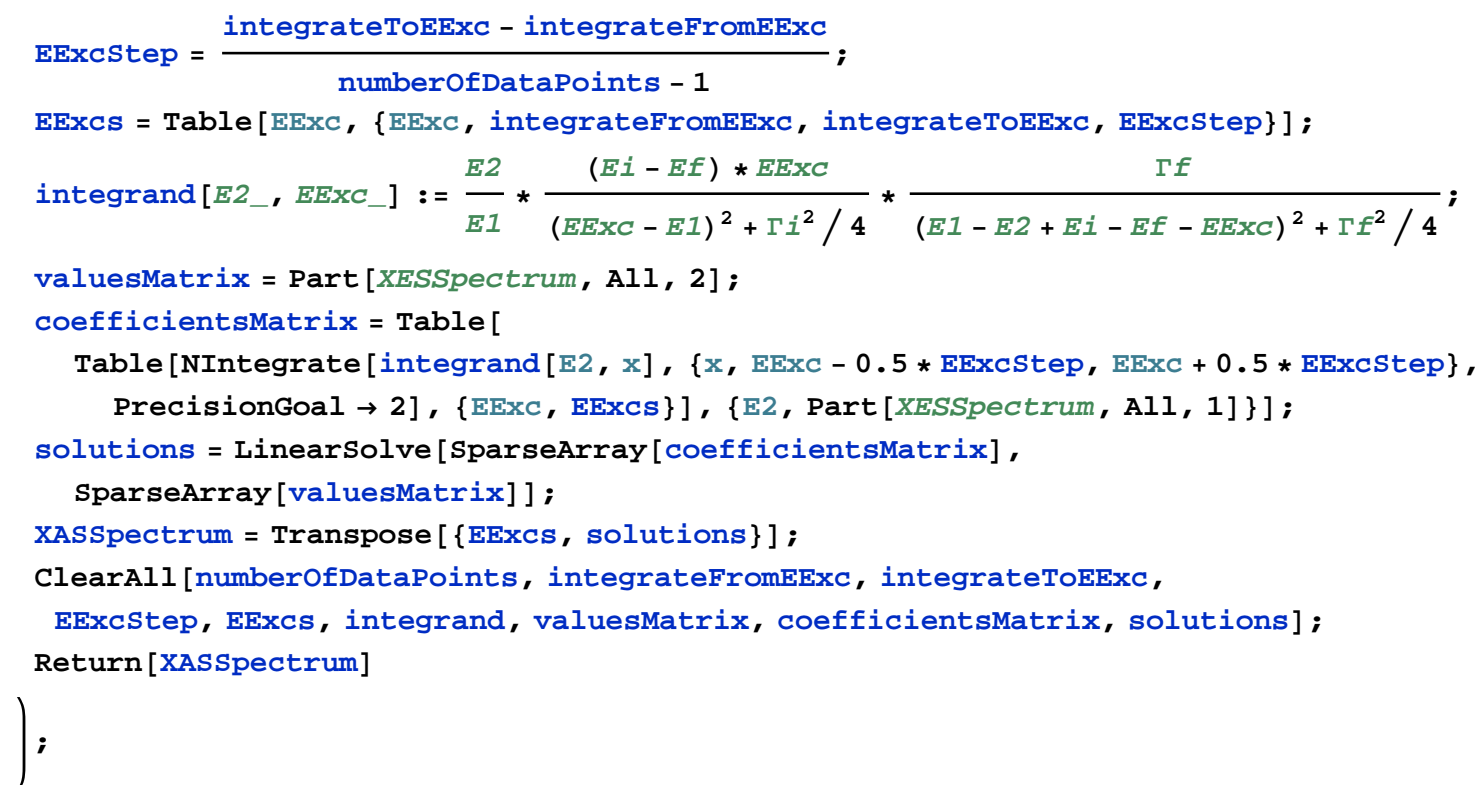

Another approach developed to obtain XANES spectra taking into account the final state lifetime broadening is based on an iterative procedure. In this approach every iteration of calculation of XANES is followed by calculation of an off-resonant XES spectrum based on the last XANES curve obtained. The calculated emission spectrum is compared to the input XESSpectrum data and corrections are found from the ratio of the two emission spectral curves. These corrections are applied to the last iterated XANES and the next iteration is started with the corrected XANES. This procedure continues until satisfactory convergence between the input XESSpectrum data and subsequent calculated emission spectra is reached. The convergence is specified by the minPrecision parameter which is the demanded minimal average ratio between the calculated and the original data points. Usually already the value of 0.01 put on the minPrecision parameter provides satisfactory result and is reached typically after up to ten iterations. The maxNumberofIterations parameter was also introduced to terminate the calculation after specified number of iterations performed (which is useful in cases of slowly converging iterations).

The following example of an iterative approach used for XANES calculation is dedicated to cases where two decay channels contribute to the measured off-resonant emission spectrum. Mo $L \alpha_{1,2}$ HEROS spectrum presented in Fig. II.9 (a) can serve as an example. Here the recorded spectrum contains overlapping contributions from both $M_{5} \rightarrow L_{3}$ and $M_{4} \rightarrow L_{3}$ deexcitations, which is a consequence of proximity of the two final states' energies $\left|E_{M_{5}}\right|$ and $\left|E_{M_{4}}\right|$ (for molybdenum $\left.\left|E_{M_{4}}\right|-\left|E_{M_{5}}\right|=3.2 \mathrm{eV}\right)$. In such cases two final states' energies $E f 1$ and $E f 2$ need to be specified as well as their lifetime broadenings $\Gamma f 1$ and $\Gamma f 2$. The ratio of oscillator strengths for the two decay channels also needs to be provided in the variable oscillatorsStrengthsRatio (for the mentioned case with Mo, oscillatorsStrengthsRatio is equal to 0.11). Note that the iterative algorithm presented below can be easily adapted to cases with one final state by removing from the code the variables Ef2, $\Gamma f 2$ and oscillatorsStrengthsRatio as well as the integrand2 [E2_, EExC_] function.

XESToXASTwoLinesIterative[XESSpectrum, E1_, Ei_, Гi_, Ef1_, Гf1_, Ef2_, Гf2_, oscillatorsstrengthsRatio_, minPrecision_, maxNumberofIterations_] := (

Replace [XESSpectrum, XESSpectrum $\rightarrow$ Sort [XESSpectrum] ] ; integrand1 [E2_, EExC_] :=

$$
\frac{E 2}{E 1} * \frac{(E i-E f 1) * E E \times C}{(E E x C-E 1)^{2}+\Gamma i^{2} / 4} * \frac{\Gamma f 1}{(E 1-E 2+E i-E f 1-E E \times C)^{2}+\Gamma f 1^{2} / 4} ;
$$


integrand2 [E2, EExC_] := oscillatorsStrengthsRatio * $\frac{E 2}{E 1}$ *

$$
\frac{(E i-E f 2) * E E \times C}{(E E \times C-E 1)^{2}+\Gamma i^{2} / 4} * \frac{\Gamma f 2}{(E 1-E 2+E i-E f 2-E E \times C)^{2}+\Gamma f 2^{2} / 4} ;
$$

XESSpectrumRescaled $=$ Transpose $[$ Part $[$ XESSpectrum, All, 1] ,

Part [XESSpectrum, All, 2] / Max [Part [Select [XESSpectrum,

$$
(E 1-E f 1) * 0.999 \leq \operatorname{Part}[\#, 1] \leq(E 1-E f 1) * 1.0015 \&], A 11,2]]\}] \text {; }
$$

XAsSpectrumIteration $=$ Table $[\{$

Ei - Ef1 + E1 - Part [XESDataPoint, 1],

Part [XESDataPoint, 2] *

$$
\left(\frac{\text { Part [XESDataPoint, } 1]}{E 1} * \frac{(E i-E f 1) *(E i-E f 1+E 1-\text { Part }[\text { XESDataPoint, } 1])}{(E i-E f 1-\operatorname{Part}[\text { XESDataPoint, } 1])^{2}+\Gamma i^{2} / 4}\right)^{-1}
$$

\}$,\{$ XESDataPoint, XESSpectrumRescaled $\}]$;

integrateFromEExc $=\operatorname{Min}[\operatorname{Part}[\mathrm{XASSpectrumIteration,A11,1]}$;

integrateToEExC $=\operatorname{Max}[$ Part [XASSpectrumIteration, All, 1] ] ;

correctionsOnXESSpectrum $=$ Table $[1 .,\{$ XESSpectrumRescaled $\}]$;

iterationsSoFar $=0$;

Do $[\{$

iterationsSoFar++;

XASSpectrumIteration $=$ Transpose $[$ Part $[$ XASSpectrumIteration, All, 1$]$, Part [XASSpectrumIteration, All, 2] / correctionsOnXESSpectrum\}] ;

XASSpectrumIterationFunction [En_] := Interpolation [

XAsspectrumIteration, En, Interpolationorder $\rightarrow 1$ ] ;

XESSpectrumIteration $=$ Table $[\{$

$\mathrm{E} 2$,

NIntegrate [ (integrand1 [E2, EExc] + integrand2 [E2, EExc]) *

XASSpectrumIterationFunction [EEx] ,

$\{$ EExC, integrateFromEExc, integrateToEExc $\}$, PrecisionGoal $\rightarrow 2$ ]

\},$\{E 2$, Part [XESSpectrumRescaled, Al1, 1] \}];

XESSpectrumIterationRescaled = Transpose [ $\{$ Part [XESSpectrumIteration, All, 1] , Part [XESSpectrumIteration, All, 2] / Max [Part [Select [XESSpectrumIteration, $(E 1-E f 1) * 0.999 \leq \operatorname{Part}[\#, 1] \leq(E 1-E f 1) * 1.0015 \&], A 11,2]]\}]$;

Part [XESSpectrumIterationRescaled, All, 2]

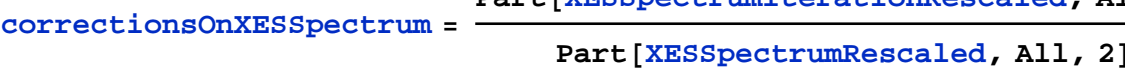

If [Abs [Mean [correctionsOnXesspectrum] - 1] s minPrecision, Break []]

\},$\{i, 1$, maxNumberOfIterations, 1\}];

ClearAll [integrand, XESSpectrumRescaled, integrateFromEExc,

integrateToEExC, correctionsOnXESSpectrum, XASSpectrumIterationfunction, XESSpectrumIteration, XESSpectrumIterationRescaled] ;

Return [ \{ Transpose [ \{ Part [XASSpectrumIteration, All, 1],

Part [XASSpectrumIteration, All, 2] / Max [Part [Select [XASSpectrumIteration, $-E i * 1.001 \leq \operatorname{Part}[\#, 1] \leq E i * 1.0015 \&], A 11,2]]\}]$,

iterationsSoFar, Mean [correctionsonXESSpectrum] \}]

) 


\section{B The lcls.py module}

The presented lcls.py module was developped to access the data in HDF5 data files recorded at LCLS. It was run on a 32-bit Windows 7 operating system with installed Python 2.7.3, NumPy 1.6.2, H5py 2.1.2 and Matplotlib 1.1.0 and no compatibility issues were encountered. The data files were stored in folders with paths specified by the variable dataFilesDirectories. The presented code contains comments preceded by the \# sign (in red) bringing an additional information that maybe useful for the reader.

Each data file corresponds to one run, i.e., series of events recorded for given LCLS parameters. Among all the runs performed only four were dedicated to the present work. The normal $\mathrm{Cu} \mathrm{K} \alpha_{1,2}$ fluorescence (meant for the spectrometer energy calibration) was detected during Run 54 and the HEROS measurements with $\mathrm{Cu}^{0}, \mathrm{Cu}^{1+}$ and $\mathrm{Cu}^{2+}$ were carried out during Runs 58, 59 and 60, respectively.

To access the data in the Run 58 from a Python console one has to first import the lcls.py module (having previously made sure that the module's location is among Python's searchable paths) and then create an object of the loadRun class defined in it. Through the created object one can retrieve different data contained in the data file as presented in the following example:

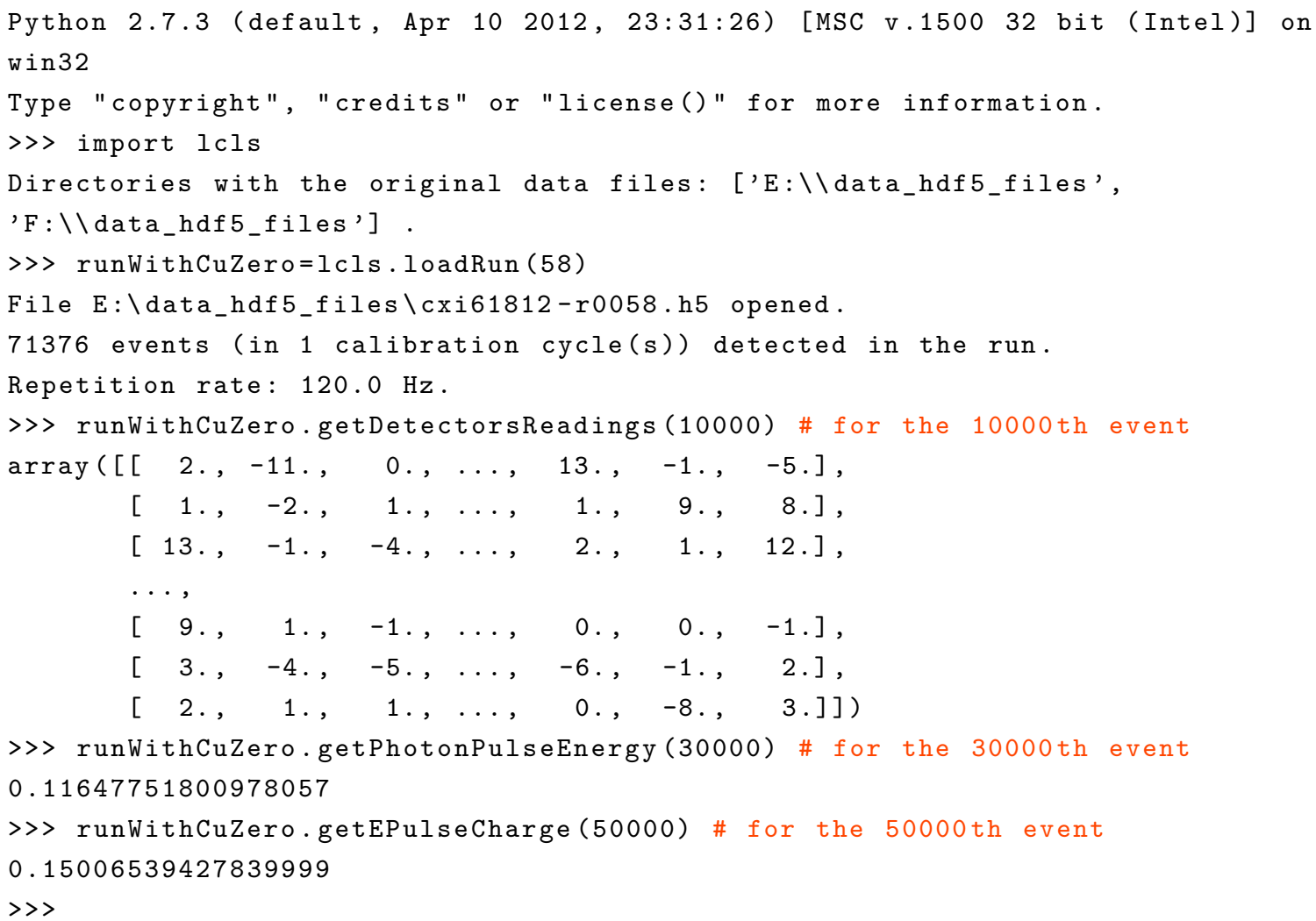

Due to the long code contained in the lcls.py module, it was split into six parts to improve its clarity. In the main part presented below, the loadRun class definition is included together with the declaration of the main variables. The remaining five parts are inserted in the loadRun class definition in the places indicated in the code. All the relevant data is located in the /Configure:0000/Run:0000 entry in the HDF5 data files, in different CalibCycle subentries (CalibCycle:0000, CalibCycle:0001, CalibCycle:0002 ...) corresponding to different z-axis sample positions (along the beam direction). In this study, however, the sample was not moved along the z-axis, therefore only one CalibCycle subentry (i.e. CalibCycle:0000) is present in the data files of interest. 


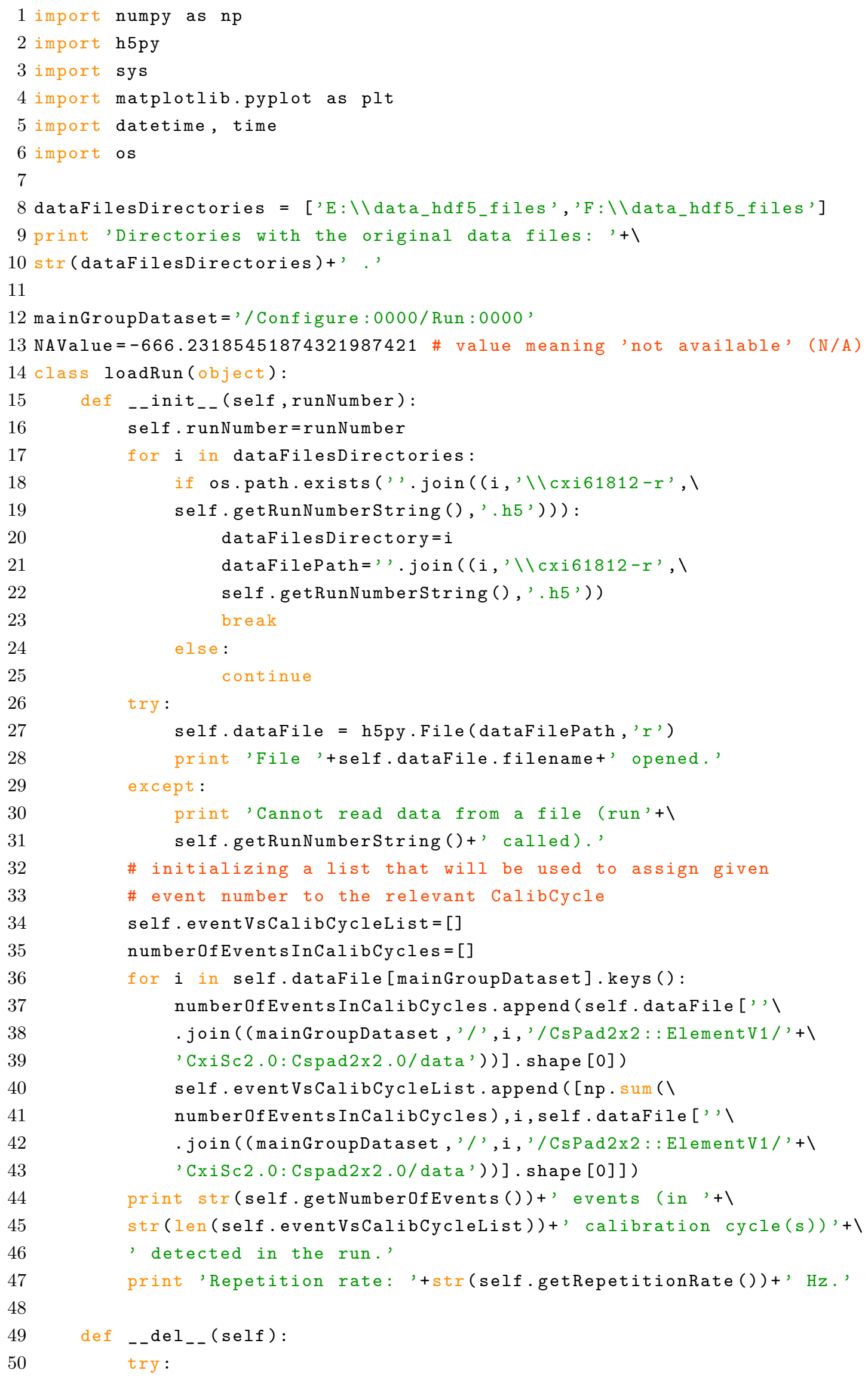




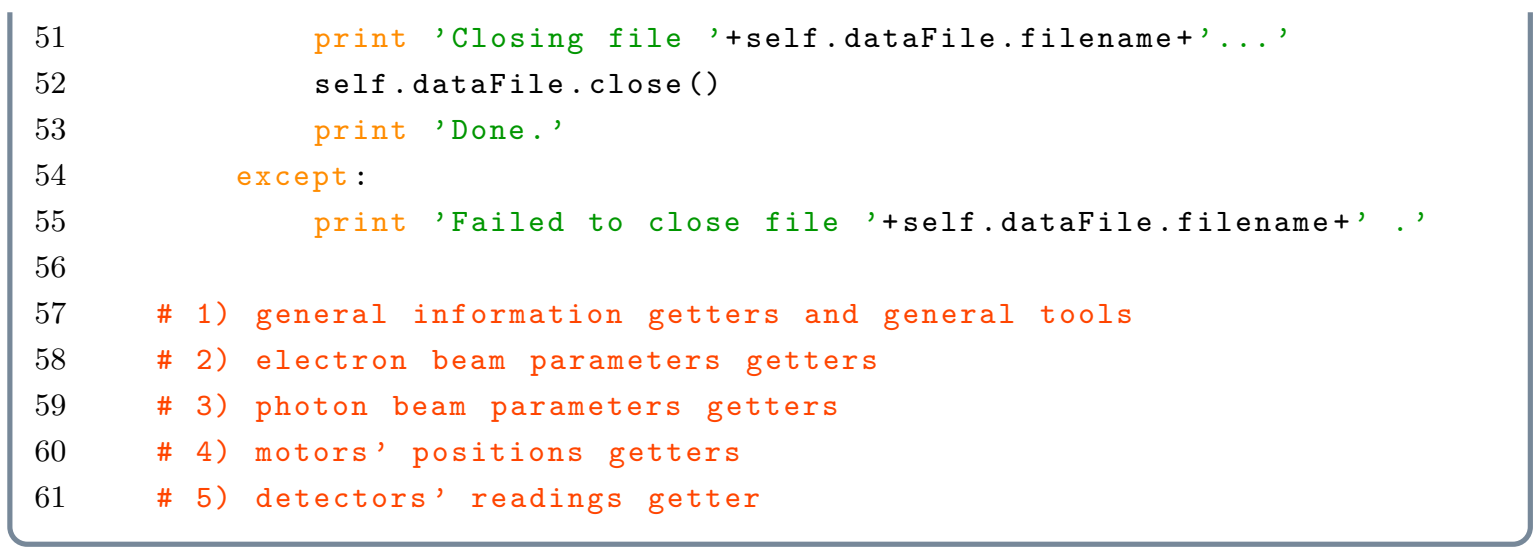

In the following part are defined getter functions granting access to the general information about the run loaded. This includes the total number of events recorded during the run, the LCLS repetition rate, the moment of acquisition of the given event (note the time shift between Switzerland and California US) which is taken as the moment of the detectors' readout.

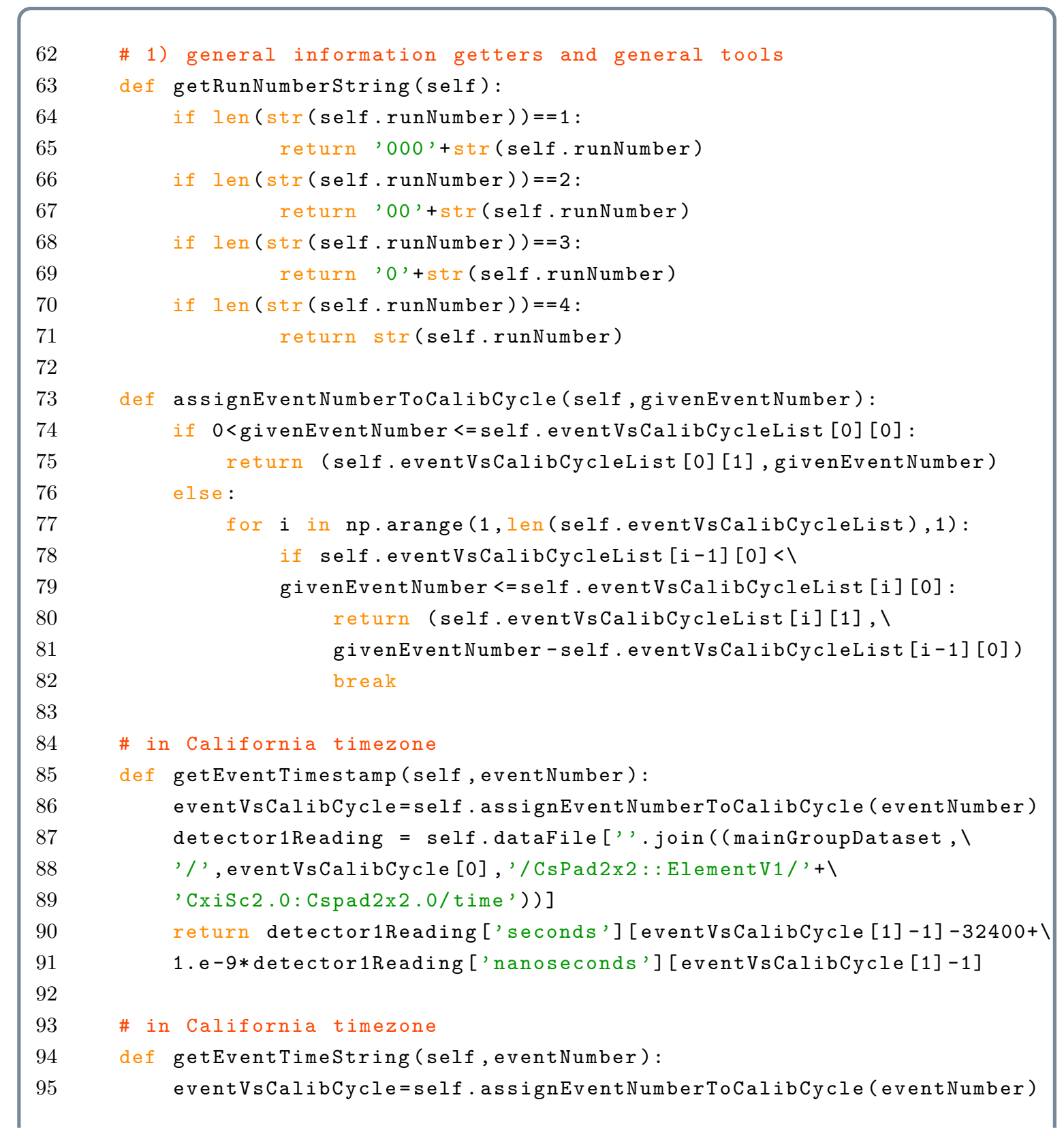




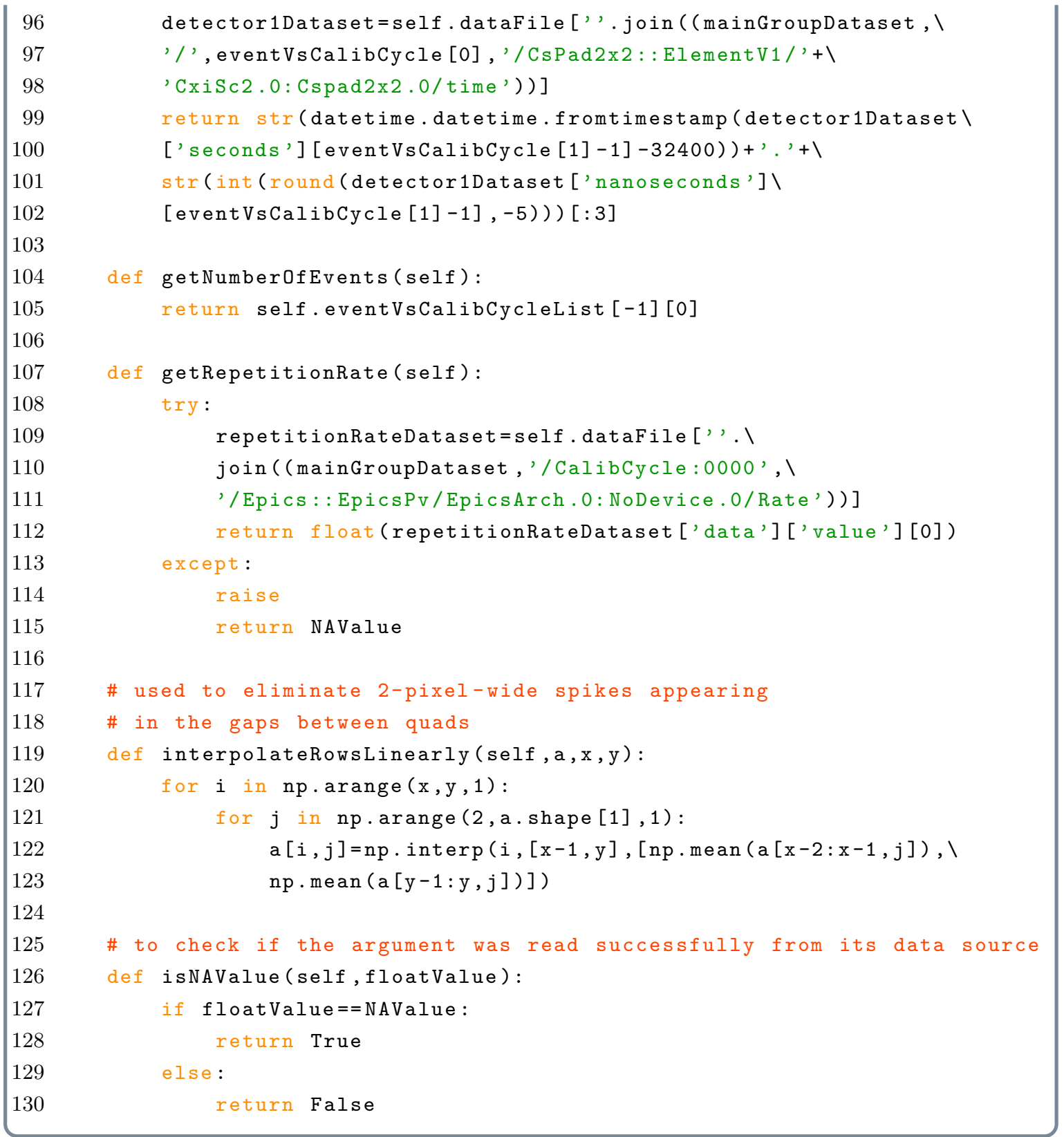

The getter functions for the electron beam parameters are defined in the part listed below. The physical units of the values returned are written in the comments. The electron pulse duration measurements were carried out not for each single pulse but in about one-second periods. In result their values needed to be interpolated.

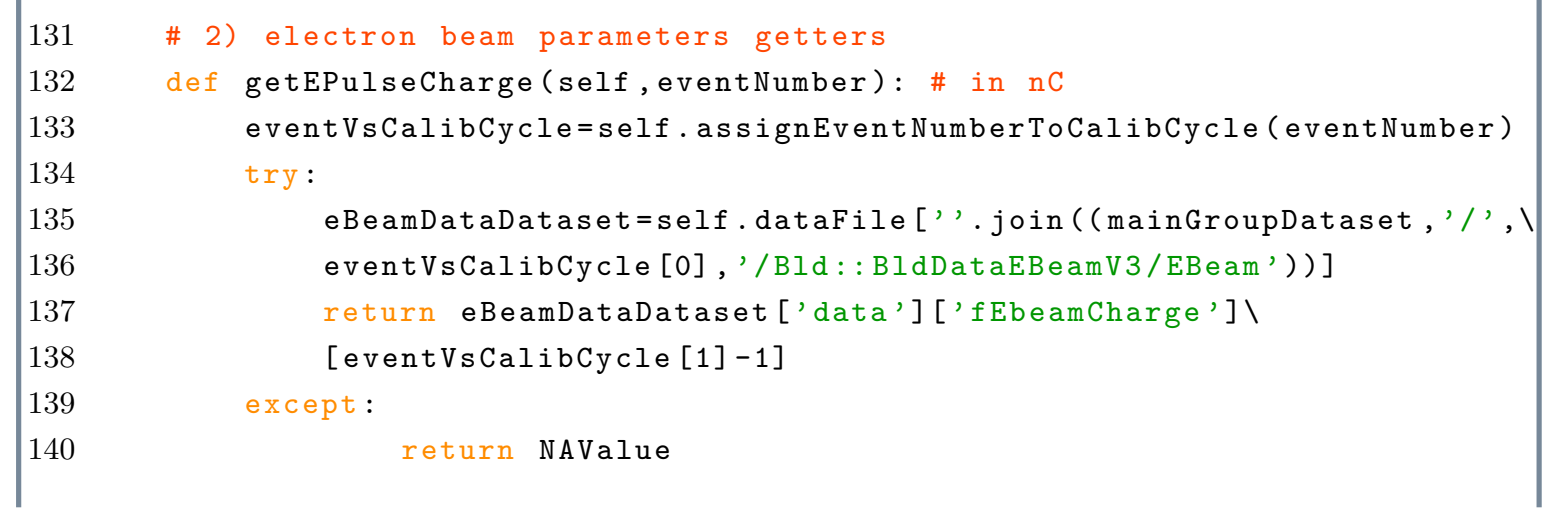




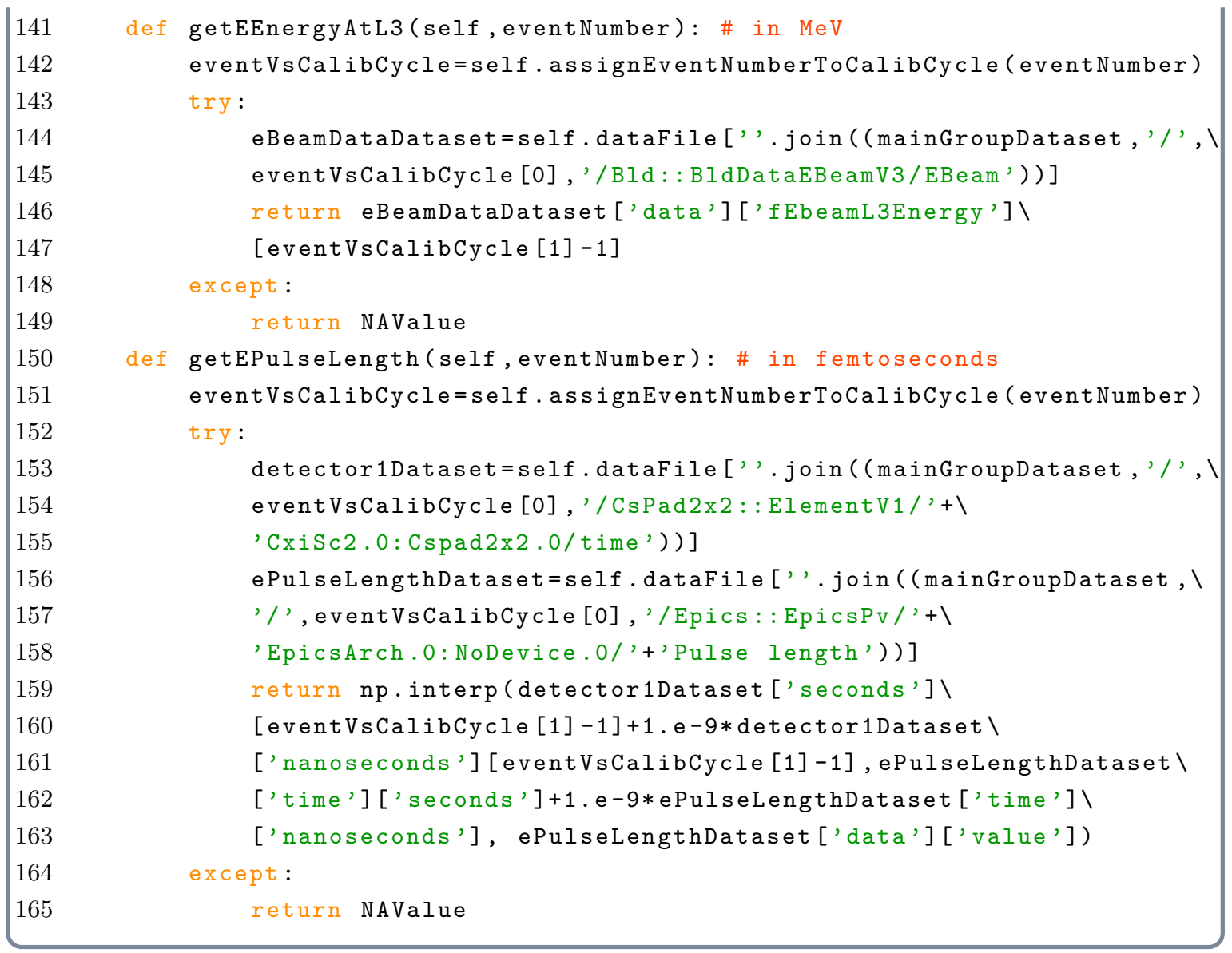

The photon pulse energy measured in the FEE gas detector is a mean of four values obtained from two different phototubes. The pulse energy measured in the upstream part of the detector is returned in the records $f_{-} 11_{-}$ENRC and f_12_ENRC and the one measured in the downstream part is in the records f_21_ENRC and f_22_ENRC.

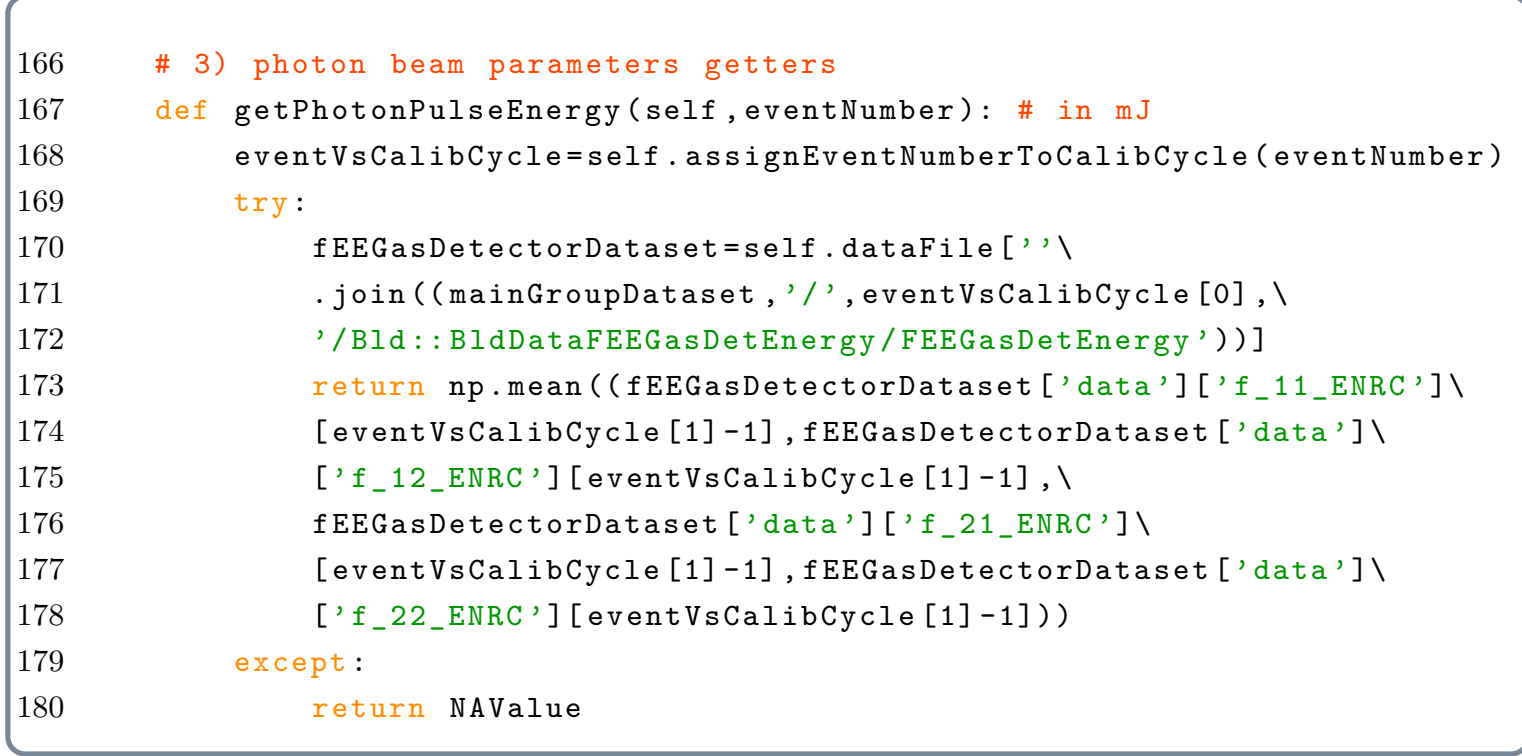

The $\mathrm{x}$ - and $\mathrm{y}$-axis stepper motor positions were probed every one second. The interpolation was done to match the moment of the event acquisition. 


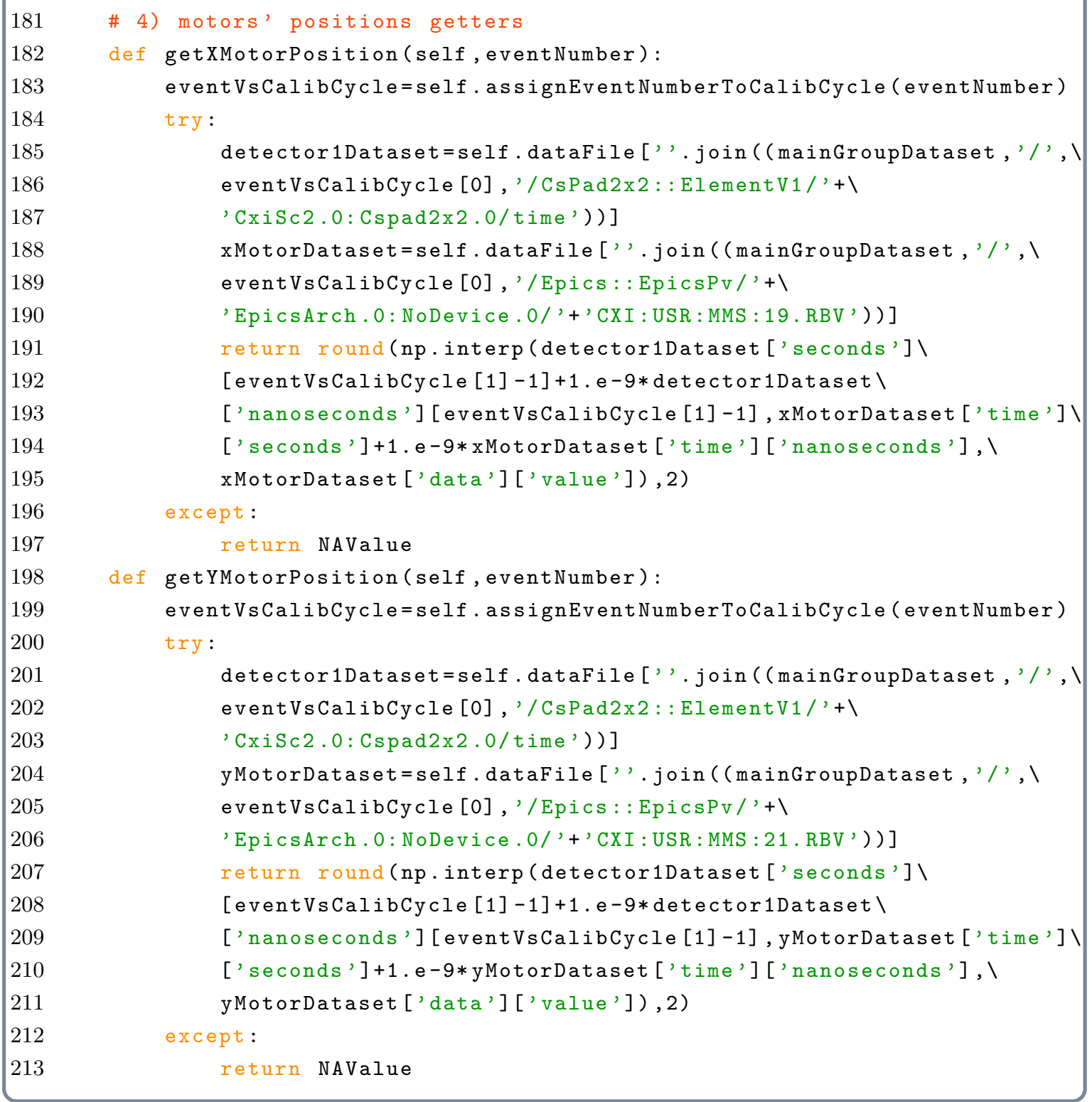

The readings from the two detectors were saved in separate datasets. The getDetectorsReadings function presented below reads and processes them and returns the result as a $2 \mathrm{D}$ array. The vertical 3-mm gap between detectors is replaced by pixels with zero values, as well as is the horizontal 5-mm gap between the pads in each detector (see V.6 and $\mathrm{V} .9$ a) for the detectors' orientation). The badPixels list contains the coordinates of the pixels that were found to be always insensitive to the measured signal. The pixels indicated in the suspectedPixels list occasionally returned wrong values.

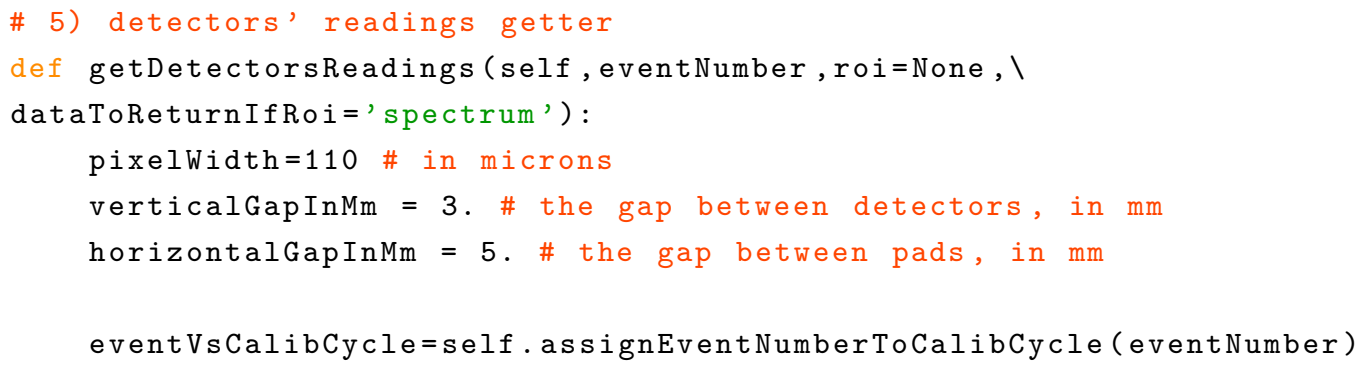


\# detectors' readings

detector1Reading = self.dataFile [', join ( (mainGroupDataset, '/', I eventVsCalibCycle [0], '/CsPad2x2 : :ElementV1/'+।

'CxiSc2.0: Cspad2x2.0/data'))] [eventVsCalibCycle [1]-1]

detector2Reading = self.dataFile [', join ( (mainGroupDataset, '/', I eventVsCalibCycle [0], '/CsPad2x2: :ElementV1/'+।

'CxiSc2.0: Cspad2x2.1/data'))] [eventVsCalibCycle [1]-1]

verticalGapInPixelsArray = np.zeros ((detector1Reading.shape [1], int (round (verticalGapInMm*1.e+3/pixelWidth))) )

rawDetectorReading =np. concatenate ( (np.transpose (detector1Reading) [0], verticalGapInPixelsArray, np.transpose (detector1Reading) [1]), । axis $=1$ )

detectorReadingTop = np. concatenate ( $\mathrm{np}$.transpose (

detector2Reading) [0], verticalGapInPixelsArray, np.transpose (

detector2Reading) [1]), axis=1)

horizontalGapInPixelsArray = np.zeros ( int (round (

horizontalGapInMm*1.e+3/pixelWidth)), rawDetectorReading.shape [1]))

rawDetectorsReading = np. concatenate ( ( rawDetectorReading, )

horizontalGapInPixelsArray, detectorReadingTop), axis =0)

del detectorReadingTop

correctedDetectorsReading=rawDetectorsReading . copy ()

\# removing the lines splitting the quads

self . interpolateRowsLinearly (correctedDetectorsReading , 193,195 )

self. interpolateRowsLinearly (correctedDetectorsReading ,608,610)

\# correcting troublesome pixels

suspectedPixels =np . array $([[132,225],[220,26],[386,421],[316,124]$, $[182,616],[183,438],[183,182],[384,793],[306,26],[388,204], \backslash$

$[70,196],[305,26],[255,77],[183,186],[131,225],[315,123], \backslash$

$[317,123],[317,125],[315,125],[178,315],[163,200],[162,2], \backslash$

$[162,1],[317,124],[315,124],[316,123],[316,125],[374,378]])$

thresholdValue=1.6 \# times the mean of local pixels

for $i$ in range (suspectedPixels.shape [0]):

if correctedDetectorsReading [suspectedPixels [i,1],

suspectedPixels $[i, 0]]>$ thresholdValue*

correctedDetectorsReading [suspectedPixels [i, 1]-1: \

suspectedPixels $[i, 1]+2$, suspectedPixels $[i, 0]-1: \backslash$

suspectedPixels $[i, 0]+2]$. mean ( ) :

correctedDetectorsReading [suspectedPixels [i, 1], ।

suspectedPixels $[i, 0]]=0$.

badPixels $=n p \cdot \operatorname{array}([[131,226],[132,224],[130,225],[317,124], \backslash$

$[315,124],[316,123],[316,125],[315,125],[317,125],[317,123], \backslash$

$[315,123],[131,226],[131,224],[130,225],[130,224],[130,226], \backslash$

$[132,226],[272,78],[371,183],[301,111],[176,441],[76,482], \backslash$

$[26,547],[390,10],[390,640],[385,744]])$

for $i$ in badPixels:

correctedDetectorsReading [i [1], i [0] ] =np.mean ( 


\begin{tabular}{|c|c|}
\hline 272 & [correctedDetectorsReading $[i[1]-1, i[0]], \backslash$ \\
\hline 273 & correctedDetectorsReading $[i[1]+1, i[0]]]$ ) \\
\hline \multicolumn{2}{|l|}{274} \\
\hline 275 & \# returning detector reading (array) if no ROI was specified; \\
\hline 276 & \# otherwise, returning projection from roi \\
\hline 277 & if $r o i==$ None: \\
\hline 278 & return correctedDetectorsReading \\
\hline 279 & else: \\
\hline 280 & if np. asarray (roi). shape $==(2$,$) :$ \\
\hline 281 & eventRoiData=correctedDetectorsReading $[:, \backslash$ \\
\hline 282 & $\min (r \circ i): \max (r \circ i)+1]$ \\
\hline 283 & roispectrum=np. empty $(($ eventRoiData. shape $[0], 2))$ \\
\hline 284 & for $i$ in range (eventRoiData. shape [0]): \\
\hline 285 & roispectrum $[i, 0]=i+1$ \\
\hline 286 & roiSpectrum $[i, 1]=\operatorname{eventRoiData}[i,:] \operatorname{sum}()$ \\
\hline 287 & if np. asarray (roi). shape $==(2,2)$ : \\
\hline 288 & $r o i=n p$. asarray $(r o i)$ \\
\hline 289 & eventRoiData $=$ correctedDetectorsReading $[\operatorname{roi}[:, 1]$ min ()$: \backslash$ \\
\hline 290 & $\operatorname{roi}[:, 1] \cdot \max ()+1, \operatorname{roi}[:, 0] \cdot \min (): \operatorname{roi}[:, 0] \cdot \max ()+1]$ \\
\hline 291 & roispectrum $=n p \cdot$ empty $(($ eventRoiData. shape $[0], 2))$ \\
\hline 292 & for $i$ in range (eventRoiData.shape [0]): \\
\hline 293 & roispectrum $[i, 0]=i+\operatorname{roi}[:, 1] \cdot \min ()+1$ \\
\hline 294 & roiSpectrum $[i, 1]=\operatorname{eventRoiData}[i,:] \operatorname{sum}()$ \\
\hline 295 & if dataToReturnIfRoi=='spectrum': \\
\hline 296 & del eventRoiData \\
\hline 297 & return roispectrum \\
\hline 298 & elif dataToReturnIfRoi==' array': \\
\hline 299 & return eventRoiData \\
\hline
\end{tabular}




\section{Acknowledgements}

This Ph.D. thesis has seen the light of day thanks to work of many people. Despite the fact that the authorship is assigned to only one person, contributions of the others is always remembered.

I wish to express my gratitude to the thesis supervisor, Dr. hab. Joanna Hoszowska, for her lively involvement in my research, patience, concern about my doings and everyday support. Thank you for always finding time for me, even when not having much of it for yourself.

I am greatly thankful to Prof. Dr. Jean-Claude Dousse, who accepted me to the Atomic and X-ray Physics group and introduced me to its research area. My research projects could not be carried out without you keeping your finger on the pulse and your interventions - always vital and on time. Thank you for sharing with me your enormous scientific knowledge and for watching my work carefully.

I would like to address my special thanks to Dr. Jakub Szlachetko from the Paul Scherrer Institute - the initiator of the HEROS method and the proposer of my research projects, for sharing his great ideas as well as his lively and cheerful enthusiasm.

I wish to express my gratitude to Dr. hab. Marc Simon from UPMC in Paris for having agreed to be the referee of my Ph.D. thesis.

I would like to address my sincerest thanks to my colleagues: Dr. Yves Kayser, Dr. Stanisław Nowak, Yves-Patrik Maillard and Faisal Zeeshan for all these years spent together. During this time you gave me a lot of help inseparably with much of true kindness.

It is my pleasure to thank Dr. Jacinto Sá from Uppsala University and Polish Academy of Sciences in Warsaw, whose knowledge on chemistry and experience in scientific research was of crucial importance in the project showing the applicability of HEROS in the time-resolved chemical speciation. I also wish to thank Dr. Szeto, Dr. De Mallmann and Dr. Taoufik from CNRS-LCOMS, Université Lyon 1, for samples and valuable discussions. I thank Dr. Maarten Nachtegaal from the Paul Scherrer Institute for his worthy contribution in publishing the results from the experiment demonstrating the self-absorption-free feature of the HEROS approach.

Not without a mention should stay the contributions of Prof. Dr. Marek Pajek and Dr. Dariusz Banaś from the Jan Kochanowski University in Kielce, thanks to whom I have learned about the opportunity of doing Ph.D. studies at the University of Fribourg. Thank you for your huge part in my education during my university studies in Kielce.

I thank my colleagues from the University of Fribourg for the time shared with me. I thank the administrative staff and the technical personnel at the Physics Department for their swift support whenever it was needed.

And finally I thank my dearest family whose invaluable help is not estimable in any manner. You are the silent heroes in the life journey of mine and inspire me to be a hero myself. Dziękuję. 



\section{Curriculum vitae}

\section{Personal details}

\begin{tabular}{ll}
\hline First name \& family name: & Wojciech Błachucki \\
Date and place of birth: & 22nd December 1987, Kielce, Poland \\
Nationality: & Polish \\
Marital status: & single \\
Current address: & Route Wilhelm-Kaiser 11, 1700 Fribourg, Switzerland \\
Languages: & Polish (native), English (fluent), French (basic)
\end{tabular}

\section{Education \& research}

\begin{tabular}{|c|c|}
\hline 2011 - present & $\begin{array}{l}\text { University of Fribourg } \\
\text { Ph.D. studies on High energy resolution off-resonant X-ray spectroscopy } \\
\text { activities: participation in experiments at facilities: Linac Coherent Light Source (Menlo Park, California, USA), } \\
\text { Swiss Light Source (Paul Scherrer Institute, Villigen, Switzerland), European Synchrotron Radiation Facility } \\
\text { (Grenoble, France) and in other in-house experiments; contributions to conferences: TXRF2013 (2013, Osaka, } \\
\text { Japan), EXRS2014 (2014, Bologna, Italy), Annual Meeting of the Swiss Physical Society (2014, Fribourg, Switzer- } \\
\text { land), 43rd Congress of Polish Physicists (2015, Kielce, Poland) } \\
\text { other achievements: certificate of completing 'Hands-on Python' programming course; certificate of completing 'C2 } \\
\text { (target level) Academic English II' language course }\end{array}$ \\
\hline $2009-2011$ & $\begin{array}{l}\text { Jan Kochanowski University of Humanities and Sciences in Kielce } \\
\text { MS degree in } 2 \text { majors: Medical Physics, Physics with Informatics (teaching specialization) } \\
\text { thesis title: Optimization of dose distribution for patients with prostate cancer } \\
\text { treated with external beams } \\
\text { other activities and achievements: Erasmus scholarship at University of Bergen, Norway (January } 2010 \text { - June } \\
\text { 2010); certificate of passing English for Business exam at Level } 3 \text { (corresponding to the Common European Frame- } \\
\text { work level B2 - C1) issued by London Chamber of Commerce and Industry }\end{array}$ \\
\hline $2006-2009$ & $\begin{array}{l}\text { Jan Kochanowski University of Humanities and Sciences in Kielce } \\
\text { BS degree in } 2 \text { majors: Medical Physics, Physics with Informatics (teaching specialization) } \\
\text { thesis title: Calculation of recombination coefficient for radiative recombination of } U^{92+} \text { ions } \\
\text { with electrons on the L-shell } \\
\text { other activities and achievements: certificate of obtaining pedagogical background to teach Physics in schools; par- } \\
\text { ticipation in events popularizing physics among schoolchildren }\end{array}$ \\
\hline $2003-2006$ & Jan Sniadecki Secondary School in Kielce \\
\hline $2000-2003$ & $\begin{array}{l}\text { No. } 8 \text { Junior High School in Kielce } \\
\text { other achievements: winner of a regional competition in Physics }\end{array}$ \\
\hline 11 - present & $\begin{array}{l}\text { University of Fribourg } \\
\text { Graduate assistant } \\
\text { activities: assistant in laboratory experiments for first-year and advanced students; participation in events popular } \\
\text { izing physics among the public }\end{array}$ \\
\hline
\end{tabular}





\section{List of publications}

\section{Refereed articles}

J. Szlachetko, C. J. Milne, J. Hoszowska, J.-Cl. Dousse, W. Błachucki, J. Sá, Y. Kayser, M. Messerschmidt, R. Abela, S. Boutet, C. David, G. Williams, M. Pajek, B. D. Patterson, G. Smolentsev, J. A. van Bokhoven, M. Nachtegaal, "The electronic structure of matter probed with a single femtosecond hard x-ray pulse," Structural Dynamics, vol. 1, no. 021101, 2014, http://dx.doi.org/10.1063/1.4868260

Y. Kayser, W. Błachucki, J.-Cl. Dousse, J. Hoszowska, M. Neff, V. Romano, "Laboratory-based micro-X-ray fluorescence setup using a von Hámos crystal spectrometer and a focused beam X-ray tube," Review of Scientific Instruments, vol. 85, no. 043101, 2014, http://dx.doi.org/10.1063/1.4869340

W. Błachucki, J. Szlachetko, J. Hoszowska, J.-Cl. Dousse, Y. Kayser, M. Nachtegaal, J. Sá, "High Energy Resolution Off-Resonant Spectroscopy for X-Ray Absorption Spectra Free of Self-Absorption Effects," Physical Review Letters, vol. 112, no. 173003, 2014, http://dx.doi.org/10.1103/PhysRevLett.112.173003.

S. H. Nowak, D. Banas, W. Błachucki, W. Cao, J.-Cl. Dousse, P. Hönicke, J. Hoszowska, L. Jablonski, Y. Kayser, A. Kubala-Kukus, M. Pajek, F. Reinhardt, A.V. Savu, J. Szlachetko, "Grazing angle X-ray fluorescence from periodic structures on silicon and silica surfaces," Spectrochimica Acta Part B: Atomic Spectroscopy, vol. 98, p. 65, 2014, http://dx.doi.org/10.1016/j.sab.2014.03.015

W. Błachucki, J. Szlachetko, Y. Kayser, J.-Cl. Dousse, J. Hoszowska, D. L. A. Fernandes, J. Sá, "Study of the reactivity of silica supported tantalum catalysts with oxygen followed by in situ HEROS," Physical Chemistry Chemical Physics, vol. 17, p. 18262, 2015, http://dx.doi.org/10.1039/c5cp02950c

\section{Conference abstracts}

Y. Kayser, W. Błachucki, J.-Cl. Dousse, J. Hoszowska, M. Neff, S. H. Nowak, V. Romano, "High-resolution micro-XRF and GEXRF applied to the investigation of the distribution of dopants in optical fibres," European Conference on X-Ray Spectrometry (EXRS2012), June 18 - 22, 2012, Vienna, Austria.

J. Hoszowska, W. Cao, W. Błachucki, M.-W. Chen, J.-Cl. Dousse, Y. Kayser, A. Kis, D. Krasnozhon, J. Szlachetko, "Probing the electronic structure of nanolayered systems with the synchrotron radiation based high-resolution GEXRFRIXS-XAS technique," 15th Conference on Total Reflection X-Ray Fluorescence Analysis and Related Methods (TXRF 2013), September 23 - 27, 2013, Osaka, Japan.

W. Błachucki, J. Szlachetko, J. Hoszowska, J.-Cl. Dousse, Y. Kayser, "L 3 -edge XAS spectra of Ta free of the selfabsorption effects measured by means of the high energy resolution off-resonant spectroscopy," 15th Conference on Total Reflection X-Ray Fluorescence Analysis and Related Methods (TXRF 2013), September 23 - 27, 2013, Osaka, Japan. 
S. H. Nowak, W. Błachucki, J.-Cl. Dousse, J. Hoszowska, Y. Kayser, F. Reinhard, P. Hönicke, J. Szlachetko, D. Banas, L. Jablonski, A. Kubala-Kukus, M. Pajek, W. Cao, "Characteristic GIXRF and GEXRF spectral features of nano-sized particles periodically and evenly distributed on $\mathrm{Si}$ and $\mathrm{SiO}_{2}$ surfaces," 15th Conference on Total Reflection X-Ray Fluorescence Analysis and Related Methods (TXRF 2013), September 23 - 27, 2013, Osaka, Japan.

W. Błachucki, J. Szlachetko, J. Hoszowska, J.-Cl. Dousse, Y. Kayser, M. Nachtegaal, J. Sá, M. Taoufik, K. C. Szeto, A. de Mallman, F. Zeeshan, "Self-absorption-free HEROS applied to time-resolved study on single site Ta catalyst," European Conference on X-Ray Spectrometry (EXRS2014), June 16 - 20, 2014, Bologna, Italy.

J. Hoszowska, J. Szlachetko, W. Błachucki, J-Cl. Dousse, R. Abela, C. David, Y. Kayser, C. J. Milne, M. Nachtegaal, B. D. Patterson, J. Sá, G. Smolentsev, S. Boutet, M. Messerschmidt, G. Williams, M. Pajek, C. T. Chantler, "Two-photon absorption and sequential ionization with ultra-intense x-ray free-electron laser radiation," European Conference on X-Ray Spectrometry (EXRS2014), June 16 - 20, 2014, Bologna, Italy.

W. Błachucki, J. Szlachetko, J. Hoszowska, J.-Cl. Dousse, Y. Kayser, M. Nachtegaal, J. Sá, "High energy resolution off-resonant spectroscopy for self-absorption-free XAS study of Ta $\mathrm{L}_{3}$-edge," Annual Meeting of the Swiss Physical Society, June 30 - July 2, 2014, University of Fribourg, Switzerland.

J. Hoszowska, J. Szlachetko, C. J. Milne, W. Błachucki, J-Cl. Dousse, R. Abela, C. David, Y. Kayser, M. Nachtegaal, B. D. Patterson, J. Sà, G. Smolentsev, S. Boutet, M. Messerschmidt, G. Williams, M. Pajek, C. T. Chantler, "Multiphoton inner-shell ionization with high-fluence x-ray free-electron laser femtosecond pulses," Annual Meeting of the Swiss Physical Society, June 30 - July 2, 2014, University of Fribourg, Switzerland.

J. Hoszowska, J. Szlachetko, W. Błachucki, J-Cl. Dousse, R. Abela, C. David, Y. Kayser, C. J. Milne, M. Nachtegaal, B. D. Patterson, J. Sá, G. Smolentsev, S. Boutet, M. Messerschmidt, G. Williams, M. Pajek, C. T. Chantler, "Multiphoton induced x-ray fluorescence of Fe atoms," Workshop "Science at FELS", September 15 - 17, 2014, Paul Scherrer Institute (PSI), Villigen, Switzerland.

J. Hoszowska, J. Szlachetko, J.-Cl. Dousse, W. Błachucki, Y. Kayser, C. J. Milne, M. Pajek, S. Boutet, M. Messerschmidt, G. Williams, C. T. Chantler, "X-ray two-photon absorption with high fluence XFEL pulses," XXIX International Conference on Photonic, Electronic and Atomic Collisions (ICPEAC), July 22 - 28, 2015, Toledo, Spain.

W. Błachucki, J. Szlachetko, J. Hoszowska, J.-Cl. Dousse, Y. Kayser, M. Machtegaal, F. Zeeshan, J. Sá, "Self-absorptionfree HEROS method applied to the real-time study of tantalum catalysts," XLIII Congress of Polish Physicists, September 7 - 11, 2015, Kielce, Poland. 

